SAND92-2844

Distribution Category UC-\$04

Printed March 1993

\title{
Development of a Quartz Digital Accelerometer \\ for Environmental Sensing and \\ Navigation Applications
}

\author{
William J. Kass \\ Optoelectronic Device Development Department
}

Paul T. Vianco

Physical and Joining Metallurgy Department

Sandia National Laboratories

Albuquerque, NM 87185-5800

Abstract A quartz digital accelerometer has been developed which uses double ended tuning forks as the active sensing elements. We have demonstrated the ability of this accelerometer to be capable of acceleration measurements between $\pm 150 \mathrm{G}$ with $\pm 0.5 \mathrm{G}$ accuracy. We have further refined the original design and assembly processes to produce accelerometers with $<1 \mathrm{mG}$ stability in inertial measurement applications. This report covers the development, design, processing, assembly, and testing of these devices. 


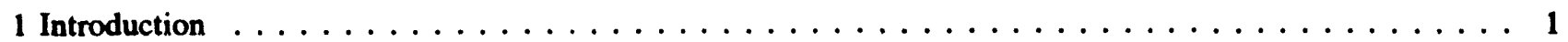

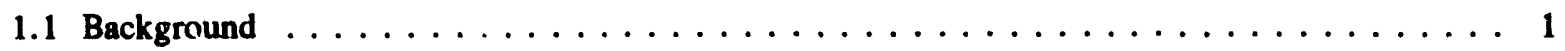

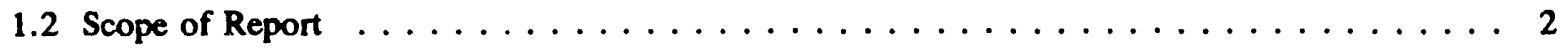

2 Device Description

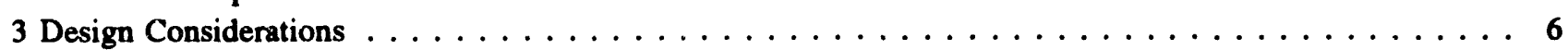

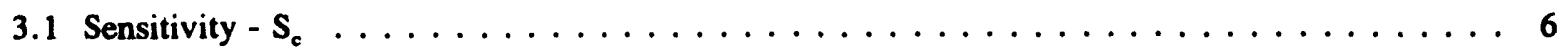

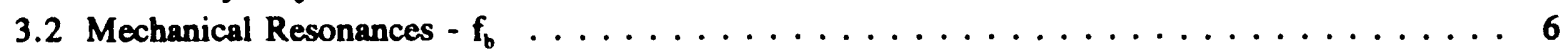

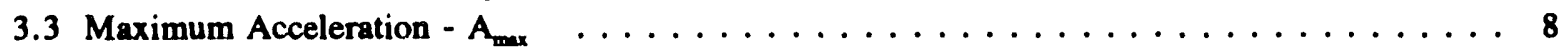

3.4 Acceleration Measurement Error Sources $-\delta$ A $\ldots \ldots \ldots \ldots \ldots \ldots \ldots \ldots$

3.5 Bias Frequency and Scale Factor Stability $-\delta \Delta \mathrm{f}_{0}$ and $\delta \mathrm{s}_{\mathrm{c}} \ldots \ldots \ldots \ldots \ldots \ldots \ldots$

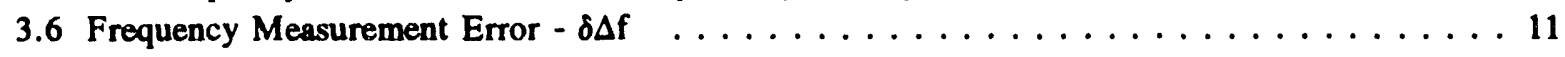

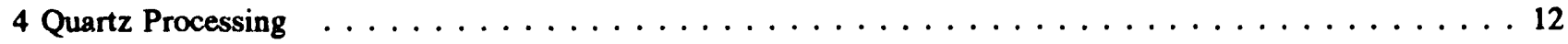

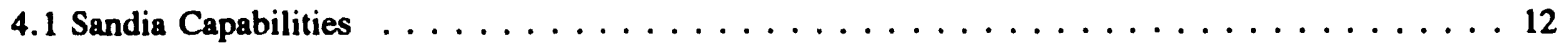

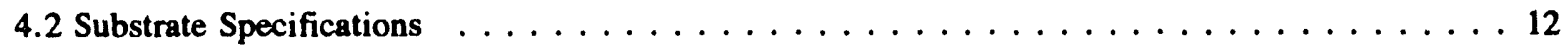

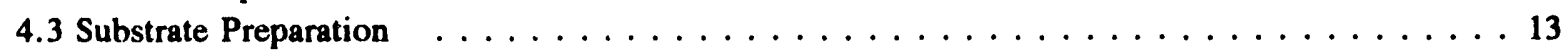

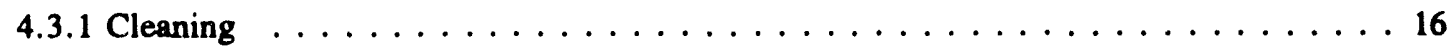

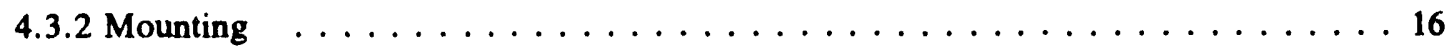

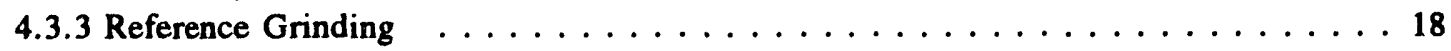

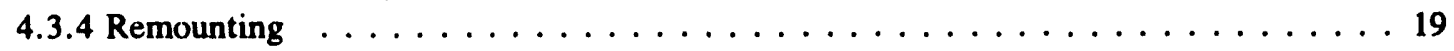

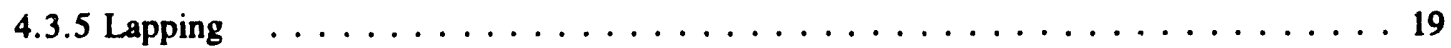

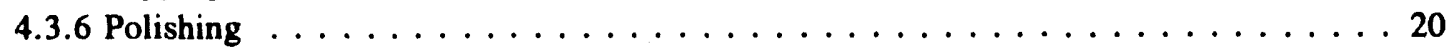

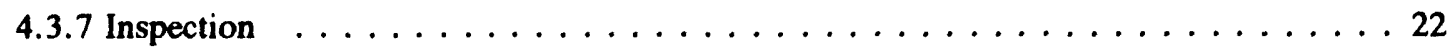

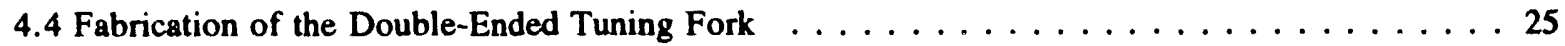

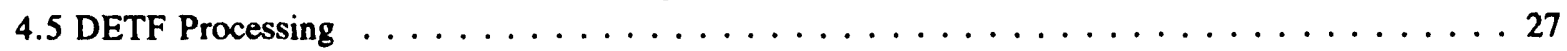

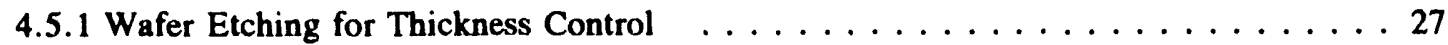

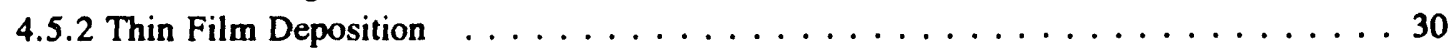

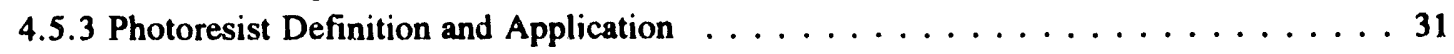

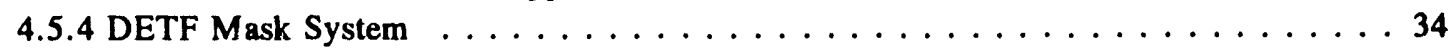

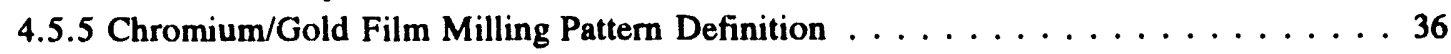

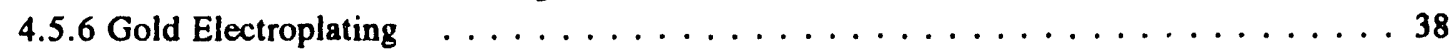

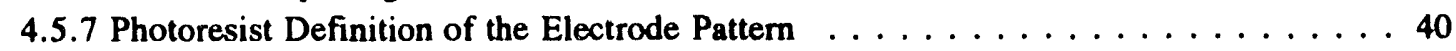

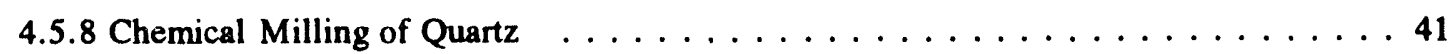

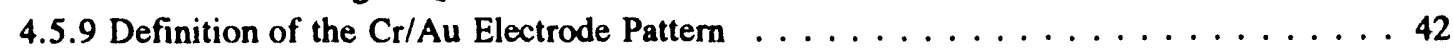

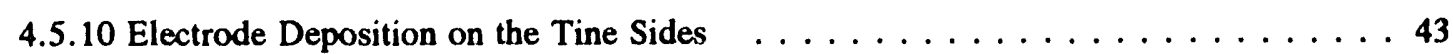

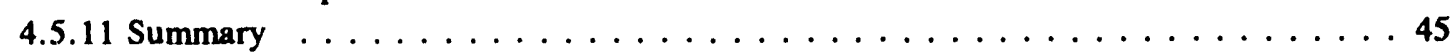

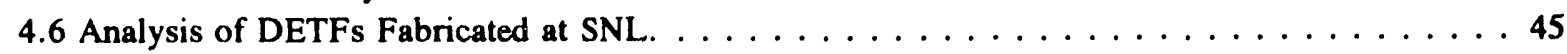

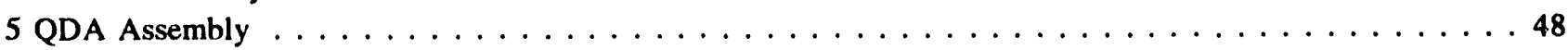

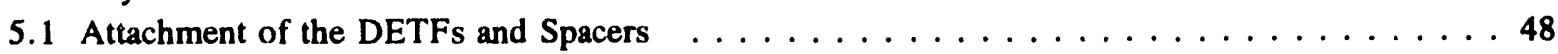

5.1.1 Batch Assembly with Nest Fixtures and Polyimide Adhesive . . . . . . . . 48

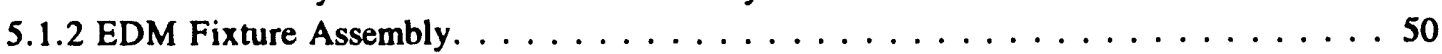

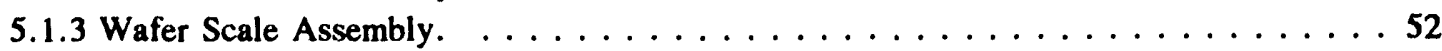

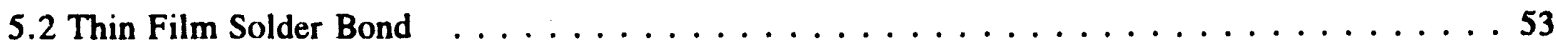

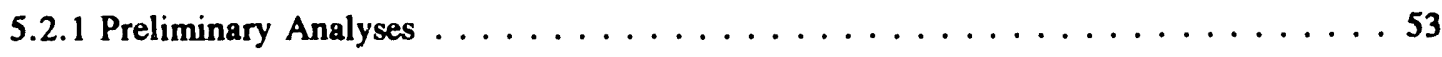


5.2.2 Eutectic Bonding Stress Calculations $\ldots \ldots \ldots \ldots \ldots \ldots \ldots \ldots \ldots$

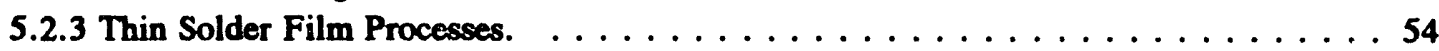

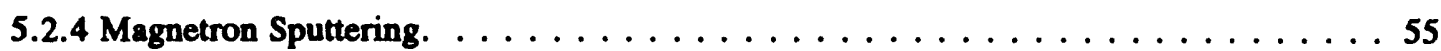

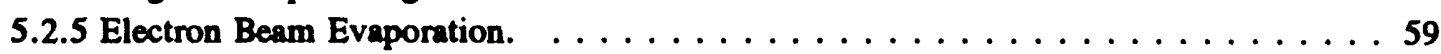

5.2 .6 Layer Deposition. . . . . . . . . . . . . . . . . . . . 60

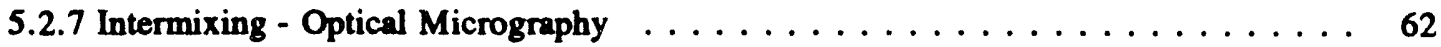

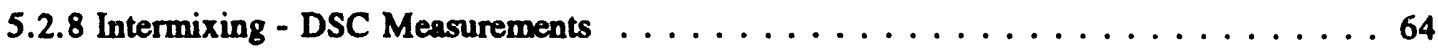

5.2 .9 Bond Formation - Transformation Front $\ldots \ldots \ldots \ldots \ldots \ldots \ldots \ldots \ldots \ldots \ldots$

5.2.10 Chromium/Gold Behavior During Solder Reflow . . . . . . . . . . . . . 67

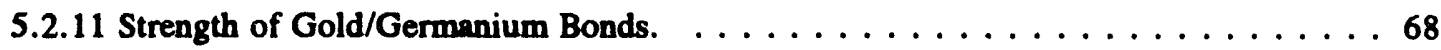

5.2.12 Thermal Shock and Thermal Cycling Tests . . . . . . . . . . . 73

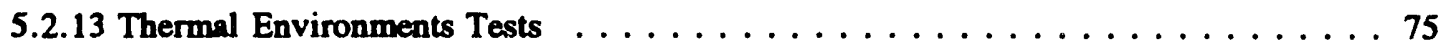

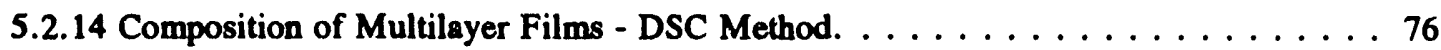

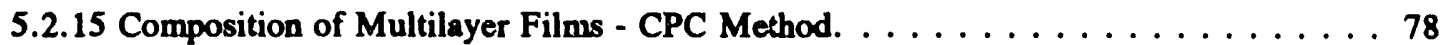

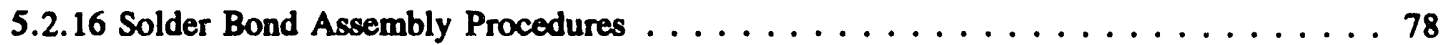

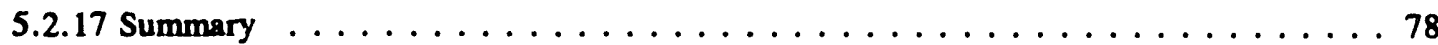

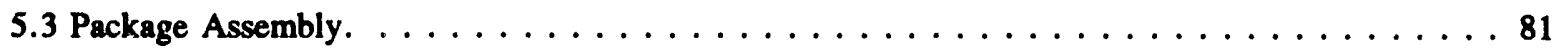

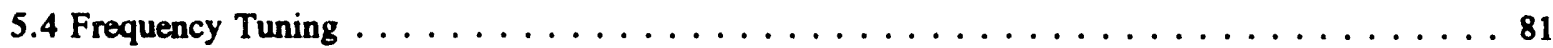

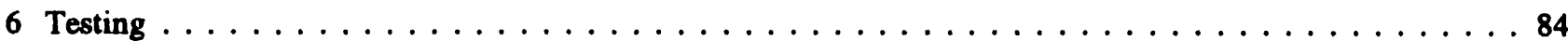

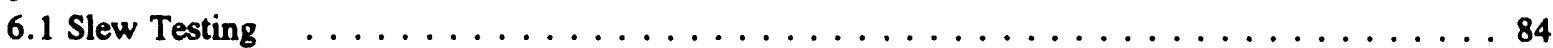

6.2 Assembly Method Slew Test Results $\ldots \ldots \ldots \ldots \ldots \ldots \ldots \ldots \ldots \ldots \ldots$

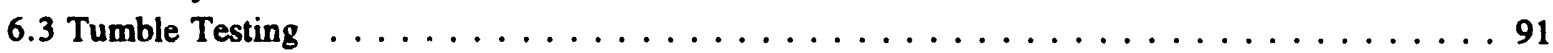

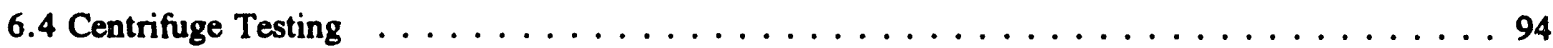

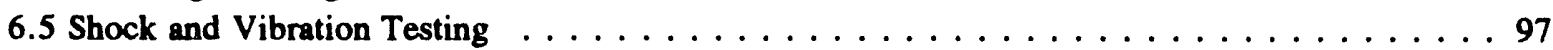

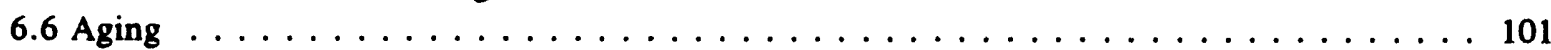

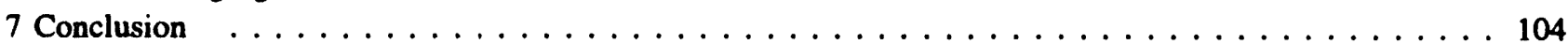

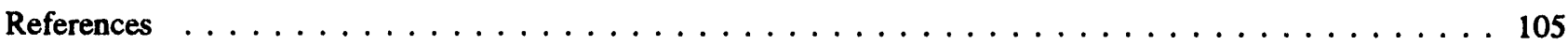

APPENDIX A: Tester Schematics $\ldots \ldots \ldots \ldots \ldots \ldots \ldots \ldots$

APPENDIX B: Frequency and Electrical Properties of Early Statek Fabricated DETFs $\ldots \ldots \ldots \ldots$

APPENDIX C: SNL Fork Parameters $\ldots \ldots \ldots \ldots \ldots \ldots \ldots \ldots \ldots \ldots \ldots \ldots$

APPENDIX D: Later Statek Fork Parameters $\ldots \ldots \ldots \ldots \ldots \ldots \ldots \ldots \ldots \ldots \ldots$

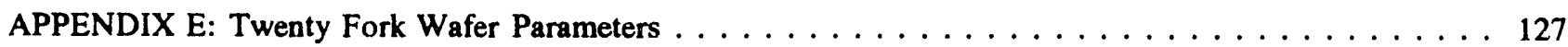

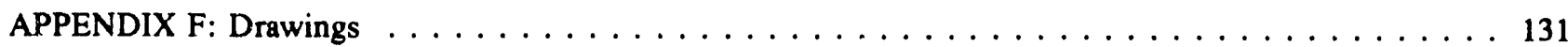




\section{LIST OF FIGURES}

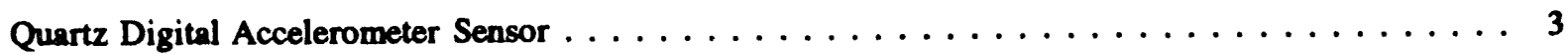
Schematic representation of the QDA sensor . . . . . . . . . . . . . . . . . Reduced frequency $\left(f_{\text {lbour }}-f_{\text {excad }}\right) / f_{\text {limoer }}$ in ppm versus acceleration for the nominal configuration of a $70 \mathrm{KHz}$

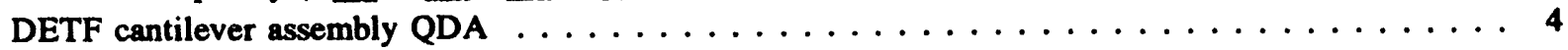

Scale factor deviation from zero acceleration value $\ldots \ldots \ldots \ldots \ldots$

Schematic of QDA sensor, oscillators and mixer $\ldots \ldots \ldots \ldots \ldots$

QDA cantilever assembly with dimensions . . . . . . . . . . . . . . . . . 6 Accelerometer Sensitivity: Constant scale factor contours as a function of double ended tuning fork

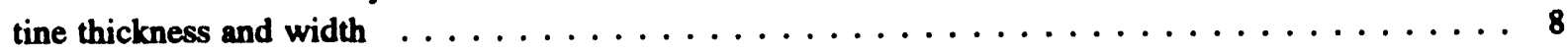
Beam Frequency: Contours of constant cantilever beam vibration frequency as a function of the tine

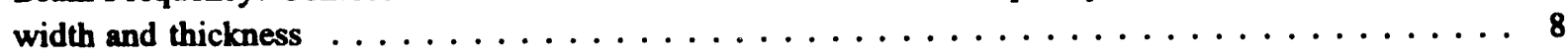
Breaking acceleration: Contours of constant breaking acceleration as a function of the tine width

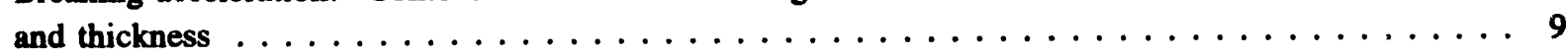
Typical temperature dependence of frequency for a $\mathrm{Z}$-cut double-ended tuning fork . . . . . . . 10 Cantilever output frequency for a cantilever composed of two DETF differing only by their nominal

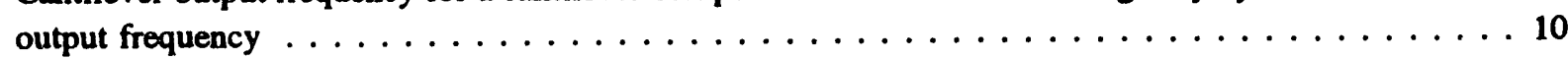

Artist's rendition of the Substrate Preparation Laboratory . . . . . . . . . . . . . . . 12

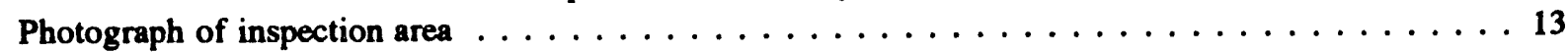

Photograph of cleaning and mounting area $\ldots \ldots \ldots \ldots \ldots$

Flow diagram of the lapping and polishing procedure $\ldots \ldots \ldots \ldots \ldots$ Large scale roughness of an as-received quartz wafer surface measured by noncontact profilometry

Three-dimensional construct of the flatness of an as-received quartz wafer from the top side, and

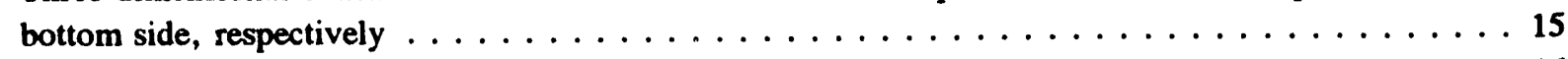
Photograph of the pattern of quartz wafers on the glass mounting block . . . . . . . . . . 16 The interference (Newton) rings between a glass mounting block and an optical flat . . . . . . . 16 Differential scanning calorimeter (DSC) plot for the wax mixture of 3 parts stacking wax to 1 part

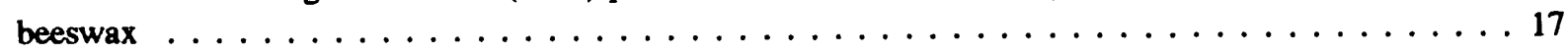
Photograph of the cleaning table used to remove excess wax from the block and wafers $\ldots \ldots \ldots$ Photograph of the non-serrated lapping table $\ldots \ldots \ldots \ldots \ldots$ Photograph of the serrated lapping table. $\ldots \ldots \ldots \ldots \ldots$ Photograph of the pressure blocking apparatus $\ldots \ldots \ldots \ldots \ldots$ Component stacking diagram for the pressure blocking process $\ldots \ldots \ldots \ldots$

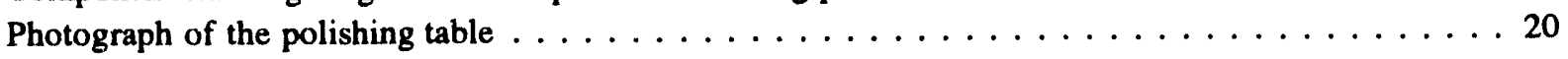
SEM micrographs of the partially polished surface of a quariz wafer $\ldots \ldots \ldots \ldots$ Non-contact surface profile of a $\mathrm{z}$ plate wafer surface after polishing for $50 \mathrm{~min}$. with $1.0 \mathrm{micron}$

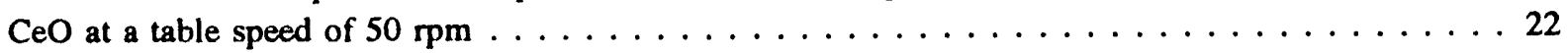
Pits in the tine of a DETF from poor metallization coverage due to insufficient polishing of the

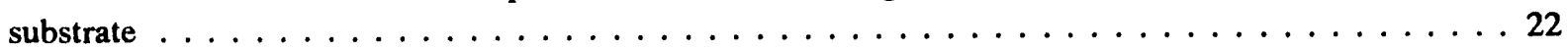

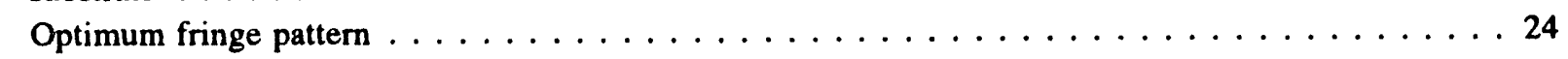

Thickness variations due to uneven bond thickness or contaminate particles . . . . . . . . . . . 24

Thickness variation due to contaminate particles . . . . . . . . . . . . . . . . . 24

Extreme example of thickness variation similar to $(b) \ldots \ldots \ldots \ldots$ 
30(e) Rounding due to excess polishing as well as linear flaw in the quartz . . . . . . . . . . . . . 24

31 Schematic diagram depicting the generation of a convex profile of the thickness of the quartz blank by a non-uniform wax layer underneath . . . . . . . . . . . . . . . . . . . 25

32 Mechanical gauge thickness dimensions of a batch of 17 wafers showing the thickness variation of approximately 50 microns between the edge and center of the wafers . . . . . . . . . . . . 25 Interference fringe pattern generated by $546 \mathrm{~nm}$ monochromatic light showing thickness variations in the wafer caused by a non-uniform wax layer under the quartz blank . . . . . . . . . . . . 25 Photograph of the Temporary Prototype Processing Laboratory (TPPL): Overall view . . . . . . . . 26

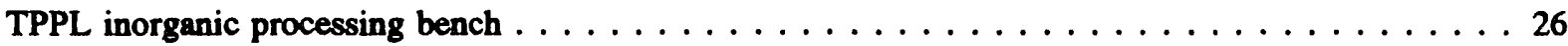

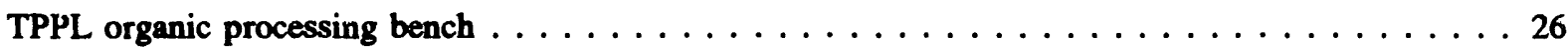

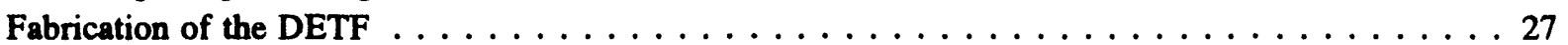
The arrangement of 32 forks on a quartz wafer $\ldots \ldots \ldots \ldots$ Photograph of thirty-two fork wafer $\ldots \ldots \ldots \ldots \ldots$ Etching rate in the $\mathrm{z}$ direction as a function of temperature for an immersion time of $2 \mathrm{~min}$. . . . . 29 Photograph of the vacuum evaporator used to deposit the Cr/Au metallization on the quartz blanks

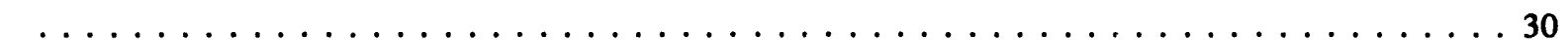

Mounting pallet used to hold the quartz wafers for the deposition of the Cr/Au metallization . . . . 30

43 View of the mounting pallet with the quartz wafers attached to the planetary system in the vacuum

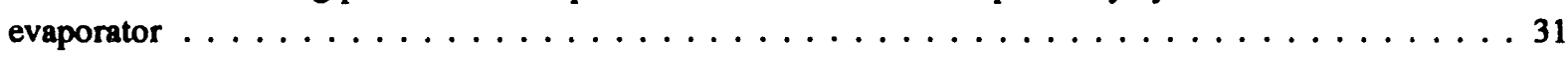

44 Scheme for pattern definition using a positive photoresist $\ldots \ldots \ldots \ldots$

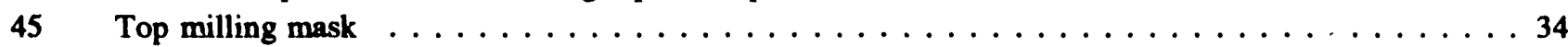

46 Drawing of the double ended tuning fork quartz resonator $(71 \mathrm{kHz}) \ldots \ldots \ldots$

47 The top and side electrode metallization patterns for the DETF $\ldots \ldots \ldots \ldots$

48 Location of the regions receiving electroplated gold $\ldots \ldots \ldots \ldots$

49 The arrangement of 20 DETFs on a quartz wafer . . . . . . . . . . . . . . . . 36

$50 \quad$ Photograph of the MJB-21 double sided mask aligner $\ldots \ldots \ldots$

51 Optical micrograph of the photoresist defining the milling pattern for the crotch region of a tuning

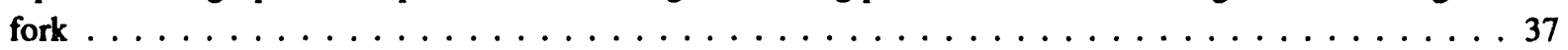

52 Photograph of the wafer substrate after the $\mathrm{Cr} / \mathrm{Au}$ had been etched to reveal the milling mrsk pattern

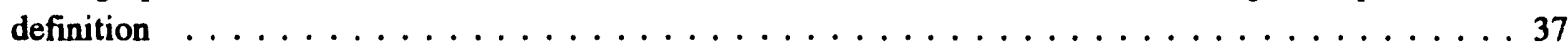

53 Photograph of a quartz wafer showing where the electroplated gold has been deposited (refer to

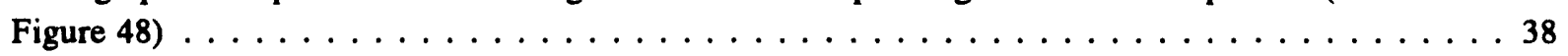
Optical micrographs of the photoresist defining the DETF electrode pattern three

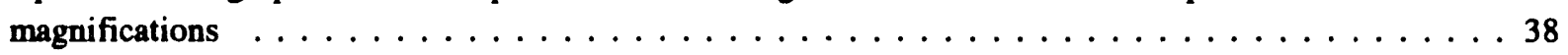
Etching (milling) of the quartz substrate to define the resonator structure $\ldots \ldots \ldots$

56 SEM micrographs of comers of the tuning fork structure demonstrating the anisotropy of the etching

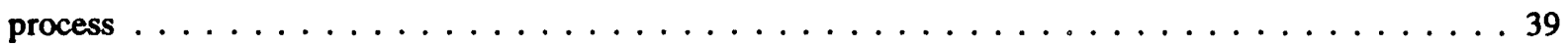
Optical micrograph of the cross section of the tines of the DETF . . . . . . . . . . . . 40

$58 \quad$ Photograph of a completed 20 fork wafer . . . . . . . . . . . . . . . . . . . 40

59 Schematic diagram showing the cross section of the aperture mask with respect to the tuning fork tines for side deposition of the $\mathrm{CrAu}$ metallization $\ldots \ldots \ldots \ldots \ldots$

60 Schematic diagram showing the cross section of the aperture mask as it develops during the milling

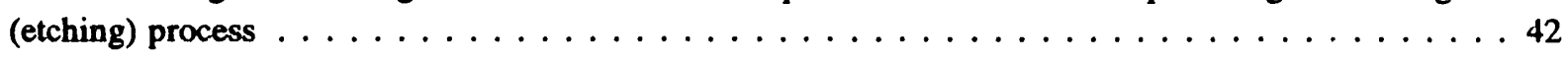

61 Flow diagram of the process to create the aperture mask $\ldots \ldots \ldots$

62 SEM micrographs of the quartz aperture mask after etching . . . . . . . . . . . . . . 44

63 Blowup of QDA sensor assembly $\ldots \ldots \ldots \ldots$ 
The support plate, mass plate, and spacer frames used to assemble the QDA $\ldots \ldots \ldots \ldots \ldots$

Assembly process sequence using the $10 \times 1$ fixture $\ldots \ldots \ldots \ldots \ldots \ldots \ldots \ldots$

Polyimide curing temperature cycle performed in flowing argon. $\ldots \ldots \ldots \ldots \ldots \ldots \ldots$

Optical micrograph of a cross section of a polyimide bonded sensor joint $\ldots \ldots \ldots \ldots \ldots$

Single unit electric discharge machined assembly fixture and alignment frames $\ldots \ldots \ldots \ldots$

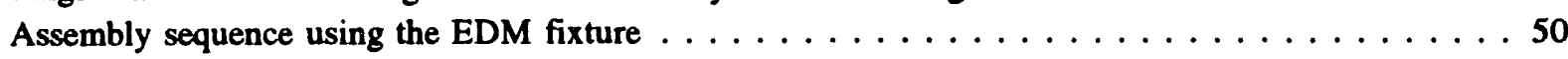

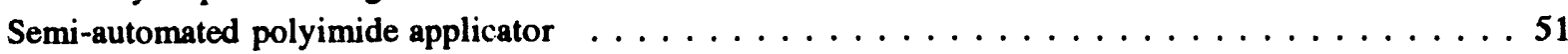

Polyimide application process using the semi-automated applicator $\ldots \ldots \ldots \ldots \ldots \ldots \ldots$

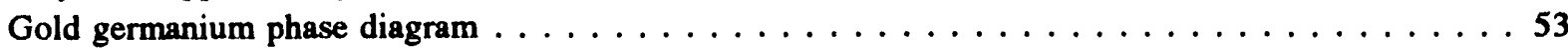

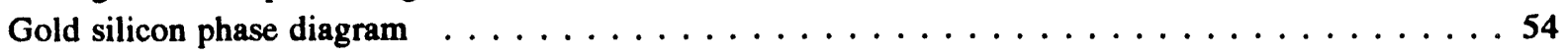

QDA AuGe eutectic bond geometry used to calculate residual stresses from thermal model $\ldots \ldots 54$
Optical micrographs showing phase separation and reflow of the $0.5 \mu \mathrm{m}$ thick sputter deposited AuGe

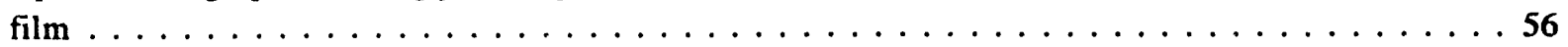

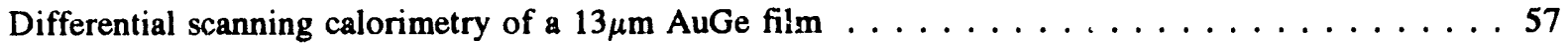

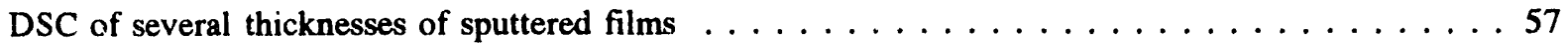

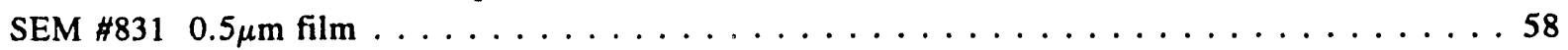

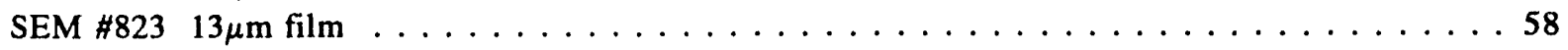

SEM photograph of the cross sectional view of $0.5 \mu \mathrm{m}$ film $\ldots \ldots \ldots \ldots \ldots \ldots \ldots$

82(a) SEM micrograph of the cross section of a $2.0 \mu \mathrm{m}$ thick multilayer AuGe film on CrAu metalized

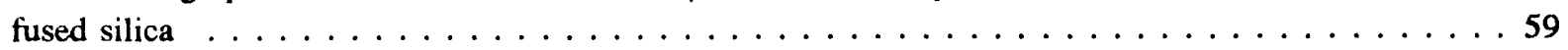

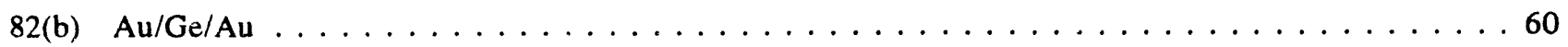

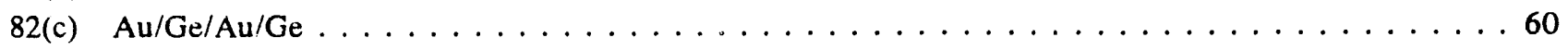

83 Optical micrographs from the reflowed multilayer solder film of the Group I sequence (GeAu) at

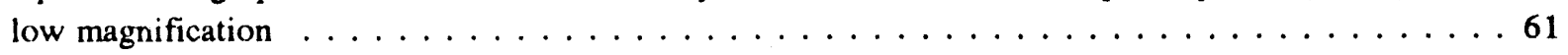

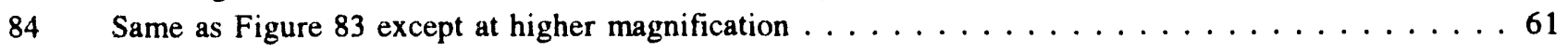

85 Metallization adherent to substrate away from the needle structure $\ldots \ldots \ldots \ldots \ldots \ldots \ldots \ldots$

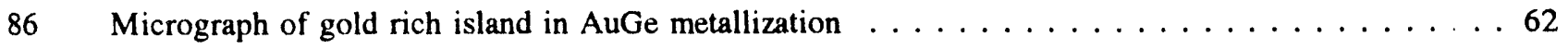

87 Micrograph of germanium rich island in AuGe metallization $\ldots \ldots \ldots \ldots \ldots \ldots \ldots \ldots \ldots$

88 (a) DSC plots of $1.0 \mu \mathrm{m}$ Group I, II, III multilayer films. Also Group II, $2.0 \mu \mathrm{m}$ film . . . . . . . 64

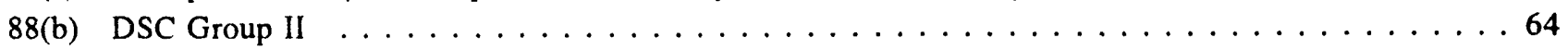

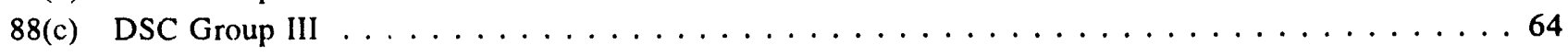

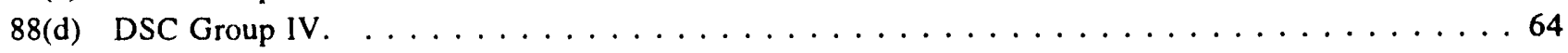

89 Optical micrographs of the phase change front on the $2.0 \mu \mathrm{m}$ thick Group I, II, III films on fused

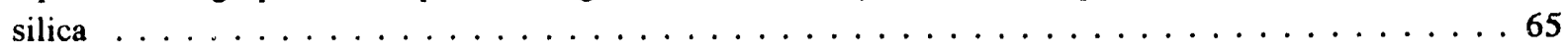

90 Surface profilometer traces across the transformation front between reflowed and non-reflowed film.

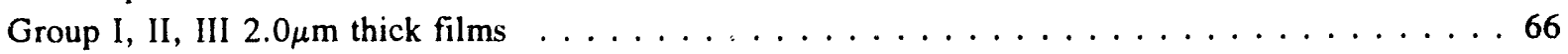

Auger spectroscopy depth profile of reverse deposited $2.0 \mu \mathrm{m}$ thick film $\ldots \ldots \ldots \ldots \ldots \ldots$

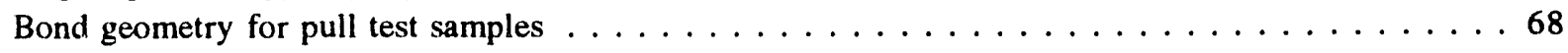

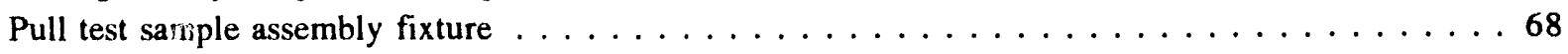

The quartz substrate and copper felt stacking sequence for fabrication of the bond sample . . . . . 69

Pull test fixture with the wedges in place; the sample fits between the wedges $\ldots \ldots \ldots \ldots . \ldots 69$

Process for attachming the bond sample to the wedges for pull testing $\ldots \ldots \ldots \ldots \ldots \ldots$

Optical micrographs of the complementary fracture surfaces of the $2.0 \mu \mathrm{m}$ thick Au-Ge solder joints.

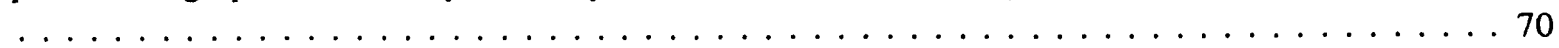

98 Optical micrographs of the fracture surface of the $2.0 \mu \mathrm{m}$ thick AuGe solder joint at higher

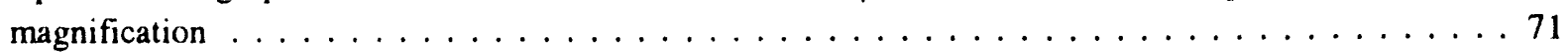


Optical micrographs of the fracture surfaces of the $1.0 \mu \mathrm{m}$ thick AuGe solder joint $\ldots \ldots \ldots 72$

Heating schedule used to reflow the 80Au20Sn solder seal for the package lids . . . . . . . . 74 Plot of the specific heat of transformation as a function of Ge concentration in the $2, \mathrm{~lm}$ thick

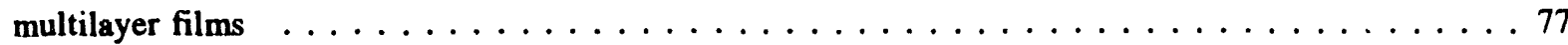
Heating cycle used to reflow the AuGe solder in the assembly of the QDA $\ldots \ldots \ldots \ldots \ldots$ Early version of the custom ceramic package used to contain the QDA $\ldots \ldots \ldots \ldots \ldots \ldots$ Revised version of the ceramic package used late in the program $\ldots \ldots \ldots \ldots \ldots \ldots$ Photograph of the QDA package in place on the precision stage $\ldots \ldots \ldots \ldots \ldots \ldots \ldots \ldots$

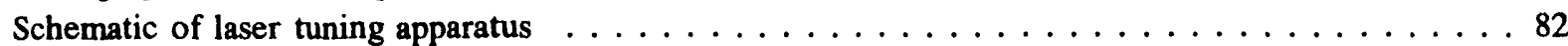
Plot of the tuning fork frequency as a function of the trimming pulse $\ldots \ldots \ldots \ldots \ldots \ldots$ Electrical model for a quartz resonator $\ldots \ldots \ldots \ldots \ldots \ldots \ldots \ldots \ldots$ Electrical parameters vs. temperature for a typical DETF in vacuum $\ldots \ldots \ldots \ldots \ldots \ldots$ Typical pre-assembly characteristics of the individual DETF and the calculated output frequency determined by subtracting the individual DETF frequencies $\ldots \ldots \ldots \ldots \ldots \ldots$ Post-assembly characteristics of the individual DETF and the calculated output frequency . . . . 86 Histogram of turnover temperatures for individual forks before assembly into a cantilever beam

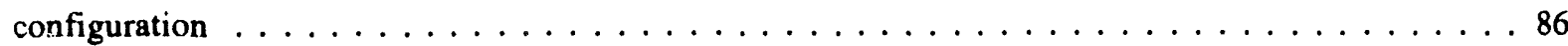
Temperature coefficient of the cantilever output frequency vs. difference in turnover temperature for

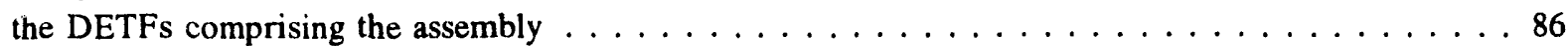

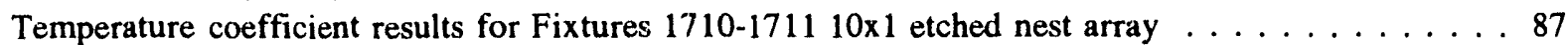
Temperature coefficient histogram for Fixture $17095 \times 2$ etched nest array . . . . . . . . . . 87 Temperature coefficient histogram for Fixture 1724 - all beryllium copper $\ldots \ldots \ldots \ldots$ Temperature coefficient results for Fixtures $1725-1730$ - EDM fixtures $\ldots \ldots \ldots \ldots \ldots$ Temperature coefficient results for Fixture 1732 - wafer scale assembly $\ldots \ldots \ldots \ldots \ldots$ Temperature coefficient for eutectic bonded wafer scale assembled cantilevers . . . . . . . . 89 Output frequency change vs. corrected acceleration for QDA2344 at $62^{\circ} \mathrm{C} \ldots \ldots \ldots \ldots \ldots$

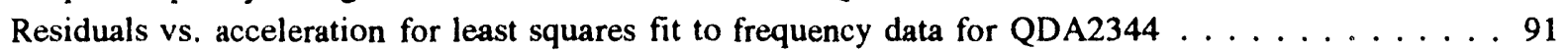

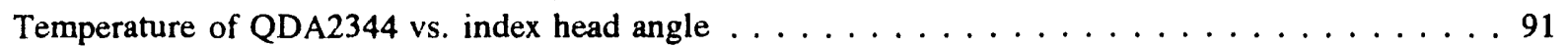

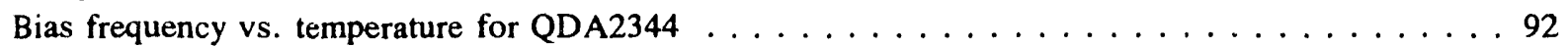

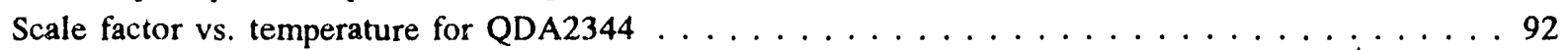

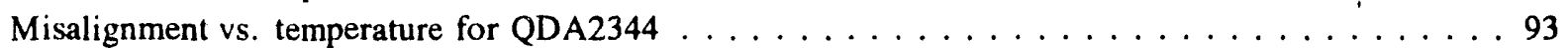
Comparison of bias frequency vs. temperature determined from slew and tumble tests . . . . . .93

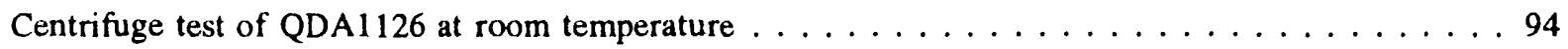
Frequency residuals vs. acceleration before and after centrifuge arm stretch correction . . . . 95

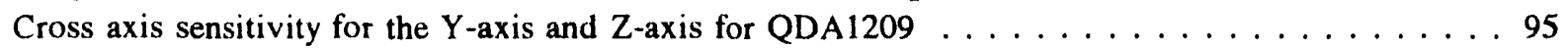
Bias frequency and scale factor comparisons between tumble tests and centrifuge tests for

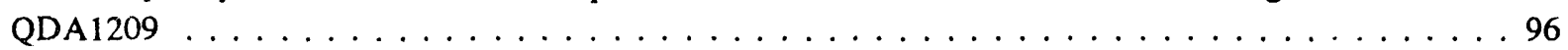
Misalignment vs. temperature determined from tumble tests and centrifuge test . . . . . . . 96

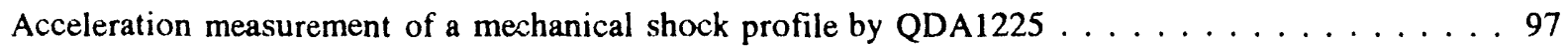

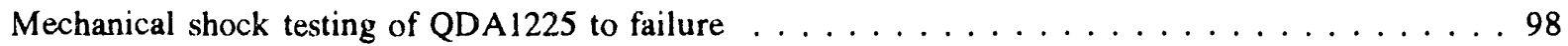

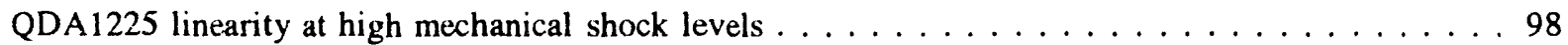
Scale factor vs. drive frequency for QDAs driven at $10 \mathrm{~g}$ peak-to-peak acceleration . . . . . . . 99 Bias shift of QDAs vs. frequency subjected to a drive frequency of $10 \mathrm{~g}$ peak-to-peak amplitude . . 99

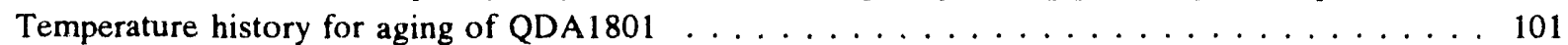

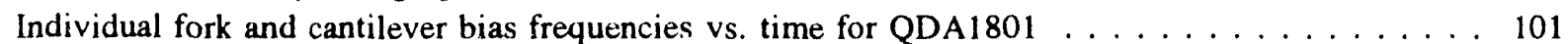

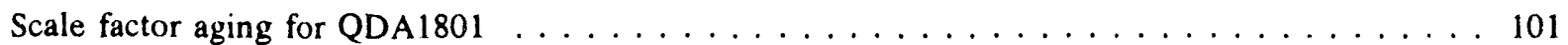

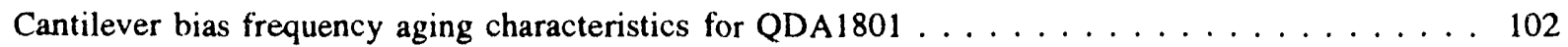




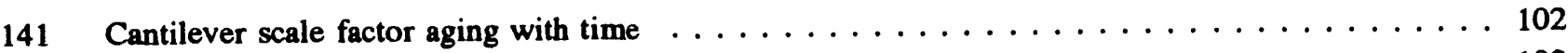

142 Temperature profile for aging of QDA1834 $\ldots \ldots \ldots \ldots \ldots \ldots \ldots \ldots \ldots \ldots \ldots \ldots$

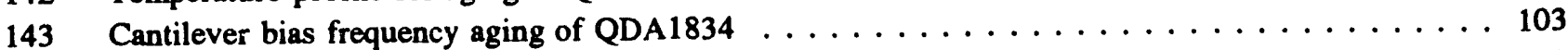

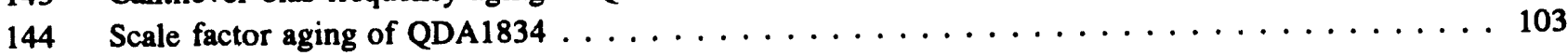




\section{LIST OF TABLES}

1

Typical dimensions and physical constants for QDA cantilever composed of nominal 70KHz double ended tuning forks, polyimide bonds and beryllium copper spacers $\ldots \ldots \ldots \ldots \ldots \ldots$

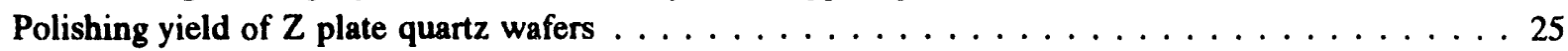

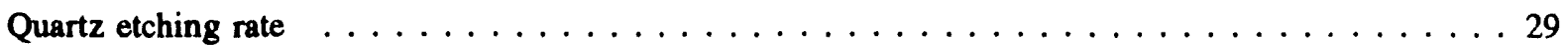

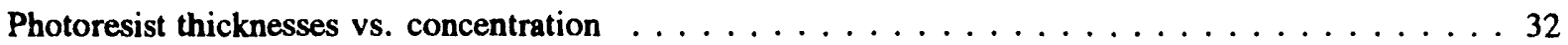

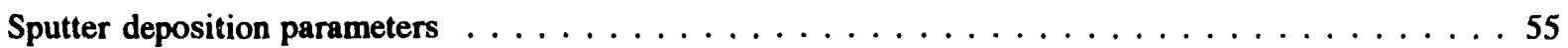

Weight percent of germanium relative to the ideal compositon $\ldots \ldots \ldots \ldots \ldots \ldots \ldots$

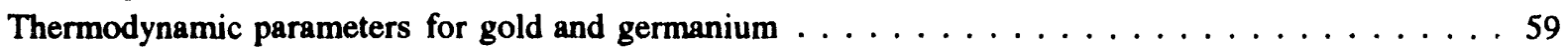

Layer sequences and thicknesses used to form the gold-germanium eutectic $\ldots \ldots \ldots \ldots \ldots$

Deposition parameters of the gold and germanium film for the multi-layer solder film . . . . . 6 61

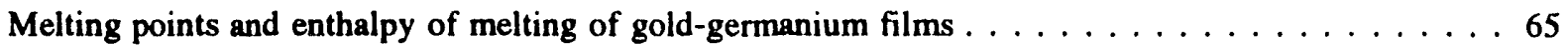

Transformation front profile properties of the multi-layer gold-germanium film $\ldots \ldots \ldots \ldots 7$

Bond strength of the $1.0 \mu \mathrm{m}$ and $2.0 \mu \mathrm{m}$ thick Au-Ge solder joints $\ldots \ldots \ldots \ldots \ldots \ldots$

Bond strength of the $0.5 \mu \mathrm{m}$ thick AuGe solder joints $\ldots \ldots \ldots \ldots \ldots \ldots \ldots \ldots \ldots$

Bond strengths of the AuGe solder joints after thermal shock and thermal cycling . . . . . . 73

Strength and failure results of $1.0 \mu \mathrm{m}$ AuGe bonds during thermal shock and thermal cycling $\ldots \ldots 74$

Bond strengths of the $1.0 \mu \mathrm{m}$ AuGe solder joints following air and vacuum annealirg $\ldots \ldots \ldots 75$

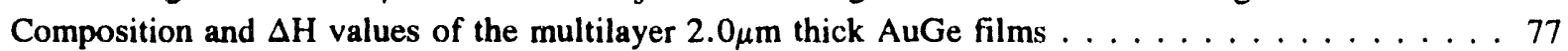

Composition and heat of formation of the multilayer AuGe films determined by AES/ICP . . . . . 79

Correspondence between simple parabolic parameters and fork model parameters . . . . . . . 85

Temperature coefficient results for various assembly techniques used for QDA assembly . . . . . . 89

Summary of breaking accelerations for three QDA $\ldots \ldots \ldots \ldots \ldots$

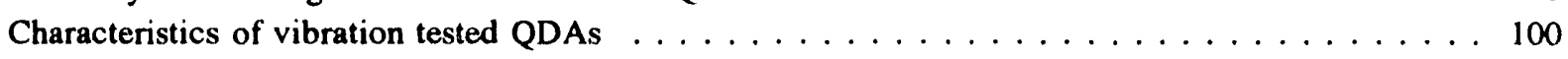

Frequency and scale factor parameters for QDAs used in aging study $\ldots \ldots \ldots \ldots \ldots$ 


\section{Introduction}

A quartz digital accelerometer (QDA) has been developed for use as an acceleration sensor in environmental sensing applications or for short term inertial guidance systems. The advantages of such a device are many. The accelerometer is a digital device in that the frequency output represents acceleration. This characteristic is particularly desirable in navigation applications where inertial navigation units collect and digitally process data. The device is inherently very simple and small. The quartz double-ended tuning forks (DETF) which comprise the cantilever can be batch fabricated using well developed quartz etching techniques. The most well known example of the use of these methods is in the quartz digital watch industry [1]. The fabrication ease for DETFs holds the promise that inexpensive sensors can be made for large volume applications. Quartz is a very stable material and is compatible with ultra-clean processing leading to long life-low aging devices. In addition, because of the common mode design and information obtained from experience with quartz resonators used in clock applications, the accelerometer should be radiation hardenable.

\subsection{Background}

The operation of this sensor depends on two concepts generated and patented at Sandia National Labs. The first concept which was developed used a DETF as a force sensor and a device using this concept was patented by EerNisse [2]. The idea entails measuring the frequency change of a DETF placed in stress by an axial load. A cantilever beam configuration of the two DETFs transforms acceleration forces perpendicular to the plane of the cantilever beam into axial stresses in the DETFs. Measurement of the change in difference frequency between the two DETFs from an acceleration load exerted by a proof mass then produces a measure of that acceleration. Koehler [3] has patented a realization of this idea.

We chose an environmental sensing device as the initial application for accelerometer development. A shock profile characteristic of an opening parachute with a maximum value of approximately $130 \mathrm{~g}\left(1 \mathrm{~g} \approx 9.8 \mathrm{~m} / \mathrm{s}^{2}\right)$ and a duration ranging from $100 \mathrm{~ms}$ to $3 \mathrm{~s}$ is a typical environment. The initial design goal was to make measurements of this type of shock profile with about $\pm 0.25 \mathrm{~g}$ accuracy. We also desired to maintain this accuracy over a wide temperature range $(-55 \mathrm{C}$ to $+85 \mathrm{C})$ and various vibration environments without immediate pre-use calibration. Furthermore, the accelerometer was to survive handling shocks up to about $1000 \mathrm{~g}$. Early in the development program, we realized that the influence of temperature on the behavior of the sensors was the most prominent characteristic affecting the sensor performance and the one most in need of development effort and improvement.

As development proceeded, we modified the initial design to produce a less rugged but more sensitive sensor for successful utilization in inertial measurement applications. Although the requirements for an inertial quality sensor initially seem inconsistent with an environmental shock sensor, they are not that different with regard to very good temperature stability. An inertial sensor requires milli-g stability but has the benefit of using temperature control or temperature measurement and modeling of the temperature behavior of the sensor. Consequently, both sensor applications require a temperature coefficient of acceleration of a few milli-g per Celsius. The sensor design anticipates this need for low acceleration temperature dependence by using two DETFs to obtain common mode rejection of temperature and other environmental effects. 


\subsection{Scope of Report}

This report covers the QDA development from September 1984 to September 1989. Previous development activities have been described in earlier reports [4] [5] [6] as well as a more recent paper [7]. During the early development period, the primary focus was on a lower sensitivity-highly rugged sensor. Later, higher sensitivity inertial measurement quality sensors evolved from this original design. This report focuses on the higher sensitivity sensors and their environmental testing. In addition, we describe the development capabilities to manufacture quantities of sensors. To improve our understanding of the temperature characteristics of the cantilever beam, an extensive finite element modeling program was undertaken [8] [9].

A significant amount of effort was expended in the development of the electronic circuits used for the oscillators, mixer, filter and digital measurement unit. These circuits coupled to the sensor make up what we consider a complete accelerometer requiring only power and a reference clock for acceleration measurements. In this report, the focus will be on the sensor development with a minimum amount of circuit development given. 


\section{Device Description}

The QDA consists of two quartz double ended tuning forks connected together in a frame configuration (Figure 1 and Figure 2). An inboard spacer of beryllium-copper or quartz and a proof mass (outboard spacer) of quartz, beryllium-copper or gold are bonded to the tuning forks. The bonding materials are either polyimide adhesive or a gold-germanium eutectic. The tuning forks are chemically etched from crystalline Z-plane cut quartz. Since quartz is a piezoelectric material, this effect is used to excite mechanical resonance of the DETF. A unique pattern of chromium-gold metallized contacts are deposited to excite the tines at their lowest in-plane resonance. The geometry of each tuning fork is such that the frequencies are nominally $70 \mathrm{KHz}$ and $71 \mathrm{KHz}$.

The frame is mounted in a ceramic package in a cantilever beam configuration. The package is vacuum sealed using sapphire covers and a gold-tin eutectic solder. Transparent sapphire covers are required so the frequency of the tuning forks may be laser tuned to yield an exact difference (output) frequency between the two forks. This output frequency at zero acceleration (bias frequency) is typically $1000 \mathrm{~Hz}$. A net output frequency change results when the acceleration force on the proof

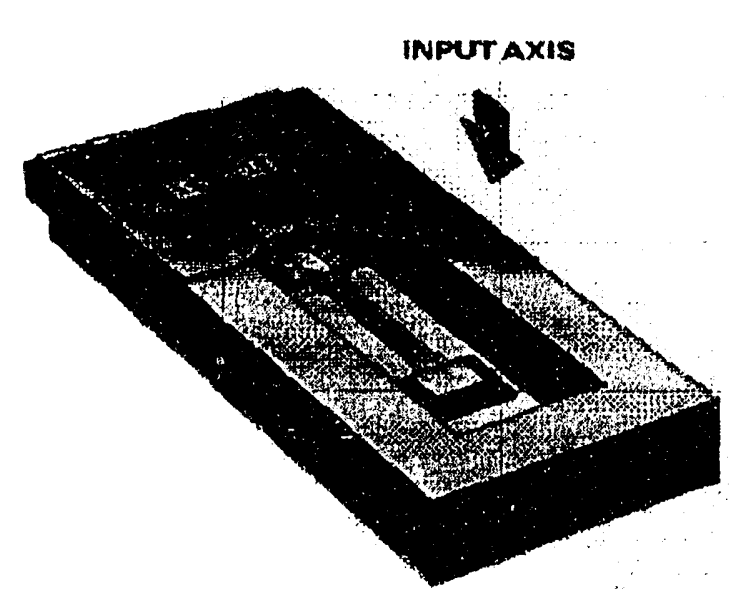

Figure 1 Quartz Digital Accelerometer Sensor mass establishes tension in one fork (fork frequency increases) and compression in the other fork (fork frequency decreases). The sensitivity of the device is typically $1 \mathrm{~Hz} / \mathrm{g}$ to $10 \mathrm{~Hz} / \mathrm{g}$. The output frequency then varies between about $900 \mathrm{~Hz}$ and $1100 \mathrm{~Hz}$ for full scale accelerations in the range of $10 \mathrm{~g}$ to $100 \mathrm{~g}$.

Figure 2 shows a cross sectional representation of an assembled cantilever configuration containing two double-ended tuning forks. If one assumes fixed joints at the bonded areas between the spacers and tuning forks, a simplified frame [10] analysis yields eq. (1) for the tension $\mathrm{T}$ per tine in the tines of the upper tuning fork.

$$
T=\frac{L M A}{4(D+t)}
$$

The length of the beam to the center of the proof mass is $L, D$ is the thickness of the spacer, and $t$ is the thickness of the double-ended tuning forks. The mass of the proof mass is $M$ and $A$ is the acceleration we wish to measure.

The frequency expressed in Hertz of the tuning fork as a function of the tension in the tines is given by [11] [12]

$$
f=f_{0} \sqrt{1+B T}
$$

where

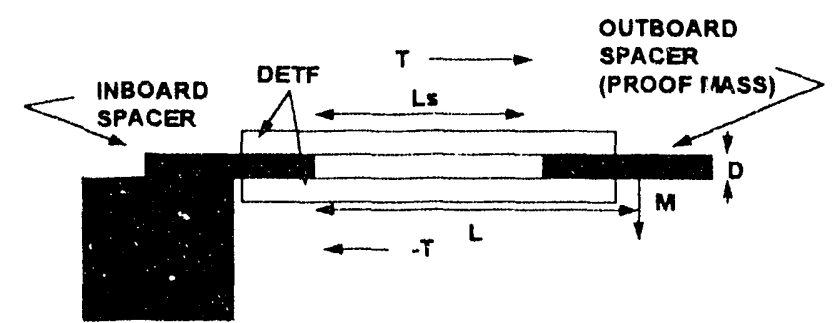

Figure 2 Schematic representation of the QDA sensor. 


$$
\begin{gathered}
f_{0}=a_{0} \frac{w}{L_{s}^{2}} \sqrt{\frac{E}{\rho}}, \\
B=\frac{a_{s} L_{s}^{2}}{E t w^{3}}, \\
a_{s}=0.294, a_{0}=1.03 .
\end{gathered}
$$

The behavior of output frequency versus tension (acceleration) described by eq. (2) is quite linear if we limit the operation to small values of BT. Consequently, eq.(2) becomes:

$$
f=f_{0}\left(1+\frac{B T}{2}\right) \text {. }
$$

We show the linearity of the individual DETF frequency change with acceleration in Figure 3 as well as the linearity of the output frequency for the nominal geometry' of the QDA. The figure shows the change in frequency of a $70 \mathrm{KHz}\left(\mathrm{f}_{\varepsilon}\right)$ and a $71 \mathrm{KHz}\left(\mathrm{f}_{\mathrm{b}}\right)$ tuning fork found by subtracting the exact solution of eq. (2) from the approximate linear solution of eq. (4). We have plotted the deviation in frequency for each fork. Also shown is the change in output frequency $\left(f_{c}\right)$ derived by

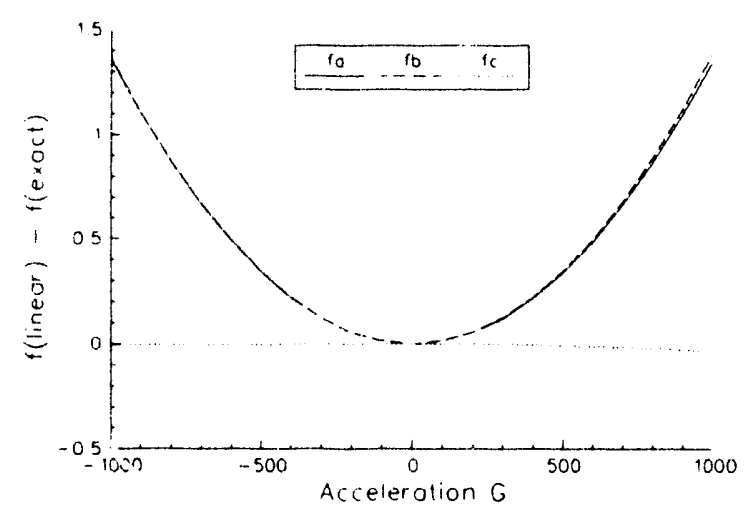

Figure 3 Reduced frequency $\left(f_{\text {linear }}-f_{\text {exac }}\right) / f_{\text {iinecia }}$ in ppm versus acceleration for the nominal configuration of a $70 \mathrm{KHz}$ DETF cantilever assembly QDA. subtracting the individual fork frequencies deviations. The maximum deviation of the individual fork frequencies from the exact solution is about $1.4 \mathrm{~Hz}$ while the maximum deviation of the difference output frequency is $0.04 \mathrm{~Hz}$ ai $1000 \mathrm{~g}$. We define the scale factor, $S$, of the accelerometer as the change in frequency per unit acceleration. Thus

$$
S=\frac{d f}{d A}=\frac{f_{0} B}{2} \frac{d T}{d A}
$$

which, if we apply the tension versus acceleration relation of eq.(1) to eq.(5) and express the acceleration in $\mathbf{g}$, becomes

$$
S=\frac{0.147 G f_{0} L_{s}^{2} M}{E t w^{3}} \frac{L}{4(D+t)}
$$

where $g$ is the gravita ional acceleration. The expression for scale factor given above is the scale factor for one tine or for one DETF. The tines of a given DETF are fabricated to the same geometry and will find a common frequency at which to resonate.

Applying these results to eq.(4), we can write the expression for the frequency change with acceleration for one (upper) fork as

$$
f_{a}=f_{0 a}+S_{a} A
$$

and for the other (lower) fork as

$$
f_{b}=f_{o b}-S_{b} A
$$

since the tension of the lower fork has the opposite sign from that of the upper fork.

Figure 4 depicts the variation of the scale factor of each fork as a function of acceleration. This variation is greater than $6000 \mathrm{ppm}$ at $1000 \mathrm{~g}$. When we combine the tivo tuning fork scale factors, the variation substantially cancels. The maximum 
combined variation for the cantilever assembly $\left(S_{c}\right)$ becomes approximately $100 \mathrm{ppm}$ at $1000 \mathrm{~g}$.

Figure 5 shows the electrical schematic for the sensor and electronic circuits used to generate the output frequency signal representative of the accelerometer. Each DETF comprises the resonant element of an oscillator circuit. The fork geometries determine the resonant frequency of about $70 \mathrm{Khz}$ and $71 \mathrm{Khz}$. Intentionally fabricating the forks to have slightly different tine lengths causes the frequencies to differ. This effect produces a nonzero output frequency at zero acceleration. A practical lower limit on this difference frequency is about $200 \mathrm{~Hz}$. Closer individual fork frequencies than $200 \mathrm{~Hz}$ tend to lock together. The mixer in the circuit forms the sum and difference frequencies and a filter in the mixer rejects the sum frequency.

The output of the mixer then consists of a difference frequency given by:

$$
\Delta f=f_{0 a}-f_{0 b}+\left(S_{a}+S_{b}\right) A
$$

For geometries typical of the QDA baseline design, the difference frequency $\left(\Delta f_{0}=f_{a_{a}}-f_{o b}\right)$ is $1 \mathrm{KHz}$ and the scale factor is between $1 \mathrm{~Hz} / \mathrm{g}$ and $10 \mathrm{~Hz} / \mathrm{g}$.

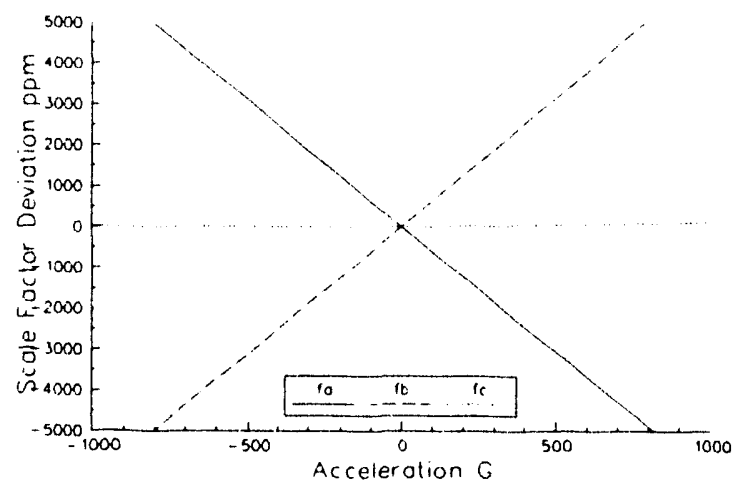

Figure 4 Scale factor deviation from zero acceleration value. The subscripts $a$ and $b$ refer to the DETFs and $c$ refers to the assembled cantilever.
Because the tine geometries of the upper and lower tuning forks are approximately the same the two scale factors, $S_{\mathrm{a}}$ and $S_{\mathrm{b}}$, are also approximately equal. The working output frequency of the QDA is then given by:

$$
\Delta f=\Delta f_{0}+S_{c} A
$$

where $S_{c}=2 S_{a}=2 S_{b}$. The second reason for choosing a non-zero bias frequency $\left(\Delta \mathrm{f}_{0}\right)$ is apparent from this equation. Both positive and negative accelerations may now be measured with this scheme to the limit where a negative acceleration results in a zero output frequency or locking together of the two DETF frequencies.

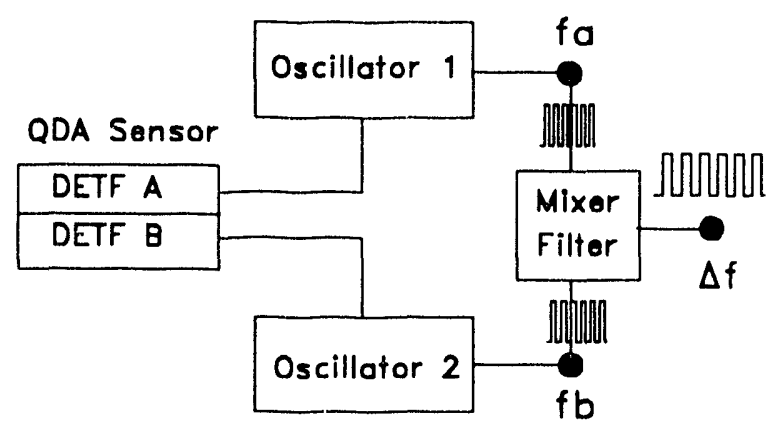

Figure 5 Schematic of QDA sensor, oscillators and mixer. 


\section{Design Considerations}

Most sensor designs are compromises based on measuring the desired quantity in the presence of other competing environmental stimuli. In the case of an accelerometer, desired accelerations must not only be measured in a variable temperature environment, for example, but must also consider variable unwanted acceleration environments such as shock and vibration. In most cases, this consideration is limired to surviving and maintaini.g accuracy in these environments. The geometries of the individual DETF and the cantilever beam configuration are the primary factors which are subject to design optimization. Figure 6 shows the geometry of the QDA for the nominal baseline design utilizing $70 \mathrm{KHz}$ double ended tuning forks. Table 1 gives a description of the dimensions and their values; in addition, the symbols used in the design equations is given where appropriate.

\subsection{Sensitivity $-S_{c}$}

The factors which affect the sensitivity or scale factor have been described earlier in this report. As the sensitivity of the device is increased by increasing the proof mass, the accuracy and acceleration bias stability are improved. The tradeoff is that the device mechanical resonances and frequency response are lowered. In addition, unless the motion of the cantilever is constrained, the ruggedness of the device to withstand mechanical shocks is reduced.

The expression for the scale factor of the frame cantilever [6] is:

$$
S_{c}=\frac{0.077 M L}{\sqrt{\frac{E}{\rho}} w^{2} t(D+t)}
$$

Figure 7 shows contour values of the scale factor calculated from eq. (11) for a range of tine widths and thicknesses for a QDA with the other dimensions as shown in Table 1. The specific value of tine width and thickness of the baseline QDA design is also shown by the marker in Figure 7. EerNisse and Paros [13] have described possible frequency interferences between different vibrational modes of the double ended tuning fork as the fork is stressed during operation. The various modes have different frequency dependence on stress and the frequencies can coincide as stress is varied if certain geometric constraints are not met. These avoidance regions are shown as the shaded areas and dotted lines in Figure 7.

\subsection{Mechanical Resonances - $\mathbf{f}_{b}$}

In an accelerometer mode of operation where an acceleration measurement [14] must be made below the lowest excited resonant frequency of the system, the mechanical resonances of the cantilever beam have an obvious direct effect on the measurement bandwidth. Well below the frequency of
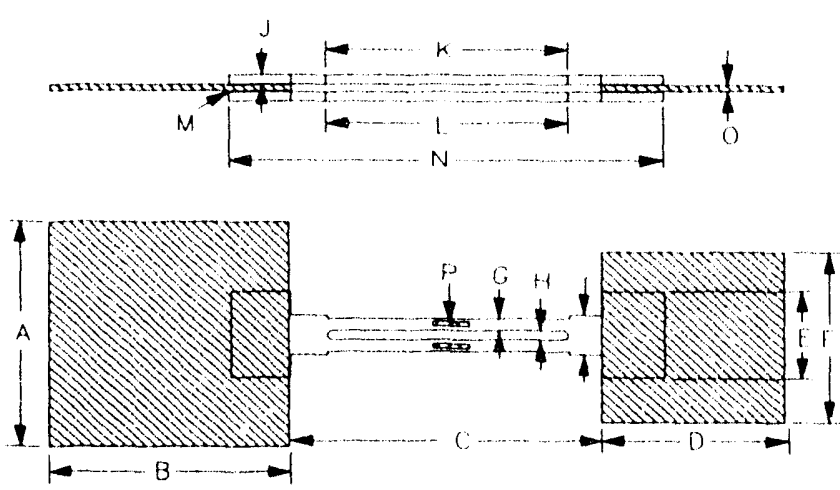

Figure 6 QDA cantilever assembly with dimensions (Also see Table 1). 
mechanical resonance the acceleration output mechanical resonance is more closely approached, becomes non-linear. As the frequency of large amplitude oscillations of the cantilever may be

Table 1 Typical dimensions and physical constants for QDA cantilever composed of nominal 70KHz double ended tuning forks, polyimide bonds and beryllium copper spacers.

\begin{tabular}{|c|c|c|c|}
\hline Dimension & Value (mm) & Description & Symbol \\
\hline A & 3.78 & Inboard Spacer Width & \\
\hline B & 3.78 & Inboard Spacer Length & \\
\hline $\mathrm{C}$ & 4.80 & Spacer-Spacer Length & \\
\hline $\mathrm{D}$ & 1.88 & Proof Mass Length & \\
\hline $\mathrm{E}$ & 1.40 & Fork Tab Width & \\
\hline$F$ & 1.88 & Proof Mass Width & \\
\hline G & 0.178 & Tine Width & $w$ \\
\hline $\mathrm{H}$ & 0.135 & Slot Width & \\
\hline I & 0.66 & Shoulder Width & \\
\hline$J$ & 0.152 & Tine Thickness & $\mathrm{t}$ \\
\hline $\mathrm{K}$ & 3.73 & Tine Length - Upper Fork & 1 \\
\hline $\mathrm{L}$ & 3.71 & Tine Length - Lower Fork & $l_{s}$ \\
\hline $\mathrm{M}$ & 0.025 & Bond Thickness & \\
\hline $\mathrm{N}$ & 6.8 & Fork Length & \\
\hline $\mathrm{O}$ & 0.127 & Spacer Thickness & D \\
\hline $\mathbf{P}$ & $0.075 \times 0.5$ & Tuning Pads & \\
\hline \multirow[t]{4}{*}{$\mathrm{C}+\mathrm{D} / 2$} & 5.74 & Moment Arm & $\mathrm{L}$ \\
\hline & $4.0 \mathrm{mg}$ & Mass of $\mathrm{BeCu}$ Proof Mass & $\mathbf{M}$ \\
\hline & $2650 \mathrm{~kg} / \mathrm{m}^{3}$ & Density of Quartz & $\rho$ \\
\hline & $7.81 \times 10^{10} \mathrm{~N} / \mathrm{m}^{2}$ & Elastic Modulus of Quartz & $\mathrm{E}$ \\
\hline
\end{tabular}




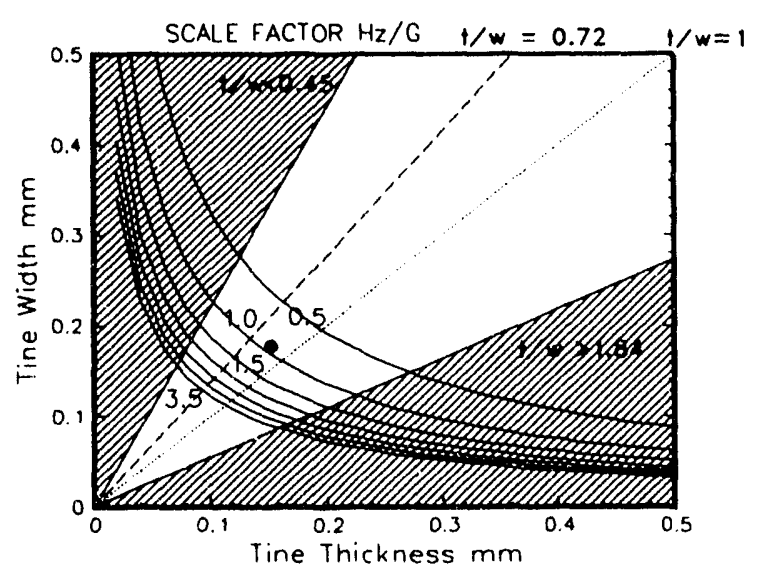

Figure 7 Accelerometer Sensitivity: Constant scale factor contours as a function of double ended tuning fork tine thickness and width.

generated. Physical damage from such oscillations may be largely prevented by constraining the motion of the cantilever either by mechanical or electrical damping [15]. These techniques, however, add complexity to the system. In the case of the QDA, neither electrical damping nor mechanical constraints are used.

The expression for the frequency [16] of a cantilever beam of mass $m$ with a lumped mass $M$ at the free end is [17]:

$$
f_{b}=\frac{1}{2 \pi} \sqrt{\frac{k}{M+.23 m}}
$$

where $k=2 k_{f}$ is the stiffness of the frame assembly and $k_{f}$ is the stiffness of each individual tuning fork and $k_{f}=12 E I / L^{3} . \quad E$ is the elastic modulus and $\mathrm{L}$ the length of the beain.

For vibration along the input axis of the accelerometer

$$
I=\frac{2 w t^{3}}{12}
$$

where $w$ is the tuning fork tine width and $t$ the thickness of the tine (and fork).

The natural frequency of the beam along the input axis of the sensor is therefore

$$
f_{b}=\frac{1}{2 \pi} \sqrt{\frac{4 E w t^{3}}{L^{3}(M+.92 w t L \rho)}}
$$

where $\rho$ is the density of quartz.

Figure 8 shows the constant contours for the beam frequency calculated from eq. (14) using the same parameters used to calculate the scale factor in Figure 7. The original design goal was to maintain the lowest resonant beam frequency greater than $2000 \mathrm{~Hz}$ for environmental sensing applications, the baseline design meets this goal with $\mathrm{f}_{\mathrm{b}}=2200 \mathrm{~Hz}$. The beam frequency decreases as the cross section area of the tine is decreased, thereby limiting the scale factor of the baseline design to about $1.0 \mathrm{~Hz} / \mathrm{g}$. For navigation applications, the resonant frequency may be lower $(500 \mathrm{~Hz}-1000 \mathrm{~Hz})$ and accelerometers

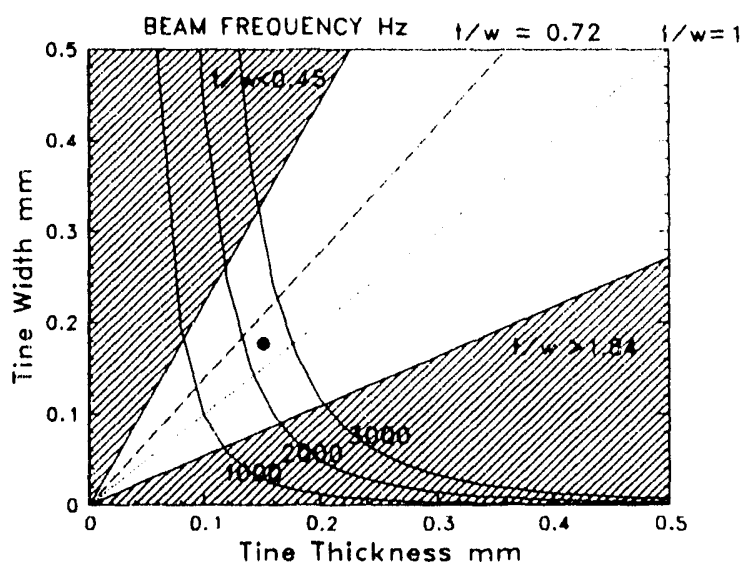

Figure 8 Beam Frequency: Contours of constant cantilever beam vibration frequency as a function of the tine width and thickness. 


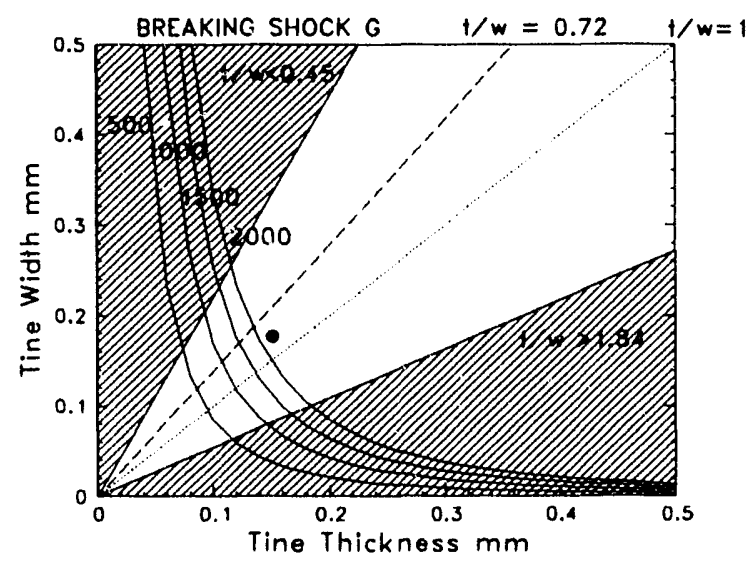

Figure 9 Breaking acceleration: Contours of constant breaking acceleration as a function of the tine width and thickness.

with scale factors as large as $10 \mathrm{~Hz} / \mathrm{g}$ have been built.

\subsection{Maximum Acceleration - $\mathbf{A}_{\max }$}

The maximum acceleration which an accelerometer will withstand before fracturing is determined by the maximum tensile stress of quartz. This value is taken as $100 \mathrm{MPa}(15000 \mathrm{psi})$ [18]. The maximum stress in the cantilever beam occurs at the base of the tuning fork tines near the mounting shelf. This stress is:

$$
T_{\max }=\frac{3 M A L}{4 w t^{2}}
$$

Figure 9 shows the values of tine width and thickness for various breaking accelerations in $\mathbf{g}$. Again as one might expect, the smaller the tine cross section the more fragile the device.

\subsection{Acceleration Measurement Error Sources - $\delta \mathbf{A}$}

The acceleration is found by rearranging eq. (10) to give:

$$
A=\frac{\Delta f-\Delta f_{0}}{S_{c}}
$$

The differential of this expression gives the total acceleration error:

$$
\delta A=\frac{1}{S_{c}}\left(\delta \Delta f-\delta \Delta f_{0}-A \delta S_{c}\right)
$$

The terms in this equation constitute the error sources for an acceleration measurement. Physically, $\delta \Delta \mathrm{f}$ is the frequency measurement error, $\delta \Delta f_{0}$ is the instability or variation of the bias frequency over time, temperature and other environments, $\delta \mathrm{S}_{\mathrm{c}}$ is the variation of the sensitivity or scale factor over the same environments.

We can see from eq. (17) that an increase in the scale factor decreases the acceleration measurement error assuming that the bias frequency stability is not affected. The following sections on sensitivity, mechanical resonances and maximum acceleration are all limits on the ability to design a sensor with high sensitivity given that other considerations (e.g. survivability, producibility, measurement bandwidth, etc.) exist.

\subsection{Bias Frequency and Scale Factor Stability $-\delta \Delta \mathrm{f}_{0}$ and $\delta \mathrm{S}_{\mathrm{c}}$}

The acceleration bias stability is the tendency of the device to have a constant output under a constant zero acceleration load. Factors which affect the bias frequency stability are temperature, electrical noise, long term aging, shock and vibration. An expression of the treatment of these errors is given below; although, in many cases, it may be more appropriate to find the square root of the sum of the squares of the error terms. We have chosen to treat the errors more conservatively and add the errors 


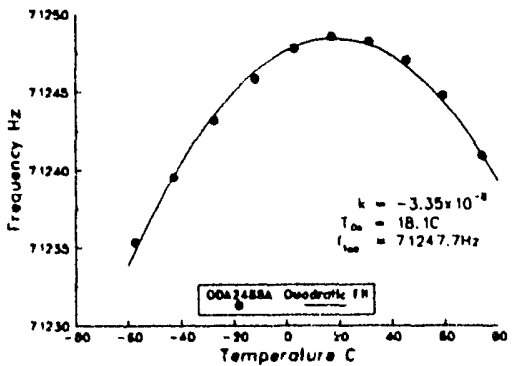

Figure 10 Typical temperature dependence of frequency for a Z-cut double-ended tuning fork. The parameters which fit the data are: $\mathrm{k}=-3.35 \times 10^{-8}, \mathrm{~T}_{0_{\mathrm{H}}}=18.1 \mathrm{C}$, and $\mathrm{f}_{\mathrm{TOa}_{\mathrm{a}}}=71247.7 \mathrm{~Hz}$.

linearly without regard to sign until a root sum of squares approach is thought to be more descriptive.

$$
\begin{aligned}
8 \Delta f_{0}= & 8 \Delta f_{o r}+8 \Delta f_{0 \text { molse }}+8 \Delta f_{0 \text { age }} \\
& +8 \Delta f_{0 \text { shock }}+8 \Delta f_{0 \text { vib }}
\end{aligned}
$$

Likewise, we can write:

$$
\begin{aligned}
8 S_{c}= & 8 S_{C T}+8 S_{C \text { noise }}+8 S_{C \text { age }} \\
& +8 S_{C \text { shock }}+8 S_{C \text { vib }}
\end{aligned}
$$

Experimental data characterizing electrical noise and aging will be presented later in this report. Shock may also affect the bias frequency by causing a permanent shift. Vibration can produce vibration rectification to give an apparent change in bias frequency. These effects have also been measured.

The major advantage of the dual DETF design is common mode rejection of an external stimulus such as temperature. The temperature cancellation effect is especially important because the individual fork frequency temperature dependence is well known to be large compared to the desired response to acceleration.

For a Z-cut quartz crystal, the frequency of one DETF $\left(f_{0 a}\right)$ versus temperature may be described by:

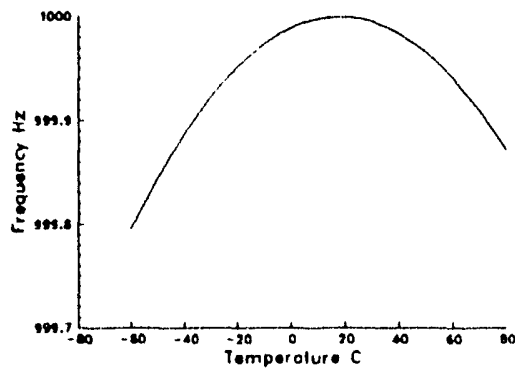

Figure 11 Cantilever output frequency for a cantilever composed of two DETF differing only by their nominal output frequency.

$$
\frac{f_{\alpha_{a}}-f_{T a_{a}}}{f_{T a_{a}}}=k\left(T-T_{\infty a}\right)^{2}
$$

where $f_{T 0}$ is the frequency of one DETF at the turnover temperature $\mathrm{T}_{0 \mathrm{a}} ; \mathrm{T}_{\mathrm{Oa}}$ and $\mathrm{k}$ are constants determined by the material parameters and crystal cut.

If the frequency of a second fork with the same turnover temperature $\left(\mathrm{T}_{0 \mathrm{a}}\right)$ and $\mathrm{k}$ is subtracted from the first DETF, the following output frequency results:

$$
\Delta f_{0}=k\left(f_{T 0 a}-f_{T O b}\right)\left(T-T_{0 a}\right)^{2}+f_{T O a}-f_{T O b}
$$

The temperature behavior of output ficquency $\left(\Delta \mathrm{f}_{0}\right)$ is plotted in Figure 11 for two forks with the same parameters found in Figure 10; the forks are assumed only to differ by $1000 \mathrm{~Hz}$ in their turnover frequencies $\left(f_{\mathrm{TOa}}, f_{\mathrm{TOb}}\right)$. It can be sesan that the residual frequency dependence on teinperature is greatly reduced. In fact, the reduction factor is $\Delta \mathrm{f}_{0} / \mathrm{f}_{0 \mathrm{a}}$.

As will be shown later, this ideal case combination of two DETF to yield a cantilever output frequency with a small temperature dependence is the focus of 
finite element modeling and assembly processing techniques. The stresses associated with assembly shift the turnover temperatures of the individual tuning forks. This shift in turnover temperatures results in less cancellation of the inherent fork frequency temperature dependence and a large temperature dependence for the cantilever output frequency.

\subsection{Frequency Measurement Error - $\delta \Delta f$}

An important consideration in the QDA design is the choice of output frequency; a higher output frequency allows for greater measurement bandwidth but requires a faster reference clock to maintain accuracy. The lower of the first beam mechanical resonance $f_{b}$ or output frequency $f_{o}$ determines the bandwidth of the QDA. The following analysis is included to present the errors associated with frequency measurement. In order to measure a frequency $f$, it is necessary to determine the length of the fundamental period $\lambda_{0}$. This is typically accomplished by measuring a known number of cycles $n$ of the unknown frequency by counting the ticks $n_{T}$ of a reference clock of known frequency $f_{r}$. The measured frequency is given by:

$$
f=\frac{n f_{r}}{n_{r}}
$$

The total differential of this expression may be used to find the error contributions to $f(\delta f)$ from the various measurement error sources.

$$
\delta f=\frac{f_{r}}{n_{r}} \delta n+\frac{n}{n_{r}} \delta f_{r}+\frac{n f_{r}}{n_{r}^{2}} \delta n_{r}
$$

Typically, the measured frequency is counted for a known number of cycles so that $\delta \mathrm{n}=0$, and the maximum error in the reference clock counts is $\delta n_{r}$ $= \pm 1$. In addition if we recognize that the sampling frequency $f_{s}=f / n$ and substitute into the previous equation, the expression for error in the unknown frequency is

$$
\delta f=\frac{\left(\delta f_{r}+f_{s}\right) f}{f_{r}}
$$

The absolute frequency measurement accuracy is determined by the reference clock accuracy and the quantization error determined by the sampling frequency.

For typical values of $f_{r}=4 \mathrm{MHz}, \delta f_{r} / f_{r}=100 p p m$, $\mathrm{f}_{\mathrm{s}}=500 \mathrm{~Hz}$ and $\mathrm{f}=1000 \mathrm{~Hz} ; \delta \mathrm{f}=0.225 \mathrm{~Hz}$. The error in acceleration from frequency measurement alone is $0.225 \mathrm{~g}$ for a scale factor of $1 \mathrm{~Hz} / \mathrm{g}$. Reduction in this error can occur by increasing the scale factor, increasing the reference clock speed, improving the reference clock accuracy, or decreasing the sample frequency. 


\section{Quartz Processing}

\subsection{Sandia Capabilities}

Two capabilities required for QDA prototyping not previously existent at SNL were implemented for the f...jrication of quartz DETFs, spacers, and proof masses. The of development of manufacturing capabilities included:

(1) the preparation of the quartz blanks (or wafers) and

(2) the photolithographic definition of the geometry and metallization patterns for the DETF, spacers and proof masses from the quartz blanks.

\subsection{Substrate Specifications}

The single crystal quartz substrates were obtained from one of the following sources:
(1) Statek Corporation [19];

(2) P.R. Hoffman Materials Proc. [20];

(3) Sawyer Crystal Systems [21].

The first source of quartz wafers, Statek, did not fabricate the wafers so that a material specification and history were not readily available; however, the majority of the initial resonators were made with quartz from Statek. A thorough specification of the quartz material was drawn up and used to procure material from the latter two sources. The quartz zplates wafers measured $23.6 \pm 0.8 \mathrm{~mm}$ $\left(0.930 \pm 0.030^{\prime \prime}\right)$ in the $x$-(crystallographic) direction; $26.9 \pm 0.76 \mathrm{~mm}\left(1.060 \pm 0.030^{\prime \prime}\right)$ in the $y$ direction; and $0.30 \pm 0.08 \mathrm{~mm}\left(0.012 \pm 0.003^{\prime \prime}\right)$ in the thickness or $\mathrm{z}\left(-2^{\circ}\right)$-direction. The as-received material had a surface which corresponded to that resulting from a rough lapping process using $30 \mu \mathrm{m}$ or finer alumina.

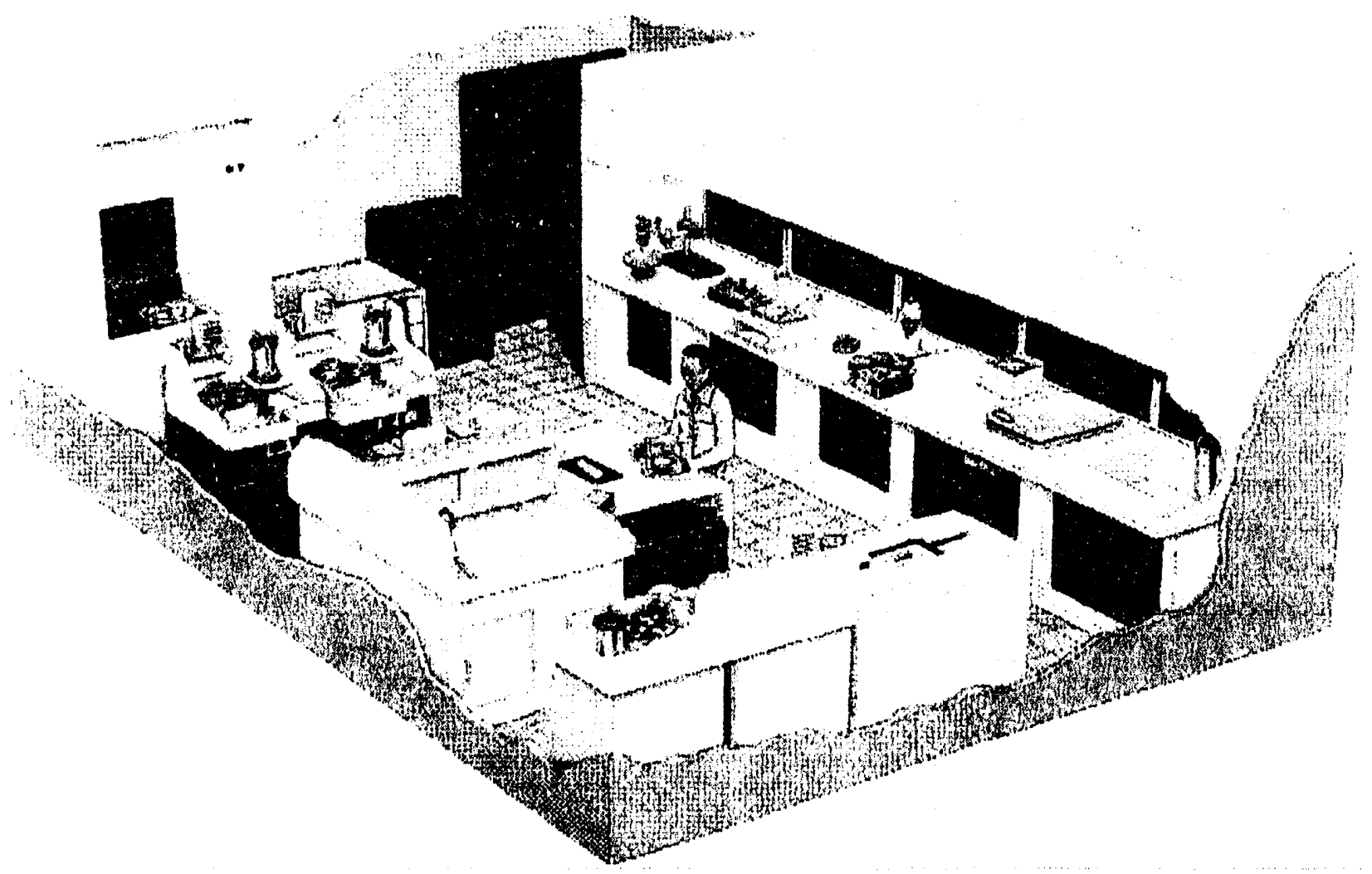

Figure 12 Artist's rendition of the Substrate Preparation Laboratory. 


\subsection{Substrate Preparation}

Lapping and polishing processes were required to provide quartz wafers with an optical pclish on both sides that was free of gross defects such as cracks and chips. The thickness of the final quartz blanks was designated as $156.2 \pm 0.5 \mu \mathrm{m} \quad(6150 \pm 20$ microinches) as measured on the mounting block and $156.2 \pm 1.2 \mu \mathrm{m}(6150 \pm 50$ microinches) after removal from the mounting block (deblocking). The two major surfaces of the wafer were to be parallel to within $1.2 \mu \mathrm{m}$ (50 microinches) over $80 \%$ of the surface area after deblocking. The manufacture of the quartz wafers meeting these dimensional specifications was achieved by a singlesided lapping and polishing technique developed by XECO Inc. [22]. The lapping and polishing processes were performed in the Substrate Preparation. Laboratory [23] depicted in Figure 12. Two photographs showing the wafer cleaning and blocking stations appear in Figure 13 and Figure 14. All cleaning and blocking procedures were performed in the laminar flow benches which maintained the air volumes between class 100 and 200.

The surface preparation process is outlined in the flow chart in Figure 15. The wafers are received from the manufacturer(s) with the surface finish that results from the rough lapping process $(30 \mu \mathrm{m}$

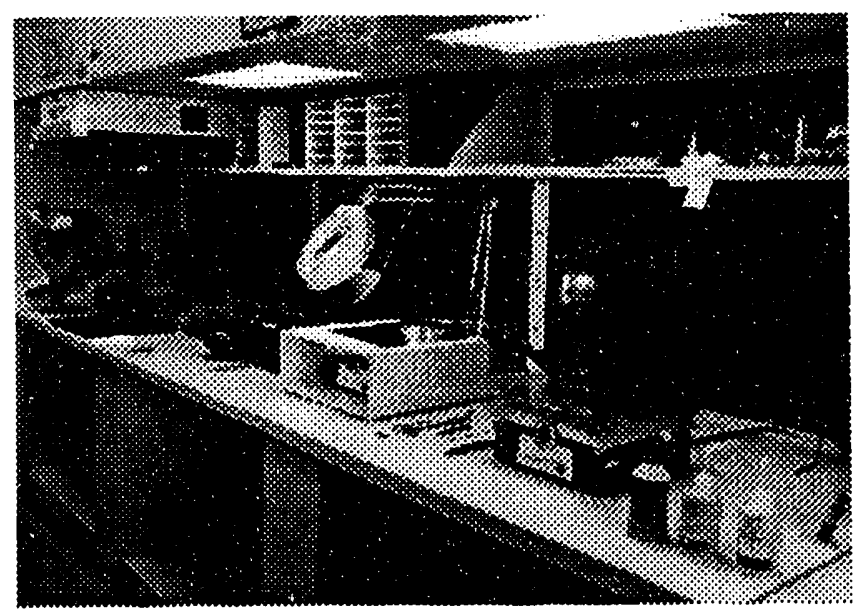

Figure 13 Photograph of inspection area. abrasive) necessary to meet the requested thickness specifications. The surface roughness and flatness of an as-received wafer is summarized in Figure 16. The surface roughness measurements were made with a non-contacting surface profilometer [24]. Large scale fluctuations of $3.3 \mu \mathrm{m}$ ( 130 microinches) peak-to-peak are shown in the top half of Figure 16 while the smaller scale variations of 8000 to $9000 \AA$ (peak-to-peak) are displayed in the bottom half; both categories of surface roughness were unacceptable for thin film deposition or satisfactory device performance. In addition to contaminants on the wafer surface, the cutting process also introduced considerable stress into the near-surface regions of the blanks. These stresses are evident in Figure 17 which shows the loss of flatness [25] due to bowing of the wafer under the residual stress resulting from the cutting operation. The goals of the substrate preparation procedure were to condition the wafer surfaces to an optical polish, obtain the dimensional tolerances noted above and to remove sub-surface stresses which affect the wafer dimensions and thereby influence the resonator properties of the DETF.

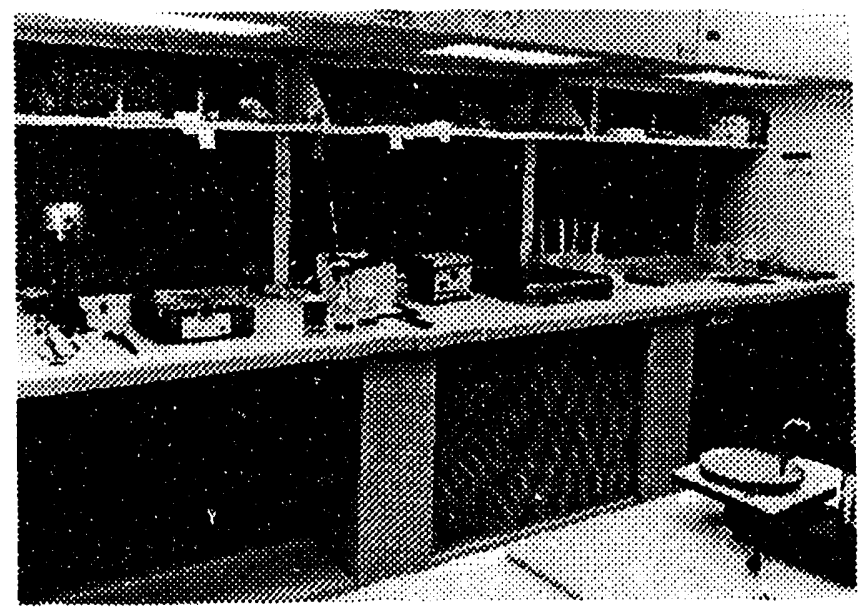

Figure 14 Photograph of cleaning and mounting area. 

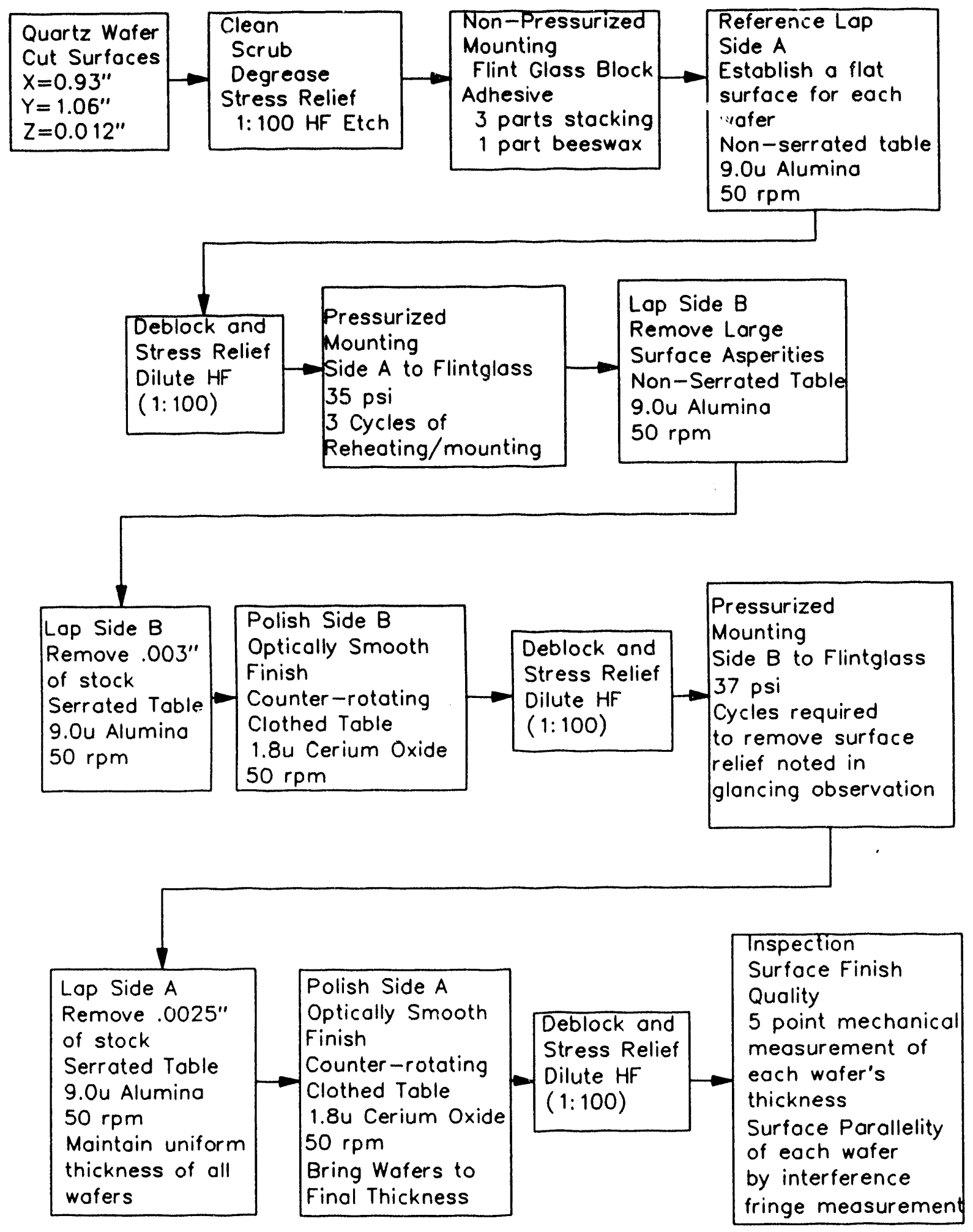

Figure 15 Flow diagram of the lapping and polishing procedure. 

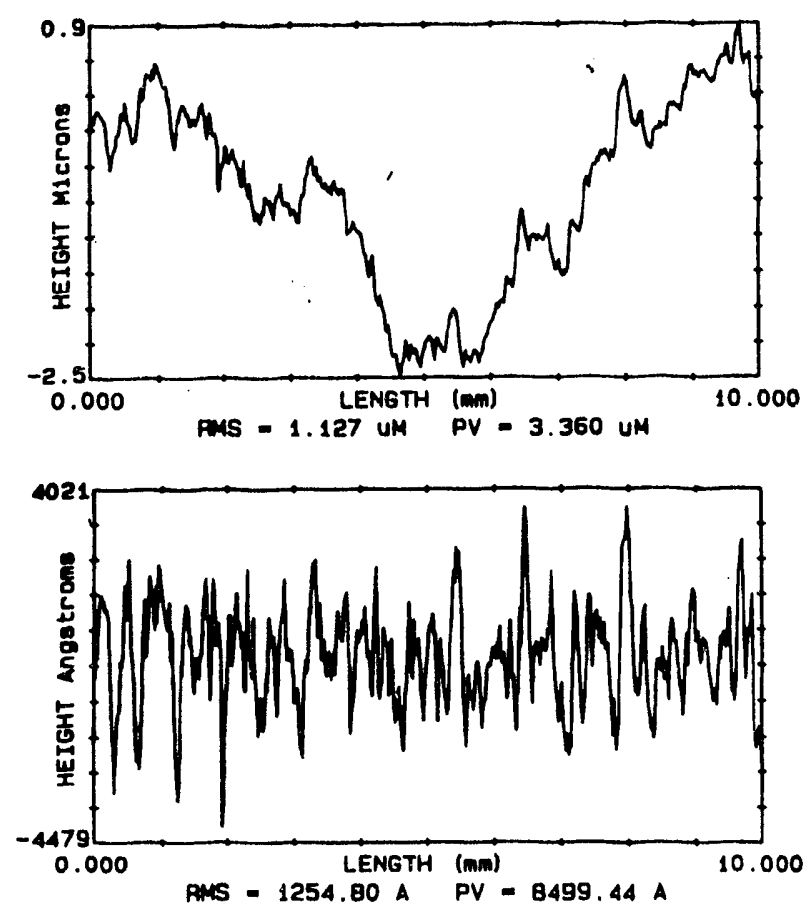

Figure 16 Large scale roughness of an as-received quartz wafer surface measured by non-contact profilometry.
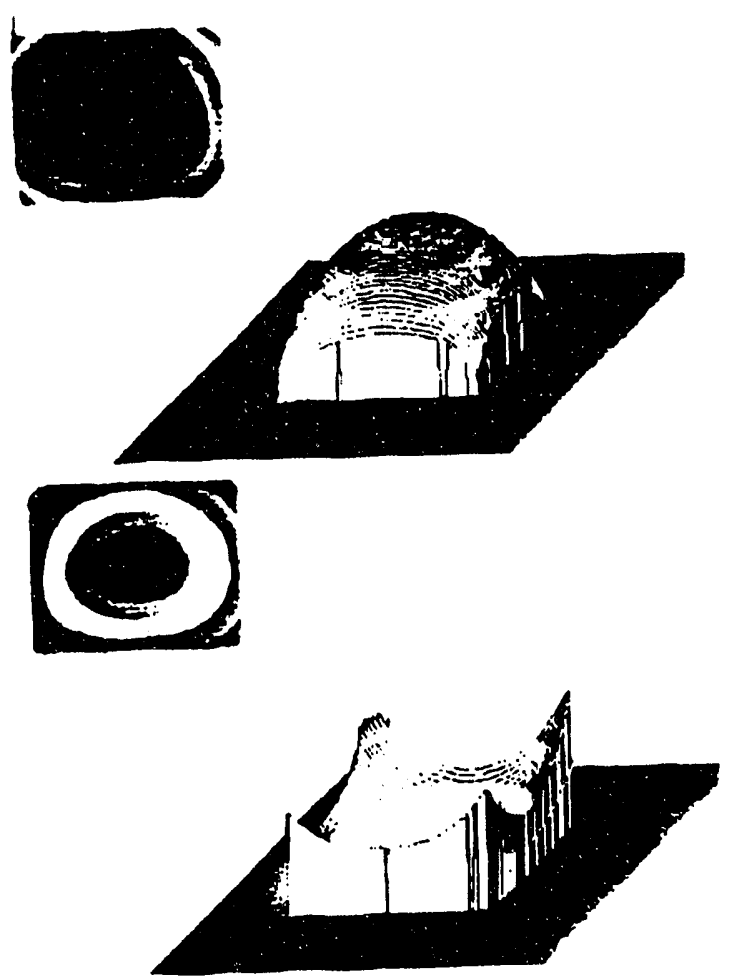

Figure 17 Three-dimensional construct of the flatness of an as-received quartz wafer from the top side and bottom side, respectively. 


\subsubsection{Cleaning}

A batch of between 14 and 17 wafers was cleaned and stress relieved. Cleaning was performed by scrubbing each wafer in soapy water followed by a cascade rinse in deionized water with a resistivity equal to or greater than $10 \mathrm{Mn}-\mathrm{cm}$ at $25^{\circ} \mathrm{C}$ in the bath. The wafers were next degreased by immersion in a vapor cloud of boiling 1,1,1trichloroethane (TCE) followed by an ultrasonic cleaning in a bath of TCE held at $26^{\circ} \mathrm{C}$. The wafers were then stress relieved by immersion for 10 minutes in hydrofluoric acid (HF) which had been diluted $1(\mathrm{HF}): 10\left(\mathrm{H}_{2} \mathrm{O}\right)$.

\subsubsection{Mounting}

The blanks were mounted on flint glass blocks [26] measuring $152 \mathrm{~mm}\left(6^{\prime \prime}\right)$ diameter and $19 \mathrm{~mm}\left(0.75^{\prime \prime}\right)$ thick. The pattern is shown in Figure 18 (14 wafer pattern). Prior to mounting the quartz wafers, the glass blocks were contoured on the serrated lapping table so that the surface became 0.8 to $1.3 \mu \mathrm{m}$ (30 to 50 microinches) convex (or higher at the center than at the edges). The curvature was measured by the number of Newton's rings formed between the block and an optical flat

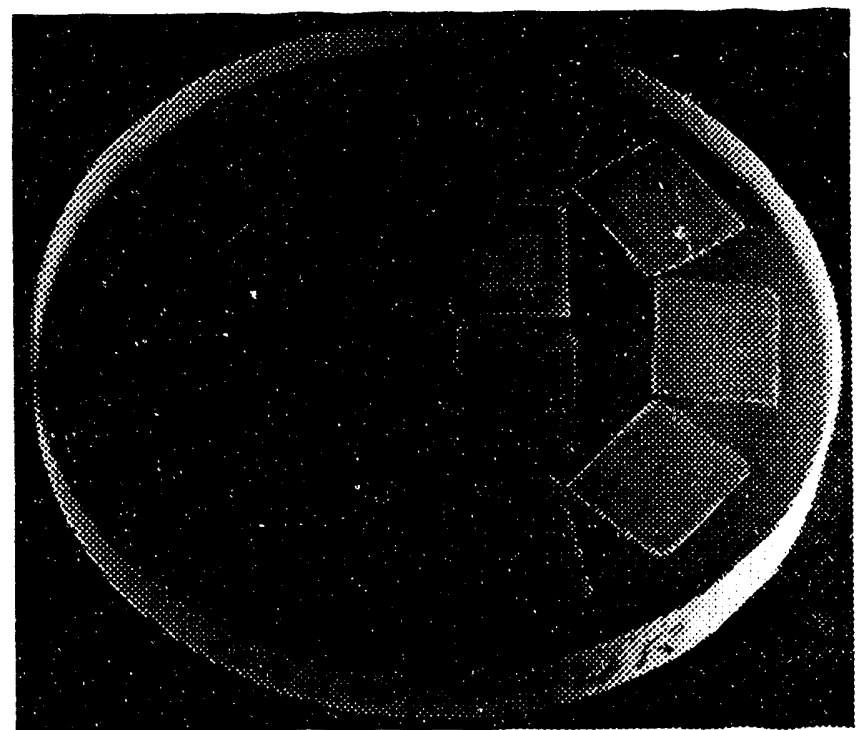

Figure 18 Photograph of the pattern of quartz wafers on the glass mounting block. The block is 6 in diameter. positioned under a monochromatic light source of $546 \mathrm{~nm}$ wavelength (Figure 19). Between two fringes, the separation between the glass block and the optical flat is approximately $0.27 \mu \mathrm{m}(10.8$ microinches). The glass block in Figure 19 has 3 to 4 fringes positioned from the center to the edge which are equivalent to a height difference of 0.8 $1.0 \mu \mathrm{m}$ (30-40 microinches). The reason for introducing a curvature to the block (and the group of wafers on it) was to assure the parallelism specification to the wafers following the polishing process to be discussed later. The quartz wafers were bonded to the glass block by an adhesive formed from 3 parts stacking wax and 1 part beeswax. The differential scanning calorimeter (DSC) thermogram of the wax mixture (Figure 20) shows that the onset to melting begins at approximately $24^{\circ} \mathrm{C}$ (room temperature) and is completed at approximately $60^{\circ} \mathrm{C}$ for the heating rate of $10^{\circ} \mathrm{C} /$ minute. The plot is reversible upon cooling. The wax was used at $130^{\circ} \mathrm{C}$ in order to maintain enough fluidity of the liquid to form the thin bond joint between the wafer and the glass block. Although pure beeswax is sufficiently fluid at less than $100^{\circ} \mathrm{C}$, it cannot provide the strength

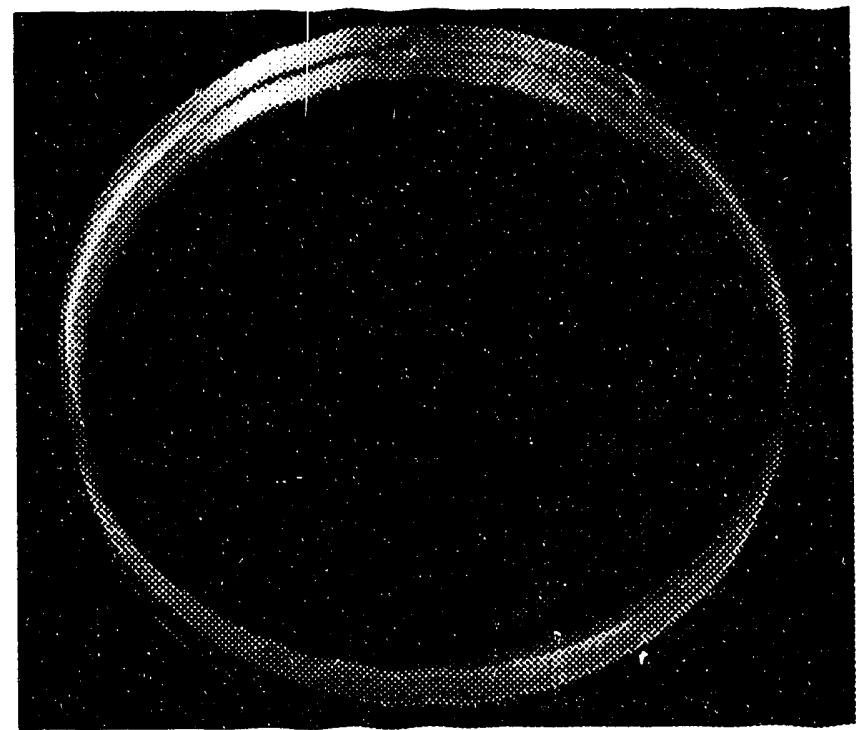

Figure 19 The interference (Newton) rings between a glass mounting block and an optical flat. The monochromatic light source was at $546 \mathrm{~nm}$. 
necessary to hold the wafers in place at such small joint thickness, hence the addition of the stacking wax. The fluidity of pure stacking wax was inherently low so that it was difficult to form a uniformly thin layer of wax in the joint. Temperatures in excess of $135^{\circ} \mathrm{C}$ for long periods of time caused degradation to the beeswax structure and a significant drop in the fluidity.

The glass block was placed on a hot plate and heated to $130^{\circ} \mathrm{C}$ as measured on the block surface. A drop of the preheated wax mixture was placed on the block. Next, a quartz wafer which had been preheated to $125-130^{\circ} \mathrm{C}$ was placed onto the wax drop. Capillary action formed a thin layer of wax between the wafer and the block. The block and the batch of fourteen wafers were allowed to cool. Next, the assembly was cleaned of excess wax by placing it on a rotating table [27], operating at $50 \mathrm{rpm}$, which was covered with a detergent soaked scrubbing pad. This equipment is shown in Figure 21. The block of wafers was held in place by a stainless steel retaining ring. A weight of approximately $5.2 \mathrm{~kg}$ was placed on top of the glass block.

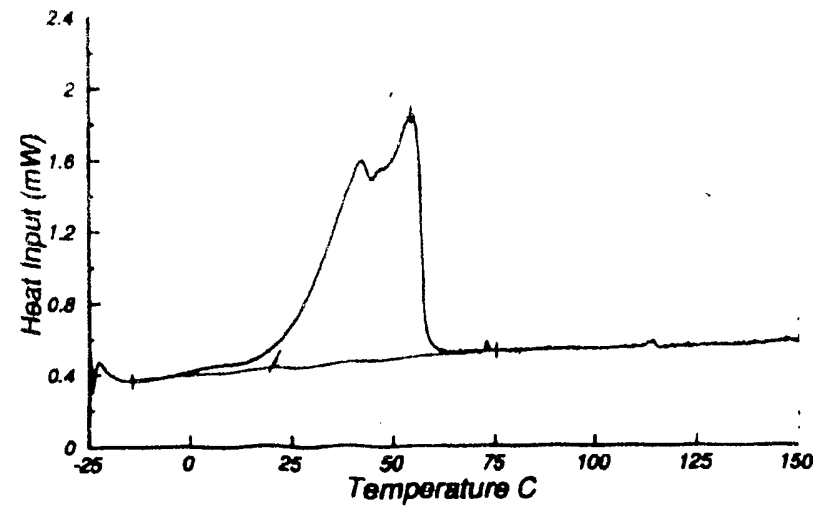

Figure 20 Differential scanning calorimeter (DSC) plot for the wax mixture of 3 parts stacking wax to 1 part beeswax. The heating rate was $10^{\circ} \mathrm{C} / \mathrm{min}$.

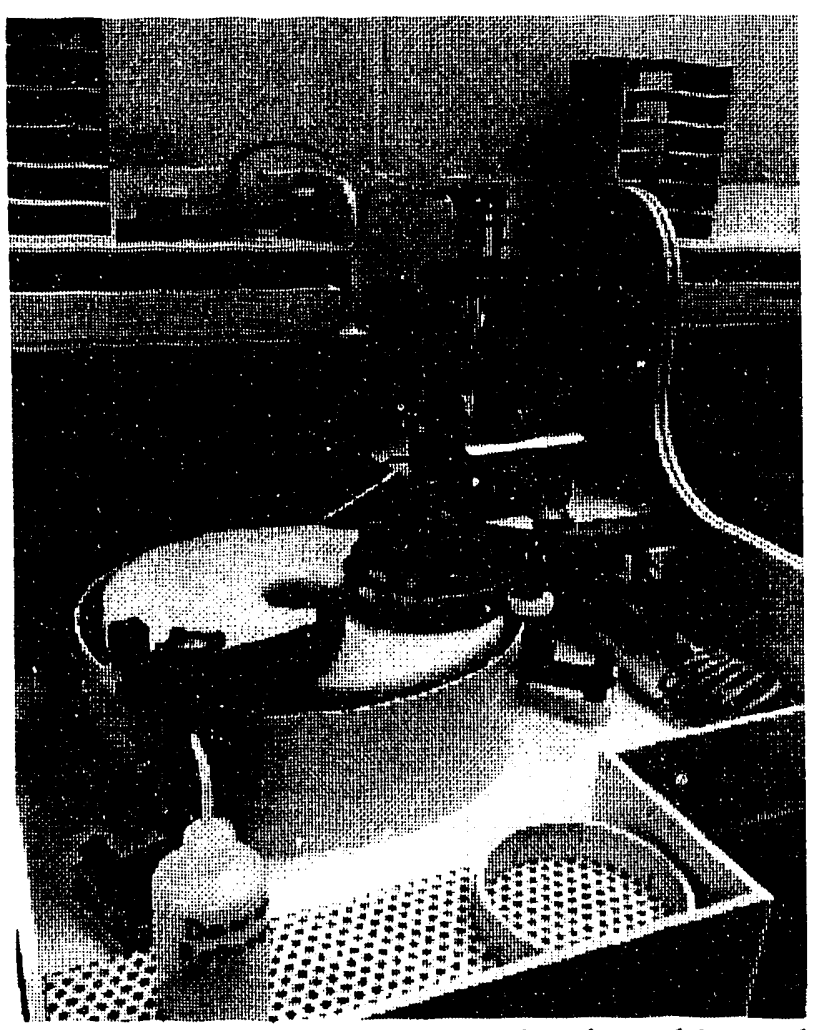

Figure 21 Photograph of the cleaning table used to remove excess wax from the block and wafers. 


\subsubsection{Reference Grinding}

A reference grind was performed on the wafers (side $A$ in the flow chart in Figure 15) using the non-serrated lapping table shown in Figure 22. The non-serrated table has a slower material removal rate than the serrated table (Figure 23) but was less likely to chip or crack the wafers due to surface asperities of the as-received blanks. The cast iron surface table rotated at $50 \mathrm{~mm}$. As on the wax cleaning table, the block of wafers was held in place by a stainless steel ring which also helped to distribute the abrasive slurry. A $5.2 \mathrm{~kg}$ weight was placed on top of the block. The table surface was contoured over the annular region to be 0.25 to $0.8 \mu \mathrm{m}$ (10-30 microinches) co xcave (lower at the center than at the edges). Note that this concavity rearly matches the convexity of the glass block so that the wafers would develop the same thickness over the curved surface of the block during the

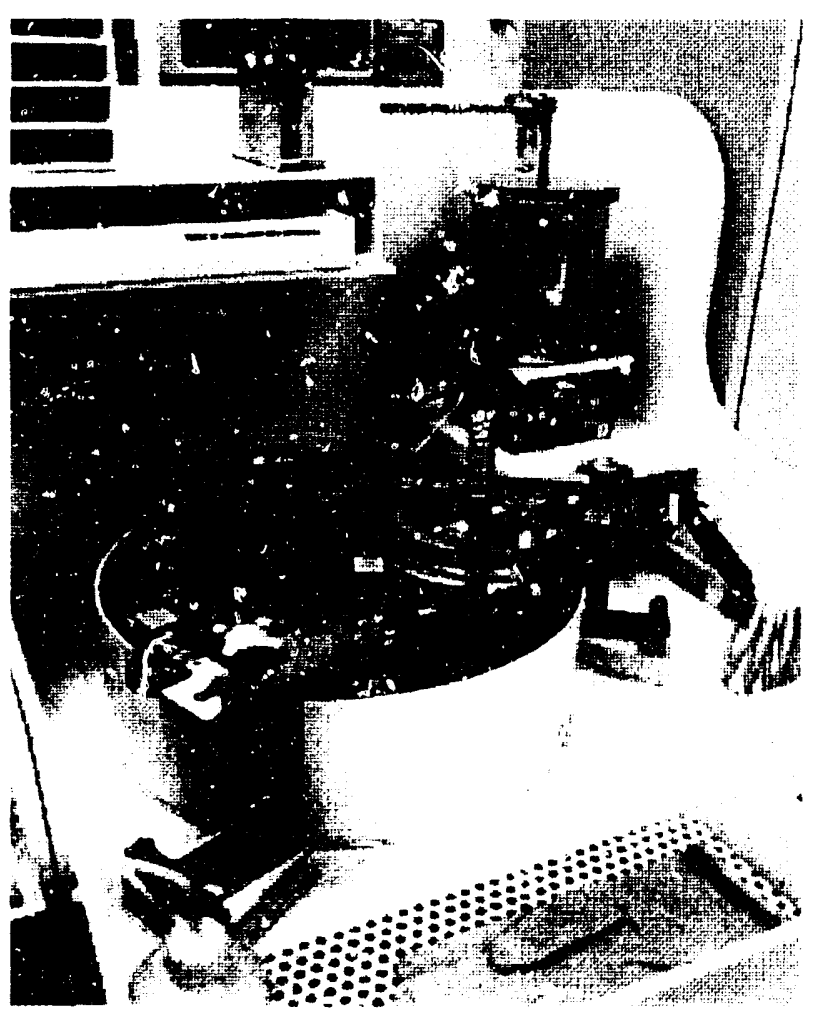

Figure 22 Photograph of the non-serrated lapping table. lapping process. The slight difference between the concavity and convexity of the table and block, respectively was adjusted to optimize the thickness uniformity of the wafers. The lapping slurry consisted of $700 \mathrm{~g}$ of $9.0 \mu \mathrm{m}$ alumina powder mixed in 4 liters of deionized water. The material remjval process was purely mechanical abrasion. The purpose of the reference grind step was to establish a relatively flat surface on one side of each of the wafers from which to begin the controlled reduction of thickness. Approximately $25 \mu \mathrm{m}(0.001 \mathrm{inch})$ of material was removed as part of this procedure. Upon completion of this lapping step, the glass block with the wafers was reheated to melt the svax compound and release the wafers. The wafers were degreased of the wax residues (as was the glass block) and then stress relieved by immersion in the diluted HF.

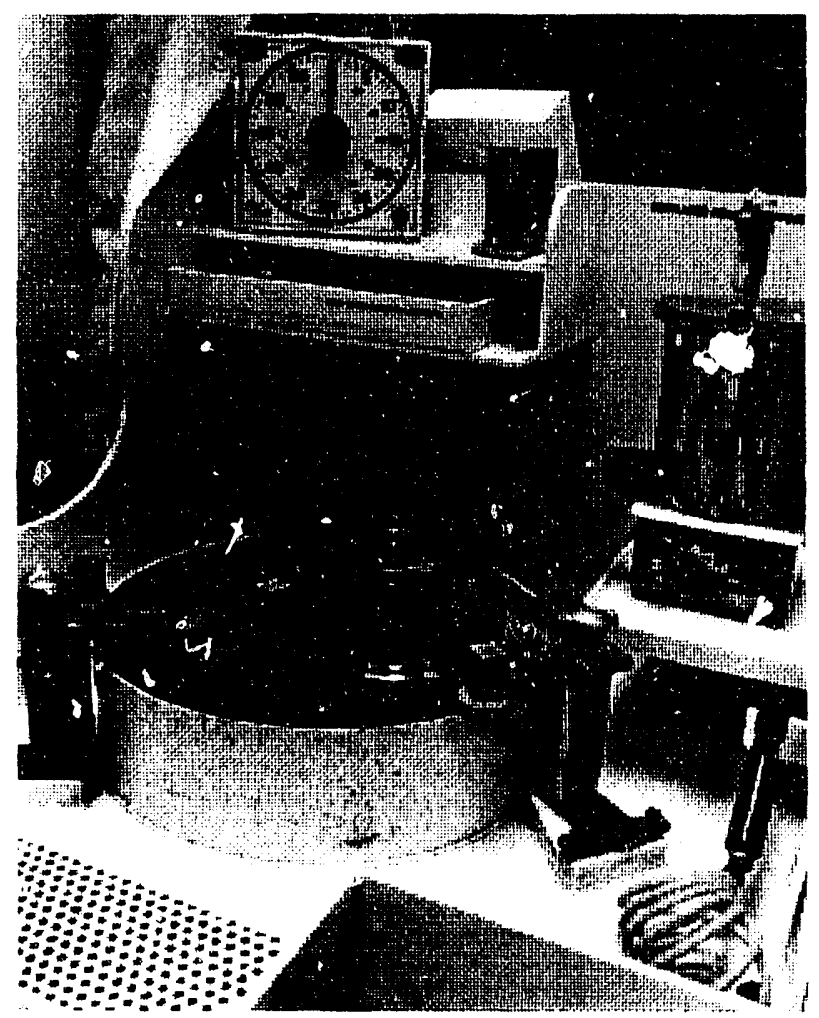

Figure 23 Photograph of the serrated lapping table. 


\subsubsection{Remounting}

After being stress relieved, the wafers were remounted onto the glass block. This time the previously lapped side A (Figure 15) was next to the glass surface so that side B (Figure 15) would be conditioned. In this step, however, the wafers were not permitted to settle on the molten wax under gravity and capillary action and remain so until the wax had solidified. Instead, after all of the wafers were in place and while the wax was still molten, the block was placed in the pressure blocking apparatus shown in Figure 24. The goal of this procedure was to form a very thin, but more important, uniformly thick layer of wax between the wafers and the glass block. The uniformity of the wax layer had a direct effect on the final parallelism and flatness of the wafers.

The formation of a uniformly thin wax layer involved stacking various materials as shown in Figure 25. An $3.1 \mathrm{~mm}$ thick heated aluminum plate previously contoured to be approximately $0.8 \mu \mathrm{m}$ concave to match the contour of the mounted wafers was included in this stack. The entire assembly was placed in the pressure blocking apparatus which applied a pressure of 37 psi onto the wafers at the same time that the cooling plate, which formed the

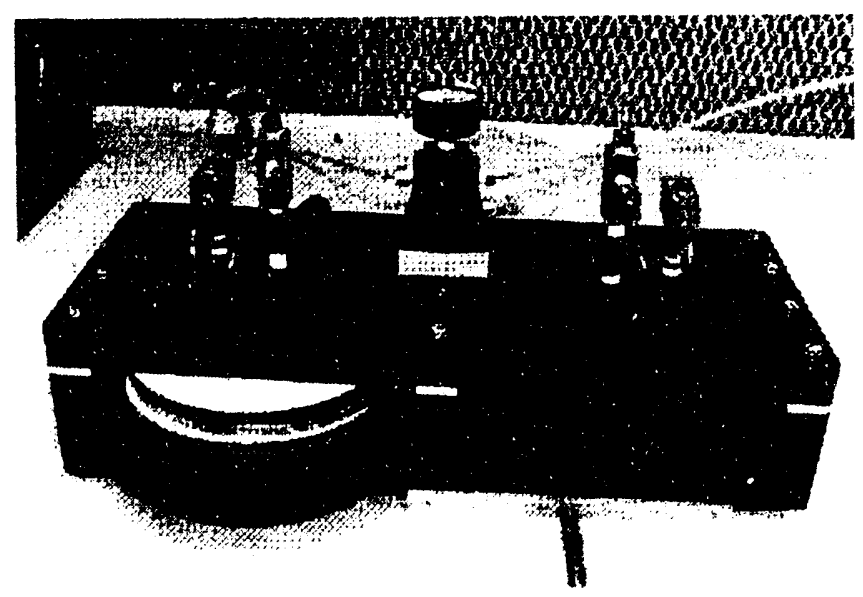

Figure 24 Photograph of the pressure blocking apparatus. bottom of the apparatus, accelerated the solidification of the wax. After the block had cooled, it was removed from the pressure blocker and placed atop a hot plate to reheat the wax. The pressure blocking procedure was then repeated. The remelting and (pressure) solidification cycle was repeated three times to minimize the wax layer thickness. Performing the cycle more frequently removed too much wax so that some areas of the wafers separated fron. the glass block during the lapping process. The wafers and block were cleaned of excess wax for each repetition of the procedure.

\subsubsection{Lapping}

The wafers were lapped initially on the non-serrated table (Figure 22) to smooth out severe surface asperities that would cause chipping or cracking to the wafers if first lapped on the serrated table. Then the block was transferred to the serrated table. The table was contoured to be 0.8 to $1.2 \mu \mathrm{m}$ ( 30 to 47 microinches) concave. The glass blocks were 0.8 to $1.2 \mu \mathrm{m}$ convex so that the block of wafers and the table would fit together and maintain parallelity between the two wafer surfaces in spite of the curved contour of the glass block. The serrated lapping table, which was also cast iron, was operated at $50 \mathrm{rpm}$.

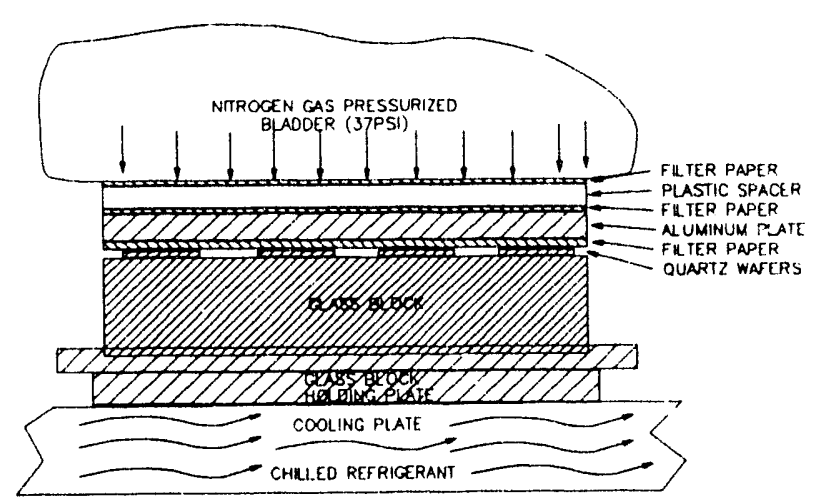

Figure 25 Component stacking diagram for the pressure blocking process. 
The grinding medium was a slurry of 9.0 micron alumina (in the same proportions of water and powder as described previously) and was continuously dispensed onto the table surface ( 2 drops/sec). Approximately $2 \mu \mathrm{m}$ of material was removed from the thickness of the wafers in a time period of about 30 minutes with a loading weight of $5.2 \mathrm{~kg}$. The application of a $5.2 \mathrm{~kg}$ load onto onehalf of the block during lapping was used to correct for thickness variations along the circumference of the block as determined by periodic height inspection of the wafers during the lapping period. When lapping was complete, the block of wafers was thoroughly cleaned to prevent carryover of the lapping compound to the polishing station.

\subsubsection{Polishing}

The polishing process was performed on a rotating table similar to the lapping apparatus (Figure 26)

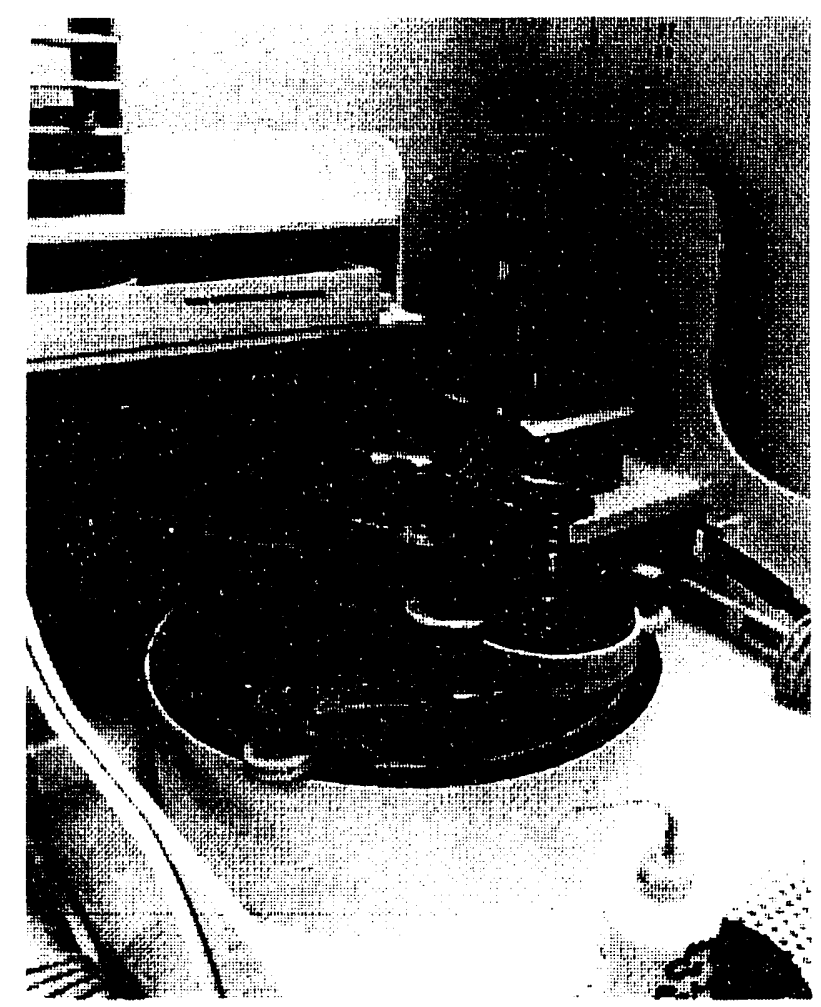

Figure 26 Photograph of the polishing table. except that the base plate was aluminum. The table had been contoured to be $5 \mu \mathrm{m}$ convex in the annular region. The actual polishing surface was a Rodel $^{\mathrm{TM}}$ 205/II polishing pad [28]. The rotation speed was $50 \mathrm{rpm}$. The polishing slurry was comprised of $420 \mathrm{~g}$ of $1.8 \mu \mathrm{m}$ cerium oxide powder in 4 liters of deionized water and was dispensed at a rate of 5-10 drops per second.

The contour of the polishing table, $5 \mu \mathrm{m}$ (197 microinches) convex, and that of the glass blocks, 0.8 to $1.2 \mu \mathrm{m}$ (30 to 47 microinches) convex, were determined by experiment to give optimum thickness uniformity over all of the wafers upon completion of the process. Several trials were conducted in which the convexity of the polishing table was reduced to as low as $1 \mu \mathrm{m}$ (39 microinches). The result was that as the table was flattened, the material removal rate of the quartz increased going from the center to the perimeter of the glass block. This caused a large thickness variation (or anti-parallelism of the thickness) over the quartz blanks after processing, particularly for those wafers which were situated on the outer perimeter of the glass block. For example, approximately $2 \mu \mathrm{m}$ ( 79 microinches) more material was removed from the wafer positions along the outer perimeter of the glass block than was removed from those wafers near the center of the block when the table was $1 \mu \mathrm{m}$ (39 microinches) convex. This uneven polishing was found to be eliminated when the table contour was raised to 4 to $5 \mu \mathrm{m}$ (157 to 197 microinches).

The uneven polishing was not a function of the age of the polishing cloth. It should be pointed out that in the development of the lapping/polishing procedure, the dimensions of the lapping tables, polishing table, and glass block were determined to meet the quartz wafer specifications while reducing the extent of the processing time. Because each piece of equipment is different, the parameters 
selected for our operation were determined by trial and error from loose parameters provided by the vendor.

As in the lapping process, the tendency of material removal variations along the circumference of the block was countered by the application of an approximately $2 \mathrm{~kg}$ weight to one-half of the block surface where it was necessary to remove more material.

The extent of polishing was determined by the quality of the surface finish desired. The criterion for a final product was the elimination of cracks and the "orange peel" topography (Figure 27) caused by the fracture and break-out mechanism responsible for material removal during the lapping process. Shown in Figure 28 is a surface profile of a wafer polished for 50 minutes. Insufficient polishing is indicated by the peak-to-valley height of $4142 \AA$. For a thin film metal coating of $2200 \AA$, incomplete coverage of the quartz surface would result. As a consequence, pits were formed in the quartz where the metallization was absent (Figure 29), after the HF etching step in the photolithography process (see 4.4). The minimum total polishing time to produce a satisfactory surface was between 60 and 120 minutes. Continuing the polishing process optimized the surface profile to $730 \AA$, RMS or $2770 \AA$, peak-to-valley. Polishing for periods in excess of 120 minutes caused an increase in the amount of rounding of the wafer edges. Upon completing the polishing process, the wafers were removed from the glass block, cleaned of wax residues through the degreasing process, and stress relieved in diluted HF.

The entire lapping and polishing process was repeated for the other side of the wafers (Figure 15) which originally received the reference lapping treatment.
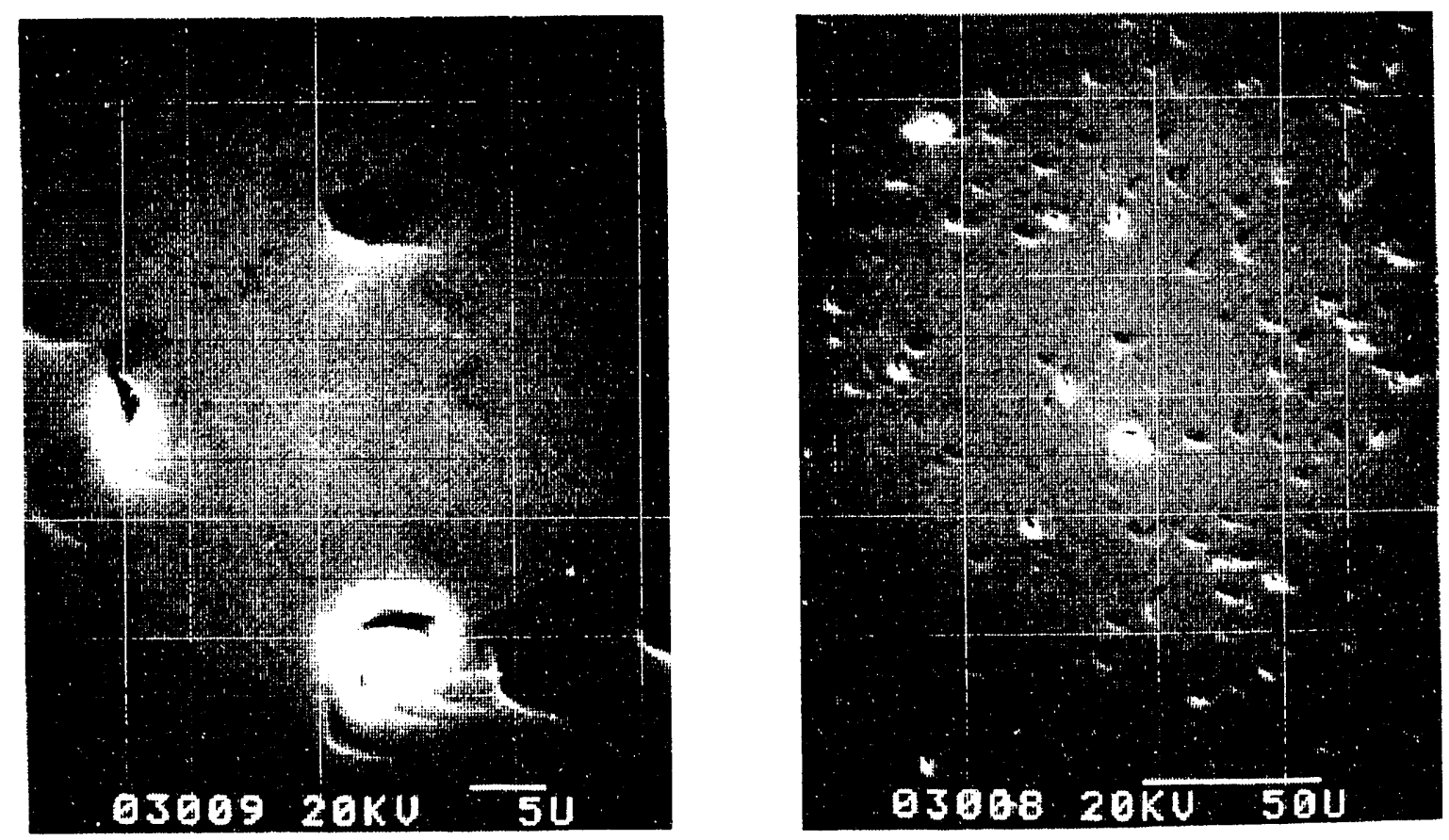

Figure 27 SEM micrographs of the partially polished surface of a quartz wafer. 


\subsubsection{Inspection}

Final inspection of the wafers involved three observations. First, the wafers were visually reexamined for surface cracks, scratches, or chips to the wafer edges. Second, the dimensions of the wafers were checked at all four corners (at a distance of approximately $2-3 \mathrm{~mm}$ from either side) as well as at the center of the wafer using a mechanical gage [29]. The displacement repeat-ability was $\pm 0.5 \mu \mathrm{m}$. The marks left by the gage probe were not at locations which would contain working devices. Third, each wafer was examined under the monochromatic light source in normal incidence of both the light and the viewing directions to determine the parallelity of the two surfaces. This measurement was determined by the number of dark fringes resulting from the interference of the light reflected from the top surface and that reflected from the inside of the bottom surface of the wafer. One fringe of a $546 \mathrm{~nm}$ light source was equivalent to $0.27 \mu \mathrm{m}$ (11 microinches) of height deviation between the two surfaces (i.e., out of parallel).

Shown in Figure 30(a) is an optimum wafer which shows a pattern of 1 to 2 dark fringes beyond the reference fringe in the center of the crystal. In

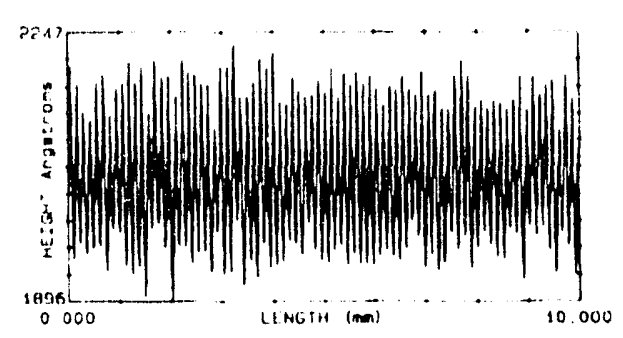

Figure 28 Non-contact surface profile of a $z$ plate wafer surface after polishing for $50 \mathrm{~min}$. with 1.0 micron $\mathrm{CeO}$ at a table speed of $50 \mathrm{rpm}$. No large scale surface relief was noted on preliminary scans.
Figure $30(\mathrm{~b})$ is a wafer with 2 to 3 fringes. The wavy character of the fringes as well as the isolated dark patches indicate slight thickness variations caused by uneven bond thicknesses or contaminant particles. As the fringes became more numerous, their appearance became more well defined as is evident when Figure 30(c) and Figure 30(d) are compared with Figure 30(a) and Figure 30(b). It was also apparent from Figure $30(c)$ and Figure 30(d) that, depending upon the position of the wafer on the glass block (Figure 18), the maximum out-of-parallel direction (which would be a direction normal to the fringe length) varied between wafers. The wafer in Figure 30(e) shows two features. First, the fringes along the outside edges indicate the rounding of those edges due to prolonged polishing. In this case, the rounded edges would not affect the devices. Second, the
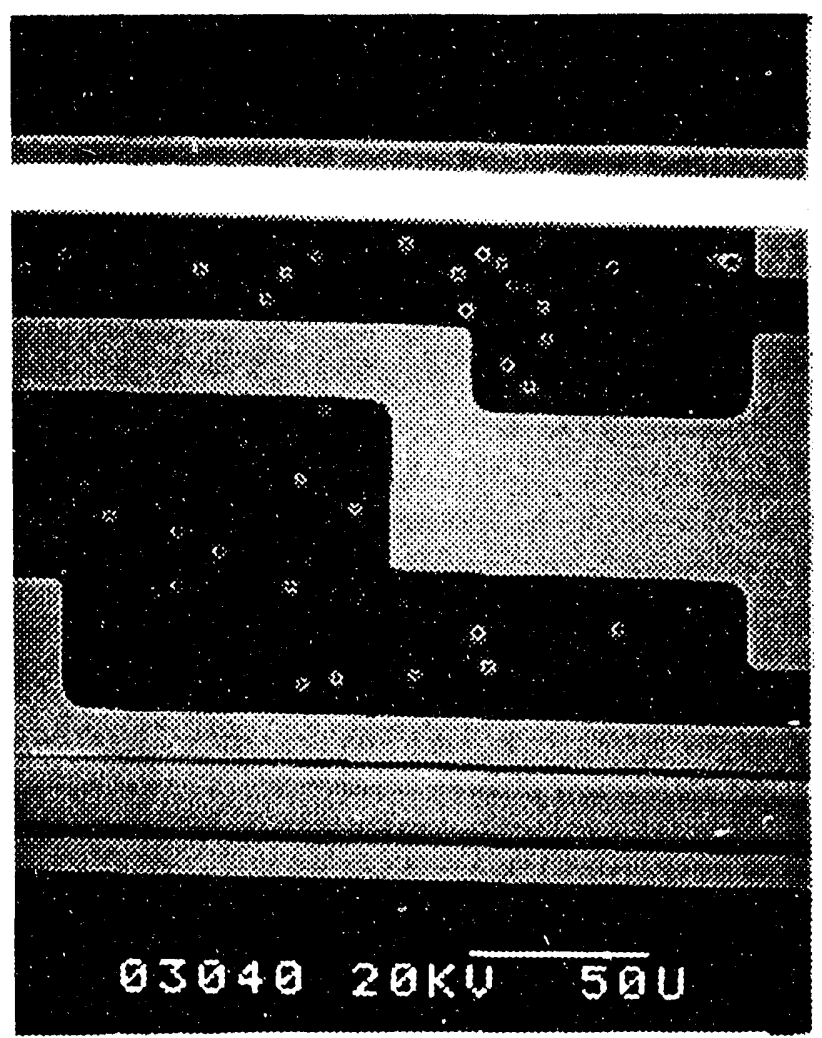

Figure 29 Pits in the tine of a DETF from poor metallization coverage due to insufficient polishing of the substrate. 
fringe pattern shows a linear shaped artifact diagonally across the wafer. This phenomenon was caused by a flaw in the quartz material that had a polishing rate different from the remaining material.

The pressure blocking procedure was found to be critical to the final dimensions of the wafers. In the absence of an adequate pressure application to the block of wafers, the wax tended to segregate to the center of each wafer, causing the wafer to be domed (Figure 31). After lapping and polishing the wafer, the center region became thinner relative to the edges. The problem was further compounded when the other side was processed because even when adequate pressure was present, it was preferentially applied to the edges, thus preventing the removal of excess wax from the center. The result was a doubly convex wafer with center-toedge thickness variations as large as $50 \mu \mathrm{m}$ (1970 microinches). The dimension variations of a batch of such wafers is shown in Figure 32. It is noted that the thickness of the centers of the wafers was much less than the thicknesses taken at the four corners. Surface flatness measurements by interferometry confirmed that the wafers were indeed doubly convex. The problem was remedied by the multiple blocking process as described earlier.

The production of doubly convex wafers was the extreme result of inadequate pressure applied to the wafer during blocking. At pressure levels between poor and adequate, localized regions of wax buildup occurred under the wafer. In such areas, the bulge in the wafer caused excessive material removal which resulted in small indentations in the wafer. This phenomena was clearly seen in the interference fringes upon inspection. Such a case is shown in Figure 33. The appearance of closed, tight contours represents regions of thickness variation caused by wax mounds formed during mounting.
As noted earlier, the wafers used for fabrication of the DETFs had to meet the following specifications:

(1) The thickness of the wafers was to be $156.2 \pm 1.2 \mu \mathrm{m} \quad(6150 \pm 50$ microinches $)$ after removal from the mounting block.

(2) The parallelity of the major faces was to be $1.2 \mu \mathrm{m}$. (50 microinches) total deviation over $80 \%$ of the area.

(3) The surfaces were to be free of cracks and scratches.

The greatest effort was directed towards maintaining the parallelity between the two faces. The other two criteria were readily met.

Shown in Table II is an outline of the progress made towards achieving the parallelity criteria as determined by the yield of wafers from 3 batches produced at the end of the period. The initial effort began in January 1989. By April 1989, 66\% of the wafers met the specification. At that time, the parallelity had improved for some wafers to 0.5 to $0.8 \mu \mathrm{m}$ (20 to 30 microinches) over the indicated area which taxed the measuring accuracy of the mechanical gage. Therefore, the monochromatic light source was used exclusively to measure the parallelity. Between the period of April 1989 to December 1989, the yields dropped sharply as new techniques were attempted. These trials included different curvatures to the both lapping and the polishing tables and variations to the pressure blocking process parameters. The establishment of the optimum process parameters resulted in a $98 \%$ yield as compiled from 3 batches of wafers produced in January 1990. 


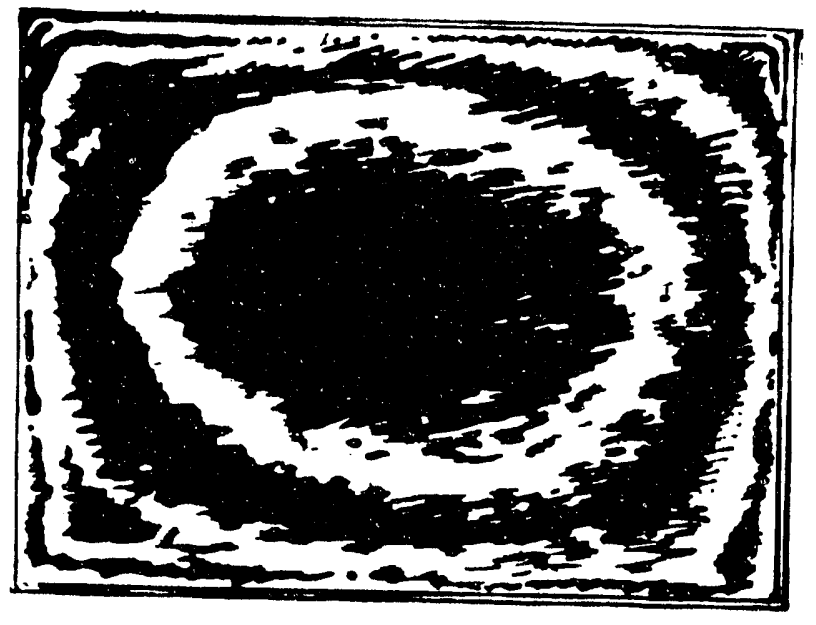

Figure 30(a) Optimum fringe pattern.

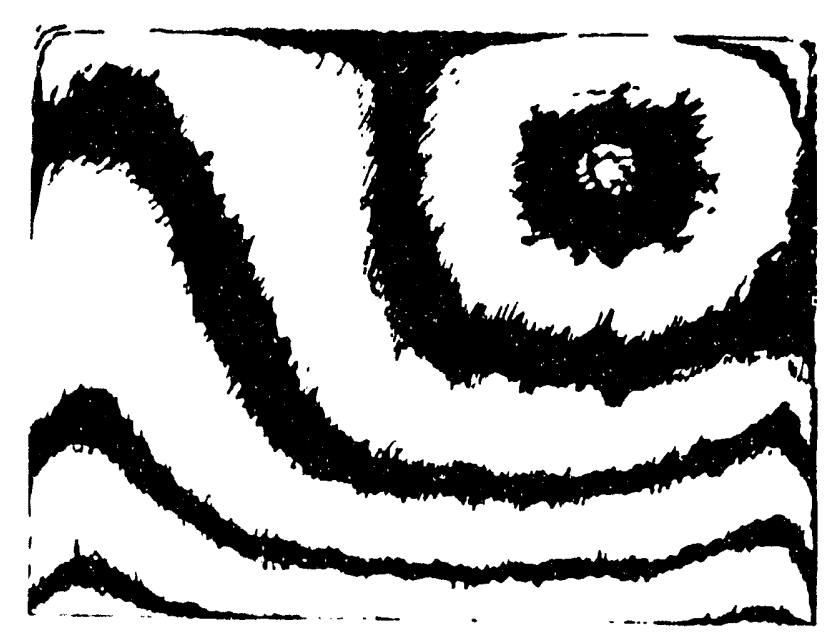

Figure 30(c) Thickness variation due to contaminate particles.

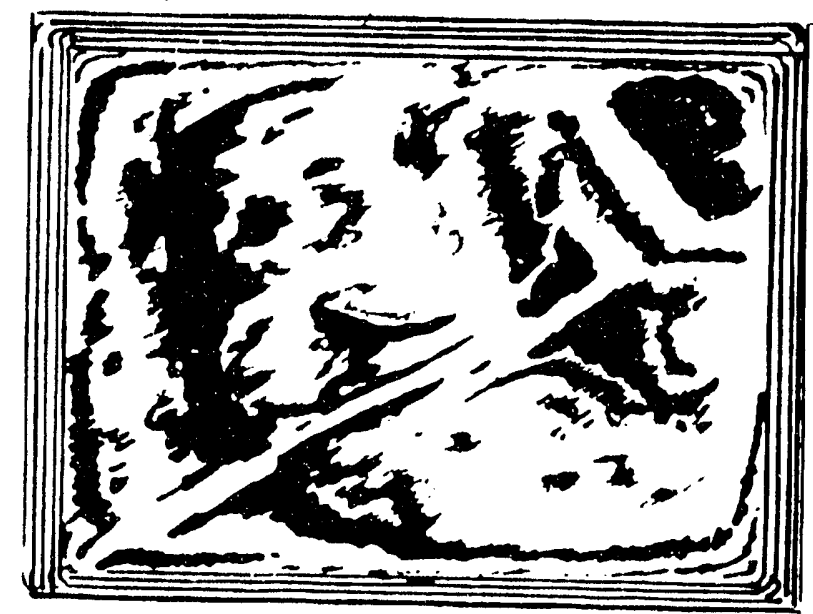

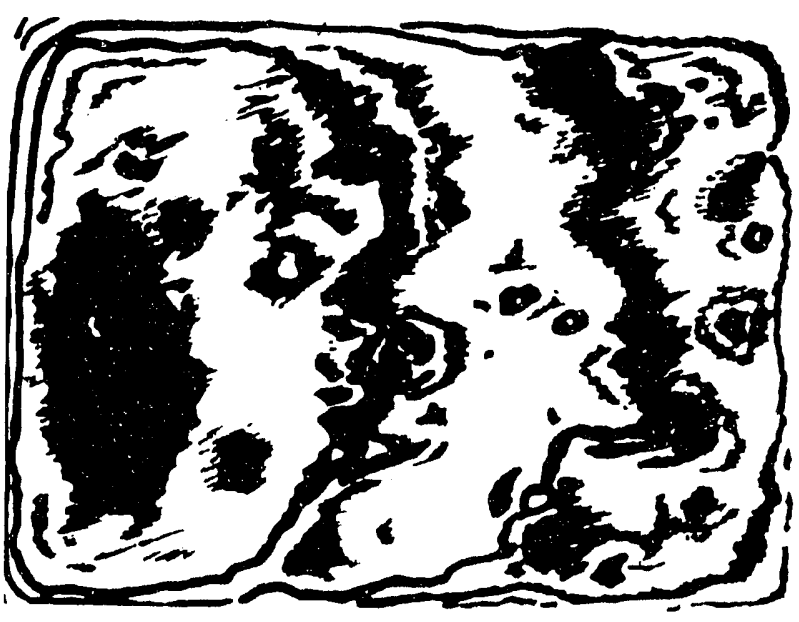

Figure 30(b) Thickness variations due to uneven bond thickness or contaminate particles.

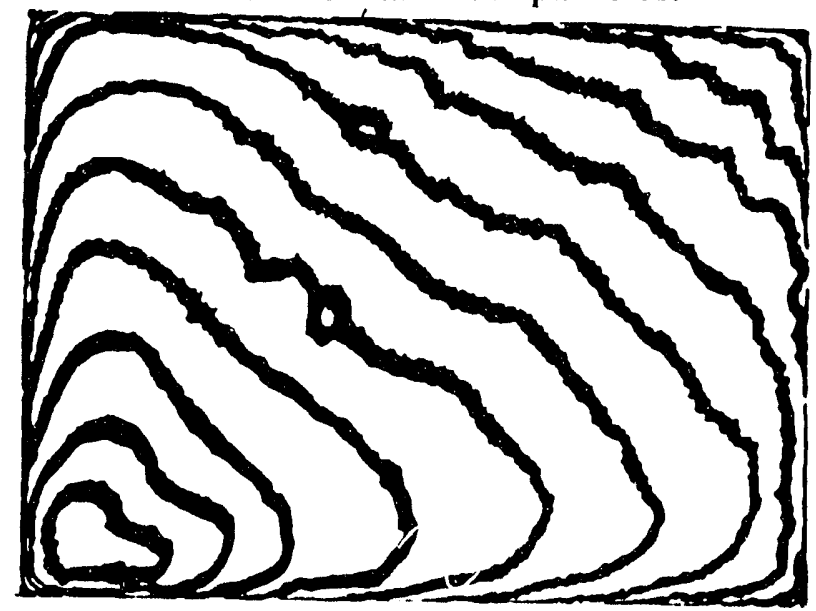

Figure 30(d) Extreme example of thickness variation similar to (b).

Figure 30(e) Rounding due to excess polishing as well as a linear flaw in the quartz. All fringes were generated using a $546 \mathrm{~nm}$ light source. 


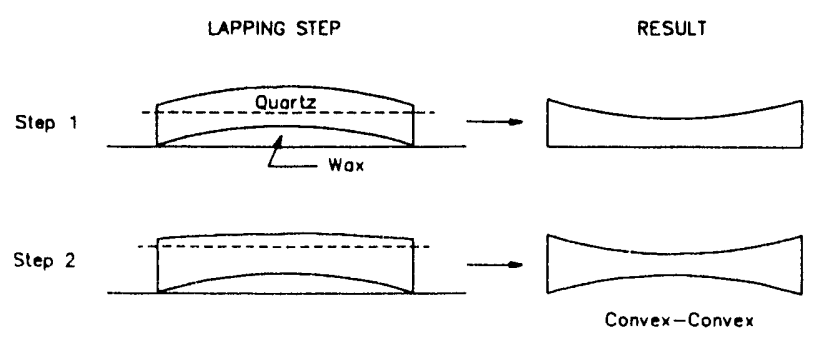

Figure 31 Schematic diagram depicting the generation of a convex profile of the thickness of the quartz blank by a non-uniform wax layer underneath.

\subsection{Fabrication of the Double-Ended Tuning Fork}

The manufacture of the DETF from the finished quartz substrates involves two principle tasks: (1) the physical features of the tuning fork must be created from the quartz wafer and (2), the metal thin film electrodes for excitation of the piezoelectric effect must be defined on the tuning fork surface. A photolithographic process, developed by Statek Corporation was used to accomplish both tasks and will be described below.

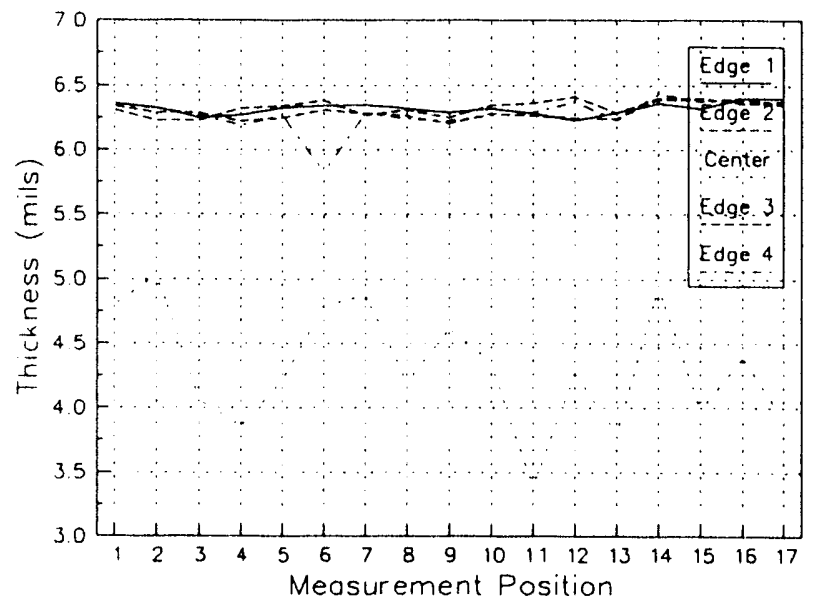

Figure 32 Mechanical gauge thickness dimensions of a batch of 17 wafers showing the thickness variation of approximately 50 microns between the the edge and the center of the wafers.

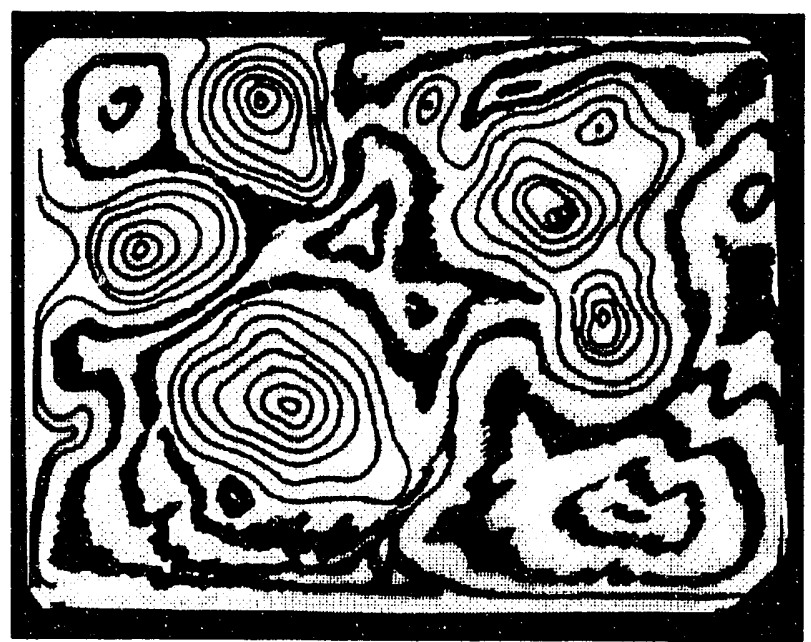

Figure 33 Interference fringe pattern generated by $546 \mathrm{~nm}$ monochromatic light showing thickness variations in the wafer caused by a non-uniform wax layer under the quartz blank.

The fabrication of the DETF was performed in the Temporary Prototype Processing Laboratory (TPPL) [30]. A view of the facility appears in Figure 34. All processing and assembly was conducted within laminar flow benches that maintained a class 100 to 200 clean space. Outside the benches, the room volume was class 1000 to 10000. The mask aligner, photoresist spinner and baking oven appear to the left in the photo. An inspection microscope and surface profilometer are on the immediate right of the view. Shown in

Table 2 Polishing yield of $\mathrm{Z}$ plate quartz wafers.

\begin{tabular}{cccc} 
Date & Yield & $\begin{array}{c}\text { Measurement } \\
\text { Technique }\end{array}$ & $\begin{array}{c}\text { Measure } \\
\text { ment } \\
\text { Error }\end{array}$ \\
\hline \hline $1 / 1989$ & $0 \%$ & Mechanical & $\pm 254 \mathrm{~nm}$ \\
$3 / 1989$ & $51 \%$ & Mechanical & $\pm 254 \mathrm{~nm}$ \\
$4 / 1989$ & $66 \%$ & Optical & $\pm 127 \mathrm{~nm}$ \\
$1 / 1990$ & $98 \%$ & Optical & $\pm 127 \mathrm{~nm}$ \\
\hline
\end{tabular}

"Yield for a thickness variation of less than $1270 \mathrm{~nm}$ over $80 \%$ of the wafer surface area. 
Figure 35 is the chemical bench for inorganic processing. The three tubs on the left are heated baths for controlling the temperature of the quartz etching solutions. The two tubs in the middle of the bench contain the chromium and gold etching solutions, respectively. The covered vat on the far right end is the gold plating bath consisting of an electrode plate as the anode, the sample holder, and a pump to circulate the plating solution. Organic chemistry, which included the development and stripping of the photoresist, was performed in the clean bench in Figure 36.

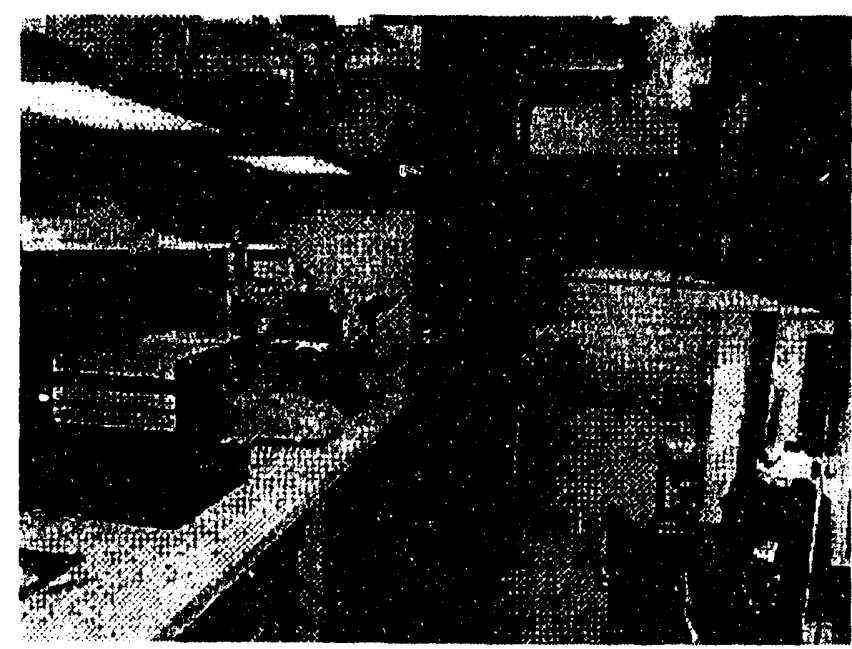

Figure 34 Photograph of the Temporary Prototype Processing Laboratory (TPPL): Overall view.

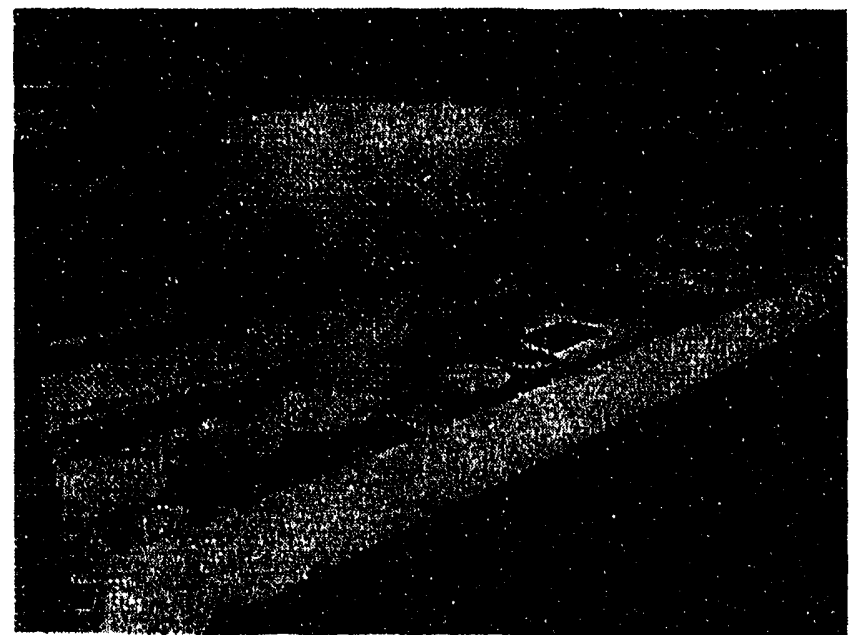

Figure 35 TPPL inorganic processing bench.

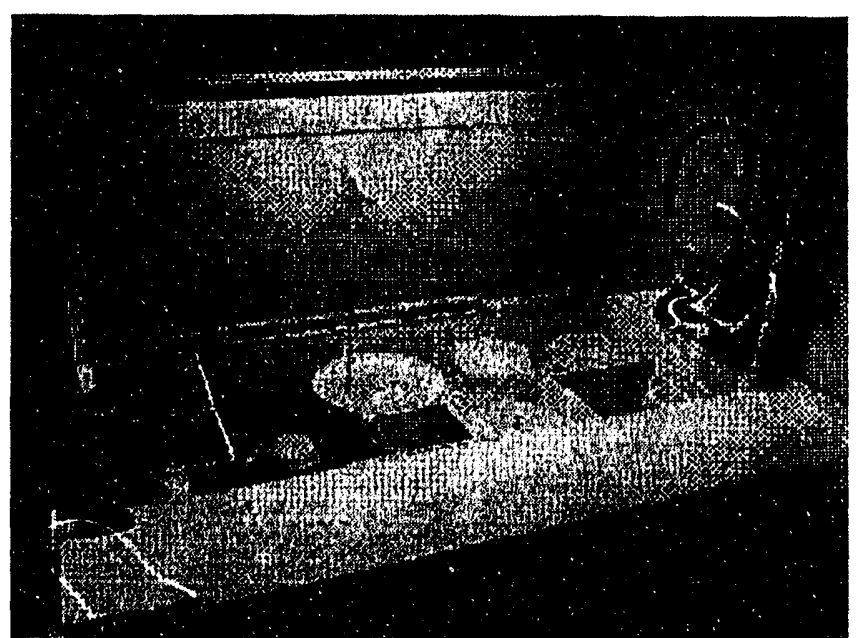

Figure 36 TPPL organic processing bench. 


\subsection{DETF Processing}

The photolithographic process for the manufacture of the DETF is outlined in Figure 37. Each of the steps will be described below. The goal was the production of wafers of DETFs shown schematically in Figure 38 and photographed in Figure 39.

\subsubsection{Wafer Etching for Thickness Control}

The quartz wafers produced by the techniques described in section 4.3 were targeted to have a final thickness of $156.2 \pm 1.2 \mu \mathrm{m}$ (6150 microinches) which is $3.8 \mu \mathrm{m}$ (150 microinches) larger than the design specification of $152.4 \mu \mathrm{m} \quad(6000$ microinches). The extra material was removed by

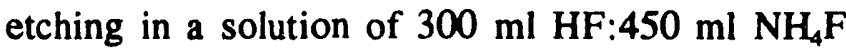
operated at $76 \pm 2{ }^{\circ} \mathrm{C}$. The time required to reduce the thickness of the wafers by an amount $\Delta h$ is given by equation (25):

$$
t(\min )=\frac{4620 \Delta h}{1+0.044(T-80)}
$$

where $\Delta h$ is measured in inches and the temperature, $\mathrm{T}$, is in ${ }^{\circ} \mathrm{C}$. For a temperature value of $76^{\circ} \mathrm{C}$, the time to remove $3.8 \mu \mathrm{m}(150$ microinches) of quartz is $50 \mathrm{sec}$. The purpose of removing the last $3.8 \mu \mathrm{m}$ of material by etching was

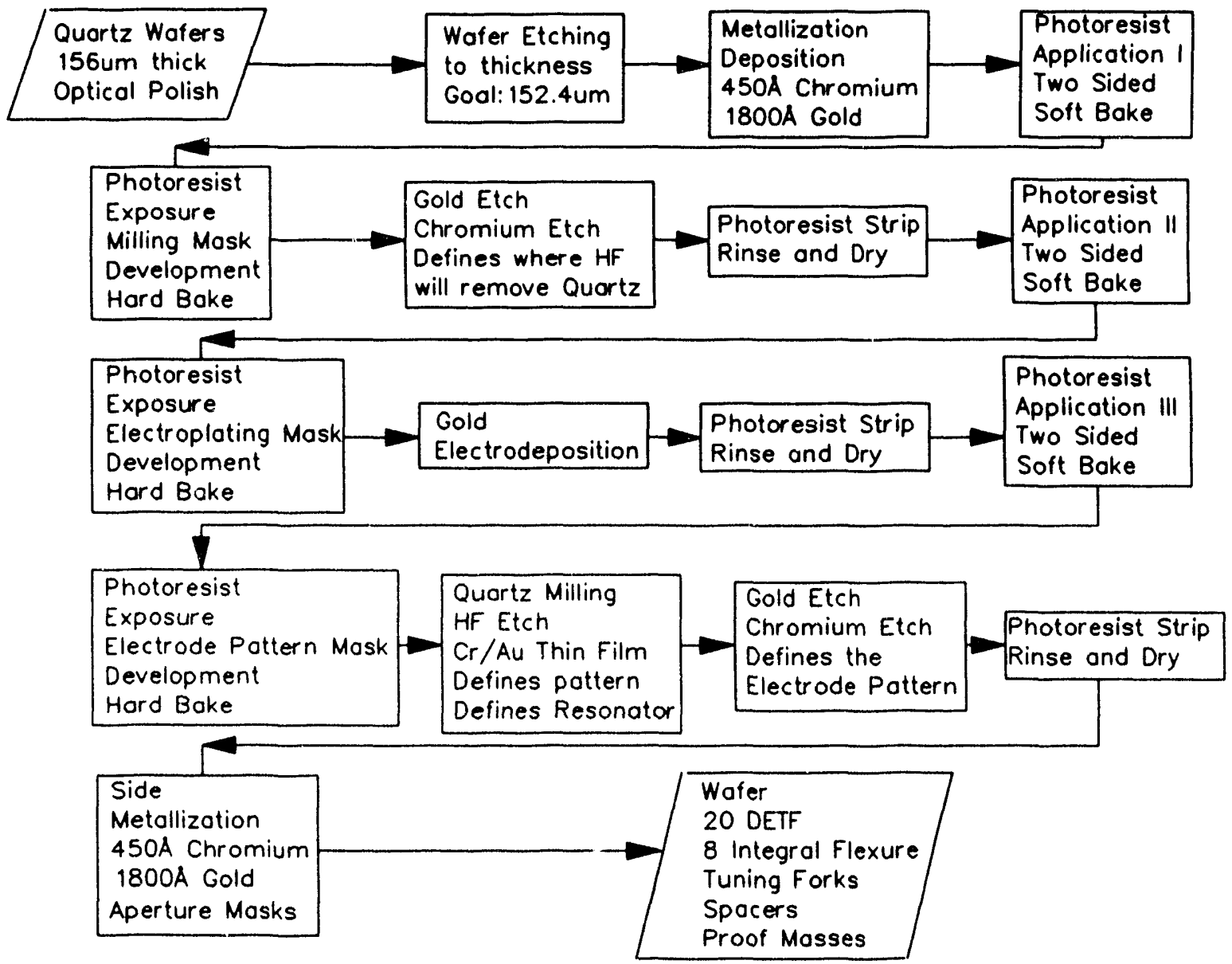

Figure 37 Fabrication of the DETF. Block diagram of the manufacturing process. 

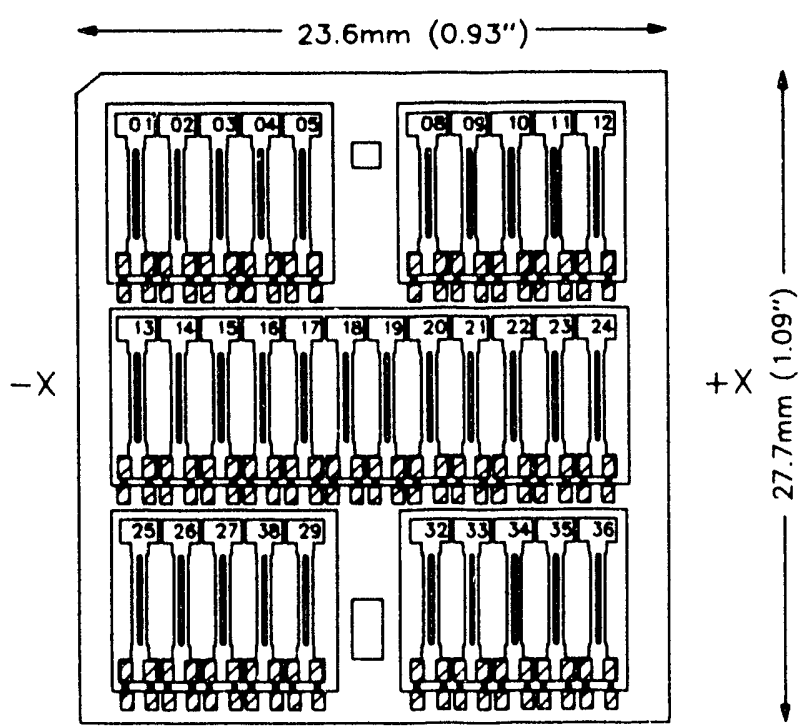

Figure 38 The arrangement of $\mathbf{3 2}$ forks on a quartz wafer.

to eliminate the presence of a damage layer underneath the wafer surface caused by the abrasive action of the polishing process. Also, the slower rates of material removal by the etching process offer a much tighter control over the final thickness necessary for later processing and resonator performance. After etching, the wafers were rinsed in de-ionized water and spun dry.

In a given batch of 14 wafers, the spread of thicknesses of the wafers (as designated by an average of the measurements at the four corners and the center) varied by $2.5 \mu \mathrm{m}$ (100 microinches) in the earlier batches. Improved process control in later batches brought this figure down to typically 1.2 to $1.5 \mu \mathrm{m}$. As opposed to processing one wafer at a time to account for individual thicknesses, it was determined that the wafers with thicknesses within a range of $1.2 \mu \mathrm{m}$ could be processed together as determined by the allowed tolerances on

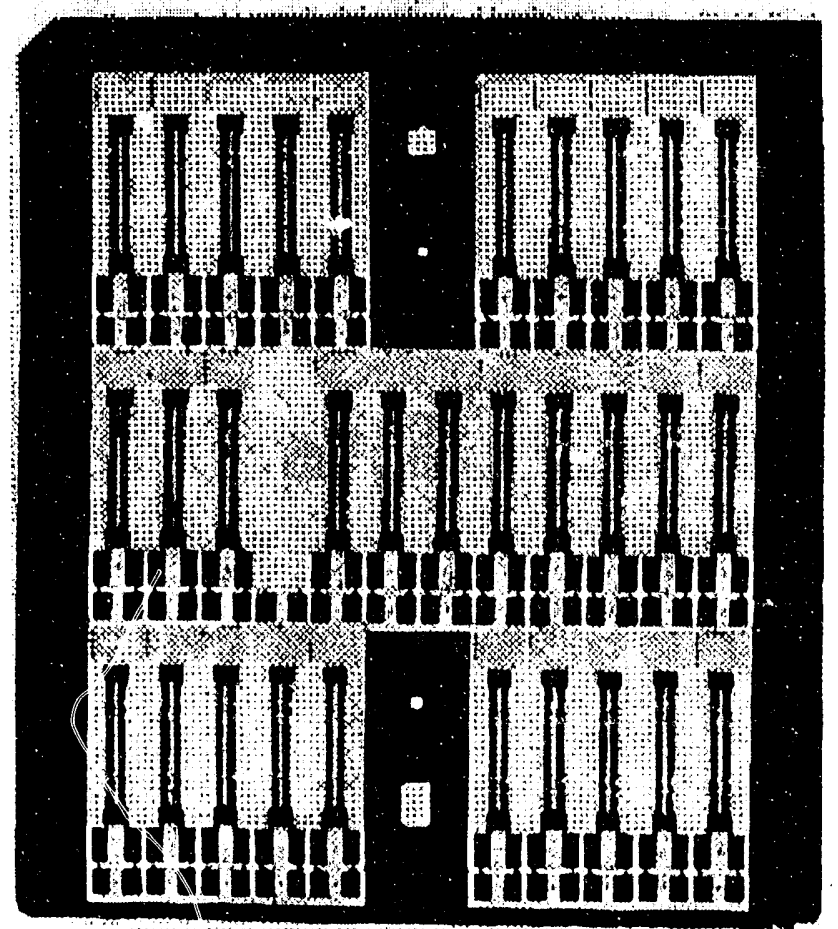

Figure 39 Photograph of thirty-two fork wafer.

the thickness.

An investigation was conducted to obtain first-hand experience of the sensitivity of the etching process to the conditions of temperature and short time periods ( $<15$ minutes) and compare the results with those predicted by equation (25), which was observed to work very well at longer time periods (>30 min). In the first set of experiments, polished z-plate wafers were placed in the $\mathrm{HF}: \mathrm{NH}_{4} \mathrm{~F}$ bath for 2 minutes. The temperature of the bath was varied between $72,76,80$, and $84^{\circ} \mathrm{C}$. Temperatures in excess of $84^{\circ} \mathrm{C}$ caused the bath to start boiling, resulting in extremely fluctuating results. The thickness of the wafers was measured mechanically to an absolute error of $\pm 0.5 \mu \mathrm{m}$ ( \pm 20 microinches). Ten wafers were etched per each temperature condition. The amount of material removed from a wafer during an etching period was an average determined from measurements taken from 5 locations. It was noted 
in the data that the absolute thickness of the wafer had no bearing on the etching rate. Shown in Figure $\mathbf{4 0}$ is a plot of the etching rate as a function of bath temperature. It will be noted that the etching rates predicted by equation (25) are much larger than those shown in Figure 40. Therefore, it was concluded that the etch rate was a function of time. This observation is not unusual in the chemical (or electrolytic) etching of materials since a time period is required to establish an equilibrium surface morphology characteristic of the etching kinetics.

Etching rate as a function of time in the bath was investigated experimentally by a second set of experiments in which the bath temperature was kept constant and the etching time was varied between 2 minutes (to confirm the data in the first set of experiments) and 10 minutes. The same procedures were used in these tests as were explained for the first trials noted above. The results appear in Table 3. The general trend was indeed an increasing rate (by nearly 7\%) between a time of 2 and 10 minutes. Equation (25) predicts an etching rate of $4.3 \mu \mathrm{m} /$ minute for a temperature of $76^{\circ} \mathrm{C}$.

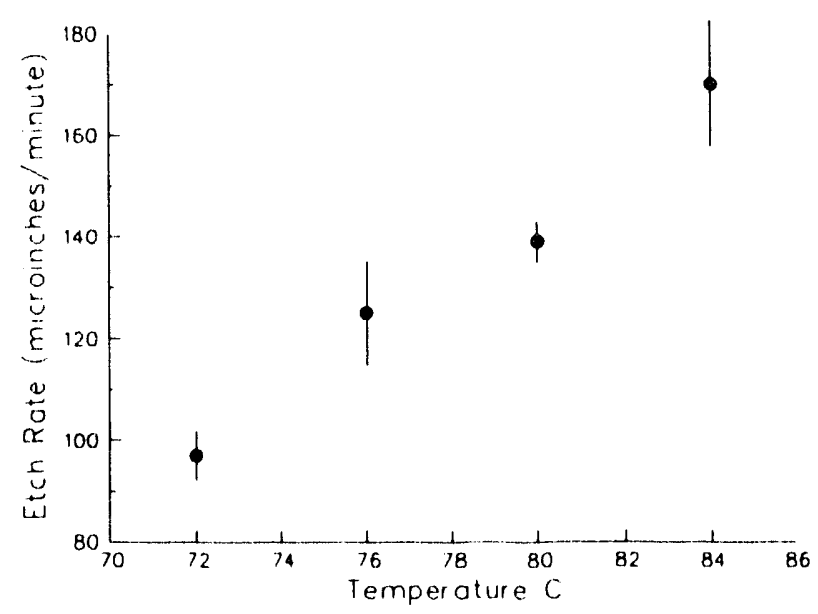

Figure 40 Etching rate in the $z$ direction as a function of temperature for an immersion time of 2 min. The solution was $300 \mathrm{ml} \mathrm{HF}$ and $450 \mathrm{ml}$ of $\mathrm{NH}_{4} \mathrm{~F}$.
Therefore, the experimental results confirm that, at the shorter time periods, the etching rates were less than those predicted by equation (25), but increased with the longer times to approach the value predicted by equation (25). Using the etching rate from the 2 minute data in Table 3 , the time required to remove $3.8 \mu \mathrm{m}$ of quartz was $72 \mathrm{sec}$ compared to $50 \mathrm{sec}$ from equation (25).

\begin{tabular}{c|c|c}
$\begin{array}{c}\text { Table 3 } \\
\begin{array}{c}\text { Etch } \\
\text { Time } \\
\text { (minutes) }\end{array}\end{array}$ & $\begin{array}{c}\text { Thickness } \\
\text { Etched } \\
\text { (microinches) }\end{array}$ & $\begin{array}{c}\text { Rate } \\
\text { (microin/minute) }\end{array}$ \\
\hline 2 & 248 & 124 \\
\hline 4 & 549 & 137 \\
\hline 6 & 764 & 127 \\
\hline 8 & 1071 & 133 \\
\hline 10 & 1333 & 133
\end{tabular}




\subsubsection{Thin Film Deposition}

After the wafers had been etched to the desired thickness in the HF solution, they were thoroughly rinsed in preparation for the metallization deposition step. The metal thin films selected for the electrode pattern were $450 \AA$ of chromium deposited on the quartz followed with $1800 \AA$ of gold. The chromium layer provided adhesion between the quartz and the gold layer. Deposition of the chromium and gold films was performed in the vacuum evaporation system shown in Figure 41.

The chromium was deposited on the substrates by electron beam evaporation from a Temescel ${ }^{\mathrm{TM}}$ [31] four-turret hearth. The maximum pressure during the deposition was $5.26 \times 10^{-6}$ torr. The substrate temperature increased slightly due to indirect heating by the source to at most $40^{\circ} \mathrm{C}$. The deposition rate was 6 to $12 \AA / \mathrm{sec}$ (at $17 \%$ power).

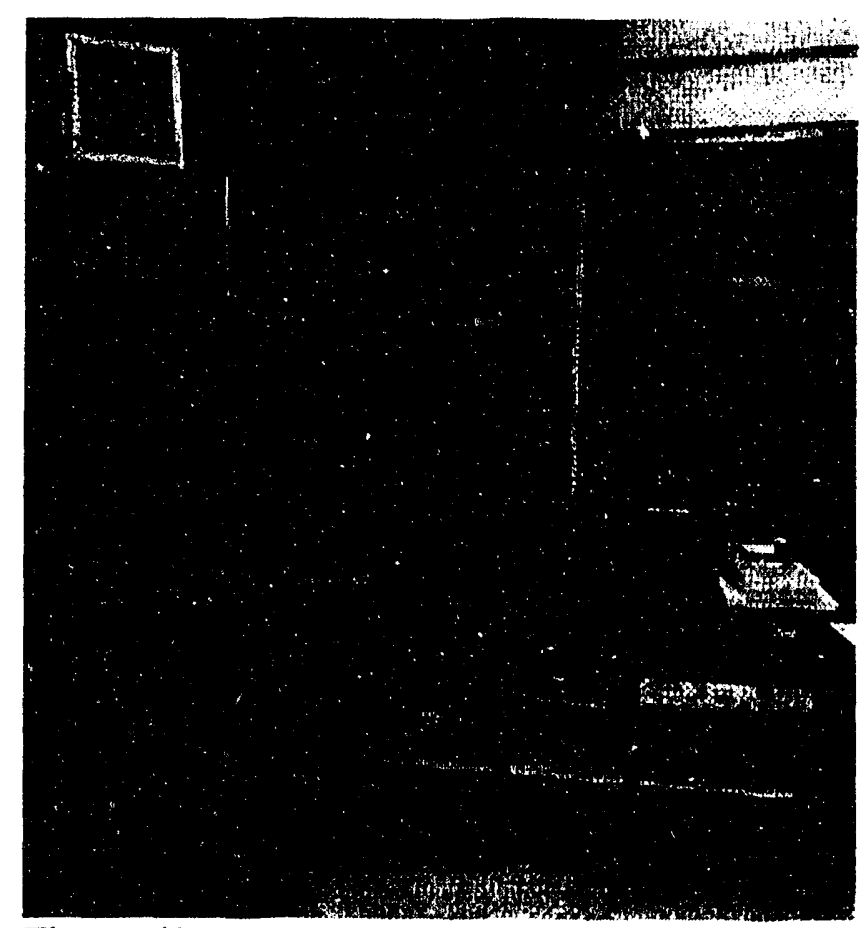

Figure 41 Photograph of the vacuum evaporator used to deposit the $\mathrm{CrAu}$ metallization on the quartz blanks.
The gold film was evaporated from a resistance heated molybdenum boat coated with alumina. The maximum pressure during the coating process was $2.8 \times 10^{-6}$ torr. The maximum substrate temperature due to indirect heating was $60^{\circ} \mathrm{C}$; a typical value was $50^{\circ} \mathrm{C}$. The film was deposited at $25 \AA / \mathrm{sec}$. No bakeout procedure was performed prior to deposition.

The wafers were placed in a fixture (or pallet) as shown in Figure 42. A maximum of 9 wafers fit in each of 3 such pallets so that 27 wafers could be coated at a time. The pallets were mounted into a planetary rotation system inside of the evaporator (Figure 43). The rotation system was capable of rotating and flipping the pallets $180^{\circ}$ so that both sides of the wafers could be uniformly coated without risk of contamination from opening the chamber to atmosphere. The first side received the complete coating of both chromium and gold before the pallet was flipped for depositing on the other side. Upon completion of the evaporation process, the wafers were removed from the pallets and

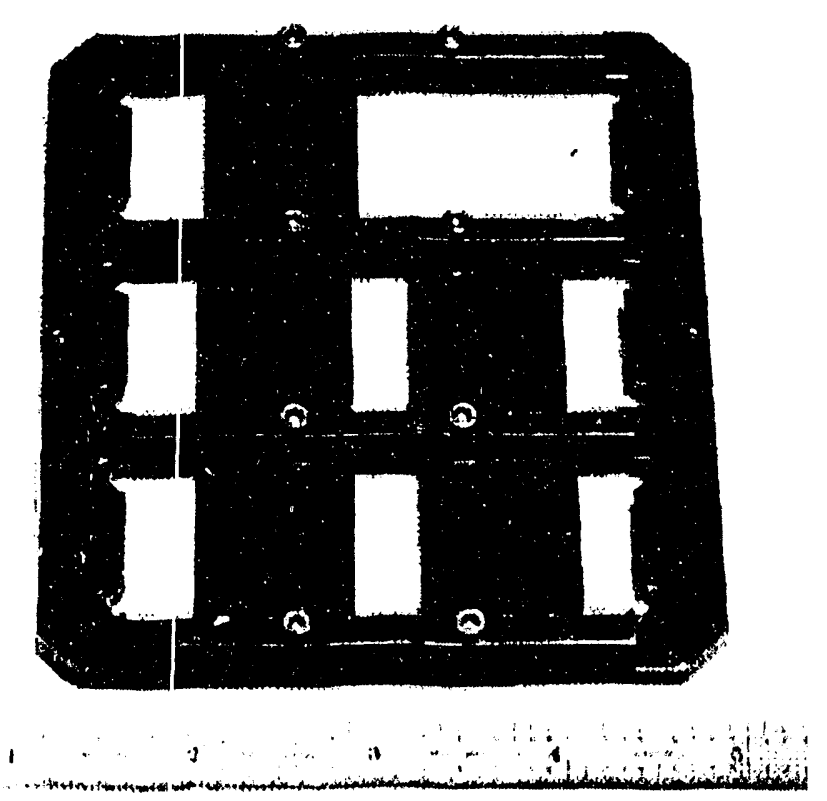

Figure 42 Mounting pallet used to the quartz wafers for the deposition of the $\mathrm{CrAu}$ metallization. 
stored in a dry box to prevent contamination of the film surface. The blanks were ready to begin the photolithographic process.

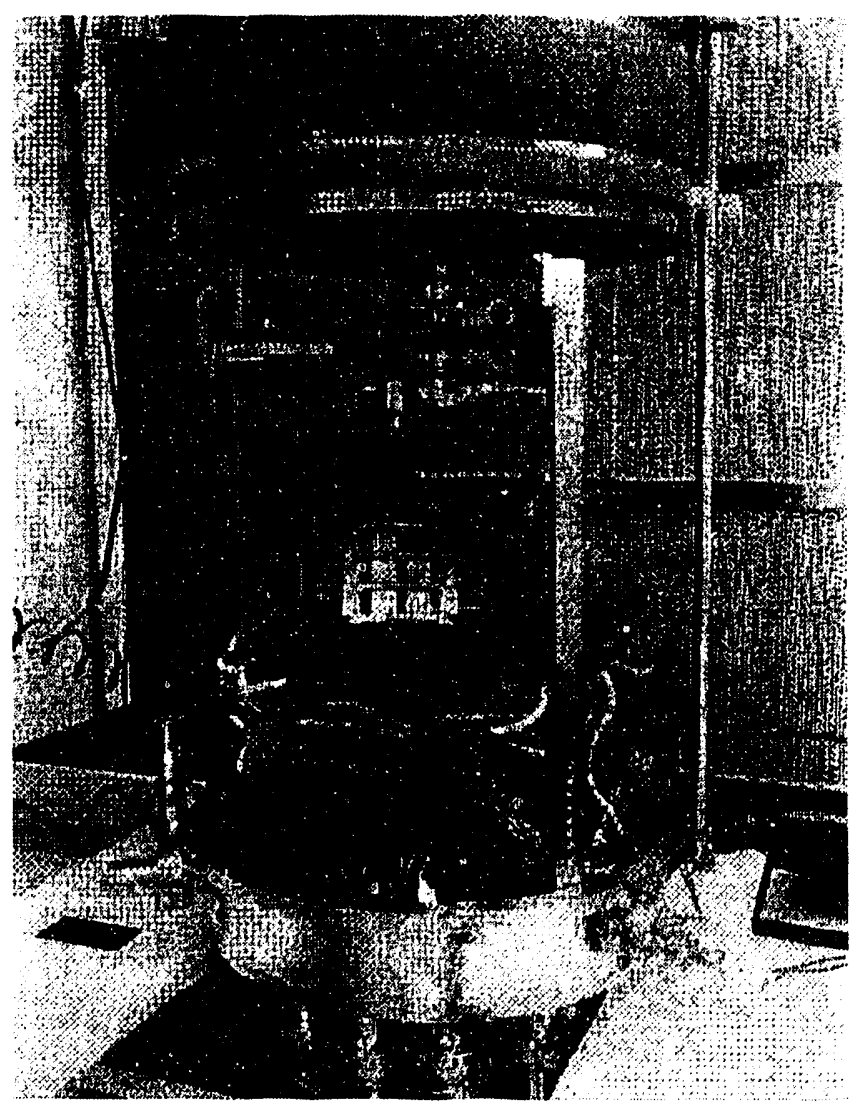

Figure 43 View of the mounting pallet with the quartz wafers attached to the planetary system in the vacuum evaporator.

\subsubsection{Photoresist Definition and Application}

The first step was to define a working pattern on the substrate by means of a photoresist layer. Prior to w,rk ig with the quartz substrates, it was necessiny to determine the process parameters that would give a resist film thickness of about $1.0 \mu \mathrm{m}$. A qualitative assessment of the photoresist film was made by evaluating:

(1) the reproducibility of the mask pattern dimensions;

(2) the completeness with which the photoresist was developed away from designated areas; and (3) the ability of the photoresist to withstand the various chemical environments such as the metal etchants and the chemicals in the electroplating bath.

The processing parameters which were varied included:

(1) the viscosity of the photoresist;

(2) the rotation speed of the photoresist spinner; and

(3) the exposure time of the pattern under the mask aligner.

The substrates used in this series of experiments were glass plates measuring $25 \times 25 \times 1.5 \mathrm{~mm}(1.0 \times$ $1.0 \times 0.062 ")$ which were coated with $450 \AA$ chromium and $1800 \AA$ gold. The photoresist was Shipley Microposit ${ }^{\mathrm{TM}}$ S1400-31 [32]. This material is a positive resist; that is, the areas

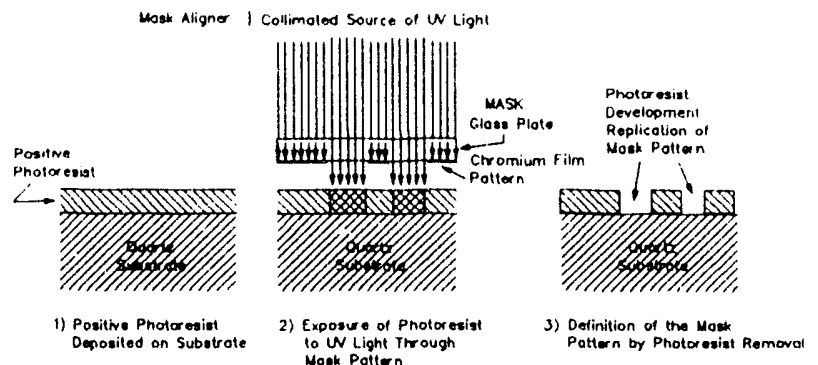

Figure 44 Scheme for pattern definition using a positive photoresist. 
exposed to the light source are removed during development (Figure 44). The viscosity of the photoresist was varied by diluting it with Shipley Thinner A. The levels of dilution were selected to match the concentrations (or viscosity) variations of S1400 available as separate prorlucts from the manufacturer and designated as S:400-xx. Eight drops of photoresist dilution was placed on one side of the wafer. The wafer was then spun at a prescribed speed for $30 \mathrm{sec}$, allowing the resist to coat the surface by centrifugal force. The glass plate was then put in an air oven and heated at $95^{\circ} \mathrm{C}$ for $5 \mathrm{~min}$ as an initial soft bake; soft in the sense that the photoresist was not fully hard but hard enough to prevent 2 mage to the layer during the next step of spinning photoresist on the other side. After the second side had been coated, the wafer was held at $95^{\circ} \mathrm{C}$ for 30 ininutes to complete the soft bake process. The photuiesist was exposed to the milling mask pattern (which defines the resonator shape) of the DETF through the doubie sided mask aligner (the details of which are presented later) for a prescribed exposure time. Next, the photoresist was developer. Observations were made of the photoresist pattern and measurements made of the tuning fork tine width as defined by the photoresist pattern at several locations to quantify the reproducibility of the mask pattern by the photoresist at this processing stage. Next, the plates were put into the oven for a $115^{\circ} \mathrm{C}, 30$ minute hard bake which fully cured the photoresist. The tine widths were re-measured and the photoresist thickness determined by surface profilometr'. Finally, the metallization layers were selectively etched away to define the milling mask pattern into the thin film layer. The widths of the tuning fork tines were measured once again.

Shown in Table 4 is a summary of the photoresist thickness values as a function of conceritration (viscosity); spinner speed; and exposure time in the mask aligner. Qualitative observations were also made. Use of the photoresist without dilution (50:0) resulted in a very uneven film thickness. Also, photoresist remained over areas which were exposed and developed. At a dilution of 50:3.4, the definition of the pattern lines was jagged and photoresist remained in son $\mathrm{e}$ of the exposed areas.

The pattern deñnition improved with the 50:9.6 dilution although some photoresist was still observed in exposed regions. The dilution of 50:12 produced excellent results. For dilutions of 50:17.4 and higher, the film was uneven over the surface and resulted in poor line definition. The optimum exposure time was 4 to $6 \mathrm{sec}$. Line definition deteriorated with 3 and $7 \mathrm{sec}$. exposures. The spinner rates were selected to cause the photoresist to evenly coat the surface with a uniformly ihick layer for the given viscosity.

From the experimental results described above, the following photoresist process parameters were determined for use. The photoresist, Shipley 140025 , which corresponded to the dilution, 50:12.0 and

Table 4 Photoresist ihicknesses vs. concentration.

\begin{tabular}{c|c|c|c}
$\begin{array}{c}\text { Photoresist } \\
\begin{array}{c}\text { Concentration } \\
\text { ml(Shipley } \\
\text { 1400):ml(thinner) }\end{array}\end{array}$ & $\begin{array}{c}\text { Spinner } \\
\text { Speed } \\
\mathrm{rpm}\end{array}$ & $\begin{array}{c}\text { Expose } \\
\text { Time } \\
\mathrm{sec}\end{array}$ & $\begin{array}{c}\text { Post-Bake } \\
\text { Thickness } \\
\text { nm }\end{array}$ \\
\hline $50: 0^{*}$ & $550 \mathrm{~J}$ & --- & --- \\
\hline $50: 3.4$ & 5000 & $3-4$ & 1300 \\
\hline $50: 9.6$ & 4000 & 7 & 1200 \\
\hline $50: 12.0$ & 4000 & $4-6$ & 1150 \\
\hline $50: 17.4$ & 4500 & $4-5$ & 820 \\
\hline $50: 23.8$ & 4500 & 4 & 650 \\
\hline $50: 53.3$ & 4000 & 4 & 270 \\
\hline
\end{tabular}

"Photoresist did not spread over substrate surface. Substrate: $45 \mathrm{~nm} \mathrm{Cr} / 180 \mathrm{~nm}$ Au plated glass slides 
a viscosity of $14 \mathrm{cSt}$, was selected for use. The spinner rate of $4000 \mathrm{rpm}$ and an exposure time of $5 \mathrm{sec}$. were also designated from these experiments. Some thickening of the photoresist layer at the edges of the wafers was observed; a phenomenon termed "edge bead development". This artifact did not extend into the areas where devices would be produced so that corrective measures which would lengthen processing time were not taken.

After applying photoresist to the metallized quartz blanks, the photoresist was spun on one side of the wafer and then heated in air at $95^{\circ} \mathrm{C}$ for 5 minutes (soft bake). The second side was coated and the wafer heated at $95^{\circ} \mathrm{C}$ in air for 30 minutes to complete the soft bake. The photoresist was ready for exposure in the first mask pattern. 


\subsubsection{DETF Mask System}

The mask set of the DETF consisted of 3 patterns:

(1) the milling mask (Figure 45) which defined the tuning fork resonator structure (Figure 46);

(2) the electrode mask which created the thin film pattern for excitation of the piezoelectric phenomena (Figure 47); and

(3) the electroplating mask which allowed for the electrodeposition of gold on the tuning pads and the wire bonding pads (Figure 48).

Two milling masks were used to define the pattern on both sides of the wafer. This allowed the chemical milling process to etch simultaneously the quartz structure from both sides of the wafer. Two electrode masks were used since the thin film electrode pattern was defined on both sides of the tuning fork. Only one electroplating mask was required as gold was deposited on one side of the DETF. Therefore, a total of 5 masks were required to define the resonator and the top/bottom electrode pattern by photolithography. A photograph of the top milling mask of the $71 \mathrm{kHz}$ DETF procured from Photosciences, Inc. [33] is shown in Figure 45. The mask is a glass plate $4.0{ }^{\prime \prime}$ square an approximately $0.060^{\prime \prime}$ thick. The
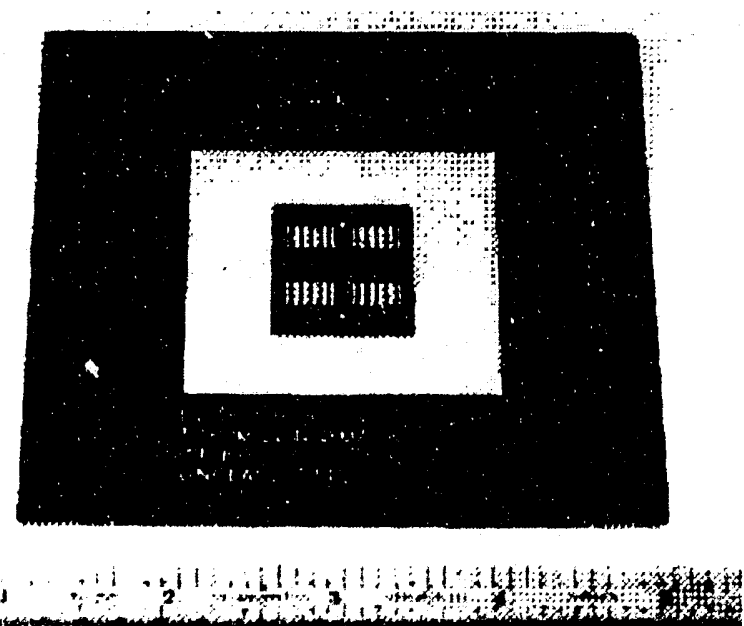

Figure 45 Top milling mask. pattern is defined by a chromium film on the plate. Referring to Figure 44, which shows how the positive photoresist functions, the dark regions of the mask pattern prohibit the ultraviolet light from striking the photoresist underneath. During the development stage, these regions of photoresist will remain. During the milling (or etching) process of the quartz which creates the resonator structure, the quartz will not be etched where the photoresist was not developed and stripped. The remaining $\mathrm{CrAu}$ film is not attacked by the quartz etch and acts as the mask. The same analysis applies to the electrode pattern. The photoresist pattern prevents the chromium and gold etchants from removing the thin metallic film where the electrodes are to be located. Therefore, the dark areas of the electrode and milling masks indicate the thin film metallic structures and the quartz, respectively, which are retained after processing.

The opposite approach applies to the electrodeposition mask. That mask is completely

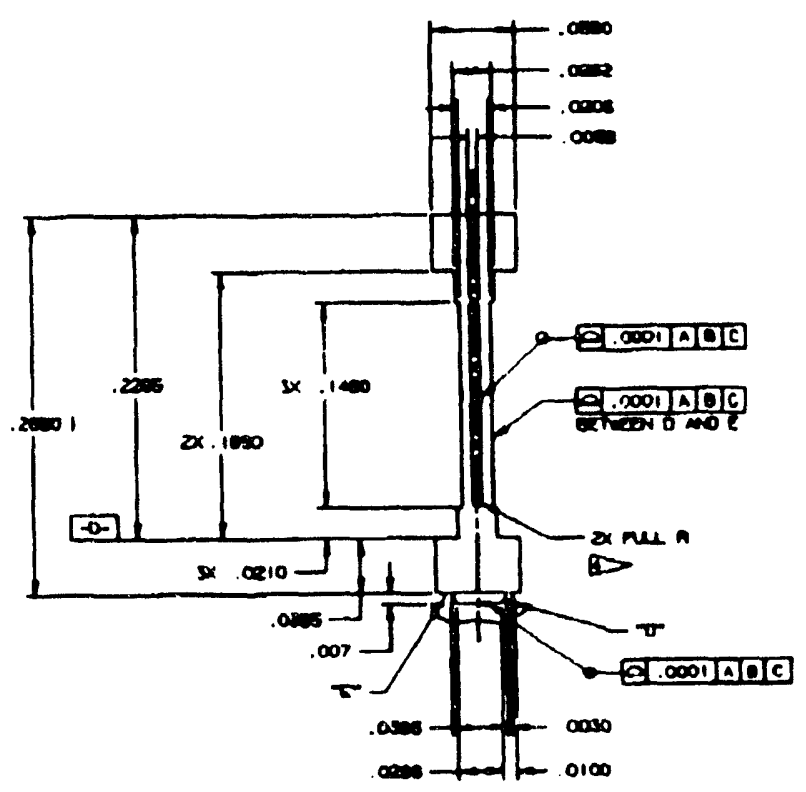

Figure 46 Drawing of the double ended tuning fork quartz resonator $(71 \mathrm{kHz})$. 
dark except where the plating is desired. The photoresist is developed and removed from those areas where plating is desired. Elsewhere, the retained photoresist protects the tuning fork from being electroplated.

Three iterations of mask sets were generated. The

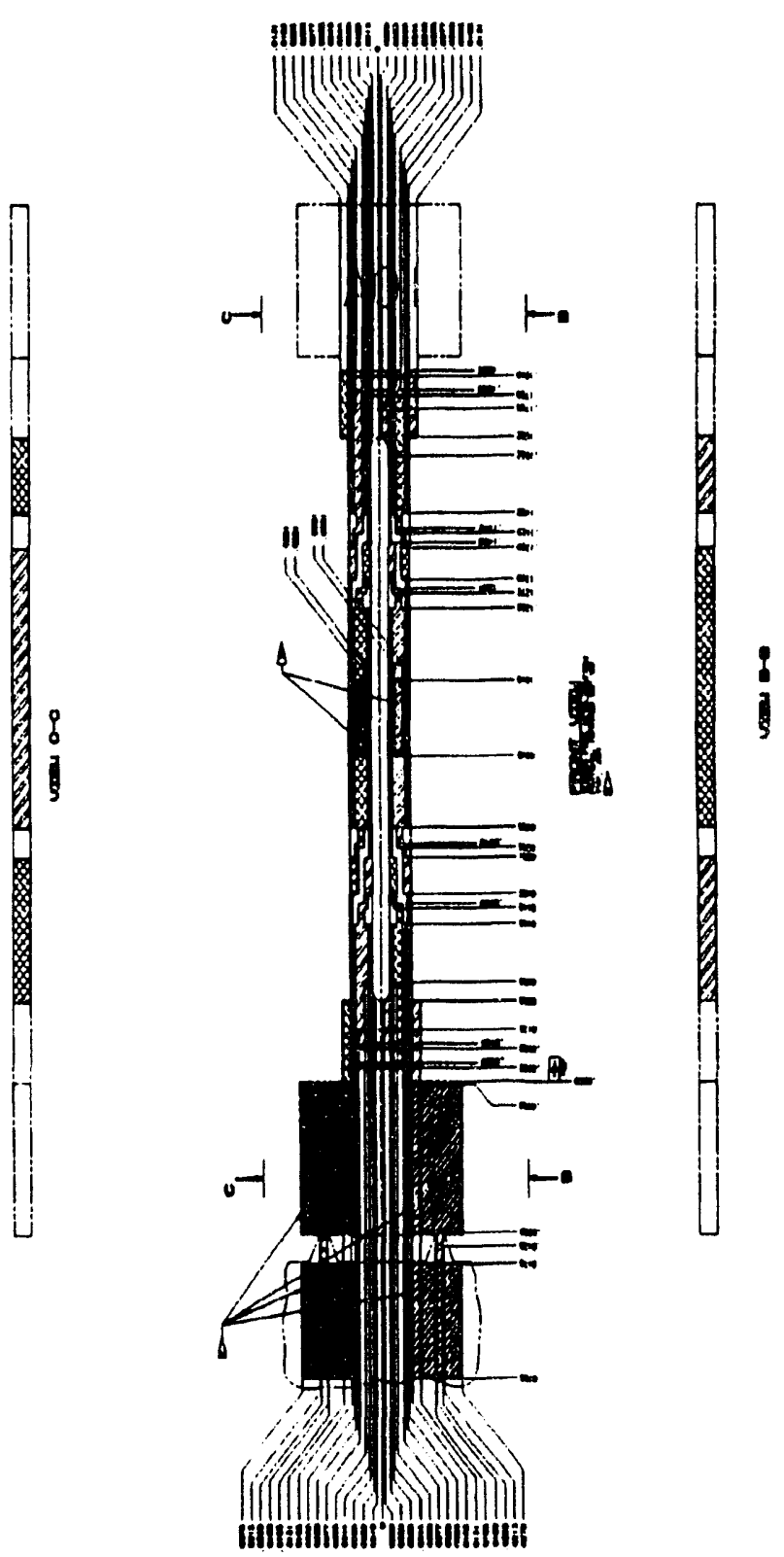

Figure 47 The top and side electrode metallization patterns for the DETF. first set of masks was created through and used by Statek Corporation to manufacture the DETF. For this iteration, 32 DETFs were on a wafer with alternating frequencies of 70 and $71 \mathrm{kHz}$ along a row. The difference in the resonator structure that accounted for $70 \mathrm{kHz}$ or $71 \mathrm{kHz}$ resonance was the length of the tines. The tuning forks from these masks were used mainly for individual accelerometer assemblies. A second set of masks were generated by XECO Inc. which defined two wafers of 32 tuning forks; one with only $70 \mathrm{kHz}$ units and the other with only $71 \mathrm{kHz}$ forks (Figure 38 and Figure 39). These wafers were used for both individual accelerometer assemblies and also for "wafer scale" assemblies in which whole wafers of tuning forks and spacers/proof masses were placed on top of one another and bonded together to form 20 or 12 accelerometers at a time (the details are discussed later).

The third and final iteration of the DETF wafer was the "20-fork" design which was a modification to the XECO mask system. A schematic diagram of the layout of the tuning forks on the wafer is shown in Figure 49. The reduction of the number of tuning forks on the wafer simplified the wafer-scale assembly technique by which whole wafers of tuning forks and spacers and proof masses were sandwiched together and bonded to form 20 accelerometer sensors at once. The 32-fork layout permitted at most 20 accelerometers (the first and

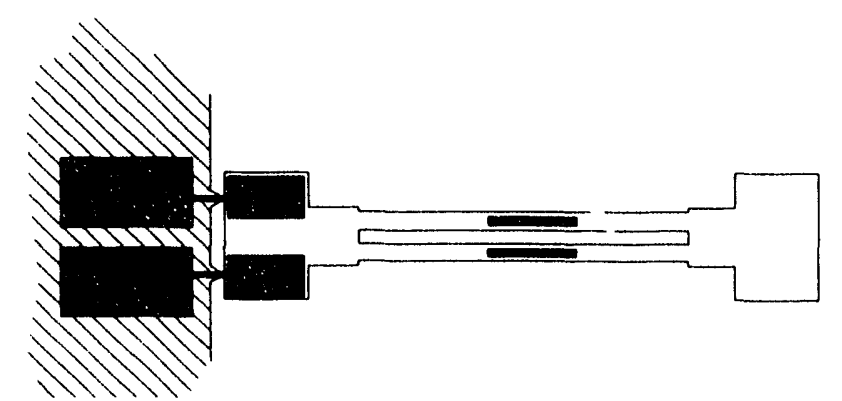

Figure 48 Location of the regions receiving electroplated gold. 
third rows, Figure 38) to be assembled. The other 12 (from the center row, Figure 38) had to be fabricated in a second step and risked being broken during the first assembly. Each wafer contained tuning forks of a single frequency of either 70 or $71 \mathrm{kHz}$. A complete set of masks which included the milling masks, electrode masks, and the electroplating mask were made for each of the two frequencies.

A fourth mask set for an enhanced design called the integral flexure DETF was also fabricated and used to produce parts. Each wafer contained eight tuning forks of a single frequency of either 70 or $71 \mathrm{kHz}$.

\subsubsection{Chromium/Gold Film Milling Pattern Definition}

At this stage in the processing, the metallized quartz wafers have been coated on both sides with a layer of photoresist which has been soft baked (Figure 37). The first pattern to be exposed into the photoresist was the definition of the resonator structure by the milling mask on both sides of the

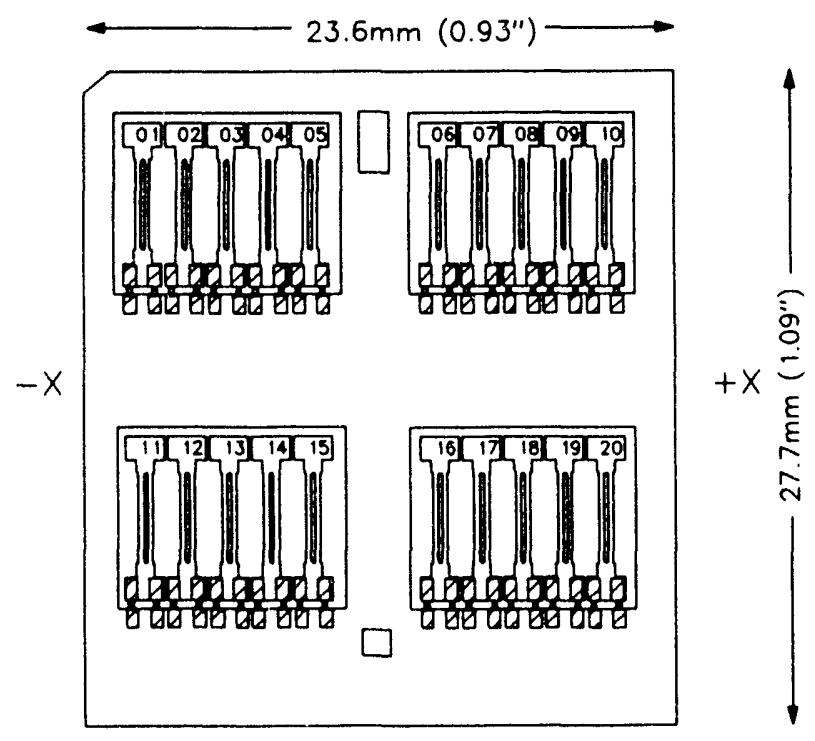

Figure 49 The arrangement of 20 DETFs on a quartz wafer. blank. This process involved first the precise alignment between the top and bottom masks in the Karl Suss ${ }^{\mathrm{TM}}$ MJB-21 mask aligner [34] (Figure 50). This step was performed with the two masks in "proximity contact"; that is, the two plates were separated by 20 to $30 \mu \mathrm{m}$.

Next, the quartz wafer was placed between the two masks and aligned according to its edges with respect to the mask underneath it. The top mask was then brought into proximity contact with the wafer. The wafer was then exposed to $365 \mathrm{~nm}$ wavelength light from a mercury vapor lamp source with an intensity of $4.5 \mathrm{~mW} / \mathrm{cm}^{2}$ which established the mask pattern in the photoresist. After exposure, the photoresist was developed by immersing for 60 $\mathrm{sec}$ in Shipley Microposit ${ }^{\mathrm{TM}} 354$ developer at $25^{\circ} \mathrm{C}$ which removed the photoresist that had been exposed to the ultraviolet light (Figure 44). The wafer was then rinsed in a deionized water cascade and spun dry in nitrogen. The wafer was then placed in a hot air oven at $95^{\circ} \mathrm{C}$ for 30 minutes to hard bake the remaining photoresist pattern to withstand the wet etching processes.

Shown in Figure 51 is a section of a wafer with the milling mask pattern in the crotch region of the

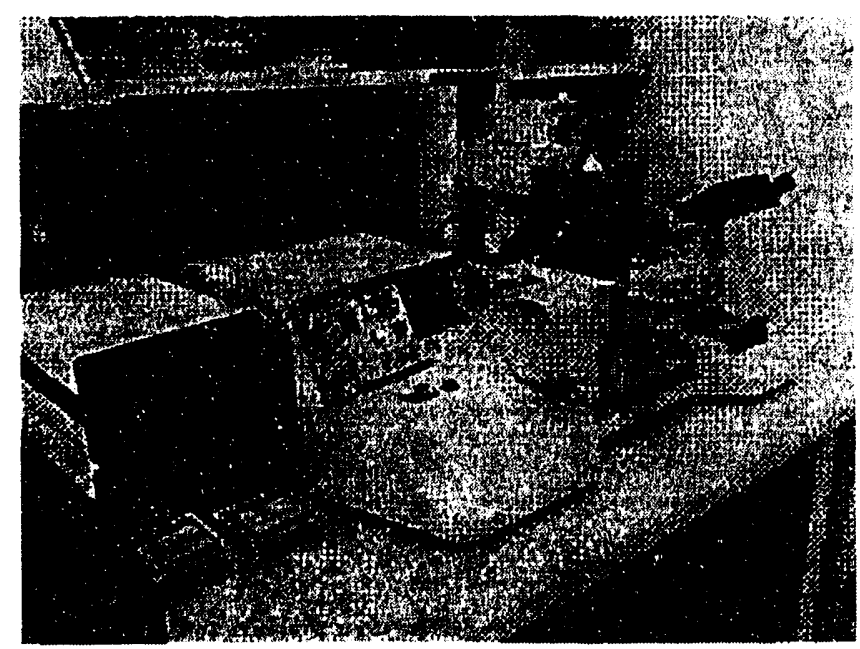

Figure 50 Photograph of the MJB-21 double sided mask aligner. 
DETF established by the photoresist. The remaining photoresist left a pattern of the DETF resonator structure.

The wafer was next immersed into the gold and chromium etchants to remove the metallization layers not covered by photoresist. The gold etchant was a solution of $19 \mathrm{~g}$ of iodine and $30 \mathrm{~g}$ potassium iodide in $750 \mathrm{ml}$ of water at ambient temperature. The etching rate was 2000 to $3000 \AA / \mathrm{min}$ so that the gold layer was removed after 50 to $60 \mathrm{sec}$ of immersion. The wafer was rinsed and then immersed into the chromium etchant (Cynatek Chemicals product CR-7) which consisted of a solution of perchloric acid (5\%) and ceric ammonium nitrate (9\%). The etching rate was 1000 to $1500 \AA / \mathrm{min}$. The solution at ambient temperature required approximately $25 \mathrm{sec}$ to etch through the $\mathrm{Cr}$ layer. After the chromium etch, a slightly gray haze was still present on the surface. This haze was removed by a second immersion in the gold etchant for $5 \mathrm{sec}$ followed by a complete rinse and spin dry. A photograph of the 20-fork design entire wafer following the metallization etching steps is shown in Figure 52.

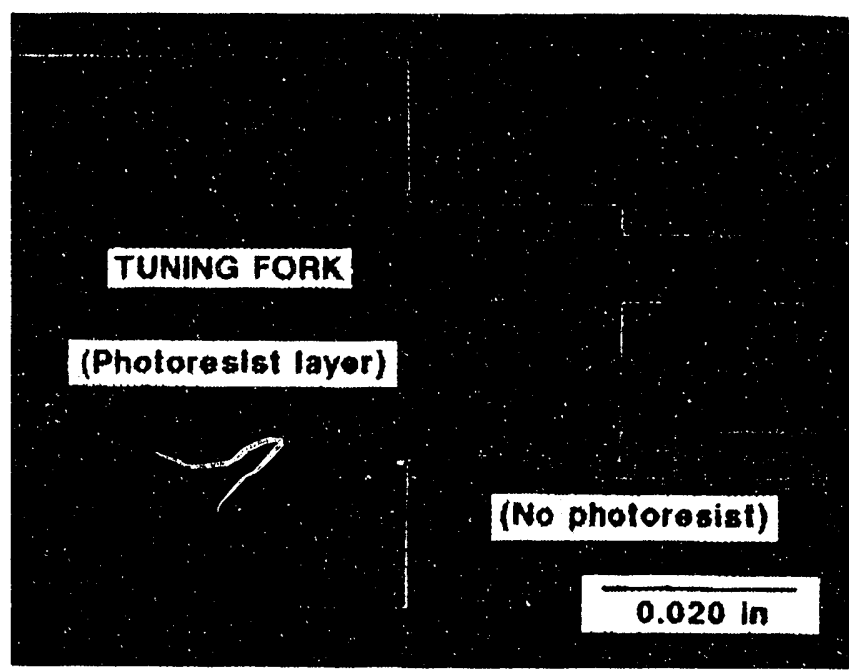

Figure 51 Optical micrograph of the photoresist defining the milling pattern for the crotch region of a tuning fork.
Qualitative Auger analysis was performed on wafers which were etched of the metal thin films to understand the residues remaining on the surfaces. The $\mathrm{Cr}$ signal was at the signal noise level. Significant $\mathrm{Au}$ and $\mathrm{Ce}$ signals were observed at the end of the process. The source of the Ce signals was cerium oxide particles embedded in the quartz during the polishing process. Nevertheless, the residue did not appear to hinder further processing of the DETF.

Next in the processing sequence, the retained photoresist was stripped away using Shipley Microprosit 1112A Remover which was diluted 1:1 in deionized water. The solution temperature was held at $70^{\circ} \mathrm{C}$ and the immersion time was $5 \mathrm{~min}$ The sample was then rinsed and spun dry. At those areas where the metallization was removed, the quartz will be chemically milled at a subsequent step in the process.

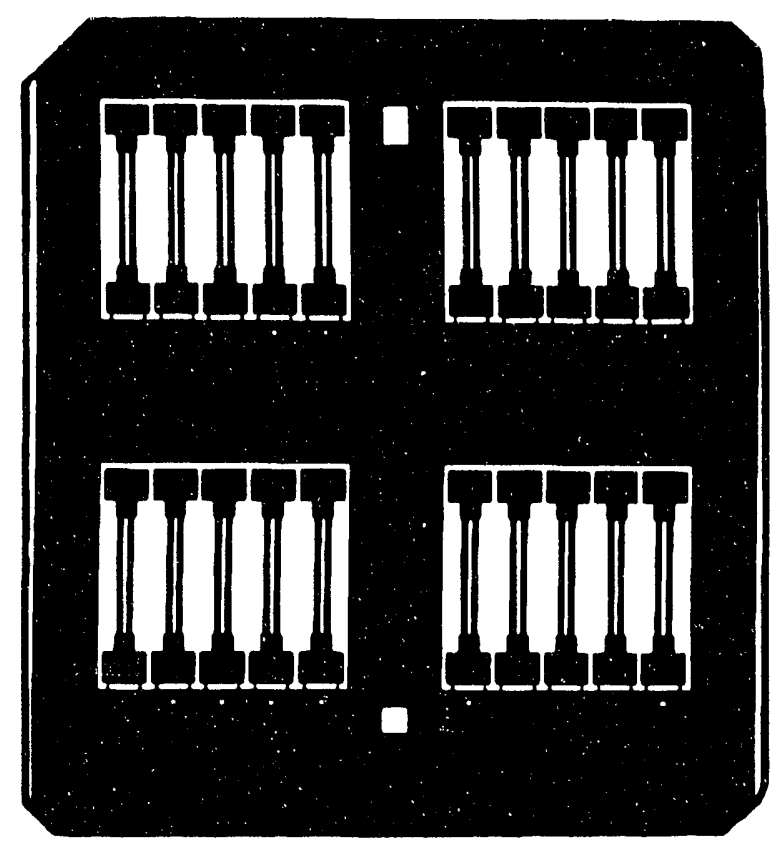

Figure 52 Photograph of the wafer substrate after the $\mathrm{Cr} / \mathrm{Au}$ had been etched to reveal the milling mask pattern definition. 


\subsubsection{Gold Electroplating}

The next series of steps defined the gold electroplating pattern on one side of the tuning fork. Photoresist was spun on both sides of the wafer and then soft baked as described earlier. The substrate was then placed into the mask aligner and exposed to the electroplating mask. A soft contact and the same exposure conditions as noted previously were used. Next, the photoresist was developed resulting in the loss of photoresist at those areas where the electroplated gold was desired, which included (i), the tuning pads on the tines; (ii), the wire bonding pads at the end of the DETF; and (iii), the inspection probe contacts on the frame structure of the wafer. The photoresist was exposed to a hard bake; the wafer was ready for the electroplating process.

The electroplating process was performed in an agitated bath comprised of Orotemp ${ }^{\mathrm{TM}} 24$ (Technic, Inc.) gold plating solution which contained 6.87 weight percent potassium gold cyanide. The surface area of the plated regions of the DETF

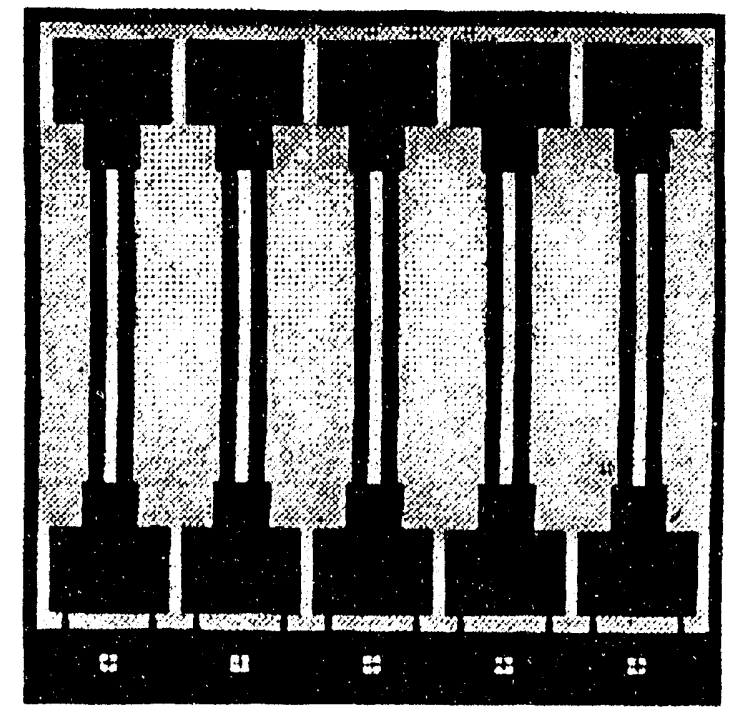

Figure 53 Photograph of a quartz wafer showing where the electroplated gold has been deposited (refer to Figure 48). were much smaller than the projected surface area of the exposed metal of the fixturing. As a result, the dimensions of the fixturing controlled the current density. Operating parameters of the bath
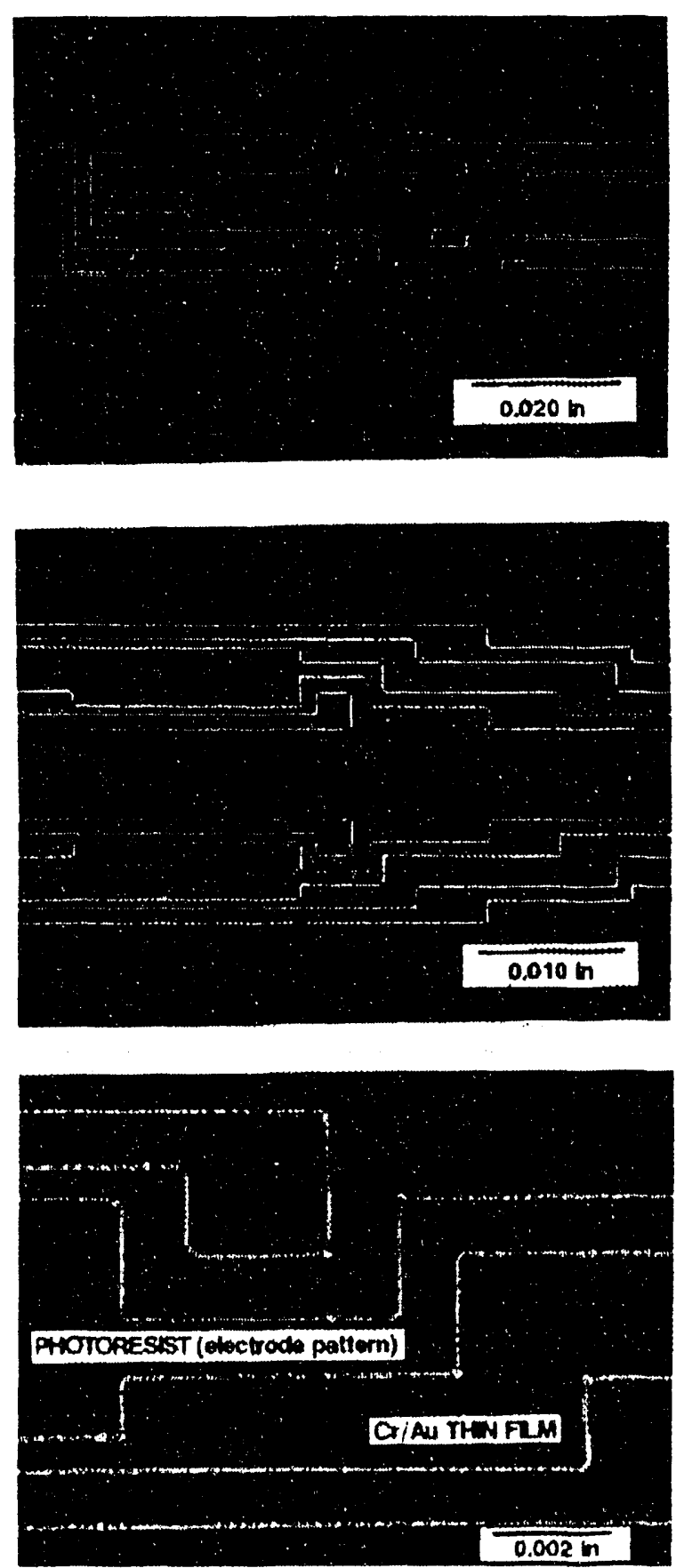

Figure 54 Optical micrographs of the photoresist defining the DETF electrode pattern at three magnifications. 

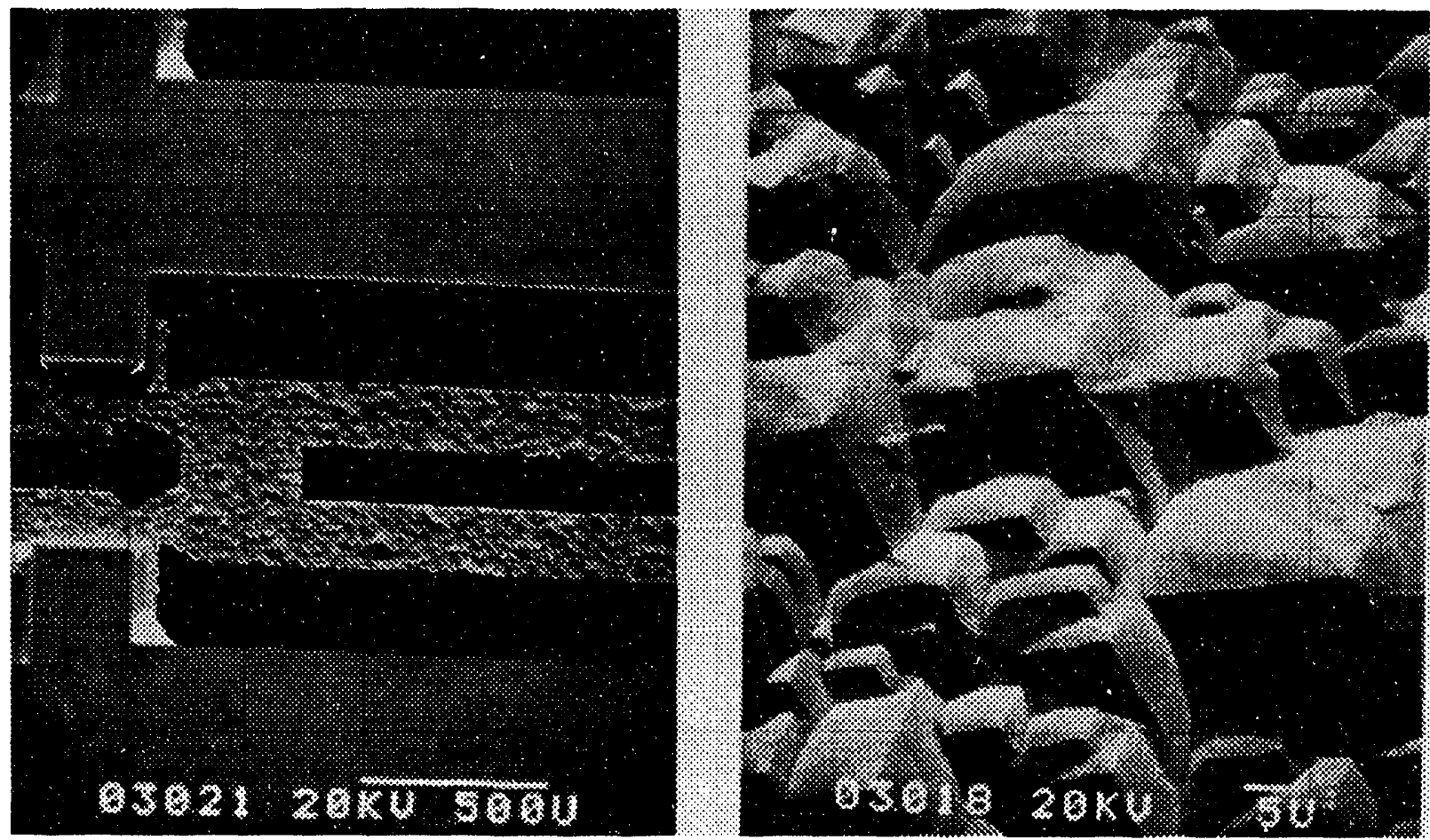

Figure 55 Etching (milling) of the quartz substrate to define the resonator structure.
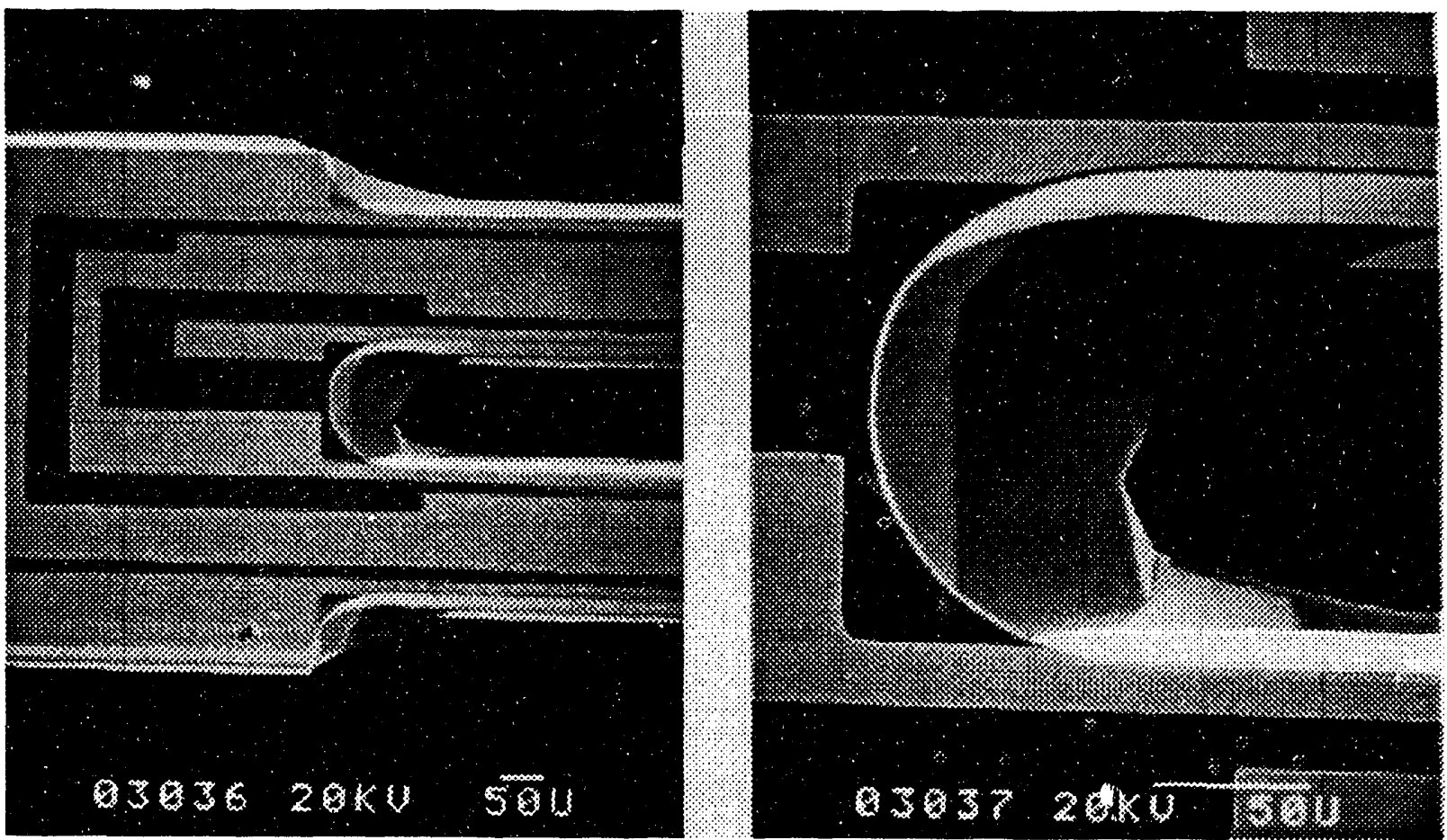

Figure 56 SEM micrographs of corners of the tuning fork structure demonstrating the anisotropy of the etching process. 


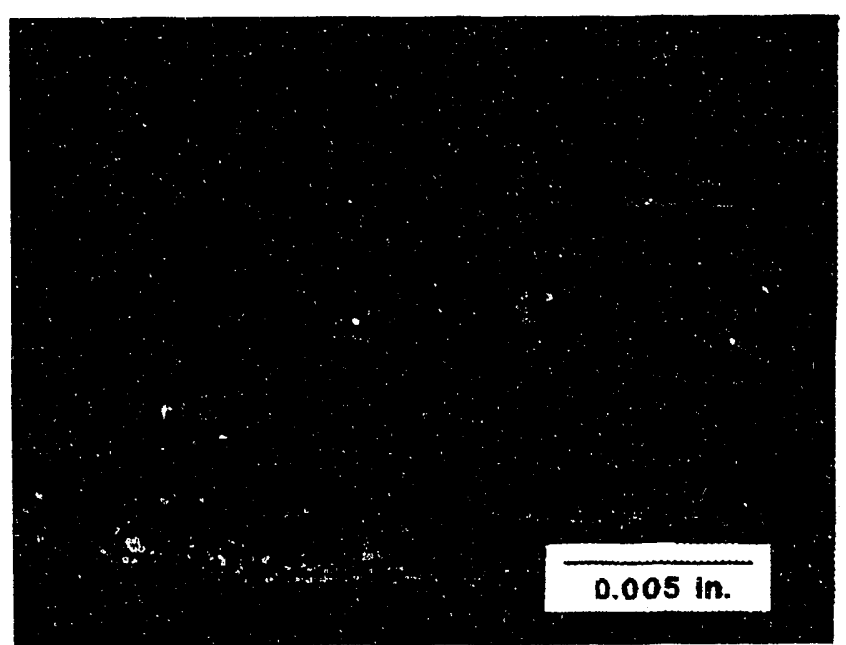

Figure 57 Optical micrograph of the cross section of the tines of the DETF.

were initially defined with the use of a grid test pattern introduced into photoresist that coated a blank $\mathrm{CrAu}$ metallized quartz wafer. The target plating thickness was $4.0 \mu \mathrm{m}$ (157 microinches). Gold was electroplated on the samples, the photoresist was stripped away, and the resulting plating thickness was measured by surface profilomentry. The optimum operating parameters for the bath were determined to be: (1) current density, $9.3 \mathrm{~mA} / \mathrm{in}^{2}$; (2) temperature, $60^{\circ} \mathrm{C}$; and (3) $\mathrm{pH}, 5.5$ to 6.0. Shown in Figure 53 is a view of a 20 -fork wafer section demonstrating the locations of the plating deposits (the lighter regions contained on the fork). After completion of the electroplating process, the remaining photoresist was stripped away.

\subsubsection{Photoresist Definition of the Electrode Pattern}

The next sequence of the process was to define the electrode pattern into the metallization on the wafers which, to this point, appear as shown in Figure 53. Each wafer was coated with photoresist on both sides and subjected to the soft bake as described earlier. The top and bottom electrode masks were placed into the mask aligner and aligned with respect to each other. The wafer was then put into the aligner. Precise registration (with an error of $\pm 1 \mu \mathrm{m}$ ) between the wafer and the

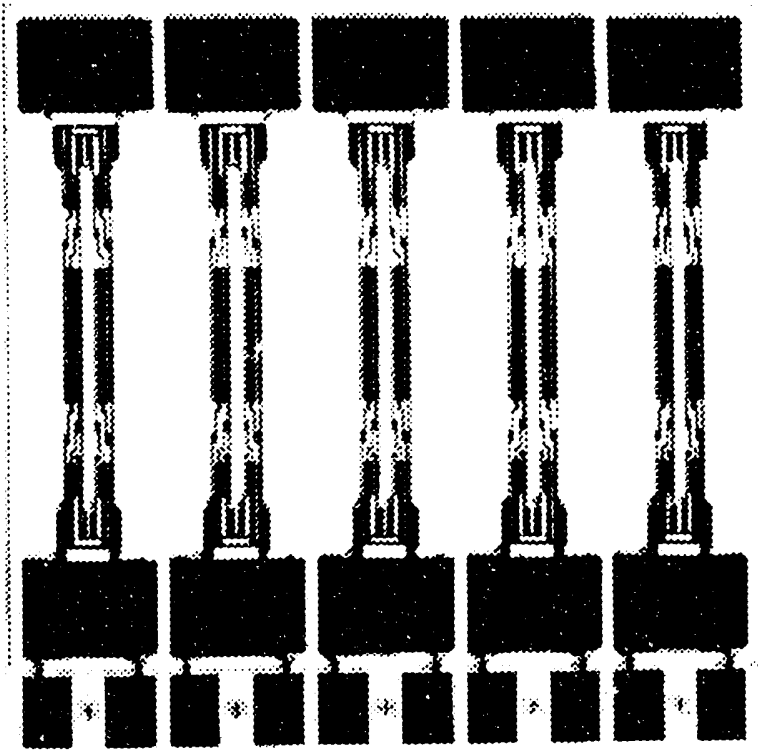

Figure 58 Photograph of a completed 20 fork wafer. 
masks was made through the use of small markers on the glass mask pattern and markers of CrAu metallization left on the wafer from the milling mask. The mask under the wafer was in soft contact and the one on top, in proximity contact, to the quartz surfaces. The same exposure conditions as outlined earlier were used in this sequence. Next, the photoresist was developed to reveal a pattern that would eventually define the electrodes for piezcelectric excitation (Figure 54). The photoresist layer was then exposed to the hard bake cycle.

Following the photoresist definition, the guartz etch was performed which actually used the $\mathrm{CrAu}$ metallization (Figure 54) to mask the action of the acid. The metallization also remained covered by the photoresist in the electrode pattern. The photoresist of the electrode pattern was deposited prior to quartz etching because the photoresist could not be evenly distributed over a wafer that had slots and holes formed from the quartz milling process. A uniform photoresist layer is required for the precise replication of the mask pattern during exposure.

\subsubsection{Chemical Milling of Quartz}

The creation of the DETF resonant structure was performed by the chemical milling (or machining) action of a solution of $300 \mathrm{ml}$ hydrofluoric acid (HF) and $450 \mathrm{ml}$ ammonium fluoride $\left(\mathrm{NH}_{4} \mathrm{~F}\right)$ operating at a temperature between 74 and $78^{\circ} \mathrm{C}$. The extensive material removed in the chemical milling process revealed the anisotropy of the etching behavior of the quartz. Shown in Figure 55 are SEM micrographs of the surface of the quartz which had been etched of approximately $50 \mu \mathrm{m}(.002 ")$ of material. The smooth surfaces in Figure 55(a) were not etched and show the smooth topography of the polished substrate. The high magnification photograph in Figure 55(b) shows the facets of the etch surface. The result of the anisotropic etching on the structure of the tuning fork resonator is shown in Figure 56. In Figure 56, the sharp corners as defined in the engineering drawing (Figure 46) and by the metallization (Figure 45) mask for the milling operation were distorted by the chemical etching process. The anisotropic etching effect is clearly shown in the structure of the crotch at the base between the two tines (Figure 56).

The equation used to determine the time required for the wafer to remain in the etching bath was given as:

$$
t(\min )=\frac{9450 \Delta h}{1+0.044(T-80)}
$$

where $\Delta h$ is the thickness in inches and $T$, the temperature in ${ }^{\circ} \mathrm{C}$. This expression takes account of etching from both sides with respect to the thickness change $(\Delta h)$. Equation (26) differs from equation (25) used to reduce the thickness of wafers prior to processing by the factor 9.45 as compared to 4.62 in equation (25). Equation (25) will predict the time necessary to etch through $150 \mu \mathrm{m}(0.006 ")$ of quartz. However, the longer immersion time predicted by equation (26) was required to reduce the dimensional artifacts caused by the anisotropy

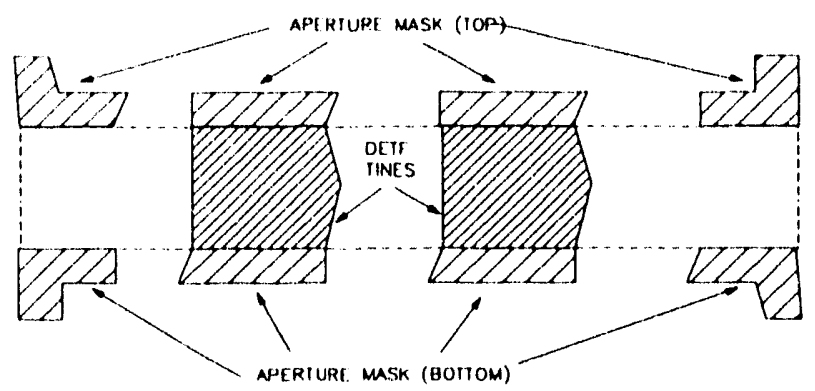

Figure 59 Schematic diagram showing the cross section of the aperture mask with respect to the tuning fork tines for side deposition of the $\mathrm{CrAu}$ metallization. 
of the quartz. Shown in Figure 57 is a photograph of the cross section of the tuning fork tines (in the length or $y$ crystallographic direction). The anisotropic removal of material by the etching process results in side walls which are not straight. The extended etching time allowed the acids to remove material in the $x$ direction (a process which is much slower than in the $\mathrm{z}$ direction) for a more vertical wall geometry. The extra etching time was limited. Over-etching resulted in undercutting of the metallization and poor dimensional definition.

At a bath temperature of $76^{\circ} \mathrm{C}$, the time to etch through 0.006 in. of quartz was $68.8 \mathrm{~min}$. Upon completion of the etching step, the parts were thoroughly rinsed in a 2 stage cascade rinse. Sufficient rinsing action was determined by the increase of the rinse water's resistivity after an initial sharp drop following immersion of the part into the water. The parts were then spun dry.

\subsubsection{Definition of the CrAu Electrode Pattern}

The next step in the process was to define the electrode pattern in the CrAu metallization. Recall that the photoresist was already patterned for development of the electrode layout. The wafer was returned to the $\mathrm{Cr}$ and $\mathrm{Au}$ etchants to remove the metallization not covered by the developed photoresist. The wafer was then rinsed and spun

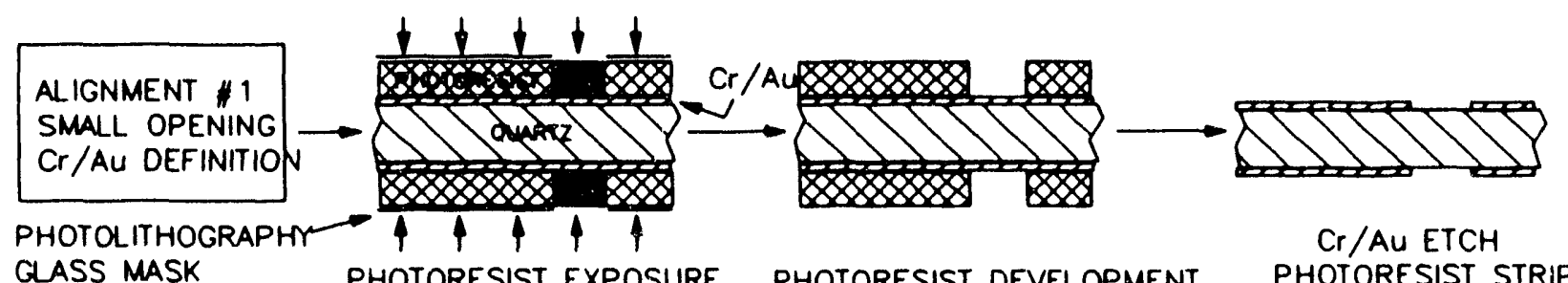

GLASS MASK PHOTORESIST EXPOSURE PHOTORESIST DEVELOPMENT PHOTORESIST STRIP
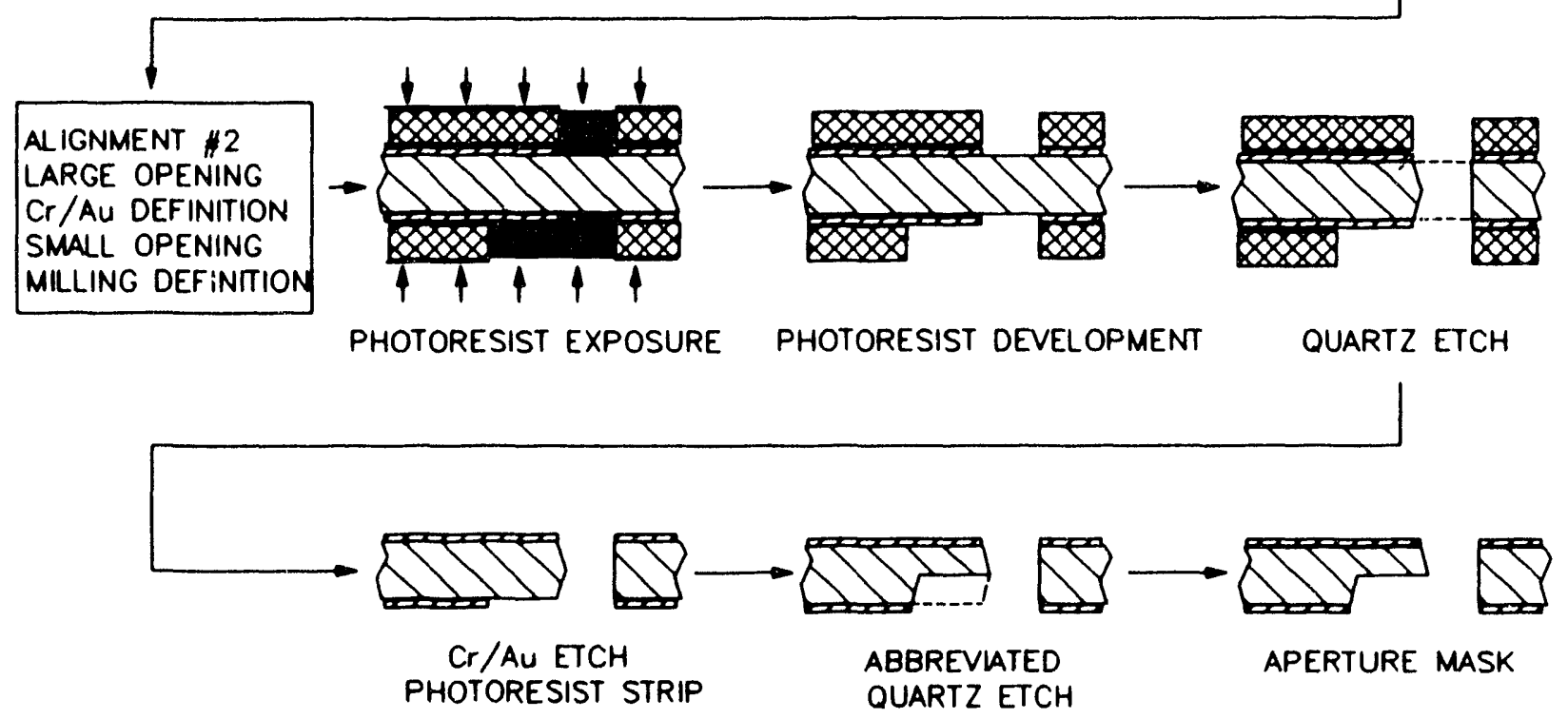

Figure 60 Schematic diagram showing the cross section of the aperture mask as it develops during the milling (etching) process. 
dry.

At this point, the photolithographic processing of the DETF was complete. A photograph of a completed wafer of 20 DETFs is shown in Figure 58. A higher magnification of one quadrant is also shown. The number on the upper left corner of the wafer is the drawing number defining the wafer. In addition, each fork is labeled with a number defining its position in the wafer.

\subsubsection{Electrode Deposition on the Tine Sides}

The final procedure in the completion of the DETF was the side metallization of the tines. Placing a metallization layer on the walls of the tines optimized the piezoelectric properties of the resonant structure. The introduction of electrodes on the sides of the tines was achieved by the use of aperture (or shadow) masks between which was placed the wafer of DETFs. Precise alignment between the masks and wafer was maintained by special fixturing. The assembly was then secured in the vacuum evaporator. The openings in the aperture mask allowed for the deposition of the $450 \AA \mathrm{Cr}$ and $1800 \AA$ Au films over selected areas which, in this case, included the sides of the tines as well as small regions on the top and bottom

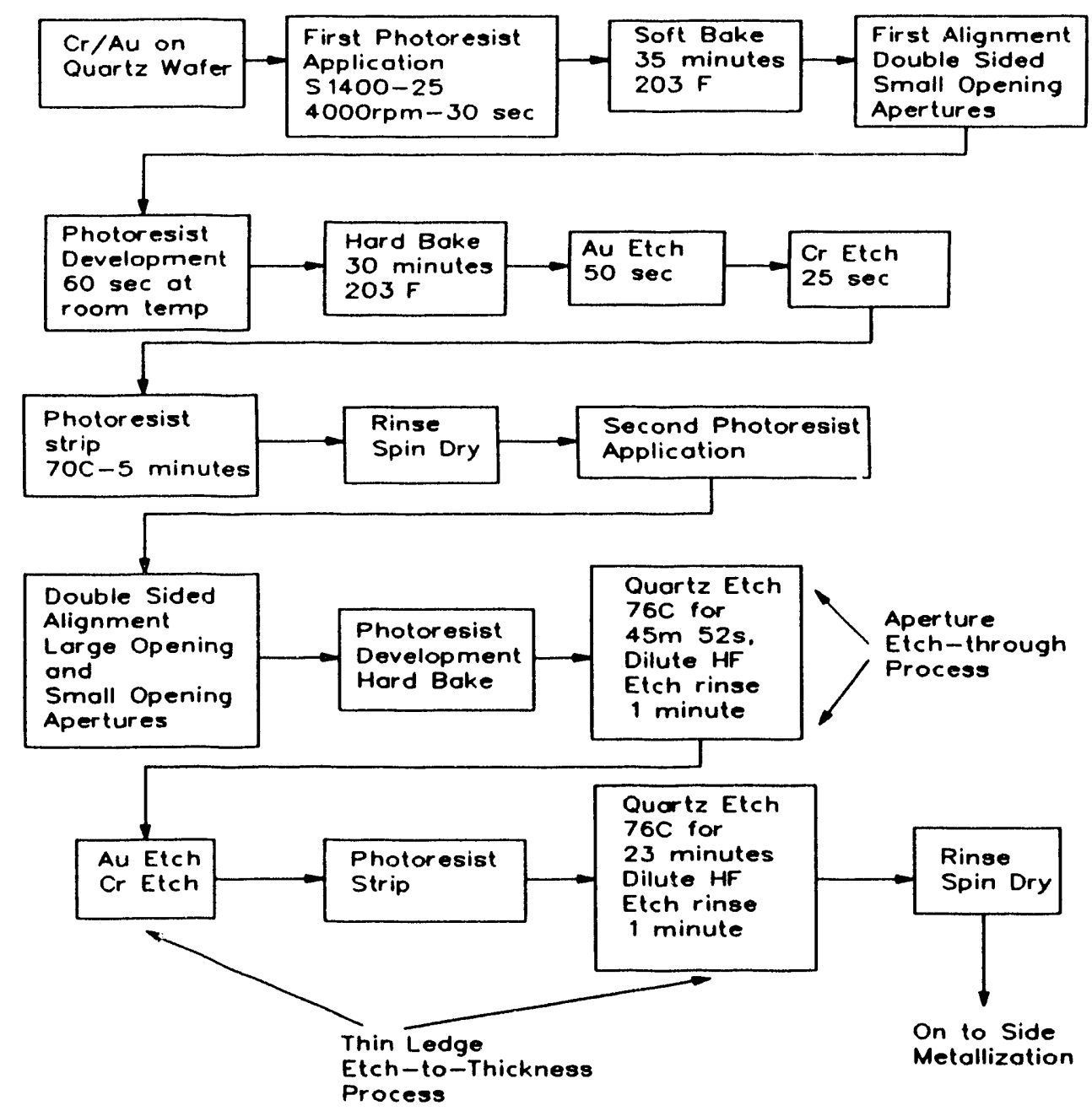

Figure 61 Flow diagram of the process to create the aperture mask. 
surfaces of the tines in order to tie the voltage signal into the side electrodes. The fabrication of the aperture masks and their assembly with the DETF wafer will be discussed in detail.

The openings in the masks were required to be precisely defined both with respect to their dimensions as well as the registration to the DETFs. Therefore, the aperture masks were fabricated from z-plate quartz wafers by the same photolithographic process used to make the DETF. The nominal thickness of the quartz substrate was $100 \mu \mathrm{m}\left(.004^{\prime \prime}\right)$. Shown in Figure 59 is a schematic diagram of the cross section of a set of DETF tines together with the aperture mask. It is observed that, in addition to creating the openings in the mask to permit thin film deposition, the mask thickness was reduced near the tines in order to increase the angle through which the sides of the tines receive the evaporated metal.

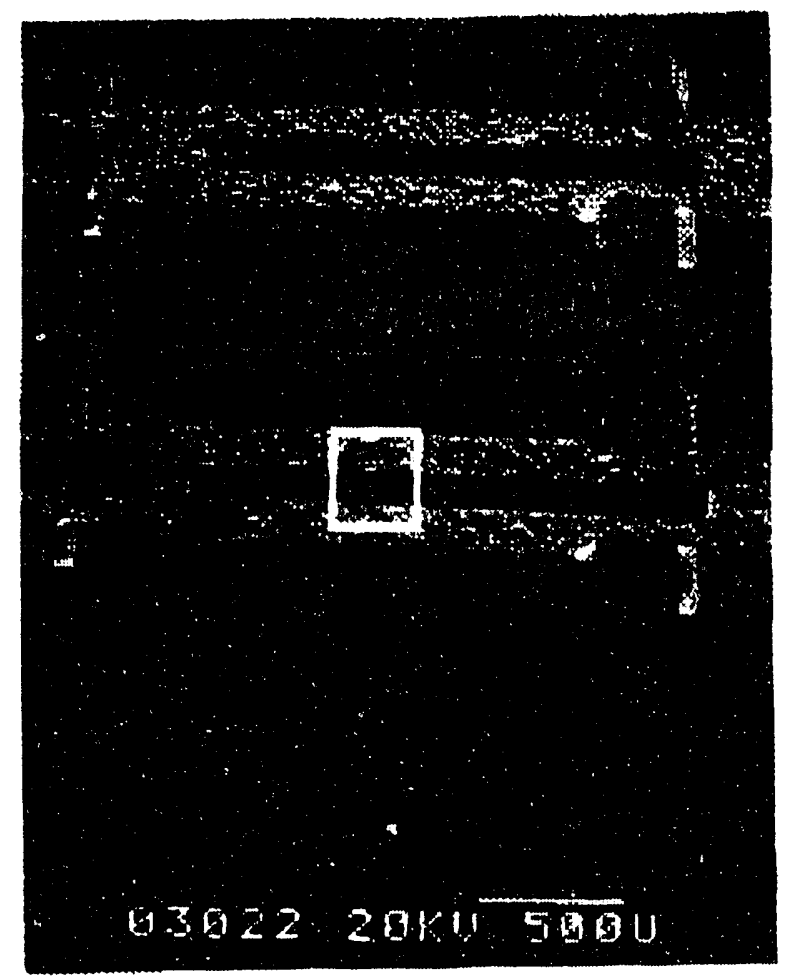

The glass photolithographic mask set used to define the aperture masks consisted of six plates; three plates for each of the 70 and $71 \mathrm{kHz}$ DETFs were required beciluse of the slightly different dimensions of the two frequencies of tuning forks. The two distinct photolithographic masks were designated as the "through-etching" mask or small-opening mask which defined the opening through the entire thickness of the quartz substrate and the "backetching" masik or large opening mask which created the step on one side of the aperture mask substrate (Figure 59). A second copy of the through-etching mask was also obtained. The milling process to create the openings and the ledge structure is diagrammed schematically in Figure 60.

A flow diagram of the process steps for fabrication of the aperture masks is shown in Figure 61. The quartz wafers were coated with $450 \AA$ of $\mathrm{Cr}$ and $1800 \AA$ of $A . u$. The photolithographic processing

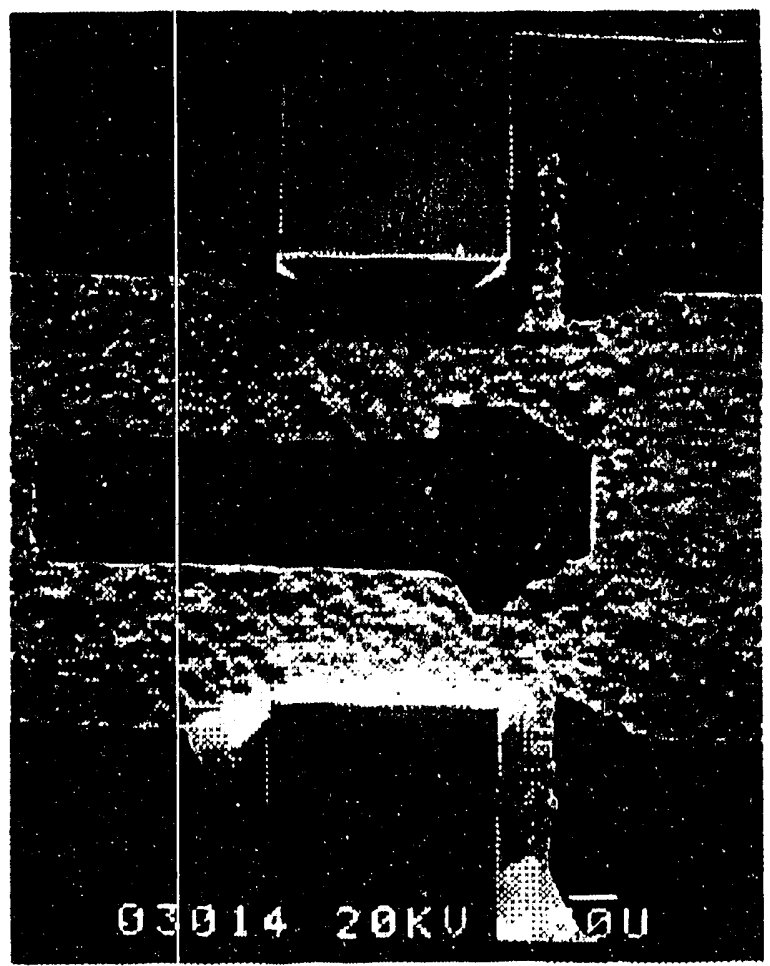

Figure 62 SEM micrographs of the quartz aperture mask after elching. 
details were exactly the same as those used to fabricate the DETFs. The small opening masks were aligned in the mask aligner. The quartz wafer (with photoresist) was then inserted between the two masks and exposed to the ultraviolet source. The photoresist was developed and that remaining on the substrate, exposed to the hard bake cycle. The wafer was then placed into the $\mathrm{Au}$ and $\mathrm{Cr}$ etchants to remove the metallization where the photoresist was absent, thus defining where the quartz was to be milled away. The quartz etching parameters were the same as those noted earlier except that the time period was adjusted for the thinner substrate. This milling process created the small opening through the full thickness of the quartz. The wafer was recoated with photoresist which was exposed to the small opening mask on one side and the large opening mask on the other side. The large opening masks exposed a small area of $\mathrm{CrAu}$ metallization that will later form the step. The wafer was put in the quartz etch at $76^{\circ} \mathrm{C}$ for 45 minutes plus a one minute clean-up etch in dilute HF. This process resulted in the formation of the small opening. The small area of exposed metallization was then etched away and the remaining photoresist was stripped. The wafer was then put into the quartz etchant for 23 minutes to form the step where the small area of metallization had been removed, followed by cleaning the wafer. Shown in Figure 62 are SEM micrographs of the openings and ledge structure of the aperture mask.

In order to perform side metallization of the DETFs, the wafer of devices was held between the two aperture masks by fixturing which used the hole and slot (on the centerline of the wafer) to precisely align the three quartz wafers. Each fixture was capable of holding four sets of DETFs plus aperture masks. The vacuum evaporation of the $\mathrm{Cr}$ and $\mathrm{Au}$ layers was performed by first depositing the films normal to one face of the wafers and then rotating the parts 180 degrees and depositing the films on a normal incidence to the other face.

\subsubsection{Summary}

A description has been given of the procedures used for the fabrication of DETFs from a z-plate quartz wafer. The manufacturing objective was the fabrication of a large number of the DETF devices (either 20 or 32 ) with as near as identical electromechanical properties as possible. In the following sections, an analysis will be made of the performance of the DETFs fabricated at SNL and compared to those of devices produced the commercial operation at Statek Corp.

\subsection{Analysis of DETFs Fabricated at SNL.}

The analysis of tuning fork paramenters was used to quantify the process of capability development. The parameters used to assess the performance of the DETFs were the frequency, $f$; the motional resistance, $\mathrm{R}_{\mathrm{m}}$; the motional capacitance, $\mathrm{C}_{\mathrm{m}}$; the static capacitance, $\mathrm{C}_{\mathrm{o}}$; and the inductance, $\mathrm{L}_{\mathrm{m}}$. Differences in the properties of DETFs on a given wafer can be caused by (1) spatial variations of the thickness and quality of the quartz (e.g., flaws such as in Figure $30(\mathrm{e})$ ); (2) errors in the photolithographic masks; and (3) discrepancies in the photolithographic processing such as uneven photoresist application or poor cleaning practices. The difficulty of reproducibility of tuning fork properties between different wafers is increased by variations in the substrate preparation procedures.

At the time that this report was prepared, a total of 24 wafers of tuning forks were produced of either the 32-fork (modified XECO mask) design, which constituted a majority of the units, or the 20 -fork (SNL mask) layout. An analysis will be presented comparing the DETFs produced by Statek Corp. 
and those manufactured at SNL.

The parts fabricated by Statek resulted from the use of a mask set designed by Statek. The XECO modified mask set used to make some to the SNL parts was found to have had defects in the electrode pattern definition. Therefore, the performance of these initial devices was relatively poor. The defects were corrected in the definition of the 20fork mask set.

Listed in Appendix B are the frequency and electrical properties of a wafer of DETFs produced by Statek Corporation early in the program (c. 1985). Statek later discovered that one of the electrodes was misconnected. This resuited in an inactive drive region in the quartz tine and gave a very high motional resistance. The error terms represent one standard deviation of the data. The wafer was divided into 2 groups of DETFs, hose with target a frequency of $70 \mathrm{kHz}$ and those with a frequency of $71 \mathrm{kHz}$. The source of the substrate material was not known. The quality factor of the resonator, $\mathbf{Q}$, is determined by the equation:

$$
Q=\frac{\left\llcorner\pi f L_{m}\right.}{R_{m}}
$$

The value of the standard deviation of the particular frequencies provided an indication of the reproducibility of each of the 32 forks on the wafer. For this particular wafer, the spread of the zlectrical parameters was larger for the $70 \mathrm{kHz}$ tuning forks than for those of $71 \mathrm{kHz}$ no'sinal frequency.

The properties of a selected number of DETFs on two wafers made by Statek later on in the program (1987) are outlined in Appendix D. For each of these wafers, tuning forks with frequencies of 71 and $72 \mathrm{kHz}$ were produced. The frequency spreads are similar to the values in Appendix B. The value of $\mathbf{Q}$ was nearly the same as the earlier forks. The decrease in motional resistance due to the corrected electrode error caused an increase in the motional inductance. Still later units would show an increase in $Q$ (to values of typically 70000 to 90000 ). The values of $\mathrm{C}_{m}$ and $\mathrm{L}_{m}$ were in the range of 3.2 to 3.5 $\mathrm{fF}$ and 1.4 to $1.6 \mathrm{kH}$, respectively. These $\mathrm{Q}$ and $R_{m}$ parameters would represent the target performance sought for devices fabricated at SNL, as defined in terms of the ability of the device to be installed into an oscillator circuit.

Shown in Appendix $\mathrm{C}$ are the frequencies and motional resistances of two wafers of tuning forks produced at SNL with the 32-fork modified-XECO masks. Each wafer had a target frequency of 71 $\mathrm{kHz}$. The actual frequencies averaged slightly above $73 \mathrm{kHz}$. Approximately $500 \mathrm{~Hz}$ of the overfrequency was due to the absence of gold plating on the tines. The remainder of the overage was caused by insufficient etching of the quartz, resulting in larger tine widths and excess material at the crotch; both are factors which would increase the tuning fork frequency. The variation in the frequency, which was nearly double that of the Statek product (Áppendix B), inaicated that etching was not uniform over the entire wafer, probably due to the wafers having a non-uniform thicknéss (which was later confirmed by the lapping and polishing data). Additionally, the motional resistances of devices from wafer 890601 were very high. One possible cause was inadequate side metallization that resulted in inefficient piezoelectric excitation of the quartz. This problem was alleviated in later batches of devices (wafer 890604).

The 32-fork design was abandoned for the 20-fork mask system which was designed and reviewed at SNL. Listed in Appendix $E$ are data from two wafers out of the lot of 20-fork wafers. The full array of electrical pr serties have been included. The target frequency was $71 \mathrm{kHz}$. For both 
wafers, the nominal frequencies were in excess of the target value. For the wafer 891502, the frequency spread was still large at $\pm 338 \mathrm{~Hz}$. The $Q$ of the SNL devices were slightly less than those made at Statek (Appendix B and D). Also, the motional resistance values were nearly eight times the target value of 80 to $90 \mathrm{kohms}$ and showed large variations, although these high motional resistances would cause this batch of devices to be unsuitable for use in an oscillator circuit. They clearly represented an enormus milestone toward the development of an extensive capability to manufacture resonators from raw quartz stock. Knowledge of the root causes of the performance defects identified in these SNL units would permit additional improvements to the SNL capability.

The process has been described for the photolithographic fabrication of DETFs on z plate single crystal quartz wafers approximately $25 \mathrm{~mm}$ square and $152 \mu \mathrm{m}$ in thick. The quality of the devices produced at SNL were slightly below those manufactured at a commercial facility as measured by the $\mathrm{O}$ factor, although improvement was made as more devices were produced. The absolute frequency of the tuning fork and the scatter of the device frequencies per wafer had not achieved the target values. The motional resistances of the SNL devices needed to be reduced in order to introduce the DETFs into an oscillator circuit. 


\section{QDA Assembly}

The QDA sensor is comprised of four components: two DETFs and two spacer plates. One of the spacer plates fastens the sensor to the package structure. The second spacer plate serves as a proof mass which transduces the acceleration into a mechanical deformation of the DETFs. This action causes the resonant frequency of the device to change. The proof mass spacer is made of quartz or beryllium-copper, depending upon the sensitivity requirements. A schematic profile of the sensor is shown in Figure 63.

Assembly of the QDA required: (1) bonding together of the two DETFs and the two spacers, (2) joining of the QDA to the package and (3) sealing the package lids to the package. A description of some early assembly techniques has been reported previously [35].

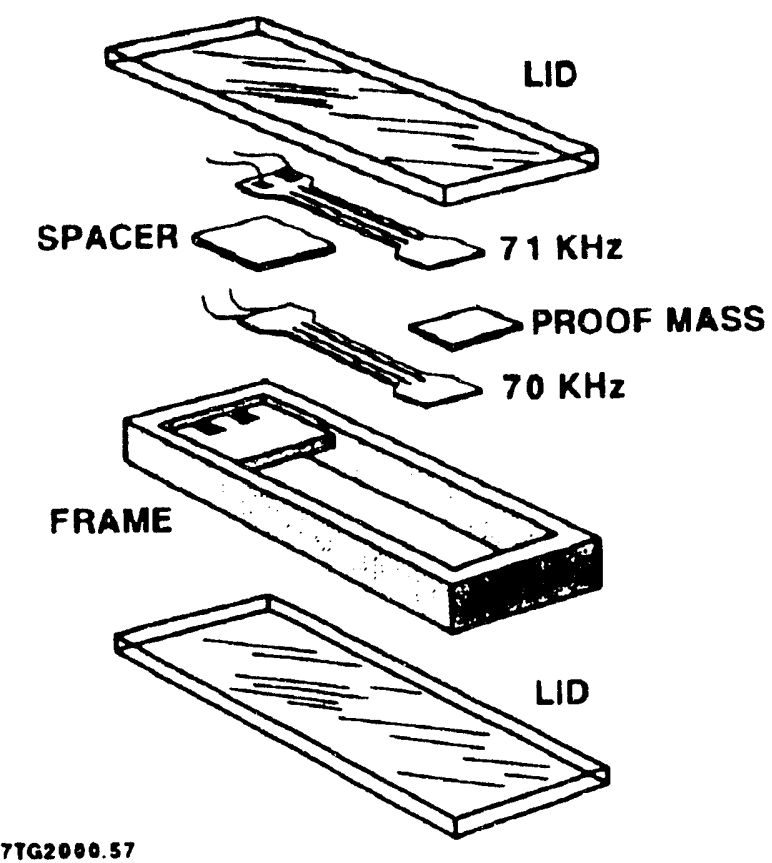

Figure 63. Blowup of QDA sensor assembly.

\subsection{Attachment of the DETFs and Spacers}

\subsubsection{Batch assembly with nest fixtures and polyimide adhesive.}

The bond used to attach the two DETFs to the spacers was required to be sufficiently strong for mechanical integrity and repeatable for precise registration of the components. A polyimide adhesive (Ablebond 71-2[36]) was initially used for these bonds. Maintaining registration between the DETFs and spacers was achieved by placing metal frames around the individual parts; all of the frames being registered by dowel pins on a support plate. This arrangement is shown in Figure 64 . The metal frames were made from $125 \mu \mathrm{m}$ thick beryllium copper sheet which had been photo-etched to form the frame. Three frames were required, one each for the 70 and $71 \mathrm{kHz}$ tuning forks and a third which held the spacers in place. The dimensional tolerances of the openings was approximately $\pm 12.5 \mu \mathrm{m}$. This error compounded into a possible maximum misregistration of $\pm 50 \mu \mathrm{m}$ between any two of the parts.

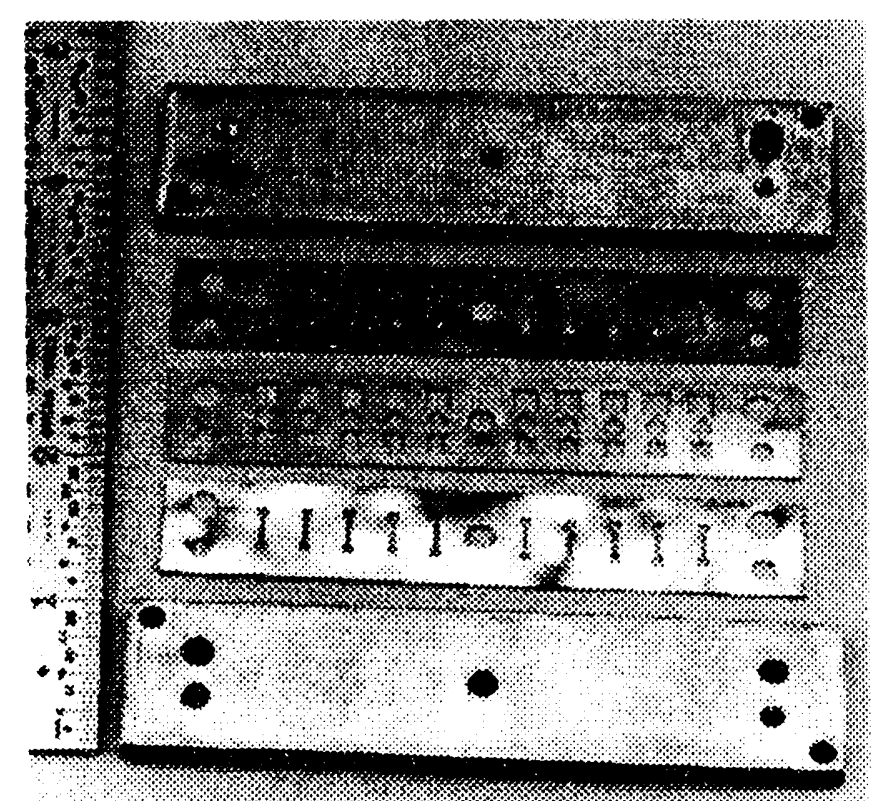

Figure 64. The support plate, mass plate, and spacer frames used to assemble the QDA. 
The assembly sequence is shown in Figure 65 . The steps are as follows:

(1) A DETF frame is placed on the support plate and a DETF is inserted into the appropriate opening.

(2) A drop of adhesive is hand placed on each of the DETF bonding areas and the spacer frame is introduced over the DETFs.

(3) The spacers are placed onto the DETF bonding pads with the adhesive.

(4) Adhesive is applied to the bonding areas of the spacers and the final DETF frame is located on top of the assembly.

(5) The second DETF is placed on the spacer and
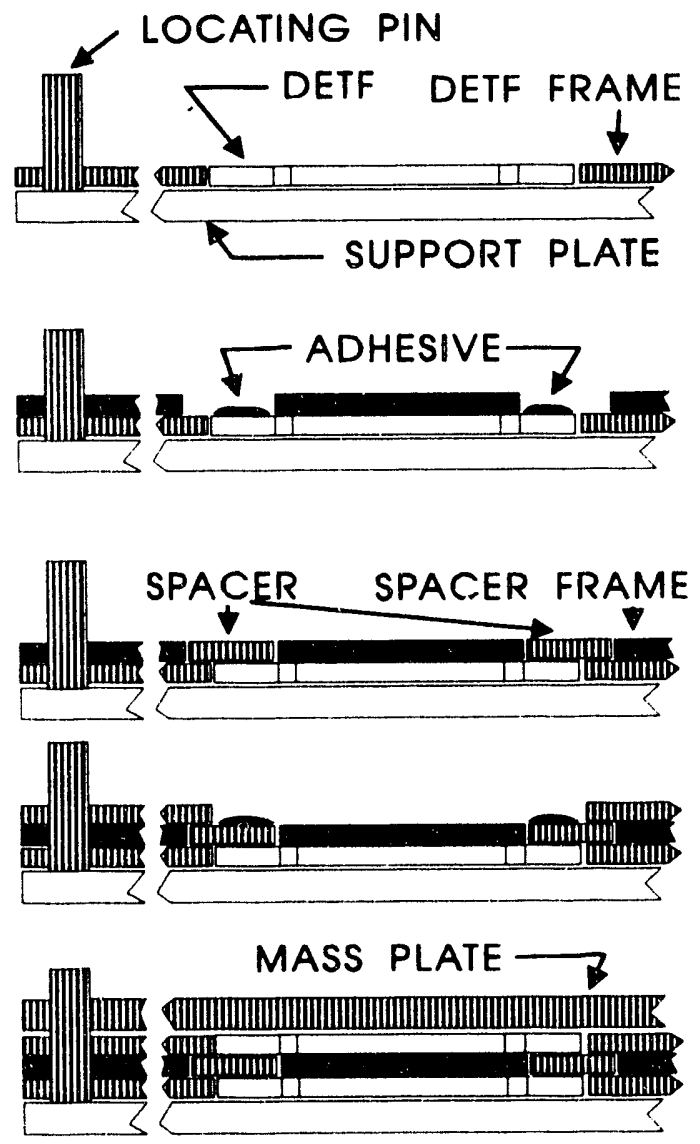

(5)

Figure 65. Assembly process sequence using the 10 $x 1$ fixture. the mass plate is located on top to press the parts together for an even bond thickness.

In order to cure the polyimide adhesive, the assembled DETF components, frames, and fixturing were inserted into an oven with flowing argon at $500 \mathrm{cc} / \mathrm{minute}$. The curing cycle is shown in Figure 66.

Several factors in this procedure detracted from the performance of the assembled QDA's. The tolerances of the metal frames caused relatively large misalignments between the DETF and the spacers. Hand application of the adhesive to the components caused excessive amounts of glue in the joints. This resulted in poor control of the bonding area dimensions, excess adhesive on the fixturing and active elements (tines) of the DETFs, and uneven bond thicknesses causing misalignment of the parts. An optical micrograph of an uneven polyimide adhesive bond joint is shown in Figure 67. Finite element modelling [37] later confirmed that uniform bond dimensions were necessary to optimize and reproduce device performance. Therefore, further refinements were made to the bonding/assembly procedure, specifically addressing part alignment and control of

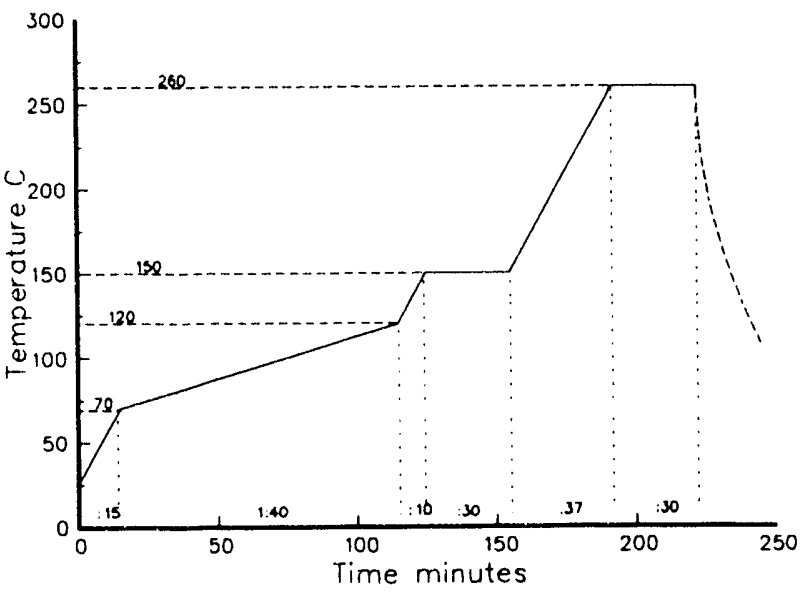

Figure 66. Polyimide curing temperature cycle performed in flowing argon. 


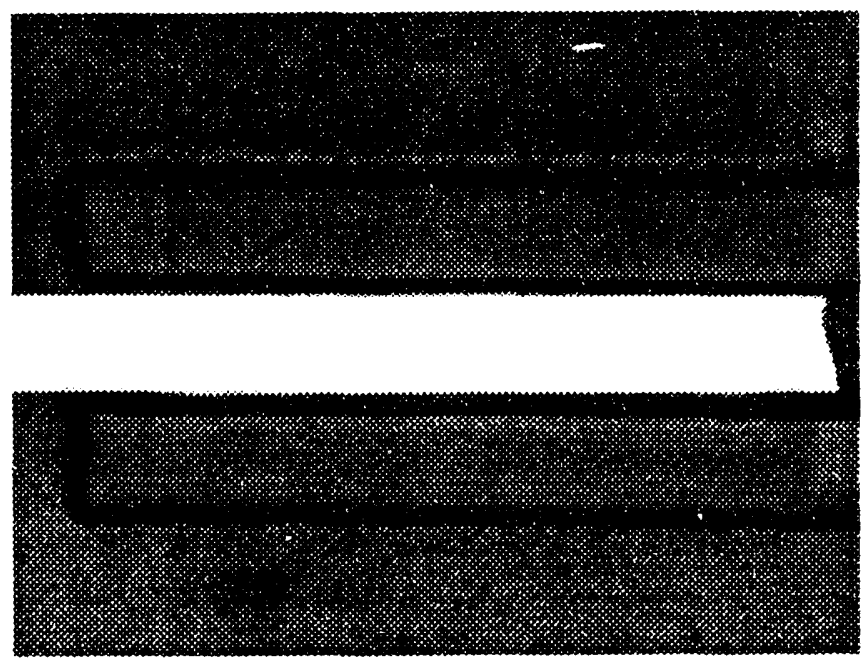

Figure 67. Optical micrograph of a cross section of a polyimide bonded sensor joint.

the quantity, location, and dimensions of the adhesive film.

\subsubsection{EDM Fixture Assembly.}

An improvement to the DETF and spacer registration was made by replacing the berylliumcopper frames with a steel plate in which the alignment pattern for the QDA components was cut out by electric discharge machining. Tolerances of the pattern dimensions and the location holes were nominally $2.5 \mu \mathrm{m}$. The total misalignment error between any two parts due to fixturing was reduced to $\pm 10 \mu \mathrm{m}$. A photograph of the tooling appears in Figure 68 and the assembly process is illustrated in Figure 69.

In the assembly of the sensor using the EDM fixture:

(1) A DETF is placed into a $150 \mu \mathrm{m}$ deep recess in the base plate.

(2) The polyimide adhesive is deposited on the bonding areas of the in-place DETF. The frame or nest plate is placed upon the base plate; alignment between the two pieces is maintained by a pair of dowel pins. The nest plate controlled the position of both the spacers and the second

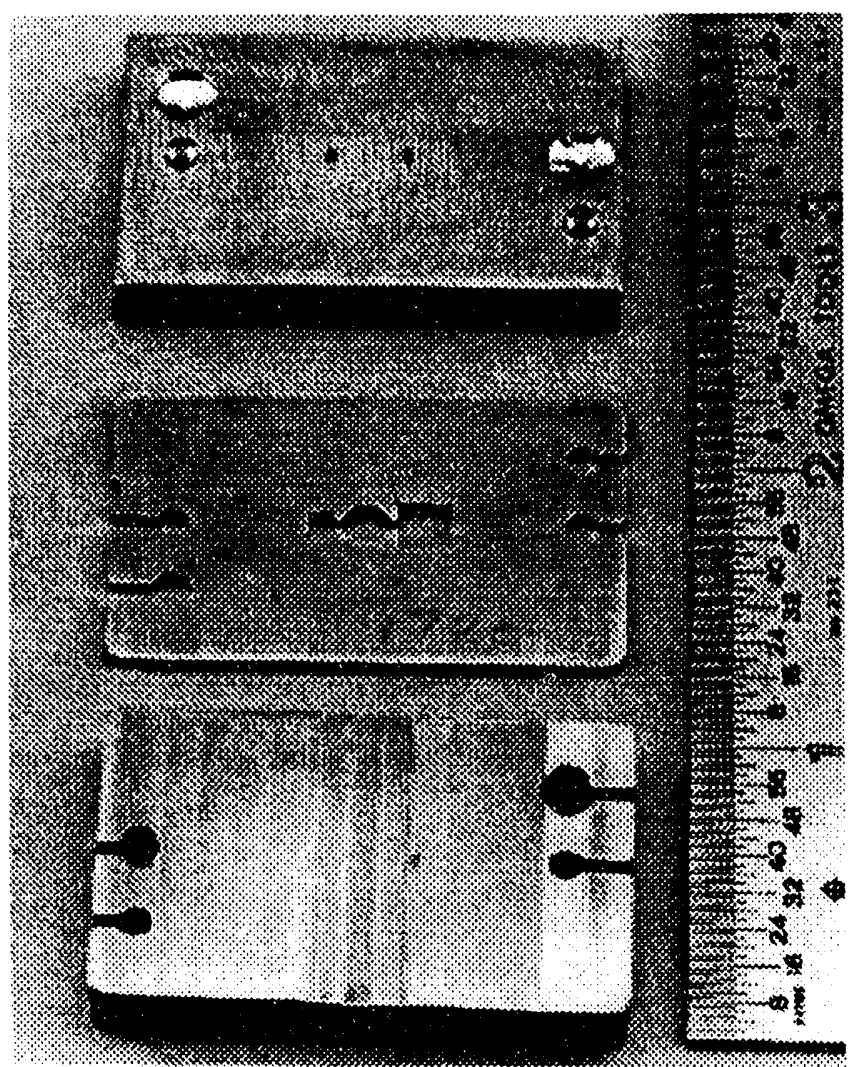

Figure 68. Single unit electric discharge machined assembly fixture and alignment frames.
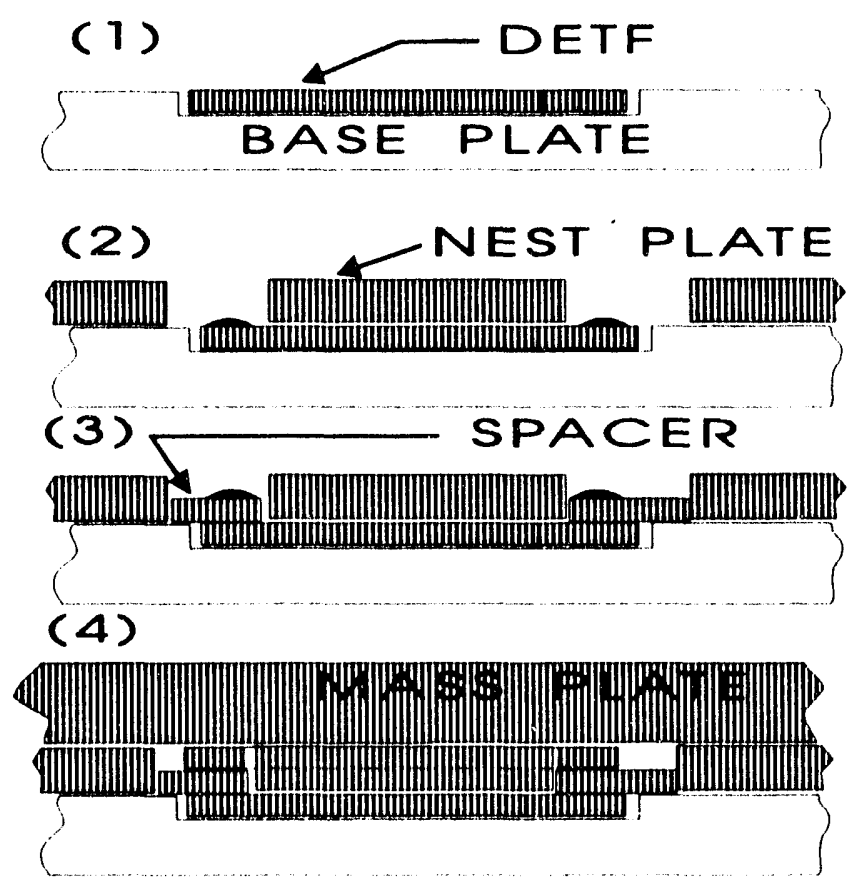

Figure 69. Assembly sequence using the EDM fixture. 


\section{DETF.}

(3) The spacers are located on top of the bottom DETF and adhesive applied on top of the spacers.

(4) The second DETF is added to the stack, followed by the mass plate which is used to apply a limited amount of pressure on the assembly. The fixture and parts were placed in the flowing argon furnace as described earlier (Figure 66) to cure the polyimide adhesive. This change to the assembly process reduced the mis-registration between the parts and correspondingly, improved the performance of the accelerometers.

A second series of innovations to the polyimide bond procedure was made to improve the control of the location and amount of adhesive delivered to the parts. To meet this objective, a semi-automated robot system was constructed which is shown in Figure 70. The same tooling as shown in Figure 68 was used to hold the components. As a part of this semi-automated system, the polyimide was no longer picked up by hand; rather, spring loaded pins were immersed into the polyimide to a controlled depth in the procedure shown in Figure 71. The immersion distance of the pins was determined by a small nub machined at the base of the pin. Withdrawal of the pin left a consistent

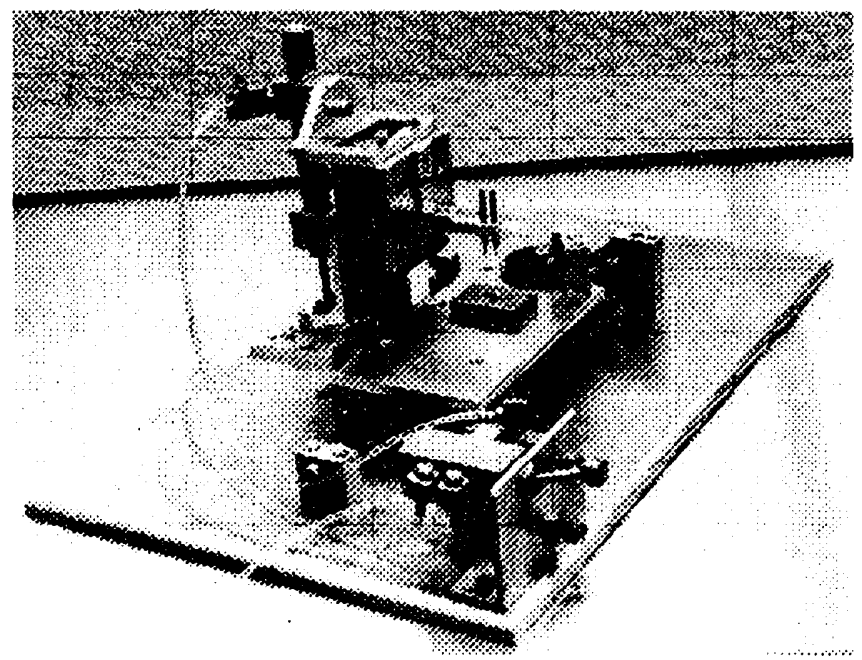

Figure 70. Semi-automated polyimide applicator. quantity of adhesive on the tip as evidenced by the dimensions of the drop of adhesive deposited. The well of polyimide and the fixtures which held the tuning fork components in place were located on a horizontal, pneumatically activated table (Figure 70). A vertically oriented sliding table, which was also pneumatically controlled, held the applicator pins. The movements of the two surfaces were controlled so that the pins deposited the polyimide precisely in the center of the bonding pads or spacers of the QDA components. Premature drying of the polyimide in the holding well was alleviated by small modifications to the pin and well structure.

This innovation improved the performance of the
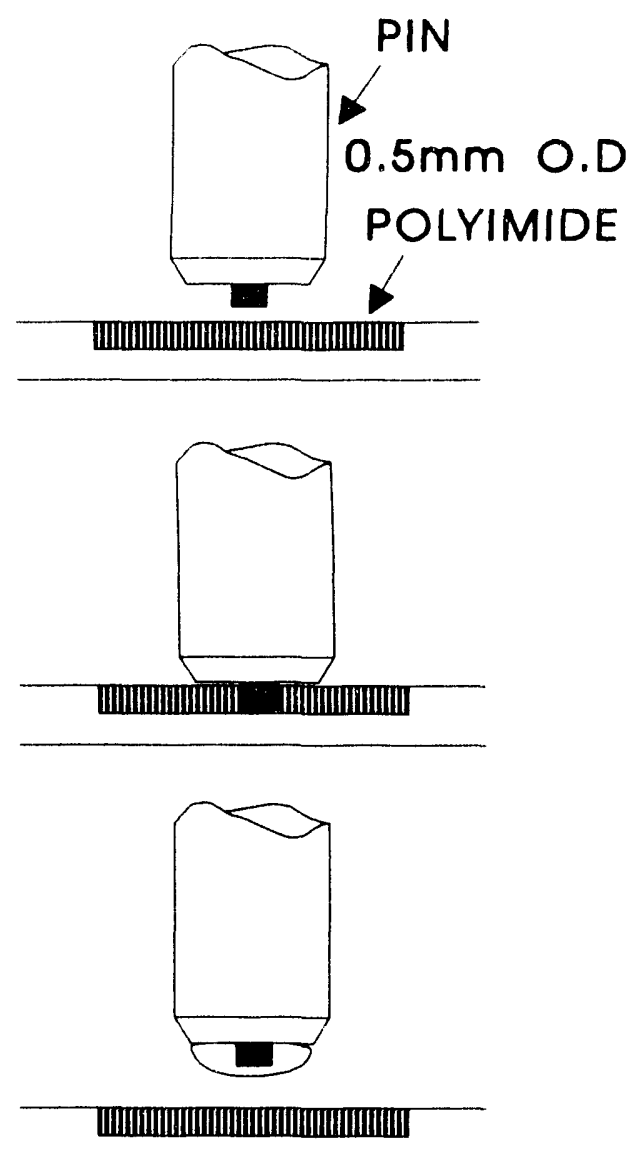

Figure 71 Polyimide application process using the semi-automated applicator. 
sensors.

\subsubsection{Wafer Scale Assembly.}

The fabrication of the QDA cantilevers was extended from the assembly of individual DETFs to the assembly of complete wafers of DETFs. The advantage of this procedure included the batch production of multiple sensors as well as the use of photolithographically defined structures for registration of the DETFs and the spacers. To take full advantage of this procedure, the spacers were fabricated exclusively from quartz wafers. The lighter mass of the quartz spacer compared to metal spacers necessitated the addition of a proof mass to the cantilevered spacer to maintain the desired sensitivity of the accelerometer.

The use of wafer scale assembly required a redesign of the fixturing for adhesive delivery and cantilever assembly. The concept was similar to that described for individual devices except that a wafer of spacers was placed on a wafer of DETFs followed by a second wafer of DETFs. Now, the deposition of the adhesive had to be extended to include all of the parts on each of the wafers. The tooling shown in Figure 70 was replaced with a programmable xy positioner (Allesi ECS-18) which allowed for the application of the polyimide adhesive to all of the units (DETFs or spacers) on a wafer. The applicator was attached to the movable head. Reworked fixtures which held the DETF or spacer wafers were stationary under the head. Upon completion of the assembly process, the fixturing was transferred to the oven in order to cure the adhesive as described earlier.

The evaluation of the fixturing and assembly methods described above resulted in an improvement in the performance of the accelerometers. However, the improvements were not sufficient to fully optimize the properties of the accelerometer. The known poor thermal expansion match of polyimide adhesive to quartz and beryllium copper as well as the inherent inabaility to accurately control the amount and location of the adhesive led to an investigation to develop a thin film solder bonding process. 


\subsection{Thin Film Solder Bond}

\subsubsection{Preliminary Analyses}

The process of solder joining the spacers and DETFs had been attempted early in the accelerometer program [38]. The solder was 87.5Au-12.5Ge (weight percent) with a eutectic melting point of $361^{\circ} \mathrm{C}$ [39] and was supplied as preforms $25 \mu \mathrm{m}$ thick (and an area similar to the bonding area). One benefit of using the solder rather than polyimide adhesive was improved stability over the anticipated shelf and service temperatures. A second benefit is that the solder does not deteriorate under assembly conditions as the polyimide adhesive does when it begins to dry in air. Problems with the use of the solder preforms, however, included difficulty handling them due to their size; positioning the preform at the center of the bonding area; and controlling the quantity of solder due to the limited dimensions of the preforms available. Therefore, alternate techniques were developed for the application of solder to the bonding area.

The solder joining technique was investigated with respect to possible alloys and an appropriate process which would precisely control the composition, location and thickness of the solder film.

An evaluation was made to determine which solder alloy was most appropriate for this application. First, the reflow temperature was restricted to values greater than approximately $350^{\circ} \mathrm{C}$ because subsequent processing steps used 80Au-20Sn alloy. The reflow point of the Au-Sn solder was $278^{\circ} \mathrm{C}$ [40], but the required process temperature was $310^{\circ} \mathrm{C}$. The upper temperature limit was approximately $550^{\circ} \mathrm{C}$, the $\alpha-\beta$ transition temperature of quartz.

The quartz substrate was coated with $45 \mathrm{~nm}$ of $\mathrm{Cr}$ followed with a top layer of $180 \mathrm{~nm} \mathrm{Au}$.

This metallization was required since most solders would not wet the bare quartz surface. Use of a Au-based alloy would limit the scavenging of the thin metallization layers. Based upon these preliminary requirements, the alloys $88 \mathrm{Au}-12 \mathrm{Sn}$ and 97Au-3Si with reflow points between 363 and $370^{\circ} \mathrm{C}$ were selected for further evaluation.

The phase diagrams of the Au-Ge and Au-Si alloys appear in Figure 72 and Figure 73 [41]. Both materials exhibit a simple eutectic. However, because the melting point of $\mathrm{Si}\left(1410^{\circ} \mathrm{C}\right)$ is nearly $500^{\circ} \mathrm{C}$ higher than that of $\mathrm{Ge}\left(938^{\circ} \mathrm{C}\right)$ and the eutectic composition of $97 \mathrm{Au}-3 \mathrm{Si}$ is lopsided in the proportion of $\mathrm{Au}$ to $\mathrm{Si}$, the liquidus line being extremely steep about the eutectic composition. As a result, small variations of the composition will cause large increases to the liquidus temperature (the temperature usually taken as the solder's melting point for process identification). Because the Au-Ge solder is less sensitive to compositional variations, this system was selected.

\subsubsection{Eutectic Bonding Stress Calculations.}

It was necessary to further evaluate use of the AuGe alloy by examining the thermal expansion mismatch between it and the quartz substrate. This

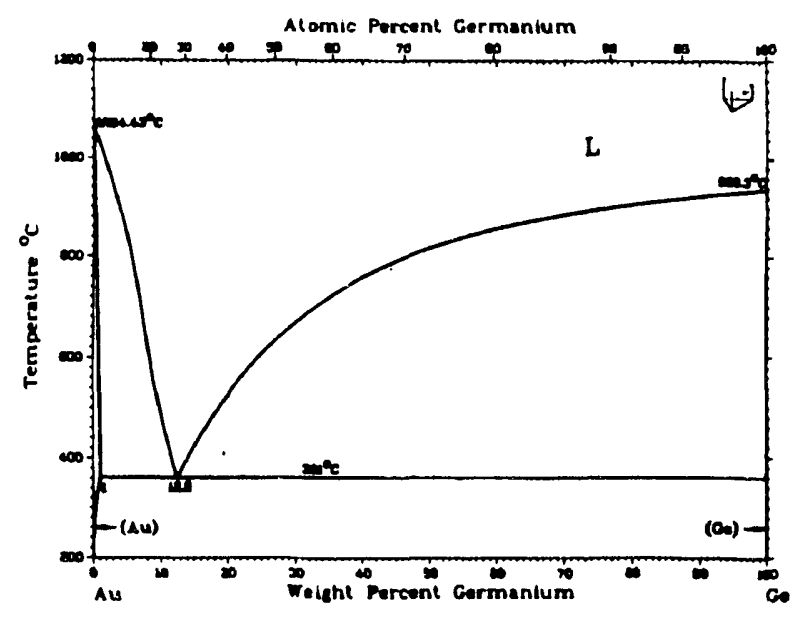

Figure 72. Gold germanium phase diagram. 
information was used to make a first order calculation of the residual stresses within the solder joint upon cool down from the reflow temperature. Excessive residual stresses could lead to fracture of the quartz or cause deterioration to the sensor's performance.

The calculation of the residual stresses was derived from the one-dimensional theory developed by Timoshenko [42]. A two-dimensional analysis was required because both in-plane dimensions are of the same magnitude. The bond geometry is shown in Figure 74.

For the z-orientation of the single crystal quartz, the $\mathbf{x}$ and $\mathbf{y}$ properties (which were the in-plane directions of the plates) are the same. A calculation of the residual stresses was conducted with parameters similar to those in Figure 74: (1) quartz, $150 \mu \mathrm{m}$ thick; (2) solder layers, $2.0 \mu \mathrm{m}$ thick; and (3) a temperature change of $300^{\circ} \mathrm{C}$ to $25^{\circ} \mathrm{C}$. Tensile stresses in the quartz layer were $1.4 \mathrm{MPa}$ and $2.9 \mathrm{MPa}$ in the $\mathrm{x}$ and $\mathrm{y}$ directions, respectively. Correspondingly, compressive stresses in the solder layers were calculated to be $-163 \mathrm{MPa}(23600 \mathrm{psi})$ and $-334 \mathrm{MPa}(-48500 \mathrm{psi})$ in the $\mathrm{x}$ and $\mathrm{y}$ directions, respectively. The tensile stresses in the quartz were nearly two orders of magnitude less than the tensile

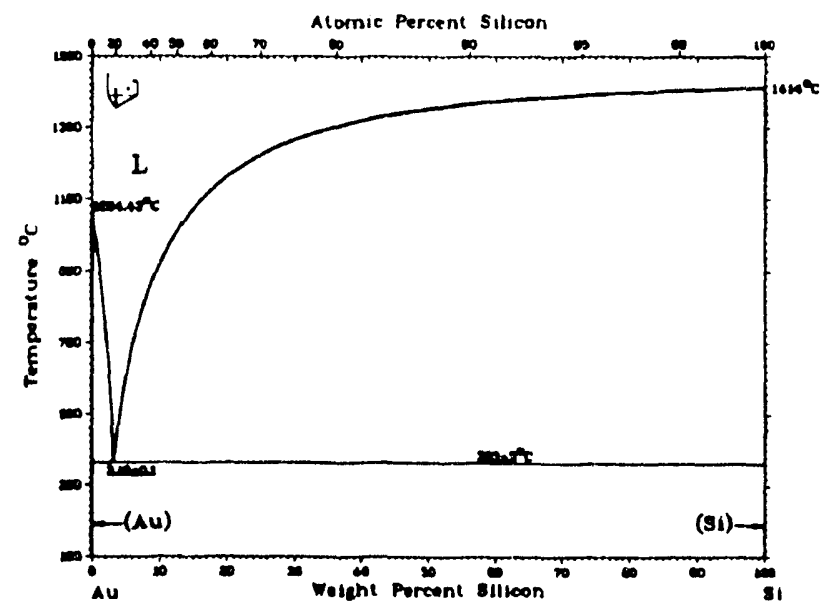

Figure 73. Gold silicon phase diagram. strength of the quartz substrates. The effects of the large compressive stresses in the solder films would await experimental analysis.

The effect of the stresses on thin film adhesion and the sensor's performance were determined experimentally. These analyses also contributed to the selection of Au-Ge as the solder for assembly of the QDA.

\subsubsection{Thin Solder Film Processes.}

It was noted earlier that optimum device performance required that the bonded region be precisely located on the DETF and that the solder layer be as thin as possible. The technique selected for study was physical vapor deposition. Assuming that the solder source composition could be reproduced on the quartz parts, this technique was capable of the controlled deposition of metal films with thicknesses from $1 \mathrm{~nm}$ to approximately $5000 \mathrm{~nm}$. The location and dimensions of the solder layer were controlled by the use of thin beryllium copper or nickel-clad copper masks. Dimensional tolerances of the mask opening were held to within $12.5 \mu \mathrm{m}$ which was well suited for the DETF parts. Three thin film deposition techniques were investigated. They were (1) magnetron sputtering from a source of $87.5 \mathrm{Au}-12.5 \mathrm{Ge}$; (2) electron beam evaporation from a source of $87.5 \mathrm{Au}-12.5 \mathrm{Ge}$; and (3) the electron beam evaporation of layers of $\mathrm{Au}$ and $\mathrm{Ge}$ with appropriate thicknesses, when intermixed, form a eutectic composition solder

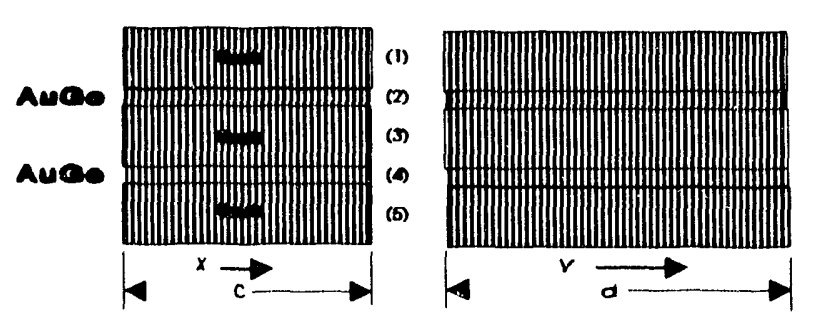

Figure 74. QDA AuGe eutectic bond geometry used to calculate residual stresses from thermal model. 
layer.

\subsubsection{Magnetron Sputtering.}

The first technique was the magnetron sputter deposition of the solder film from a 87.5Au-12.5Ge source. In this process, ions from an argon gas plasma bombard a source and displace atoms which are deposited on the target [43]. This experimental study was performed in collaboration with Midwest Thin Films, Milwaukee, WI. The target was fabricated by Cerac, Milwaukee, WI under the direction of Midwest Thin Films. The composition was certified by the manufacturer.

Z-oriented, single crystal quartz blanks $26.9 \mathrm{~mm} \times$ $23.6 \mathrm{~mm} \times .15 \mathrm{~mm}(1.060 \times 0.930 \times 0.0060 \mathrm{in}$. $)$ were coated with $45 \mathrm{~nm} \mathrm{Cr}$ and $180 \mathrm{~nm}$ Au at SNL and then sent to Midwest Thin Films for the sputter deposition of the Au-Ge film. Initial depositions were for thicknesses of $0.5 \mu \mathrm{m}, 2.0 \mu \mathrm{m}, 6.0 \mu \mathrm{m}$, and $13 \mu \mathrm{m}$. The deposition parameters are summarized in Table 5. The initial films ( $\# 815, \# 816, \# 817$, and $\# 818$ ) had a matt finish with a color from light brown to very dark brown as the film became thicker. Only the $13 \mu \mathrm{m}$ film showed an indication of residual stress as determined by the curvature of the plate; that stress was tensile. When the films were heated in air to temperatures which in some cases exceeded $400^{\circ} \mathrm{C}$, no evidence of reflow such as separation of the Au- and Ge-rich phases or the formation of solder balls was observed in any of the films.

Table 5. Sputter deposition parameters

\begin{tabular}{|c|c|c|c|c|c|c|c|}
\hline \multirow[b]{2}{*}{$\begin{array}{l}\text { Film } \\
\text { Thick. } \\
(\mu \mathrm{m})\end{array}$} & \multirow{2}{*}{$\begin{array}{l}\text { Run } \\
\text { Num }\end{array}$} & \multirow[b]{2}{*}{$\begin{array}{l}\text { Base } \\
\text { Pressure } \\
\text { (torr) }\end{array}$} & \multirow{2}{*}{$\begin{array}{l}\text { Cathode- } \\
\text { Anode } \\
\text { Spacing } \\
\text { (in) }\end{array}$} & \multicolumn{4}{|c|}{ Deposition Conditions - Pre-sputter /Sputter } \\
\hline & & & & $\begin{array}{l}\text { Gas Flow } \\
\text { Rate } \\
\text { (SCFM) }\end{array}$ & $\begin{array}{l}\text { Chamber } \\
\text { Pressure } \\
\text { (mTorr) }\end{array}$ & $\begin{array}{l}\text { Target } \\
\text { Voltage } \\
\text { (V) }\end{array}$ & $\begin{array}{l}\text { Time } \\
\text { Period } \\
\text { (minutes) }\end{array}$ \\
\hline 0.5 & 818 & $4 \times 10^{-7}$ & 3 & $13 / 12$ & $8 / 8$ & $215 / 55$ & $30 / 50$ \\
\hline 0.5 & 822 & $1 \times 10^{-6}$ & 3 & $13 / 13$ & $8 / 8$ & $55 / 55$ & $30 / 50$ \\
\hline 0.5 & 831 & $1 \times 10^{-6}$ & 3 & $12 / 12$ & $8 / 8$ & $50 / 55$ & $180 / 50$ \\
\hline 0.5 & $930^{(1)}$ & $8 \times 10^{-7}$ & 3 & $13 / 13$ & $8 / 8$ & $50 / 55$ & $10 / 50$ \\
\hline 1.0 & $931^{(1)}$ & $1.5 \times 10^{-7}$ & 3 & $14 / 14$ & $8 / 8$ & $50 / 52$ & $10 / 100$ \\
\hline 2.0 & 815 & $9 \times 10^{-7}$ & 3 & $13 / 12$ & $8 / 8$ & $215 / 60$ & $30 / 200$ \\
\hline 2.0 & $917^{(2)}$ & $1 \times 10^{-6}$ & 3 & $13 / 13$ & $8 / 8$ & $55 / 60$ & $10 / 200$ \\
\hline 2.0 & $982^{(1)}$ & $6 \times 10^{-7}$ & 3 & $14 / 12$ & $8 / 8$ & $55 / 58$ & $30 / 200$ \\
\hline 6.0 & 816 & $2 \times 10^{-7}$ & 3 & $13 / 12$ & $8 / 8$ & $215 / 55$ & $30 / 600$ \\
\hline 18. & $817^{(3)}$ & $1 \times 10^{-6}$ & 3 & $12 / 12$ & $8 / 8$ & $220 / 55$ & $30 / 1300$ \\
\hline \multicolumn{8}{|c|}{$\begin{array}{l}\text { (1) Anode temperature after run: } 41 \mathrm{C} \\
\text { (2) Anode temperature: } 26.5 \mathrm{C} \text {; substrate preheat } 300 \mathrm{C}, 20 \text { minutes } \\
\text { (3) Sputtered in two segments of } 630 \text { minutes and } 670 \text { minutes }\end{array}$} \\
\hline
\end{tabular}



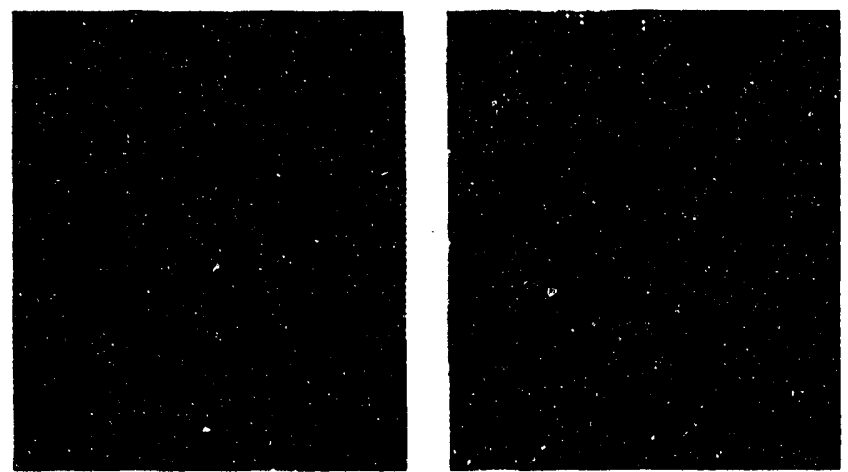

Figure 75 Optical micrographs showing phase separation and reflow of the $0.5 \mu \mathrm{m}$ thick sputter deposited AuGe film.

Some solder balls occurred around the wafer edge of the $6.0 \mu \mathrm{m}$ film and small scale phase separation was observed on the $2.0 \mu \mathrm{m}$ sample. All attempts to bond the samples to metallized quartz failed. Oxidation of the Ge-rich phase during heating was considered as a possible hindrance to reflow. Therefore, the reflow experiments were repeated in dry hydrogen and vacuum. Both atmospheres caused results similar to the air anneals, indicating that oxidation may have occurred prior to the reflow attempts.

The $0.5 \mu \mathrm{m}$ sample did show phase separation and reflow in the form of solder balls. The sequence of phase separation and solder reflow is shown in the two micrographs of the film surfaces in Figure 75. In this instance, the samples were annealed in vacuum for 30 minutes at $475^{\circ} \mathrm{C}$, nearly $100^{\circ} \mathrm{C}$ above the predicted reflow temperature. The thicker films, which were also exposed to this heat treatment, showed some signs of phase separation; however, no indication of general reflow of the films was observed.

Attempts were made to bond $\mathrm{Cr}-\mathrm{Au}$ metallized quartz to the $2.0 \mu \mathrm{m}, 6.0 \mu \mathrm{m}$ and $13 \mu \mathrm{m}$ sputtered films by vacuum annealing. The result was either no bond at all or very weak joints compared with earlier work which used solder preforms. Some satisfactory bonds were made with the $0.5 \mu \mathrm{m}$ films; however, analysis of the poorly bonded samples in this case showed that adhesion was prevented by the lack of intimate contact between the solder and the metallized quartz (probably caused by particulate contamination).

Three possible causes to the poor bonding performance of the sputtered $\mathrm{Au}-\mathrm{Ge}$ films were hypothesized. They were: (1) contamination of the films; (2) incorrect composition of the films or (3) severe oxidation of the $\mathrm{Ge}$ component prior to reflow. The film compositions were measured by Wavelength and Energy Dispersive X-ray Analysis (WDS and EDXA) quantitative Electron Microprobe Analysis and Atomic Emission Spectroscopy/Induced Couple Plasma (AES/ICP) analysis. The results are summarized in Table 6. The target was certified to be free of excessive trace contaminants. The variations in concentrations between the various electron beam techniques was caused by their sensitivities to the electron beam/detector geometries, substrate surface morphologies, and calibration procedures. Because the AES/ICP data was not sensitive to these artifacts, it was accepted as most accurate. The films were rich in Ge by 2 to 4 weight percent beyond the eutectic value. This composition shift did not significantly change the reflow properties of the solder. Differential Scanning Calorimetry (DSC) measurements of sample films indeed confirmed their melting behavior.

Shown in Figure 76 is the DSC curve of the $13 \mu \mathrm{m}$ film (\#823). As was generally observed in each of the films, the transformation temperature (taken as the intersection of the baseline and the tangent to the low temperature leg of the peak) was lower and the peak heights, smaller and broader in the initial run than for the second run. Heating cycles subsequent to the second run showed no change. The transformation point shift between the first and 
Table 6. Weight percent of germanium relative to the ideal compositon.

\begin{tabular}{|c|c|c|c|c|c|c|c||}
\hline \multirow{2}{*}{ Analysis } & \multicolumn{7}{|c|}{ Film Identification } \\
\cline { 2 - 8 } & 822 & 818 & 831 & 815 & 816 & 817 & 823 \\
\cline { 2 - 8 } & $0.5 \mu \mathrm{m}$ & $0.5 \mu \mathrm{m}$ & $0.5 \mu \mathrm{m}$ & $2.0 \mu \mathrm{m}$ & $6.0 \mu \mathrm{m}$ & $13 \mu \mathrm{m}$ & $13 \mu \mathrm{m}$ \\
\hline $\begin{array}{c}\text { Midwest } \\
\text { Film:WDS }\end{array}$ & & & 5 & 13 & 25 & & 20 \\
\hline $\begin{array}{c}\text { Midwest Film: } \\
\text { EDS }\end{array}$ & 22.5 & 24.4 & 23.1 & 26.6 & 28.1 & 28.1 & 29.7 \\
\hline EMA-1 & & & & & $32.3 \pm .3$ & $25.3 \pm .1$ & \\
\hline EMA-2 & & & & & $33 . \pm 1$. & $23.0 \pm .2$ & $23.3 \pm .3$ \\
\hline EMA-3 & & & & & $21.0 \pm .9$ & $24.9 \pm .9$ & $23.1 \pm .8$ \\
\hline AES/ICP & $33 \pm 2$ & & & $31 \pm 2$ & $34 \pm 2$ & $32 \pm 2$ & $33 \pm 2$ \\
\hline & & \multicolumn{7}{c|}{ (1) $95 \%$ Confidence Interval ; (2) $\pm 1 \sigma$} & & \\
\hline
\end{tabular}

subsequent cycles was larger as the film thickness increased. Shown in Figure 77 are the (second run) thermograms for each of $0.5 \mu \mathrm{m}, 2.0 \mu \mathrm{m}, 6.0 \mu \mathrm{m}$, and $13 \mu \mathrm{m}$ thick films. For each curve, the transformation temperature was equal to $361^{\circ} \mathrm{C}$ within experimental error. In addition, the shape of the plot was very similar to that of the cast ribbon sample. Therefore, it was concluded that the deposited films were sufficiently close to the

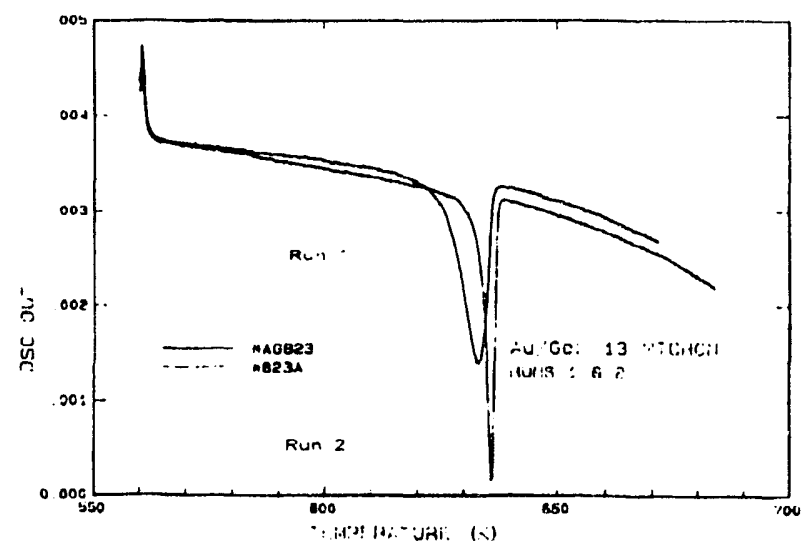

Figure 76. Differential scanning calorimetry of a 13 micron gold-germanium film. eutectic composition to have performed as the eutectic material.

Excessive oxidation of the films was investigated as the third possible cause of poor bonding. Oxidation of the Ge-rich component in as-cast Au-Ge preforms was observed during reflow. Without sufficient mechanical force to fracture the oxide of the solder, wetting was poor. On the sputtered

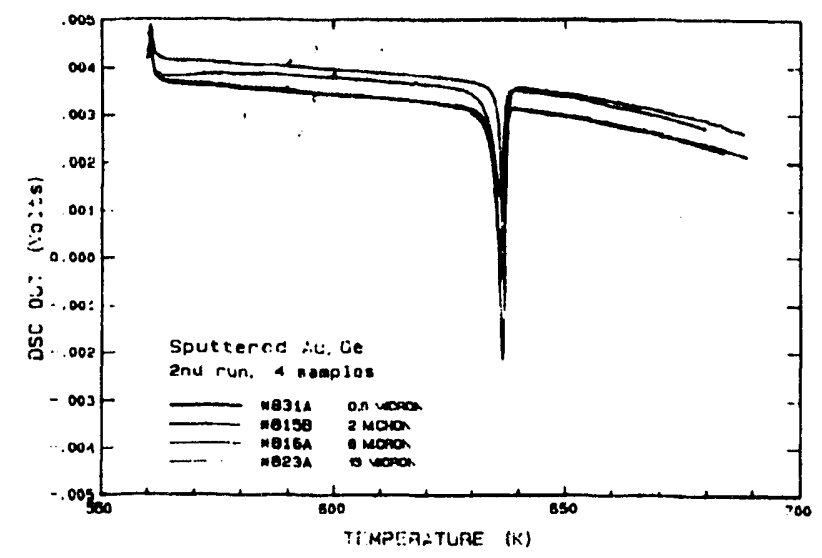

Figure 77. DSC of several thicknesses of sputtered films. 


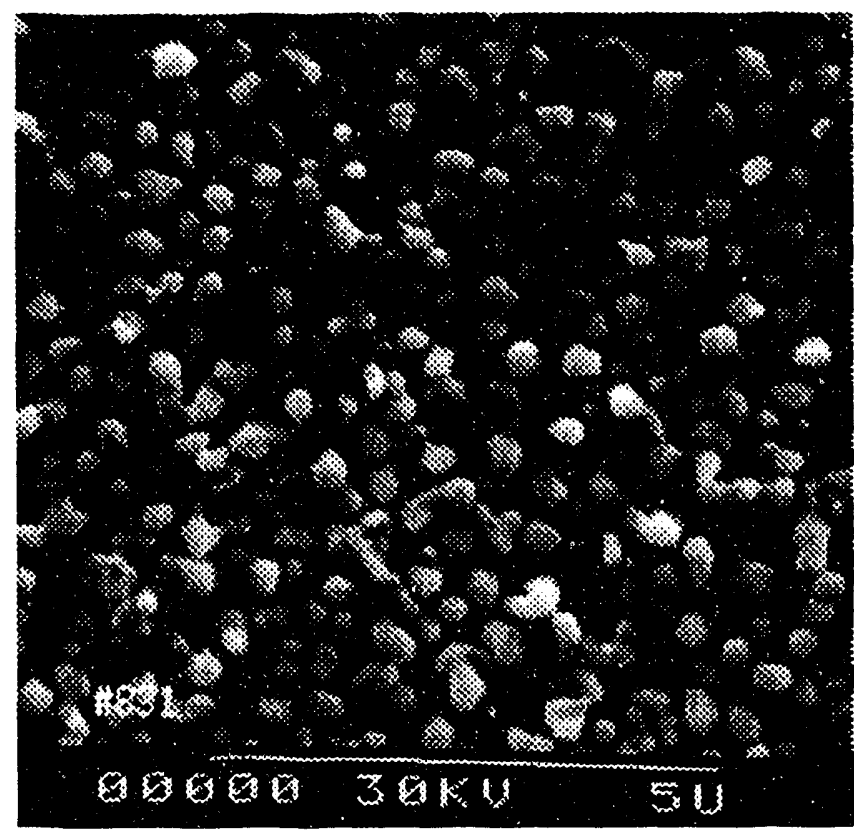

Figure 78. SEM 8310.5 micron film

films, the dark brown color was an initial indication of heavy film oxidation since a golden color was observed on freshly reflowed $\mathrm{Au}-\mathrm{Ge}$ solder. In addition, it was observed in the AES/ICP analyses that mass balance could not be obtained using only $\mathrm{Au}$ and $\mathrm{Ge}$ values. This discrepancy was beyond

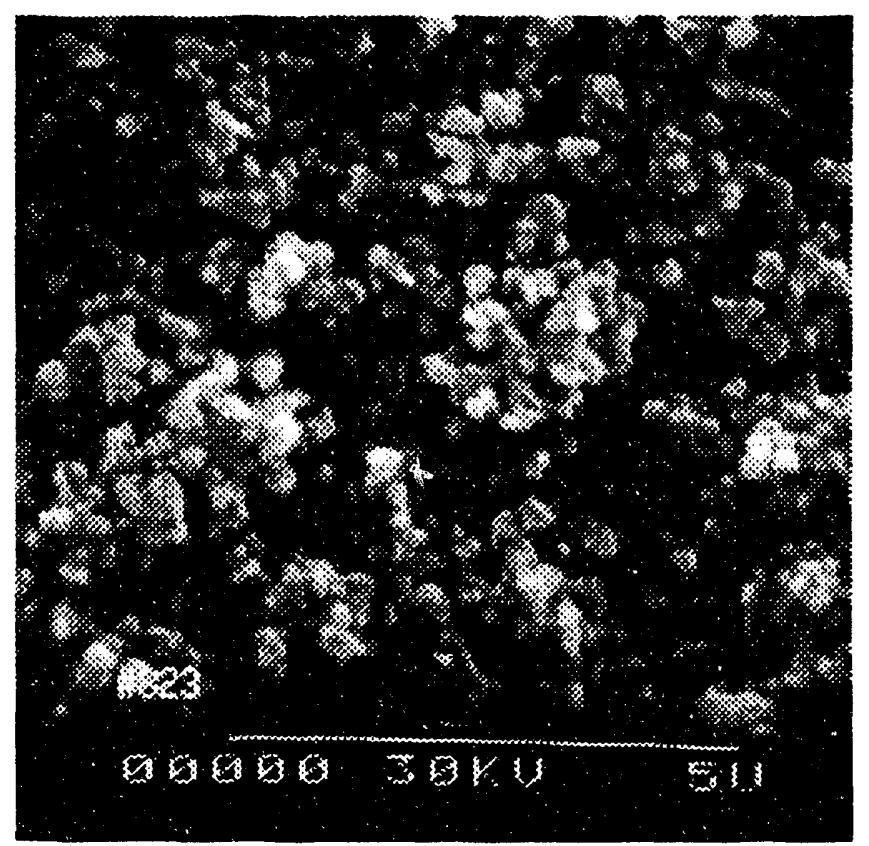

Figure 79. SEM 82313 micron film experimental error and indicated the presence of oxygen.

Porosity in the films was believed to enhance the oxidation of the Ge-rich phase. Shown in Figure 78 and Figure 79 are scanning electron micrographs of the surfaces of the $0.5 \mu \mathrm{m}$ and $13 \mu \mathrm{m}$ deposited films. Scanning electron micrographs of the film cross sections were alsu made to confirm these observations (Figure 80 and Figure 81). The $0.5 \mu \mathrm{m}$ film showed the least porosity as is noted in Figure 78 and Figure 80 . The largest extent of porosity was noted in the $13 \mu \mathrm{m}$ film (Figure 79 ). An attempt to densify the film to reduce the extent of oxidation, was made by depositing a $2.0 \mu \mathrm{m}$ thick film on a substrate held at $275^{\circ} \mathrm{C}$. No change to the film morphology was noted. Interestingly enough, when the $0.5 \mu \mathrm{m}$ thick film was deposited on a glass microscope slide, a much denser morphology was observed than for films on CrAu metallized quartz. From these data, it was concluded thlat the film morphology was dependent upon the substrate properties.

Attempts to fabricate QDA assemblies were generally unsuccessful for film thicknesses of $2.0 \mu \mathrm{m}$ and greater. Reflow of the $0.5 \mu \mathrm{m}$ solder

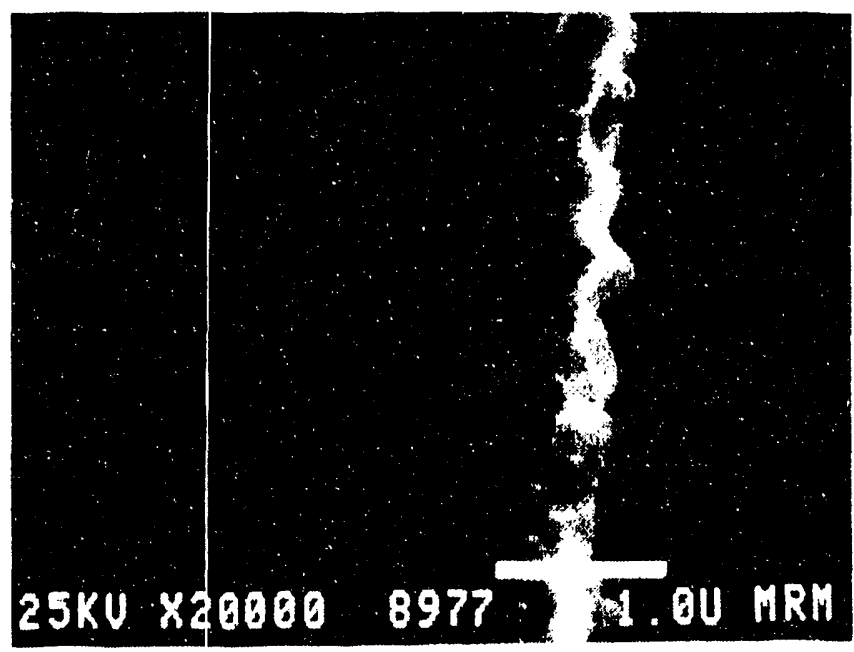

Figure 80. SEM photograph of the cross sectional view of $0.5 \mu \mathrm{m}$ film. 
Table 7. Thermodynamic parameters for gold and germanium.

\begin{tabular}{|c|c|c|}
\hline Element & $\begin{array}{c}\text { Boiling Point at } 760 \text { torr } \\
(\mathrm{C})\end{array}$ & $\begin{array}{c}\text { Heat of Vaporization } \\
(\mathrm{J} / \mathrm{mole})\end{array}$ \\
\hline Gold & 2950 & $343 \pm 10$ \\
\hline Germanium & 2870 & $327 \pm 1$ \\
\hline
\end{tabular}

layers resulted in some units being bonded. However, dust particles and slight dimensional deviations in the fixturing prevented intimate contact between the substrates for a majority of the assemblies. Therefore, it was decided that without a clear solution to the oxidation problem plaguing the sputtered films, this technique was not desirable.

\subsubsection{Electron Beam Evaporation.}

The second procedure for depositing the thin Au-Ge solder film was electron beam evaporation of a source of the $87.5 \mathrm{Au}-12.5 \mathrm{Ge}$ solder. The basis for attempting this procedure came from a cursory examination of the vapor properties of $\mathrm{Au}$ and $\mathrm{Ge}$. These elements showed similar boiling points and heat of vaporization (Table 7).

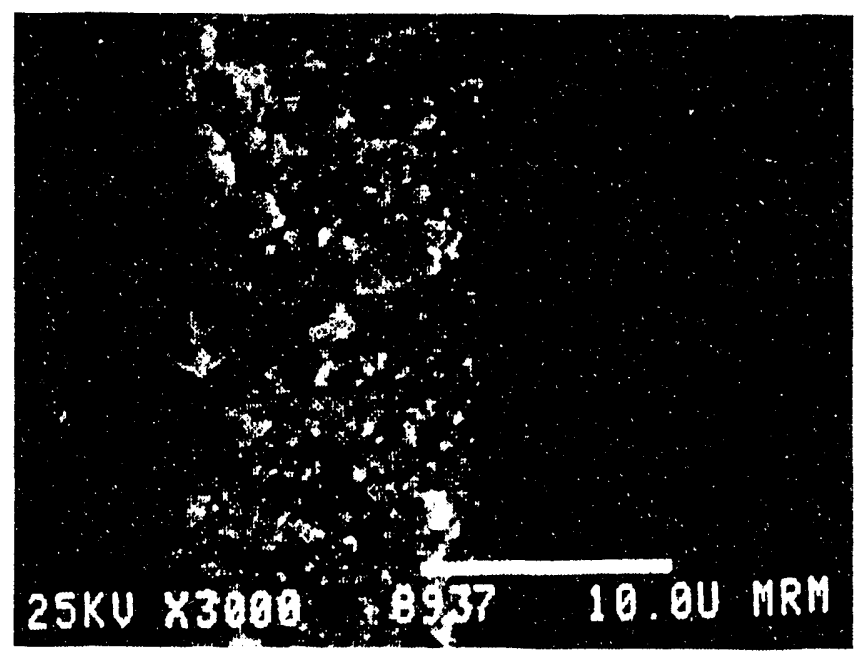

Figure 81. SEM photograph of the cross sectional view of the $13 \mu \mathrm{m}$ film.
Several films were evaporated onto substrates. The films were released from the substrates and analyzed in the DSC. The melting point and the heat of transformation (melting) were used to obtain a qualitative composition analysis. Runs made of cast $87.5 \mathrm{Au}-12.5 \mathrm{Ge}$ ribbon were used to provide the baseline values of the melting point and heat of transformation, $361 \pm 1^{\circ} \mathrm{C}$ and $77.9 \pm 0.8 \mathrm{~J} / \mathrm{g}$, respectively. The melting points of the two evaporated film samples (measured from the second DSC cycle) were $362^{\circ} \mathrm{C}$ and $356^{\circ} \mathrm{C}$. The transformation heats were 11.1 and $13.8 \mathrm{~J} / \mathrm{g}$; well below the baseline value. Therefore, it was determined that some portion of the samples was of the eutectic composition. However, the fraction of the sample with the eutectic concentration was very

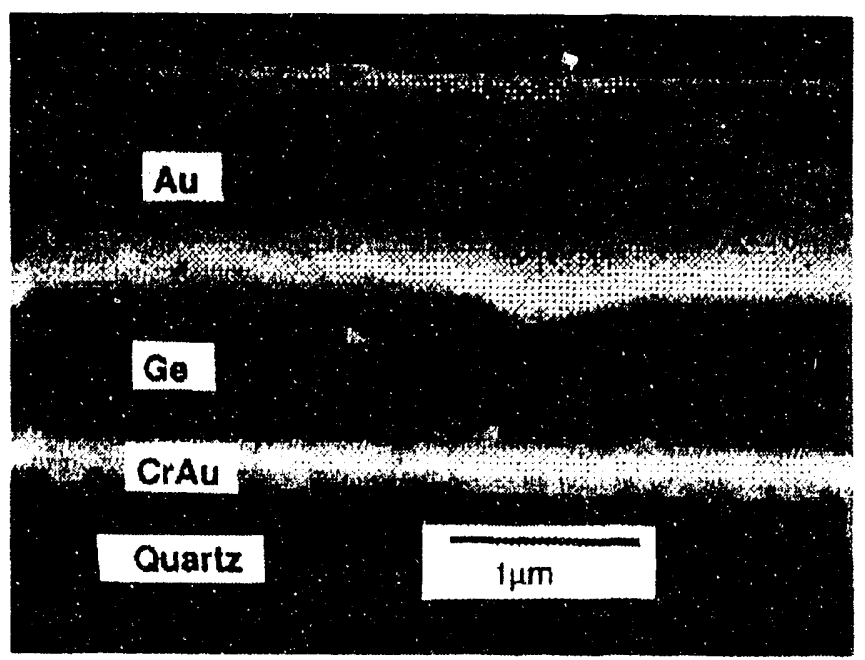

Figure 82(a). SEM micrograph of the cross section of a $2.0 \mu \mathrm{m}$ thick multilayer AuGe Film on $\mathrm{CrAu}$ metallized fused silica. a) $\mathrm{GeAu}$, b) $\mathrm{AuGeAu}$, c) GeAuGeAu. 


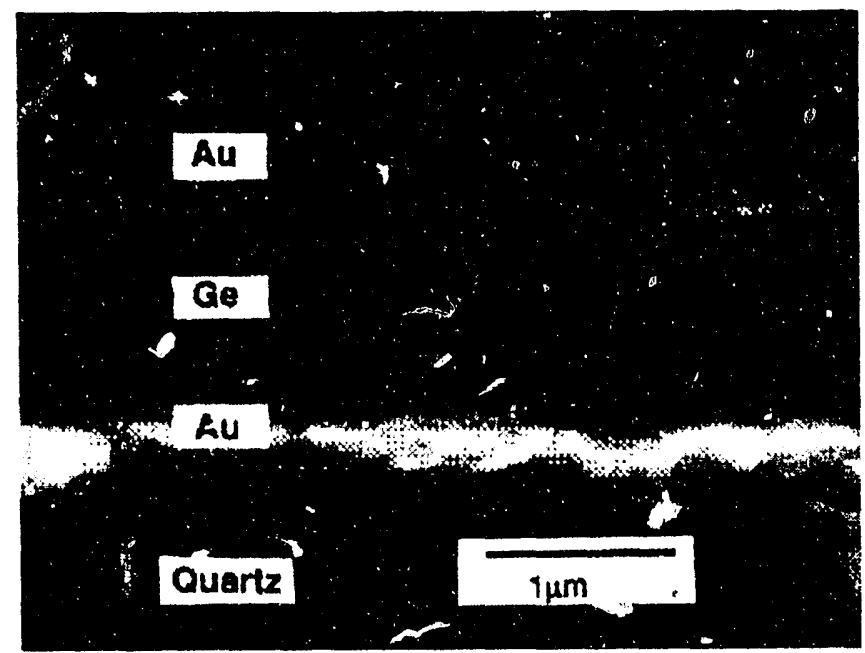

Figure 82(b) $\mathrm{Au} / \mathrm{Ge} / \mathrm{Au}$

small due to the low heats of transformation. The difference in the heat of transformation would indicate that only 10 to $20 \%$ of the material behaved as a eutectic. It was concluded that this evaporation technique would not reproduce the eutectic $\mathrm{Al}$-Ge solder

\subsubsection{Layer deposition.}

The third technique was the construction of : solder layer by the deposition of layers of the individual constituents to thicknesses corresponding to the desired eutectic concentra 'on. For a iotal solder film thickness, $t, 0.693 \mathrm{t}$ is the required $\mathrm{Au}$ thickness and $0.307 \mathrm{t}$, the Ge thickness. Ideally, heating the multilayer film would cause the Au and

Table 8. Layer sequences and thicknesses used to form the gold-germanium eutectic.

\begin{tabular}{|c|l|l|l|l|l||}
\hline GROUP & $\begin{array}{l}\mathrm{t} \\
\mu \mathrm{m}\end{array}$ & $\begin{array}{l}\mathrm{Ge} \\
\mathrm{nm}\end{array}$ & $\begin{array}{l}\mathrm{Au} \\
\mathrm{nm}\end{array}$ & $\begin{array}{l}\mathrm{Ge} \\
\mathrm{nm}\end{array}$ & $\begin{array}{l}\mathrm{Au} \\
\mathrm{nm}\end{array}$ \\
\hline $\mathrm{I}$ & 2.0 & 684 & 1316 & & \\
\hline II & 2.0 & & 658 & 684 & 658 \\
\hline III & 2.0 & 342 & 658 & 342 & 658 \\
\hline IV & 1.0 & & 329 & 342 & 329 \\
\hline
\end{tabular}

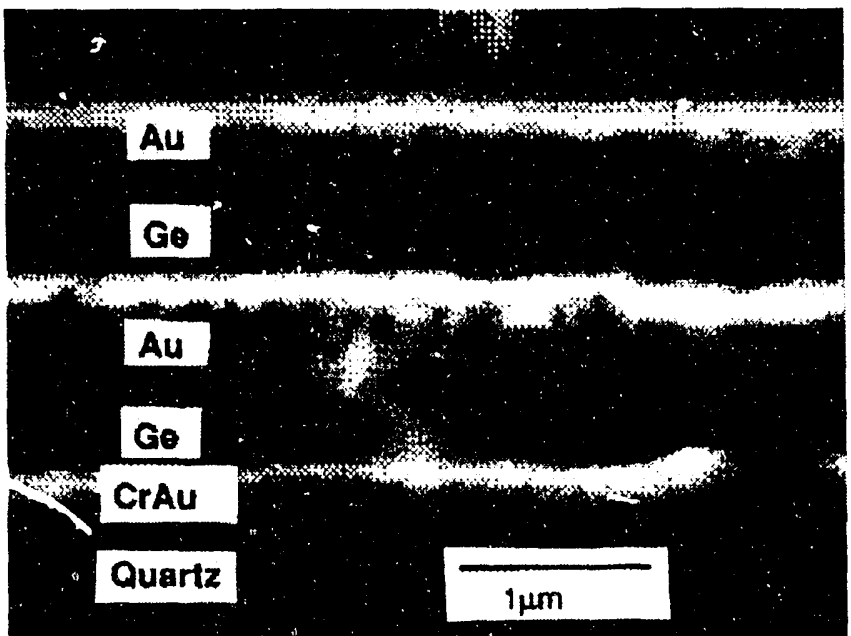

Figure 82(c) $\mathrm{Au} / \mathrm{Ge} / \mathrm{Au} / \mathrm{Ge}$

Ge to intermix, thus forming the eutectic solder. The attributes of this appr ach were: (1) The Ge layer(s) could be sandwiched between Au layers, thereby restricting the degree of oxidation of the $\mathrm{Ge}$ component and (2), the individual films could be deposited to nearly $100 \%$ of the bulk density which would also reduce oxidation of the Ge. Numerous concerns also accompanied this process foremost was whether the $\mathrm{Au}$ and $\mathrm{Ge}$ layers would intermix at temperatures near or below the customary reflow point of the bulk eutectic. Also, it was necessary to determine whether any physical artifacts, which would disrupt formation of the joint, were incorporated in the film during the intermixing process. Finally, a $2.0 \mu \mathrm{m}$ film is quite thick by evaporated film standards; such a thick film can generate very high internal stresses which, if tensile, may cause fissures and cracks in the film. If the stresses were compressive, buckling and uplift of the film could be the result. Each of these factors was considered and where applicable, the necessary experiments performed to verify the film behavior. Further evaluation of the multilayer solder film was made by adhesion strength tests.

The first trial films were used to address the adhesion and internal residual stress concerns. Three layering sequences, which gave a total solder 


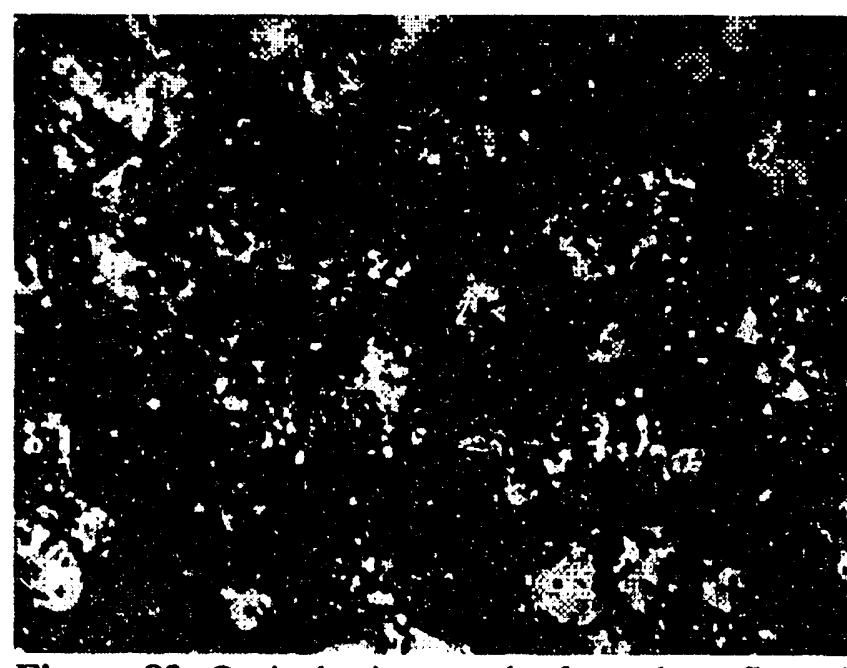

Figure 83. Optical micrographs from the reflowed multilayer solder film of the Group I sequence (Ge$\mathrm{Au})$ at low magnification.

thickness of $2.0 \mu \mathrm{m}$, were coated onto polished, fused silica substrates $1.58 \mathrm{~mm}$ thick which had been previously cleaned and coated with $50 \mathrm{~nm}$ of $\mathrm{Cr}$ followed by $180 \mathrm{~nm} \mathrm{Au}$. The deposition sequences of the $A u$ and $G e$ layers were: (1) $684 \mathrm{~nm}$ $\mathrm{Ge}-1316 \mathrm{~nm} \mathrm{Au}$; (2) $658 \mathrm{~nm}$ Au-684nm Ge-658nm $\mathrm{Au}$; and (3) $3.4 \mathrm{~nm} \mathrm{Ge}-658 \mathrm{~nm} \mathrm{Au}-3.4 \mathrm{~nm}$ Ge$6580 \mathrm{~nm} \mathrm{Au}$. A summary of the layer thicknesses for the groups of films is shown in Table 8. The deposition parameters are given in Table 9. The lower end of the deposition rates were used with sequence (1) above. The total film thickness was measured by surface profilometry. The as-deposited films adhered very well to the ( $\mathrm{CrAu}$ coated) substrates as they did not lift by the tape test. To confirm adhesion, substrates with each of the three film structures were fractured so as to reveal the

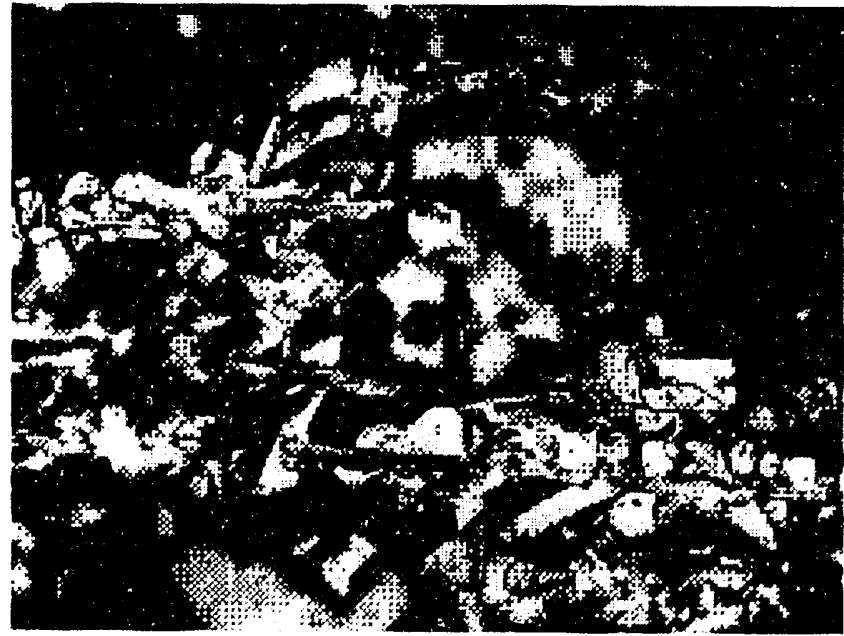

Figure 84. Same as Figure 83 except at higher magnification.

film cross section. SEM micrographs are shown in Figure 82(a), (b) and (c). It was apparent that in spite of the shock loading caused by the fracture of the fused silica, the $\mathrm{Au}$ and $\mathrm{Ge}$ layers maintained excellent adhesion to one-another as well as to the substrate.

Next, the multilayer films were subject to annealing treatments in which the intermixing process was examined as a function of temperature. Samples were placed on a hot plate that was at $400^{\circ} \mathrm{C}$. Within a period of 5 to $10 \mathrm{sec}$, the surface went from a mirror Au finish to a dull silver-gold color. Following a hold period of 20 seconds, the specimens were removed from the hot plate. The surface changed to a more golden appearance. Once again, the tape test confirmed adhesion of the reflowed film to the substrate. In conclusion, it

Table 9. Deposition parameters of the gold and germanium film for the multi-layer solder film.

\begin{tabular}{|c|c|c|}
\hline Parameters & Germanium & Gold \\
\hline Initial Pressure (torr) & $2.0 \times 10^{-7}$ & $2.4 \times 10^{-7}$ \\
\hline Final Pressure (torr) & $6.5 \times 10^{-7}$ & $1.1 \times 10^{-6}$ \\
\hline Deposition Rate $(\AA / \mathrm{s})$ & $5-15$ & $10-21$ \\
\hline
\end{tabular}




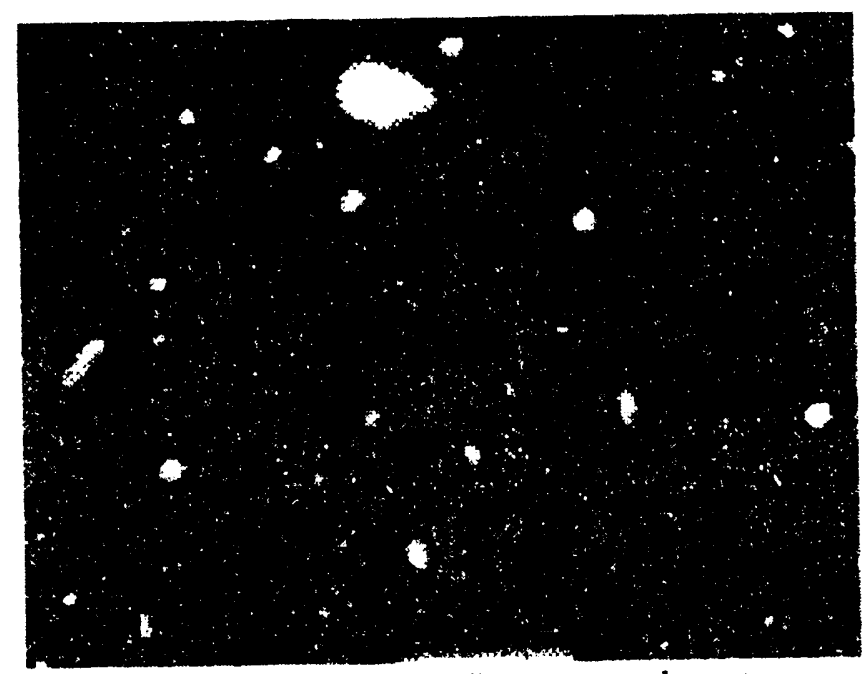

Figure 85. Metallization adherent to substrate away from the needle structure.

was apparent that the multilayer films maintained excellent adhesion both prior to and following reflow.

\subsubsection{Intermixing - Optical Micrography.}

It was necessary to evaluate the extent to which the layers mixed to form the solder upon heating. Preliminary evidence of intermixing was obtained from optical micrographs of samples from each of three film structures (to be referred as I, II, and III for the Au-Ge, Au-Ge-Au, and Ge-Au-Ge-Au

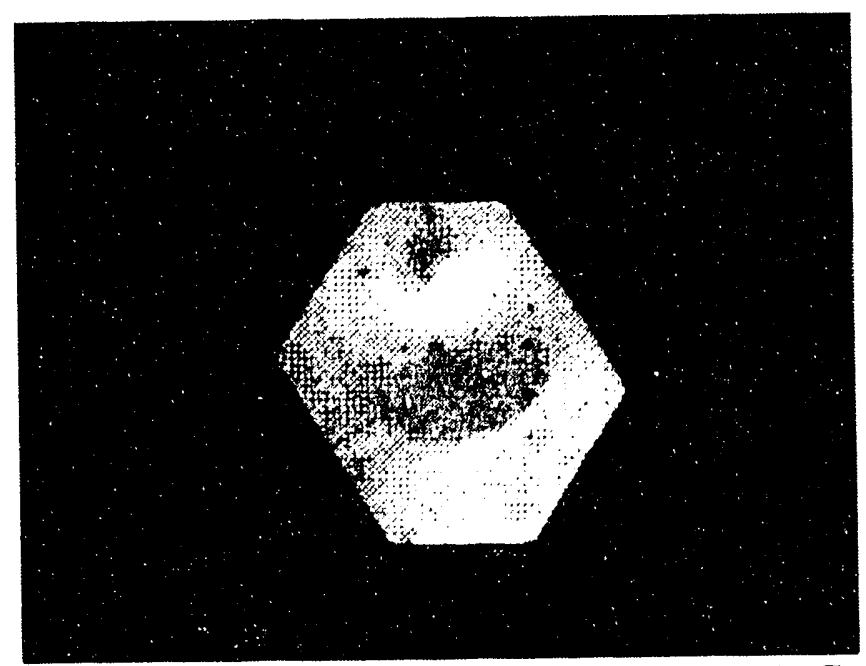

Figure 86. Micrograph of gold rich island in AuGe metallization.

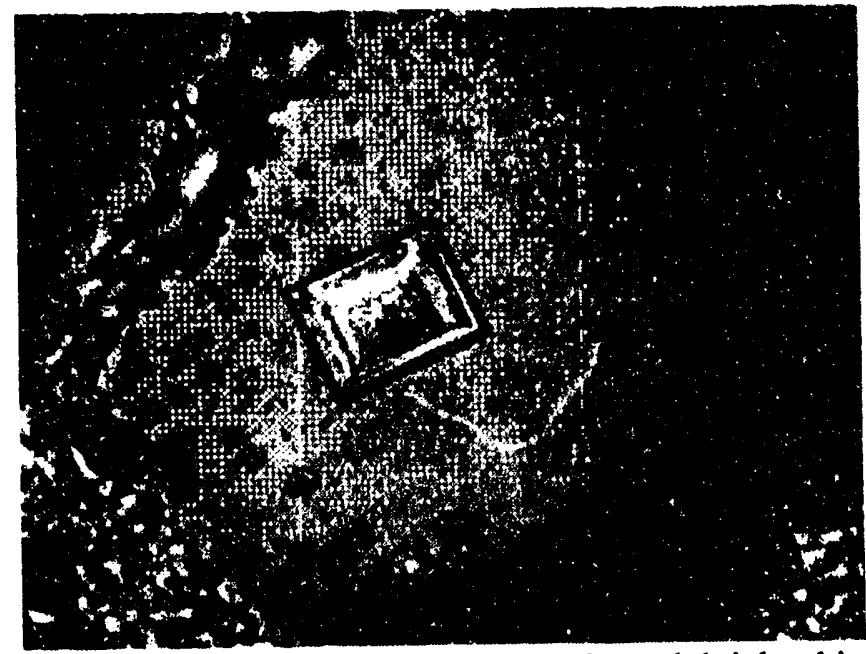

Figure 87. Micrograph of germanium rich island in AuGe metallization.

structures, respectively) which had been reflowed in vacuum at $380^{\circ} \mathrm{C}$ for 30 minutes. Shown in Figure 83 is a micrograph of the surface of the Group I sample. The microstructure is representative of the Group II and III samples as well with the hub-and-spoke (needle) structures about as equally prevalent. The heights of the needles above the substrate surface were $11.0 \mu \mathrm{m}$, $9.0 \mu \mathrm{m}$, and $7.0 \mu \mathrm{m}$ for I, II, and III, respectively. A high magnification image of one such hub-andspoke feature (Figure 84) indicated that it was formed of blue and gold regions which were the $\mathrm{Ge}-$ and Au-rich phases, respectively. Between the hub-and-spoke structures, the metallization had remained adherent to the substrate (Figure 85). Also located in this region were separate islands of the Au-rich and Ge-rich phases.

Shown in Figure 86 and Figure 87 are micrographs of the Au-rich and Ge-rich islands, respectively. The Au-rich phase (beta) is hexagonal close packed so that the view in Figure 86 is that of the basal plane since all of the angles measure approximately $120^{\circ}$. The expected hexagonal footprint is distorted by the unequal growth of the 3 pairs of prismatic faces. The Ge-rich phase (gamma) is tetragonal as is evident by the structure in Figure 87. Therefore, 
visual evidence existed that in fact, intermixing did occur. Interestingly enough, the reflowed structure of the solder after air annealing remained dense; it did not retract into separate hub-and-spoke islands of solder. However, phase separation was evident by the matrix of Au-rich (yellow) and Ge-rich (blue) regions. 


\subsubsection{Intermixing - DSC measurements}

A second technique to evaluate the extent of intermixing was to make DSC measurements of the as-deposited films. These data would be used to identify the temperature and heat of transformation for the sample as a result of solid state transformations occurring during heating.

In order to perform the DSC measurements, it was necessary to remove the as-deposited films intact from the substrate in order not to disturb the individual layers. This was achieved by depositing the films on polished, $\mathrm{NaCl}$ wafers. The $\mathrm{CrAu}$ metallization initially put on the quartz and fused silica substrates was not used; rather, the multilayers were deposited directly on the wafer. After the wafers were coated, they were placed into a 50:50 mixture of isopropyl alcohol and de-ionized water to dissolve the $\mathrm{NaCl}$ and release the film. The isopropyl alcohol buffered the dissolution process so that the film did not release too quickly and self-destruct.

Shown in Figure 88(a)-(c) are the DSC plots of the first and second runs for samples from Group I (Au-Ge), Group II (Au-Ge-Au), and Group III (Ge$\mathrm{Au}-\mathrm{Ge}-\mathrm{Au})$. The scan rate was $10 \mathrm{C} /$ minute over a

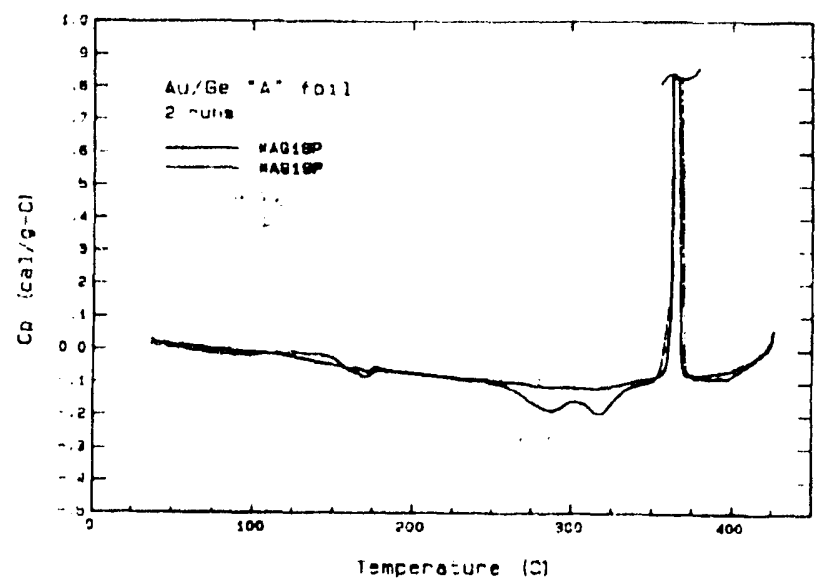

Figure 88(a). DSC plots of $1.0 \mu \mathrm{m}$ Group I, II, III multilayer films. Also Group II, $2.0 \mu \mathrm{m}$ film.

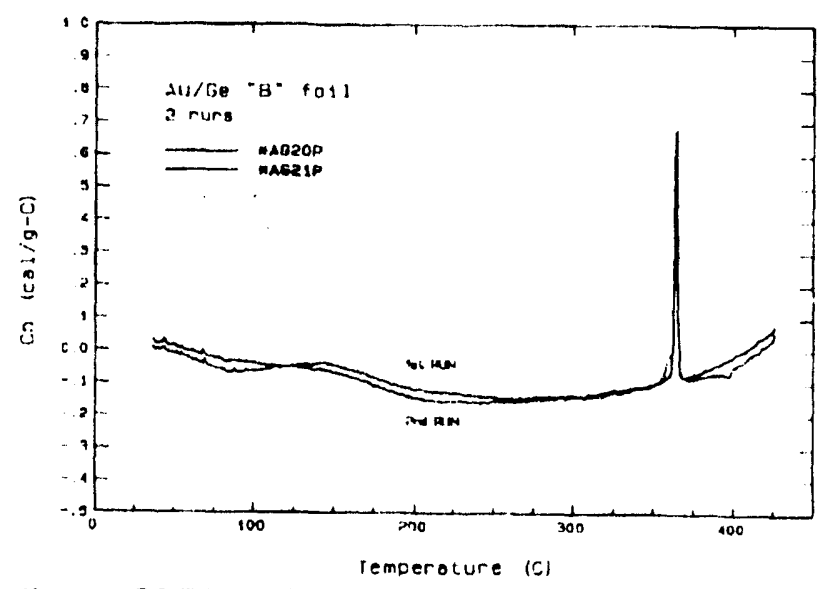

Figure 88(b) DSC Group II

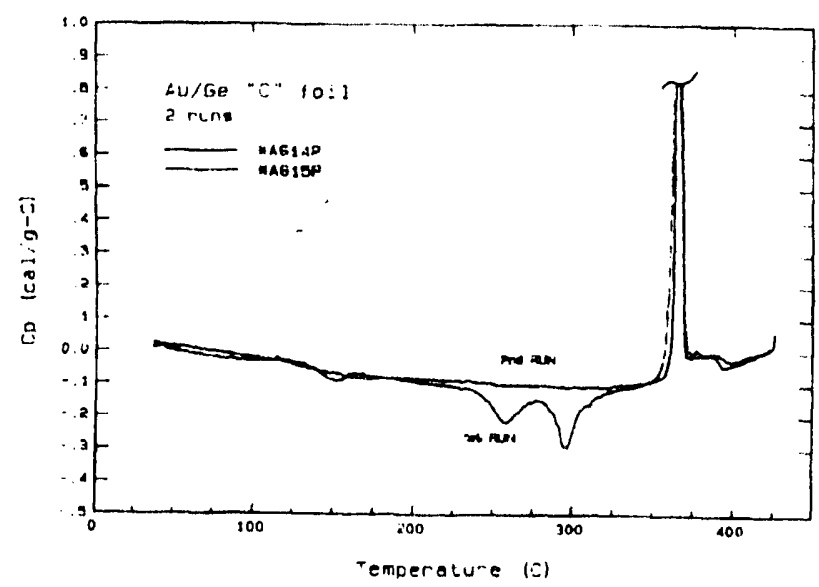

Figure 88(c) DSC Group III

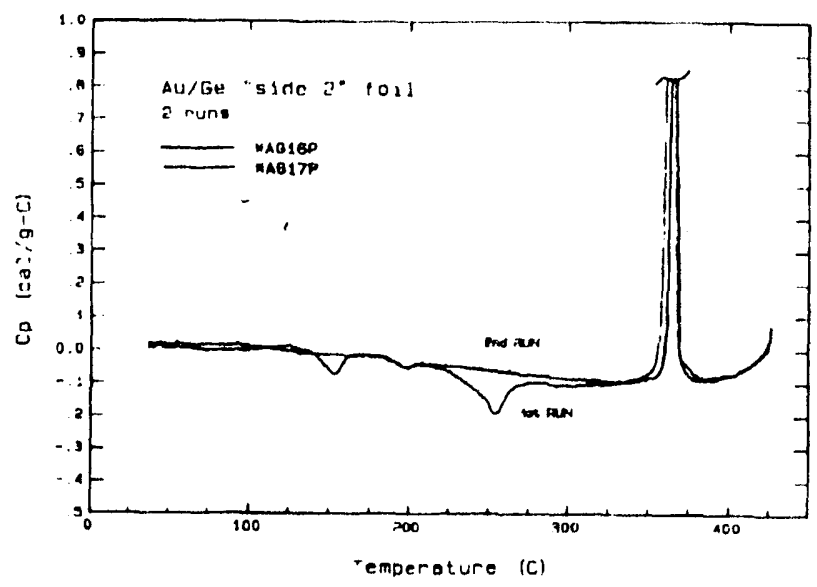

Figure 88(d) DSC Group IV. 
Table 10 Melting points and enthalpy of melting of gold-germanium films.

\begin{tabular}{|c|c|c|c|c|}
\hline \multirow{2}{*}{ Film Identification } & \multicolumn{2}{|c|}{ Melting Point (C) } & \multicolumn{2}{|c|}{ Enthalpy of Melting $(\mathrm{J} / \mathrm{g})$} \\
\hline & Run \#1 & Run $\# 2$ & Run \#1 & Run $\# 2$ \\
\hline $\begin{array}{c}\text { Group I } \\
\text { 7.0kAGe-13.0kAAu) }\end{array}$ & $362.9 \pm 0.4$ & $362.8 \pm 0.4$ & 76.1 & 73.6 \\
\hline $\begin{array}{c}\text { Group II } \\
\text { 6.0kAAu-7.0kA Ge-7.0kAAu) } \\
\end{array}$ & $362.5 \pm 0.4$ & $362.5 \pm 0.4$ & 7.9 & 8.4 \\
\hline $\begin{array}{c}\text { Group III } \\
3.5 \mathrm{k} \AA \mathrm{Ge}-6.5 \mathrm{k} \AA A \mathrm{u}-3.5 \mathrm{k} \AA \mathrm{Ge}- \\
6.5 \mathrm{k} \AA A \mathrm{~A}) \\
\end{array}$ & $362.3 \pm 0.4$ & $363.1 \pm 0.4$ & 80.3 & 75.7 \\
\hline $\begin{array}{c}\text { Group IV } \\
3.0 \mathrm{k} \AA A \mathrm{u}-3.5 \mathrm{k} \AA \mathrm{Ge}-3.5 \mathrm{k} \AA \mathrm{Au}) \\
\end{array}$ & $361.6 \pm 0.4$ & $362.9 \pm 0.4$ & 71.5 & 75.2 \\
\hline As Cast ribbon of $88 \mathrm{Au}-12 \mathrm{Ge}$ & $360.3 \pm 0.4$ & $360.3 \pm 0.4$ & 76.9 & 77.3 \\
\hline
\end{tabular}

span of 25 to $425^{\circ} \mathrm{C}$. A double exotherm was noted on the plots of Group I and Group III, albeit, it was shifted to lower temperature in the latter case. The peaks were absent in the Group II films. The exotherms probably indicated the mixing process(es) within the multilayer coatings. The shift of the exotherms to lower temperatures for Group III was due to the larger number of layers which facilitated the interdiffusion process.

A fourth film, Group IV was deposited with the Group II sequence, but to a total thickness of $1.0 \mu \mathrm{m}$ Figure 88(d). The DSC plot in Figure 88(a) has the same general artifacts as observed in the Groups I and Group III samples. These observations indicated a possible error in the film deposition sequence used to make the Group II, $2.0 \mu \mathrm{m}$ sample. The endothermic peaks resulted from the melting sequence with an onset temperature of approximately $360^{\circ} \mathrm{C}$. Listed in Table 10 are the melting onset temperatures and the enthalpies of transformation for the endothermic peaks of the multilayer films and the as-cast 87.5Au-12.5Ge ribbon. The error expression for the temperature data represents the precision of the measurement. The melting temperatures were similar to the $361^{\circ} \mathrm{C}$ value recorded for the $87.5 \mathrm{Au}$ $12.5 \mathrm{Ge}$ as-cast ribbon. The transformation temperatures differed very little between the first and second runs. Also, the enthalpy of transformation for Groups I, III, and IV were very similar between the two runs as well as agreeing with that value from the as-cast ribbon. Both of these observations indicated that the mixing process was complete prior to reflow of the solder on the

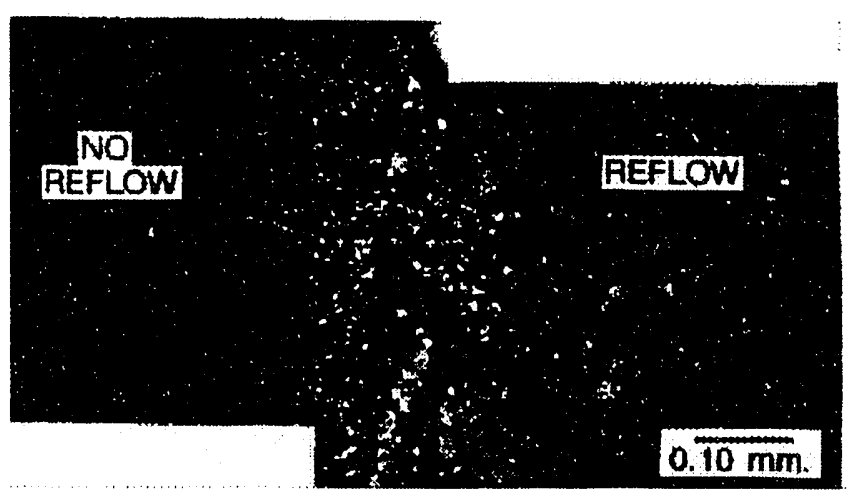

Figure 89 Optical micrographs of the phase change front on the $2.0 \mu \mathrm{m}$ thick Group I, II, III films on fused silica. 
first run as would be required for use in the assembly process; multiple heating cycles would not be required. The DSC tests provided evidence that the thin, multilayer Au-Ge films had the same thermo-physical properties as the cast Au-Ge solder ribbon.

\subsubsection{Bond formation - Transformation Front}

The third concern regarding the use of the multilayer films was the presence of physical artifacts in the films arising from the intermixing process that might cause decohesion or obstruct formation of the bond. This phenomena was addressed by the following experiment. Samples of the $2.0 \mu \mathrm{m}$ multilayer deposits using the same designation Group I, Group II, and Group III were deposited on optically polished fused silica which had already been coated with $45 \mathrm{~nm} \mathrm{Cr}$ and $180 \mathrm{~nm}$ $\mathrm{Au}$. Each sample was placed edge-on onto a hot plate being held at $420^{\circ} \mathrm{C}$. The samples remained in place until the phase change "front" had passed about one-half of the way up from the hot plate to the top of the substrate at which time, the sample was removed from the hot plate. The typical hold time for all three groups was approximately 2 minutes. Shown in Figure 89 is an optical micrograph (differential interference contrast) of the transformation front. The untransformed material is to the left; the transformed regions to the right. The physical appearance of the film surfaces was quite similar for the three sample groups. The transformed material (right) showed solder balling at the front which diminished in magnitude behind the front.

Shown in Figure 90 is the surface profile of the transformation front shown in Figure 89. Two scans were performed per sample. The common artifacts of all three samples were that first of all, only the transformation front had a noticeable volume expansion. The untransformed and fully transformed material showed the same relative heights.

Secondly, the reflowed surface was much rougher than the untransformed surface. Listed in Table 11 are the parameters of the height of the transformation front and the width (at halfmaximum) of the peaks. The values will be the average of the two data sets per specimen. The results in Table 11 show that while the peak heights were variable with no distinct pattern according to film type, the peak widths were similar. These tests clearly indicate that the intermixing process of the $\mathrm{Au}$ and $\mathrm{Ge}$ causes a temporary volume expansion which is lost when all of the multilayered material had transformed into the solder.

Three concerns about the performance of the multilayer deposition of $\mathrm{Au}$ and $\mathrm{Ge}$ layers to form an 87.5Au-12.5Ge solder have been addressed:

(1) The Au and Ge layers could be deposited at the stated thicknesses without decohesion from the substrate. The same was true of the reflowed films.

(2) The Au and Ge layers readily intermixed (for the three layer architectures examined above) at temperature below the reflow point.

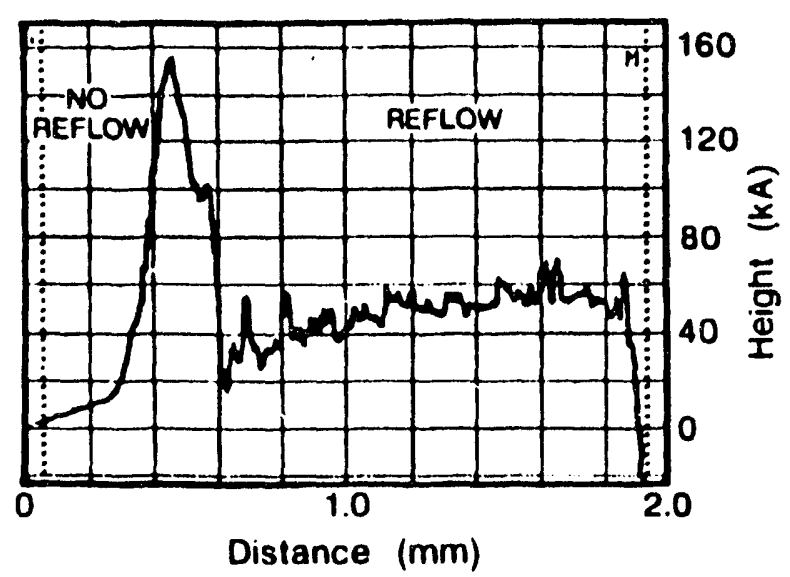

Figure 90 Surface profilometer traces across the transformation front between reflowed and nonreflowed film. Group I, II, III $2.0 \mu \mathrm{m}$ thick films. 
Table 11 Transformation front profile properties of the multi-layer gold-germanium film.

\begin{tabular}{||c|c|c|}
\hline Film Identification & $\begin{array}{c}\text { Transformation Front } \\
\text { H eight }(\mu \mathrm{m})\end{array}$ & $\begin{array}{c}\text { Transformation Front } \\
\text { Width - Half max. }(\mu \mathrm{m})\end{array}$ \\
\hline \hline Group I $(2.0 \mu \mathrm{m})$ & $5.2 \pm 0.5$ & $190 \pm 50$ \\
\hline Group II $(2.0 \mu \mathrm{m})$ & $14.0 \pm 0.5$ & $180 \pm 50$ \\
\hline Group III $(2.0 \mu \mathrm{m})$ & $8.5 \pm 0.5$ & $200 \pm 50$ \\
\hline
\end{tabular}

(3) A volume expansion of the films took place as an intermediary structure during interdiffusion. The expansion disappeared in the completely intermixed/reflowed material.

\subsubsection{CrAu behavior during solder reflow}

A short study was performed to determine the behavior of the $\mathrm{CrAu}$ metallization during the reflow process. A piece of polished fused silica was deposited with the $\mathrm{Au}$ and $\mathrm{Ge}$ layers and the $\mathrm{CrAu}$ metallization in reverse order; i.e., the $\mathrm{Au}$ and Ge layers were deposited on fused silica which had been flashed with a layer of Mo for adhesion. This process formed the $2.0 \mu \mathrm{m}$ thick solder film. Then, the $180 \mathrm{~nm} \mathrm{Au}$ and $45 \mathrm{~nm} \mathrm{Cr}$ films were deposited. The assembly was heated to $380^{\circ} \mathrm{C}$ for 30 minutes in vacuum to reflow the solder.

The film was examined for a depth profile using Ar sputtering and Auger spectroscopy. The depth profile appears in Figure 91. Both $\mathrm{Au}$ and $\mathrm{Ge}$ migrated to the surface. The movement of Au was not unexpected due to its tendency to alloy with the $\mathrm{Cr}$. The oxygen level follows the $\mathrm{Cr}$ concentration. A layer of $\mathrm{Cr}$ remained on the surface. After the start of sputtering, the $\mathrm{Cr}$ layer dropped effectively to zero as the $\mathrm{Au}$ and $\mathrm{Ge}$ layers increased. From this point on, it is difficult to interpret the $\mathrm{Au}$ and Ge concentration due to the two-phase structure of the solder. The $\mathrm{Cr}$ concentration shows a small increase deep in the film. The increase was matched by the oxygen profile. Nevertheless, this experiment confirmed that the $\mathrm{Cr}$ did not fully intermix in the solder film; rather a thin layer was retained at the solder/quartz interface to promote adhesion. Thin films of intermixed $\mathrm{CrAu}$ metallization have demonstrated exceptional adhesion to the quartz surface after high temperature annealing, confirming the presence of the $\mathrm{Cr}$ film [44]. The Ge-rich phase would also be expected to promote adhesion with the quartz since $\mathrm{Ge}$ has an affinity for oxygen similar to $\mathrm{Cr}$. This preliminary analysis indicates that in spite of the intermixing of the $\mathrm{Au}, \mathrm{Ge}$, and $\mathrm{Cr}$ constituents of the $\mathrm{Au} / \mathrm{Ge} / \mathrm{Cr}$ metal layer, there is evidence that the film should maintain good adhesion with the quartz substrate. This assumption was the object of confirmation by experimental analysis.

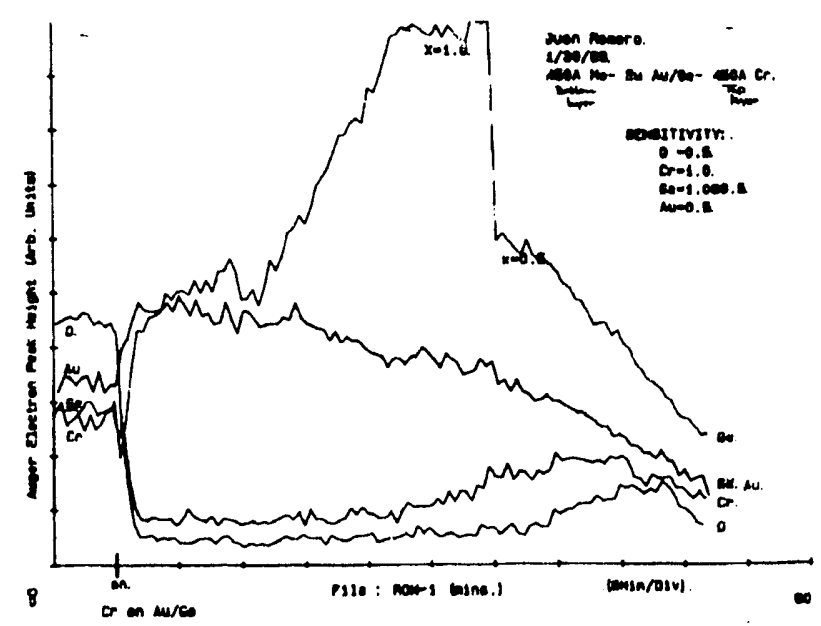

Figure 91 Auger spectroscopy depth profile of reverse deposited $2.0 \mu \mathrm{m}$ thick film. 


\subsubsection{Strength of AuGe bonds.}

Next, the tensile strength of the quartz/AuGe/quartz joint was examined. The joints were tested in the as-soldered condition as well as following exposure to thermal cycling environments. The required experimental techniques were developed to fabricate the quartz/Au-Ge/quartz bond specimens from $0.15 \mathrm{~mm}$ thick, z-oriented quartz with the appropriate metallization layers. The first of the two quartz substrates was $6.35 \mathrm{~mm} \times 6.35 \mathrm{~mm} \times$ $0.150 \mathrm{~mm} \pm .001 \mathrm{~mm}$. Both sides were optically polished. Deposited on one side was the metallization $45 \mathrm{~nm} \mathrm{Cr}-180 \mathrm{~nm}$ Au followed with the multilayer $\mathrm{Au}-\mathrm{Ge}$ film composite. The second quartz substrate started from a $150 \mu \mathrm{m}$ thick, $25.4 \mathrm{~mm} \times 25.4 \mathrm{~mm}$ wafer which was optically polished on both sides. In order to define a repeatable bonding area, photolithographic processes similar to those described in section 4.5 were used. Briefly, the quartz wafer was coated with $45 \mathrm{~nm} \mathrm{Cr}$ and $180 \mathrm{~nm}$ Au on both sides. Next, photoresist was spun on both sides. Then, the milling pattern was defined in the photoresist coating of both sides which would allow the formation of small quartz tabs $6.35 \mathrm{~mm} \times 6.35 \mathrm{~mm}$. A total of four such tabs were made from one quartz wafer. The $\mathrm{Cr}-\mathrm{Au}$ metallization was removed to reveal the bare quartz pattern to be chemically etched. After a reapplication of photoresist, the bond area pattern masks set was

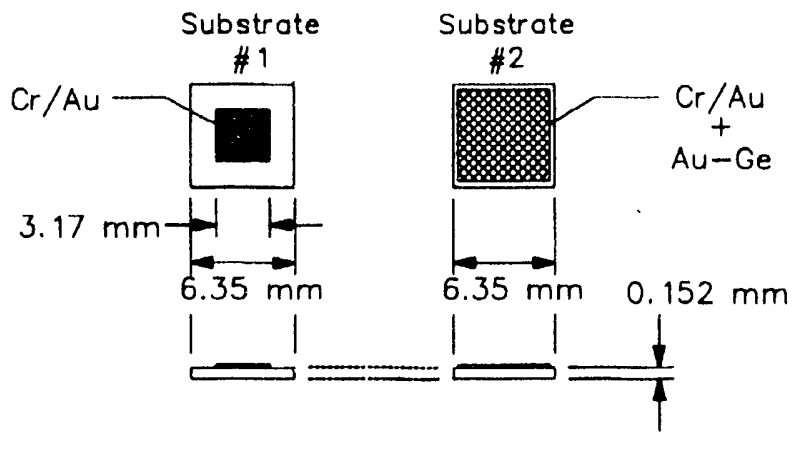

Figure 92 Bond geometry for pull test samples used to expose the photoresist. On one side, the mask defined an area of $\mathrm{Cr}$ - $\mathrm{Au}$ metallization $3.17 \mathrm{~mm} \times 3.17 \mathrm{~mm}$. On the other side, all of the metallization was removed. The quartz milling and $\mathrm{Cr}$-Au stripping procedures were performed, resulting in the following pull test sample configuration: a quartz tab $6.35 \mathrm{~mm} \times 6.35 \mathrm{~mm}$ with a square region of $\mathrm{Cr}-\mathrm{Au} 6.35 \mathrm{~mm} \times 6.35 \mathrm{~mm}$ at the center of one side. The other side remained bare quartz. The two substrates are shown in Figure 92.

The assembly of the bond sample required the AuGe layer on the one substrate to be in contact with the Cr-Au pattern of the quartz tab. The bond are. was defined by the $3.17 \mathrm{~mm}$ square $\mathrm{Cr}$-Au pattern on the tab since the $\mathrm{Au}-\mathrm{Ge}$ solder did not adhere to

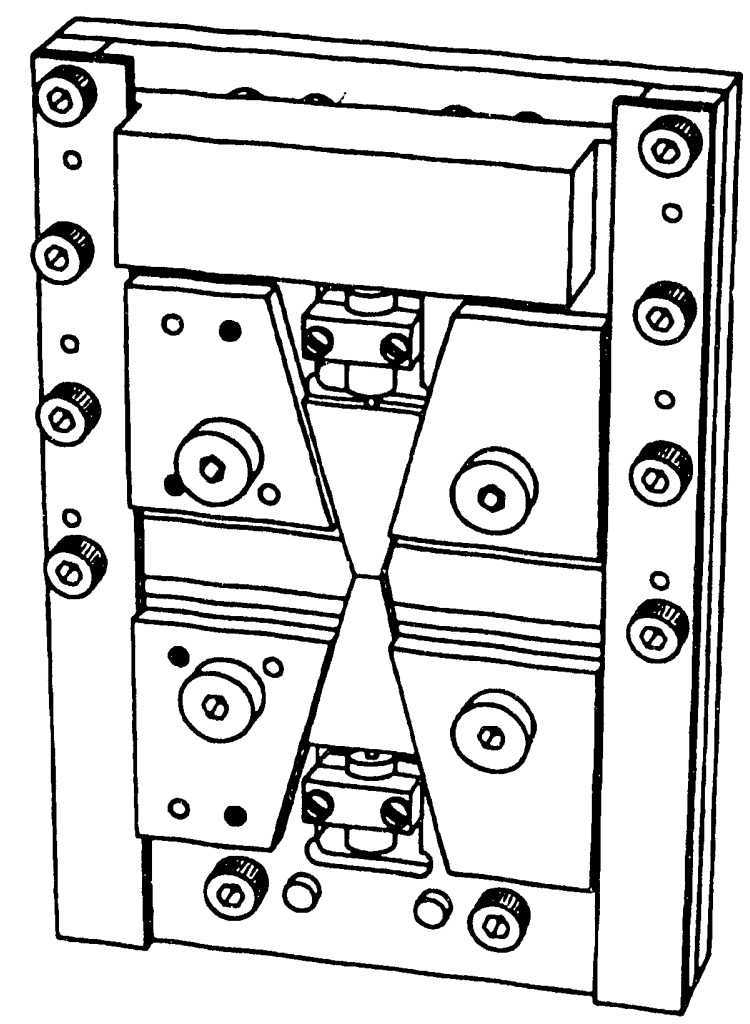

Figure 93 Pull test sample assembly fixture. The quartz substrates were placed between the two quartz wedges. 
the bare quartz. The assembly was performed on a clean bench facility using the apparatus described in Figure 93 which held the two substrates together.

Shown in Figure 94 is the stacking arrangement used to form the bond sample. Two quartz wedges fit into the grips of the testing fixture (Figure 93). Spring loaded plungers on the back of the samples and one on the top of the sliding base (not shown in the diagram) maintained a pressure at the joint. The 20\% filled copper felt was introduced to uniformly distribute the applied pressure over the bond area.

The fixture was placed in a vacuum furnace. The furnace's controlling thermocouple was inserted into a hole which had been drilled into one of the wedges. The "standard" heating schedule was:

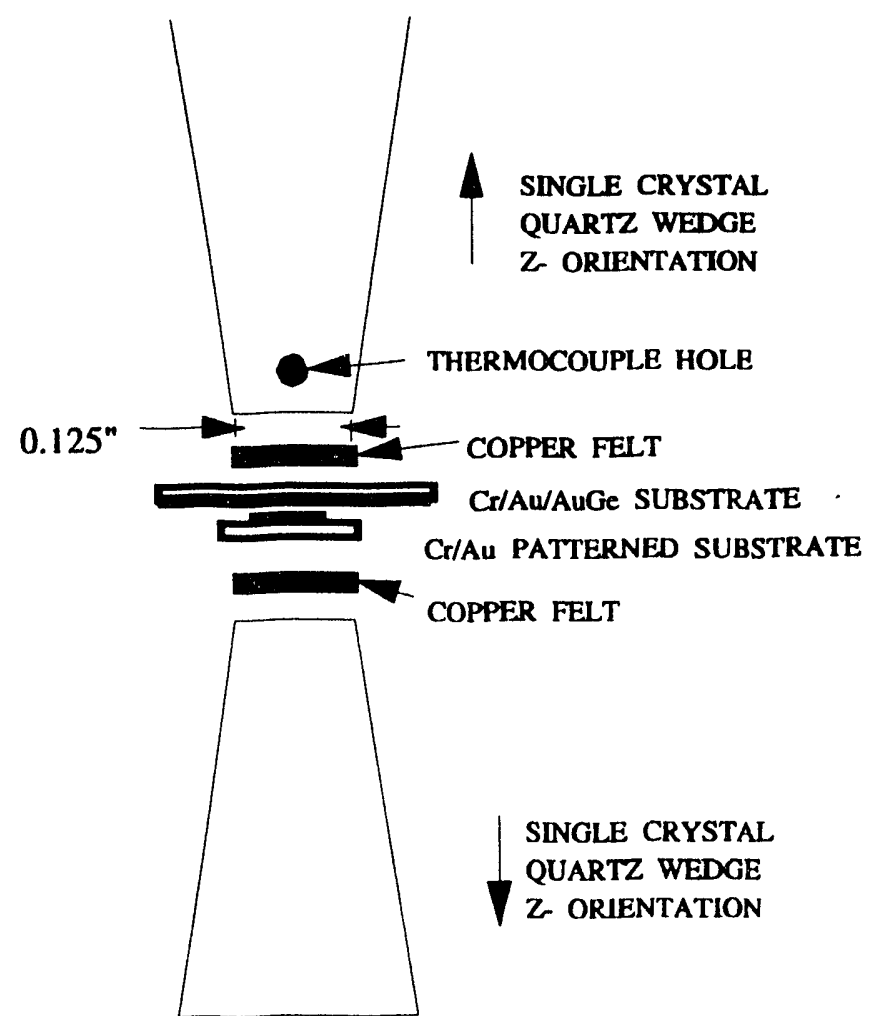

Figure 94 The quartz substrate and copper felt stacking sequence for fabrication of the bond sample.
a) 65 to $350^{\circ} \mathrm{C}, 13^{\circ} \mathrm{C} / \mathrm{min}$
b) $350^{\circ} \mathrm{C}, \min$
c) 350 to $390^{\circ} \mathrm{C}, 5^{\circ} \mathrm{C} / \mathrm{min}$
d) $390^{\circ} \mathrm{C}, 15$ minutes (REFLOW)
e) furnace cool

In several trials, the reflow time and temperature values were changed; however, the other parameters remained the same. After heat treatment, the fixture was removed from the furnace and disassembled.

Next, a process was developed to pull the bond

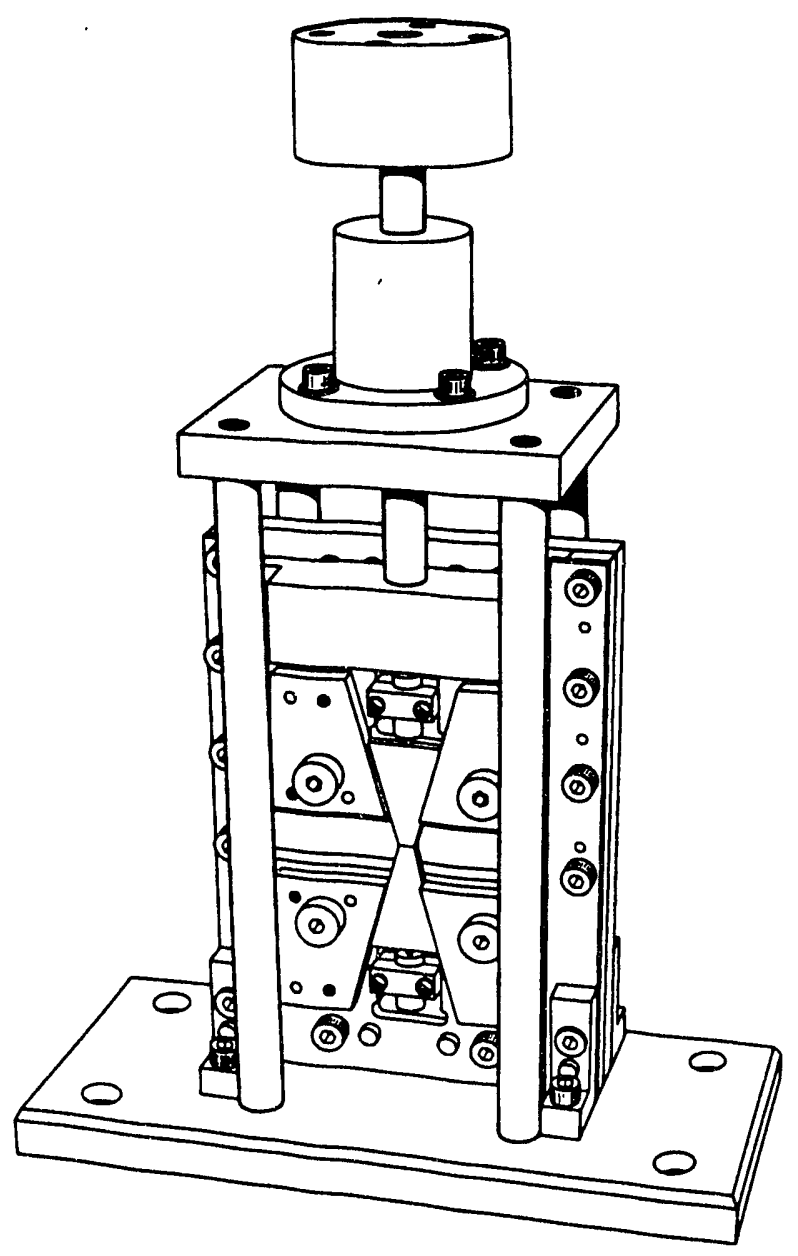

Figure 95 Pull test fixture with the wedges in place; the sample fits between the wedges. 
joint apart. A second fixture similar to that in Figure 93 was constructed with added support members to mount it into a tension test machine (Figure 95). The bond sample was attached on either surface to a copper or Kovar wedge of the same dimensions as the quartz wedges used earlier, using cold setting epoxy (Figure 96). Seven different epoxies were tried, the common deficiency being an inability to adhere to the bare quartz at strength levels exceeding that of the Au-Ge bond. The successful candidate was Epoxi-patch ${ }^{\mathrm{TM}} 6 \mathrm{C}$ Aluminum mixture.

In the first step of the assembly process, the two wedges were cleaned by rinsing in $1,1,1$ trichloroethylene followed by isopropyl alcohol. The wedges were then secured to the grips of the pull test fixture. Next, the pull sample surfaces were cleaned by wiping with cotton tipped swabs soaked in the two solvents. The two part epoxy was mixed. Although this material had a 30 minute life after mixing, it was always applied to the bond surfaces within 5 minutes. The epoxy was distributed on the surfaces of both the wedges as well as on both sides of the bond sample.

The purpose for applying the epoxy to bare surfaces was to maximize the area covered by the epoxy without inadvertently crossing the joint thereby providing a greater area to support the strength of the Au-Ge bond. This effort was required by the high strength of the quartz/Au-Ge/quartz bond. Finally, the wedges and bond samples were brought

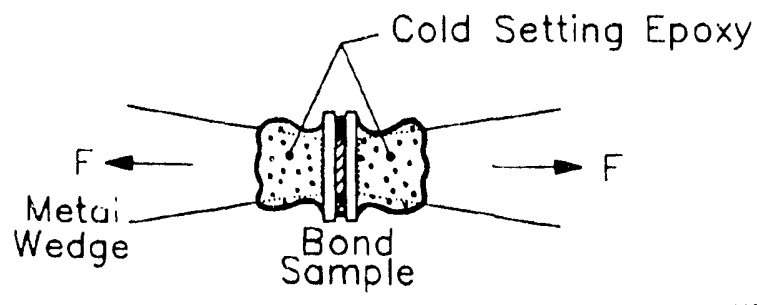

Figure 96 Process for attachment to the bond sample to the wedges for pull testing.

70 together with a moderate pressure; the epoxy was allowed to fully cure over a 24 hour period. The principle advantage of this assembly process was that precise alignment was maintained between the grips, the wedges, and the pull sample because the assembly and the pull test were performed in the same fixture.

The tension test was performed on an Instron ${ }^{\mathrm{TM}}$ 1130 load frame operated at a crosshead speed of $10 \mathrm{~mm} /$ minute. The load cell was calibrated prior

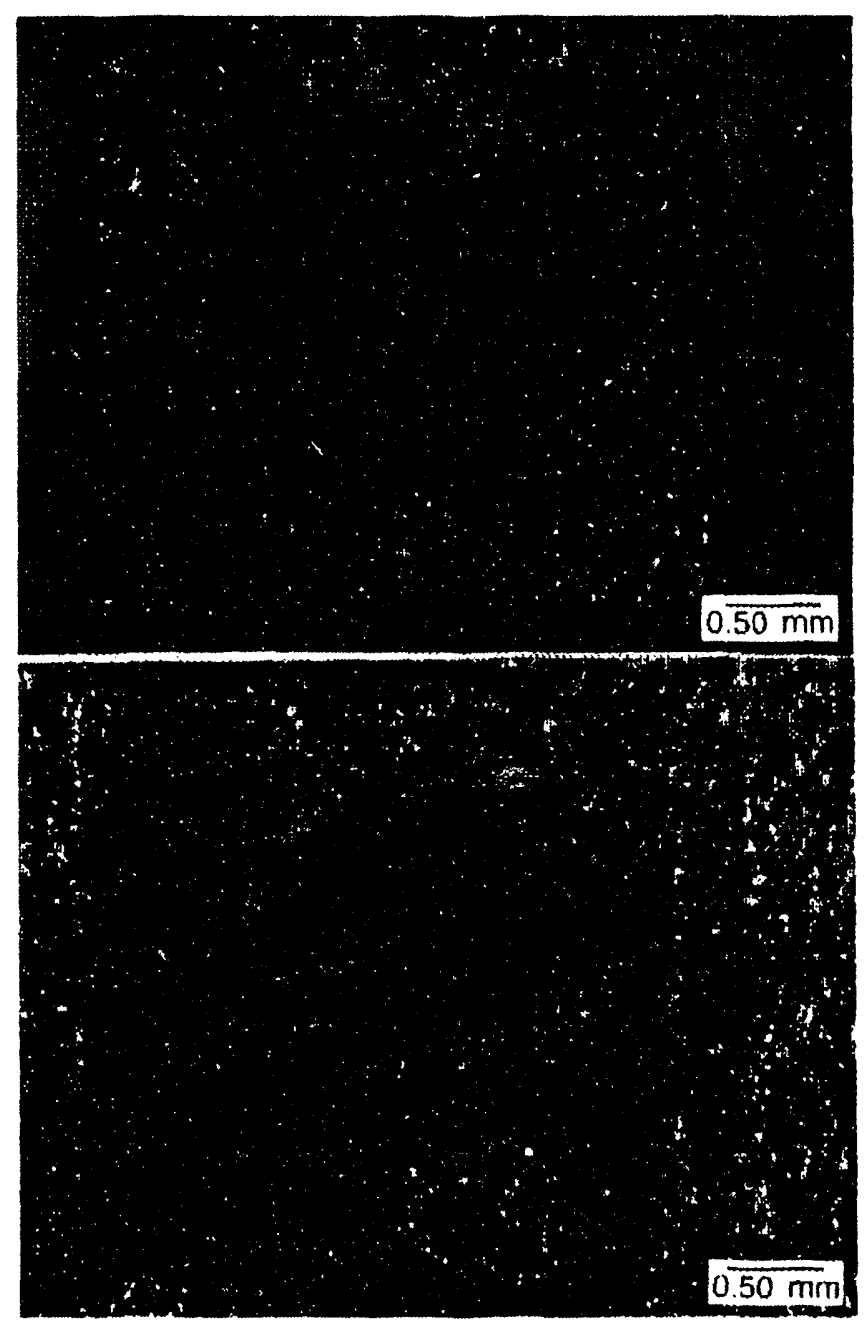

Figure 97 Optical micrographs of the complementary fracture surfaces of the $2.0 \mu \mathrm{m}$ thick $\mathrm{Au}-\mathrm{Ge}$ solder joints. The bottom micrograph is the quartz plate withe AuGe deposited on it. The top micrograph is the patterned quartz substrate. 
to each test. The failure stress was the maximum load divided by the bond area $(6.2 \mathrm{~mm} \times 6.2 \mathrm{~mm})$. After testing, the fracture surfaces were viewed and observations recorded to determine the failure mechanism.

Shown in Table 12 are the strength values for the $2.0 \mu \mathrm{m}$ and $1.0 \mu \mathrm{m}$ bonds in the as-soldered condition. The mean strength $( \pm 1 \sigma)$ of the $2.0 \mu \mathrm{m}$ and $1.0 \mu \mathrm{m}$ bonds were $18 \pm 3 \mathrm{MPa}(2570 \pm 400 \mathrm{psi})$ and $16 \pm 3 \mathrm{Mpa}$ respectively.

A "bond" failure mode referred to fracture occurring in the joint while a "quartz + epoxy" failure described the occurrence of both fracture of the quartz substrate as well as a loss of adhesion between the epoxy and the quartz. Shown in Figure 97 is the fracture surface of a $2.0 \mu \mathrm{m}$ thick Au-Ge joint. Bonding took place over the entire pattern; differences in the morphology caused the different zones to appear in the micrograph. Higher magnifications of the "central zone" on both

Table 12 Bond strength of the $1.0 \mu \mathrm{m}$ and $2.0 \mu \mathrm{m}$ thick $\mathrm{Au}-\mathrm{Ge}$ solder joints.

\begin{tabular}{||c|c|c|c|}
\hline $\begin{array}{c}\text { Bond } \\
\text { Thickness } \\
(\mu \mathrm{m})\end{array}$ & $\begin{array}{c}\text { Test } \\
\text { Num }\end{array}$ & $\begin{array}{c}\text { Strength } \\
(\mathrm{MPa})\end{array}$ & $\begin{array}{c}\text { Failure } \\
\text { Mode }\end{array}$ \\
\hline \hline 2.0 & 1 & 16 & Bond \\
\cline { 2 - 4 } & 2 & 19 & Bond \\
\cline { 2 - 4 } & 3 & 15 & Bond \\
\cline { 2 - 4 } & 4 & 21 & $\begin{array}{c}\text { Quartz }+ \\
\text { Epoxy }\end{array}$ \\
\hline \multirow{2}{*}{1.0} & 1 & 13 & Bond \\
\cline { 2 - 4 } & 2 & 18 & Bond \\
\cline { 2 - 5 } & 3 & 16 & Bond \\
\hline \multirow{2}{*}{ Absolute measurement error $= \pm 0.3 \mathrm{MPa}$} \\
\hline
\end{tabular}

surfaces appear in Figure 98. It was evident from the micrographs that failure took place primarily at the metallization/quartz interface on the quartz substrate which had the Au and Ge layers deposited on it. It was also apparent that the Au-Ge film was not continuous on this sample, rather the solder formed interconnected mesas between which was a fragmented layer of the $\mathrm{Cr}$-Au metallization. On the "solder layer quartz substrate", only isolated islands of $\mathrm{Cr}-\mathrm{Au}$ metallization remained. These morphologies were confirmed by SEM/EDXA on

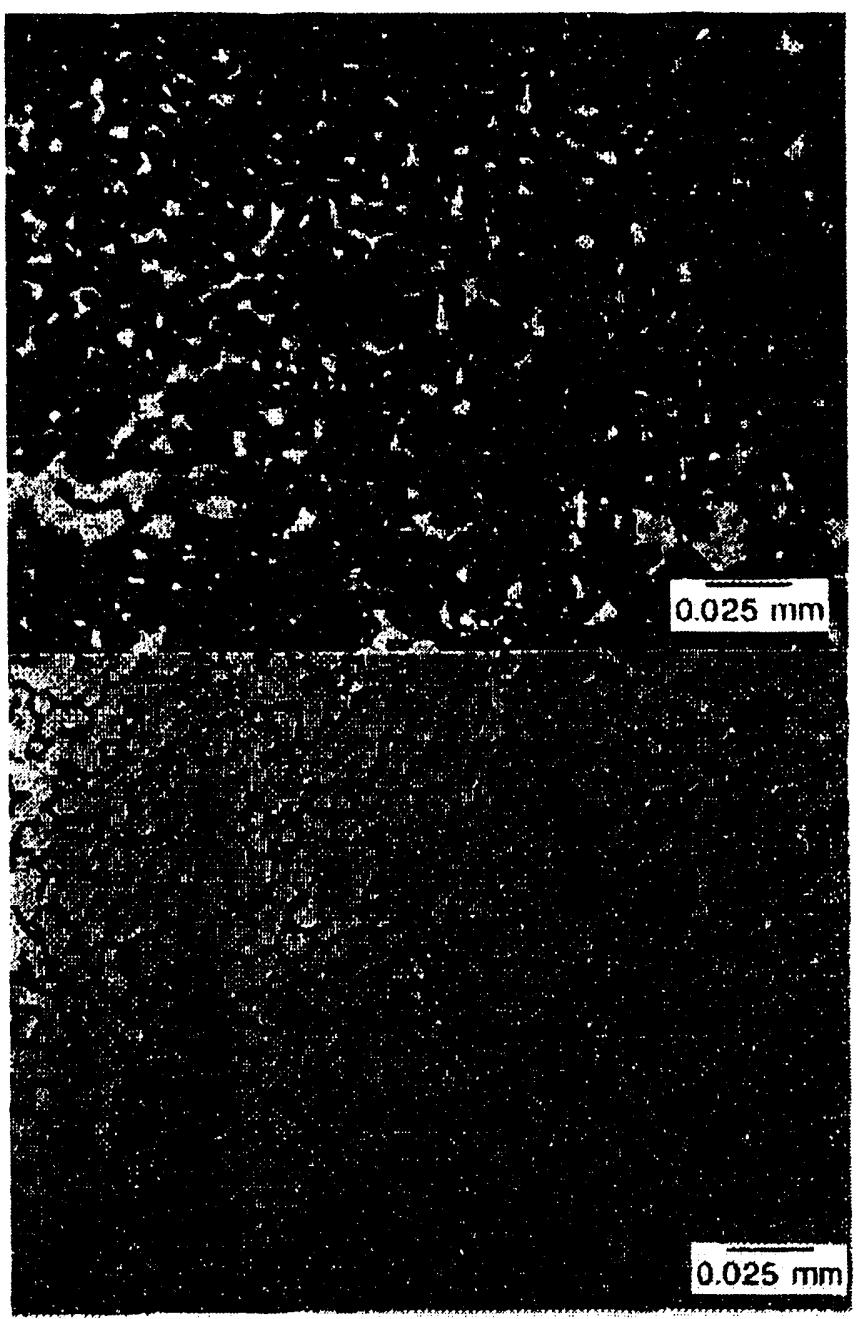

Figure 98 Optical micrographs of the fracture surface of the $2.0 \mu \mathrm{m}$ thick AuGe solder joint at higher magnification. The top micrograph is the quartz substrate coated with AuGe. The bottom micrograph had only a bare metallization pattern. 
the fracture surfaces. The structures indicated that as the solder formed and reflowed it beaded up slightly prior to contacting the opposite surface. Although this morphology was commonly observed with the $2.0 \mu \mathrm{m}$ joints, it was by no means always present.

Shown in Figure 99 are micrographs of the fracture surface of a $1.0 \mu \mathrm{m}$ thick joint. A similar morphology was observed in the $2.0 \mu \mathrm{m}$ samples which were thermally cycled or thermally shocked prior to testing. Failure took place at the metallization/quartz interface on the sample which had been coated with the solder.

The shear strength data for the $0.5 \mu \mathrm{m}$ thick Au-Ge bond are shown in Table 13 . Initially, only 4 tests were conducted. A large degree of scatter was observed in tests $1-4 ; 12.4 \mathrm{MPa} \pm 9.6(1800 \pm 1400$ psi). As a confirmation of the data scatter, a second group of samples was tested with similar results (tests $5-8,12.4 \mathrm{MPa} \pm 7.6)(1800 \pm 1100 \mathrm{psi})$. In all cases, the fracture took place within the bond at the CrAu-quartz interface of the Au-Ge coated sample. The fracture surfaces of the low test data ( $\# 3$, \#7 of Table 13) indicated that bond formation did not always take place over the entire surface; the likely source was poor substrate contact due to dust particles. In the two anomolously low readings, tests $\# 4$ and test $\# 6$, failure took place at

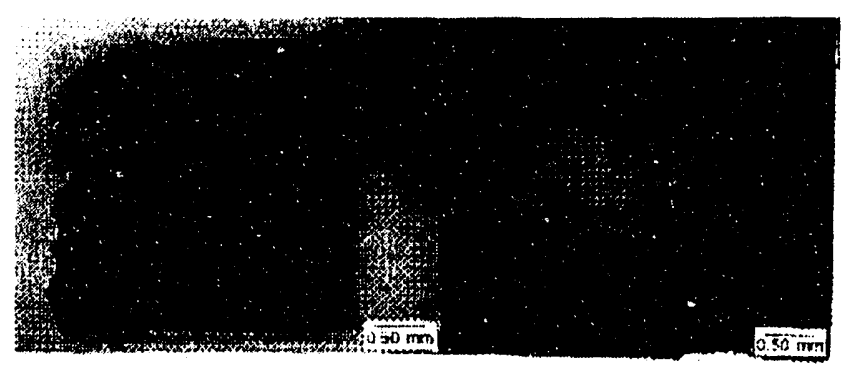

Figure 99 Optical micrographs of the fracture surfaces of the $1.0 \mathrm{~m}$ thick AuGe solder joint. The left hand micrograph is the AuGe coated substrate and the right hand micrograph is the $\mathrm{CrAu}$ metallized quartz substrate. the quartz/metallization interface. The scatter of the strength data for the $0.5 \mu \mathrm{m}$ thick joints lead to a determination that $1.0 \mu \mathrm{m}$ was the minimum thickness of solder which would be further considered. The remaining studies of the investigation were therefore conducted on the $1.0 \mu \mathrm{m}$ and $2.0 \mu \mathrm{m}$ in $\mathrm{Au}-\mathrm{Ge}$ bonds.

The heat treatment schedule for reflow of the AuGe solder was listed earlier. The peak temperature hold time was varied in order to determine the minimum value necessary to make a strong bond as determined by the tension test on the $2.0 \mu \mathrm{m}$ joint. For the peak temperature of $390^{\circ} \mathrm{C}$, three time periods were used: 30,15 , and 5 minutes. The 30 minute time period was found to be excessive. The excellent bond strengths were retained for a period of 15 minutes as exemplified in Table 14. At a 5 minute hold time, the bond strengths dropped significantly' to values of .83MPa, 2.57MPa, and

Table 13 Bond strength of the $0.5 \mu \mathrm{m}$ thick AuGe solder joints.

\begin{tabular}{||c|c|c|c|}
\hline $\begin{array}{c}\text { Bond } \\
\text { Thickness } \\
(\mu \mathrm{m})\end{array}$ & $\begin{array}{c}\text { Test } \\
\text { Num }\end{array}$ & $\begin{array}{c}\text { Strength } \\
(\mathrm{MPa})\end{array}$ & $\begin{array}{c}\text { Failure } \\
\text { Mode }\end{array}$ \\
\hline \hline 0.5 & 1 & 23 & Bond \\
\cline { 2 - 4 } & 2 & 19 & Bond \\
\cline { 2 - 4 } & 3 & 6 & Bond \\
\hline & 4 & 3 & Bond \\
\cline { 2 - 4 } & 5 & 17 & Bond \\
\cline { 2 - 4 } & 6 & 4 & Bond \\
\cline { 2 - 4 } & 7 & 8 & Bond \\
\cline { 2 - 4 } & 8 & 21 & Bond \\
\hline \hline 'Absolute measurement error $= \pm 0.3 \mathrm{MPa}$ \\
\hline
\end{tabular}


Table 14 Bond strengths of the AuGe solder joints after thermal shock and thermal cycling.

\begin{tabular}{|c|c|c|c|}
\hline Pre-Test Environment & Test Number & Strength (MPa) & Failure Mode \\
\hline \multirow{3}{*}{ As-Fabricated } & 1 & 16 & Bond \\
\cline { 2 - 4 } & 2 & 19 & Bond \\
\cline { 2 - 4 } & 3 & 15 & Bond \\
\cline { 2 - 4 } & 4 & 21 & Quartz + Epoxy \\
\hline \hline \multirow{3}{*}{$\begin{array}{c}\text { 200 Thermal } \\
\text { Shock Tests }\end{array}$} & 1 & 32 & Quartz + Epoxy \\
\cline { 2 - 5 } & 2 & 29 & Bond \\
\hline \hline \multirow{2}{*}{\begin{tabular}{c} 
Cycle Tests \\
\cline { 2 - 5 }
\end{tabular}} & 3 & 27 & Quartz + Epoxy \\
\cline { 2 - 5 } & 2 & 20 & Quartz + Epoxy \\
\cline { 2 - 5 } & 3 & 19 & Quartz + Epoxy \\
\cline { 2 - 5 } & 4 & 24 & Quartz + Epoxy \\
\hline
\end{tabular}

12.8MPa (121psi, 373psi, and $1853 \mathrm{psi}$ ) for three test samples. The $12.8 \mathrm{MPa}$ test showed the typical quartz/metallization failure (Figure 98). The lower strength specimen fracture surfaces exhibited incomplete reflow. Therefore, the 15 minute period was selected as the lowest value to maintain adequate joining at a peak temperature of $390^{\circ} \mathrm{C}$.

Selection of the peak temperature, $390^{\circ} \mathrm{C}$, was based upon the practice of using a reflow temperature 30 to $50^{\circ} \mathrm{C}$ above the melting point of the solder [45]. Two test samples were prepared under the reflow conditions of $370^{\circ} \mathrm{C}$ and 5 minutes. Extremely weak bonds were formed at $675 \mathrm{kPa}$ and 1.2MPa (98 and $174 \mathrm{psi}$ ). Incomplete reflow of the solder took place although intermixing of the $\mathrm{Au}$ and $\mathrm{Ge}$ components was clearly visible. Therefore, further samples were fabricated at $390^{\circ} \mathrm{C}$.

\subsubsection{Thermal Shock and Thermal Cycling} Tests.

Residual stresses in the bond joint could be minimized by matching the thermal expansion coefficients of the solder to the quartz. It is these residual stresses which cause thermal fatigue damage during temperature cycling. Therefore, thermal shock and thermal cycle exposures were made on the $1.0 \mu \mathrm{m}$ and $2.0 \mu \mathrm{m}$ joints after which they were tested for adhesive strength. The thermal shock cycles had temperature limits of $-55^{\circ} \mathrm{C}$ and $125^{\circ} \mathrm{C}$ using a liquid-to-liquid "instantaneous" temperature change, a hold time at the limits of 10 minutes repeated for 200 cycles. The thermal cycle exposures were $-55^{\circ} \mathrm{C}$ to $125^{\circ} \mathrm{C}$ ramped at $6^{\circ} \mathrm{C} /$ minute and 120 minute hold times at the temperature limits for 100 cycles. The strength data for the $2.0 \mu \mathrm{m}$ thick joints appear in Table 14 and those of the $1.0 \mu \mathrm{m}$ samples, in Table 15. Both tables include the as-soldered data for comparison. 
Table 15 Strength and failure results of $1.0 \mu \mathrm{m}$ AuGe bonds during thermal shock and thermal cycling.

\begin{tabular}{||c|c|c|c|}
\hline Pre-Test Environment & Test Number & Strength (MPa) & Failure Mode \\
\hline \hline \multirow{2}{*}{ As-Fabricated } & 1 & 13 & Bond \\
\cline { 2 - 4 } & 2 & 18 & Bond \\
\cline { 2 - 4 } & 3 & 16 & Bond \\
\hline \hline \multirow{2}{*}{$\begin{array}{c}\text { Shock Tests } \\
\text { Shermal }\end{array}$} & 1 & 14 & Bond \\
\hline \hline \multirow{2}{*}{$\begin{array}{c}\text { Cycle Tests } \\
\text { Cynermal }\end{array}$} & 2 & 18 & Bond \\
\cline { 2 - 4 } & 1 & 13 & Epoxy \\
\cline { 2 - 5 } & 2 & 14 & Quartz + Bond \\
\cline { 2 - 5 } & 3 & 26 & Quartz + Bond \\
\hline
\end{tabular}

For the $2.0 \mu \mathrm{m}$ bonds (Table 14 ), both the thermal shock and thermal cycle exposu ... significantly increased the bond strengths to $29 \mathrm{MPa} \pm 3 \mathrm{MPa}$ and $27 \mathrm{MPa} \pm 12 \mathrm{MPa}(4270 \pm 370 \mathrm{psi}$ and $3890 \pm 1740$ psi), respectively. Moreover, these values were lower limits as the failures were predominantly in the quartz and epoxy; the actual bonds remained intact. The $1.0 \mu \mathrm{m}$ joint had an average strength of $16 \mathrm{MPa}(2310 \mathrm{psi})$ for two tests after thermal shock

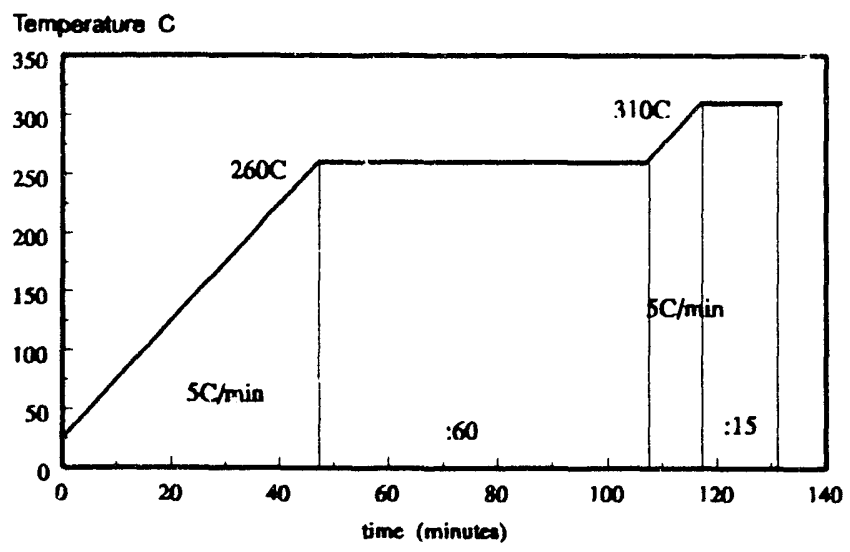

Figure 100 Heating schedule use :o reflow the $80 \mathrm{Au} 20 \mathrm{Sn}$ solder seal for the package lids. exposure, a value similar to the as-soldered bonds. The bond strength of the thermally cycled samples was $15 \pm 8 \mathrm{MPa}$ which was not significantly different from the as-fabricated strength. However, this is a lower limit value due to failure with the quartz and/or epoxy on several tests. All "bond failures" of the $2.0 \mu \mathrm{m}$ and $1.0 \mu \mathrm{m}$ samples were similar to that shown Figure 99. These results suggest that no significant weakening of the solder bonds took place.

The thermal shock and thermal cycle exposures of the $2.0 \mu \mathrm{m}$ joints had a surprising result of strengthening the bonds rather than degrading them. Because these tests were performed in air, it was construed that oxidation of the metal film $(\mathrm{Cr} / \mathrm{Au} / \mathrm{Ge})$ at the metal/quartz interface promoted an oxide-oxide bond been the metal layer and the quartz $\left(\mathrm{SiO}_{2}\right)$. A sirmilar behavior was observed for the adhesive strength of $\mathrm{CrAu}$ films on quartz after annealing in air. 
For the $1.0 \mu \mathrm{m}$ joints, the thermal shock and cycle exposures did not appear to degrade nor enhance the bond strength. The lack of increased bond strength after the air "annealing" associated with the exposure indicated that the effect was offset by another mechanism in the part. We concluded, therefore, that the $1.0 \mu \mathrm{m}$ and $2.0 \mu \mathrm{m} \mathrm{Au}-\mathrm{Ge}$ bonds were capable of withstanding the thermal fluctuations imposed by the shock and cycle tests. The $2.0 \mu \mathrm{m}$ thick joint showed superior performance to the $1.0 \mu \mathrm{m}$ samples and was selected as the candidate for the sensor assembly.

\subsubsection{Thermal Environments Tests.}

Finally, it was necessary to evaluate the integrity of the joints after exposure to thermal environments similar to those experienced by the assembled QDA during packaging. Two processes were performed as part of the packaging process: (1) the attachment of the QDA to the ceramic frame using a polyimide adhesive and (2) the sealing of the package with two sapphire lids using $80 \mathrm{Au}-20 \mathrm{Sn}$ solder. The processes were performed in air and vacuum, respectively. The polyimide attachment thermal schedule was shown in Figure 66 and that of the AuSn sealing operation is in Figure 100.

A conservative estimate of these exposure conditions was made by heat treating the bond samples at $300^{\circ} \mathrm{C}$ for 180 minutes in either air or vacuum after which the samples were pull tested. The results appear in Table 16. The bond strengths of the samples annealed in air were much higher than the as-soldered values with an average strength of $40 \mathrm{MPa}(5760 \mathrm{psi})$. When the annealing was performed in vacuum, the strength values were comparable to the as-soldered data at $16 \pm 9 \mathrm{MPa}$ $(2300 \pm 1300 \mathrm{psi})$, although the scatter was larger. The 3.0MPa value was included because there was no apparent reason to discount that result. Without that number, the vacuum heat treat strength was $20 \mathrm{MPa} \pm 3 \mathrm{MPa}(2930 \pm 460 \mathrm{psi})$ which was slightly

Table 16 Bond strengths of the $1.0 \mu \mathrm{m}$ AuGe solder joints following air and vacuum annealing.

\begin{tabular}{||c|c|c|c||}
\hline Pre-Test Environment & Test Number & Strength (MPa) & Failure Mode \\
\hline \hline \multirow{3}{*}{ As-Fabricated } & 1 & 16 & Bond \\
\cline { 2 - 4 } & 2 & 19 & Bond \\
\cline { 2 - 4 } & 3 & 15 & Bond \\
\cline { 2 - 4 } & 4 & 21 & Quartz + Epoxy \\
\hline \hline \multirow{3}{*}{$\begin{array}{c}\text { Annealed: } \\
\text { 300C - } 180 \text { minutes } \\
\text { Air }\end{array}$} & 1 & 40 & Bond \\
\hline \hline \multirow{3}{*}{$\begin{array}{c}\text { Annealed: } \\
300 C \text { - } 160 \text { minutes } \\
\text { Vacuum }\end{array}$} & 2 & 40 & Bond \\
\cline { 2 - 5 } & 1 & 3 & Bond \\
\cline { 2 - 5 } & 2 & 17 & Bond \\
\cline { 2 - 5 } & 4 & 24 & Bond \\
\cline { 2 - 5 } & 3 & 20 & Bond \\
\hline \hline
\end{tabular}


higher than the as-soldered strength.

The experiments indicated two points: (1) The postassembly processes to complete the packaging of the QDA would not degrade the bond strength. (2) The data provided further evidence of the earlier theory that the presence of oxygen at elevated temperature improved the adhesion of the $\mathrm{Cr} / \mathrm{Au} / \mathrm{Ge}$ layer at the quartz surface by a suspected oxide $\left(\mathrm{Cr}_{2} \mathrm{O}_{3}, \mathrm{GeO}\right)$-oxide $\left(\mathrm{SiO}_{2}\right)$ interaction.

The mechanical testing program provided the necessary data to evaluate the adhesive strength of the Au-Ge solder joint. It established (1) the $2.0 \mu \mathrm{m}$ joint as being the optimum thickness, (2) the reflow cycle to construct the QDA and (3) determined the reliability of the bond under fluctuating thermal exposures.

\subsubsection{Composition of Multilayer Films - DSC Method.}

A final study of the multilayer solder bond process was made to develop a method of determining the composition of the multilayer film in a quick and cost effective manner. The obvious technique of atomic emission spectroscopy would certainly have provided the necessary data; but the turnaround time for such analyses was deemed excessive. Therefore, two techniques were investigated: (1) Differential Scanning Calorimetry (DSC) and (2) Controlled Potential Coulometry (CPC). The DSC method will be examined first.

The DSC method examined the use of the specific heat of transformation at melting, $\Delta H_{t}$, as an indicator of the composition of the film. Recall from the phase diagram of the Au-Ge system (Figure 72) that at the eutectic composition, 87.5Au-12.5Ge (wt. \%), melting (or solidification) of the two phase structure occurred at one temperature $\left(360^{\circ} \mathrm{C}\right)$. If the total composition was not eutectic, then upon melting, only a fraction of the sample mass will have the eutectic composition and melt at $360^{\circ} \mathrm{C}$ with the specific heat of transformation, $\Delta \mathrm{H}_{\mathrm{t}, \mathrm{c}}$. The remaining unmelted material, which would be either proeutectic Au-rich or Ge-rich phase, would gradually melt as the temperature rises towards the liquidus point for that composition. The DSC plot would still show the onset of transformation as taking place at $360^{\circ} \mathrm{C}$. However, because the melting process will continue at higher temperatures, the peak becomes elongated toward the high temperature end of the graph. As a quantitative parameter of the film composition, the peak elongation is difficult to interpret. On the other hand, because the sample was not $100 \%$ eutectic composition, the specific heat of transformation of the sample would not equal that of the eutectic specimen. The deviation from the value $\Delta H_{t, e}$ would be used to evaluate the composition of the film.

The experimental procedure used to evaluate this hypothesis involved the deposition of 5 separate $2.0 \mu \mathrm{m}$ thick multilayer Au-Ge films (on polished rock salt) with various proportions of $\mathrm{Au}$ and $\mathrm{Ge}$ film thicknesses so as to simulate non-eutectic compositions. Then, samples from each of these films were analyzed by AES/ICP to determine their precise compositions. A second sample from each film was evaluated by the DSC over the temperature range of $25^{\circ} \mathrm{C}$ to $430^{\circ} \mathrm{C}$ at a scanning rate of $10^{\circ} \mathrm{C} /$ minute.

The analysis for $\Delta \mathrm{H}_{\mathrm{t}}$ was performed on the second of the two runs since past data showed no significant difference between the enthalpies calculated from the two runs. The accuracy of the $\Delta H_{t}$ values was $\pm 1.0 \%$. This technique assumed that regardless of composition, all of the films would interdiffuse so that each film resembled a homogeneous layer. As a reference point, the DSC analysis was performed on a specimen of as-cast ribbon that was certified at $12.65+0.35 /-1.65 \mathrm{wt}$. \% 
Table 17 Composition and $\Delta H$ values of the multilayer $2.0 \mu \mathrm{m}$ thick AuGe films.

\begin{tabular}{|c|c|c|c|c||}
\hline \multicolumn{2}{|c|}{$\begin{array}{c}\text { Nominal Composition } \\
\text { Atomic \% }\end{array}$} & \multicolumn{2}{c|}{$\begin{array}{c}\text { AES/ICP Composition } \\
\text { Atomic } \%\end{array}$} & $\begin{array}{c}\text { Heat of Reaction } \\
\Delta H \text { (J/g) }\end{array}$ \\
\hline $\mathrm{Au}$ & $\mathrm{Ge}$ & $\mathrm{Au}$ & $\mathrm{Ge}$ & \\
\hline 57 & 43 & 55.8 & 44.2 & 64.3 \\
\hline 62 & 38 & 60.8 & 39.2 & 67.4 \\
\hline 67 & 33 & 67.1 & 32.9 & 72.7 \\
\hline 77 & 23 & 74.4 & 25.6 & 63.0 \\
\hline 82 & 18 & 80.8 & 19.2 & 42.8 \\
\hline "A" 700nmGe 1300nmAu & 71 & 29 & $74.9 \pm 1.8$ \\
\hline "C" 2x350nmGe 2x650nmAu & 69.2 & 30.8 & $78.1 \pm 3.3$ \\
\hline \multicolumn{2}{|c|}{ "Side2" } & 68.6 & 31.4 & $73.5 \pm 2.7$ \\
\hline
\end{tabular}

Ge. The value of $\Delta \mathrm{H}_{\mathrm{t}, \mathrm{e}}$ was $77.1 \pm 0.2 \mathrm{~J} / \mathrm{g}$ ( \pm measurement error).

Shown in Table 17 are the data for the various films compositions, including the nominal composition, the actual composition as determined by AES/ICP, and the values of $\Delta \mathrm{H}_{\mathrm{t}}$. The data from the as-cast ribbon sample have also been listed. The results were plotted as the dark circles in Figure 101.

For each of three films, two readings were made while three readings were taken of a fourth film to examine the reproducibility of the numbers. Those data points have error bars which represent one standard deviation. In fact, this procedure has defined the Au-Ge phase diagram in terms of $\Delta \mathrm{H}_{t}$ rather than temperature as a function of composition. The shape is quite similar to that noted in Figure 72. This similarity lends further evidence that the multilayer films behaved the same as the bulk as-cast ribbon.
Also in the plot in Figure 101 are the data from three multilayer films used in previous experiments (open circles). It was observed that these results coincided very well with the "standard" curve. Therefore, given the value of $\Delta H_{t}$ of a particular $\mathrm{Au}-\mathrm{Ge}$ film, the "master plot" enabled a determination to be made of a film's composition relative to the eutectic value. However, because the master plot is bi-modal, for a given value of

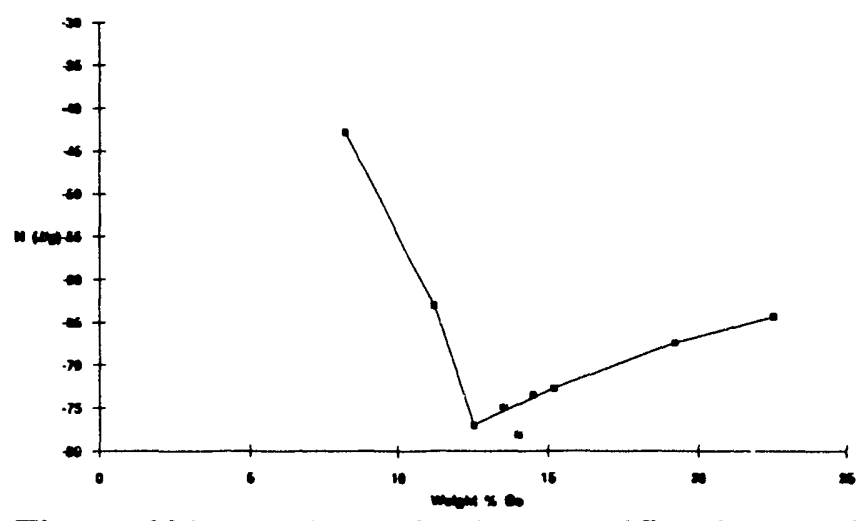

Figure 101 Plot of the specific heat of transformation as a function of $\mathrm{Ge}$ concentration in the $2 \mu \mathrm{m}$ thick multilayer films. Table 17 . 
$\Delta \mathrm{H}_{\mathrm{t}}$ it would not be possible to determine the exact composition from the heat of transformation data.

An estimate of the acceptable range of $\Delta H_{t}$ for sampled films can be determined from the expected error of the deposition process. That is, given that the target composition is the eutectic concentration, then the exact thicknesses of the $\mathrm{Au}$ and Ge layers for a $2.0 \mu \mathrm{m}$ thick solder derived from the Au-Ge$\mathrm{Au}$ architecture are $658 \mathrm{~nm} \mathrm{Au-684nm} \mathrm{Ge-658nm}$ $\mathrm{Au}$. An upper limit estimate of the thickness reproducibility in electron beam evaporation is $\pm 2 \%$. A calculation of the resulting composition range is $87.9 \mathrm{Au}-12.1 \mathrm{Ge}$ to $87.0 \mathrm{Au}-13.0 \mathrm{Ge}$.

The maximum value of $\Delta \mathrm{H}_{\mathrm{t}}$ corresponds to the eutectic, $77.1 \mathrm{~J} / \mathrm{g}$. Of the two extremes of film composition just noted, the 87.9Au-12.1Ge film gives the lowest value of $\Delta \mathrm{H}_{\mathrm{t}}$ at $72 \mathrm{~J} / \mathrm{g}$ (as determined from Figure 101). If an acceptable range of $\Delta \mathrm{H}_{1}$ from the eutectic value were $72<$ $\Delta \mathrm{H}_{\mathrm{t}}<77 \mathrm{~J} / \mathrm{g}$, then the range of Ge compositions is $12.1 \mathrm{wt} . \%$ to $12.5 \mathrm{wt}$ \% for the Au-rich film. The corresponding range for the Ge-rich film would be $12.5 \mathrm{wt}$. \% to $16.1 \mathrm{wt} . \%$.

Referring to the phase diagram for Au-Ge (Figure 72) and using the lever rule, a $16.1 \mathrm{wt} . \%$ $\mathrm{Ge}$ film would give rise to approximately $4 \%$ proeutectic Ge-rich phase which would not detract from the performance of the solder film.

In conclusion, the DSC technique can provide adequate data for the screening if the AuGe solder layer deposition. A refinement to this technique would require a series of eutectic compositiontargeted depositions to be used for determining the actual thickness variations to be expected from a particular thin film deposited system.

\subsubsection{Composition of Multilayer Films - CPC Method.}

The second technique explored for use as a monitor of the composition of the films was Controlled Potential coulometry (CPC). In this procedure, the composition was determined by measuring the $\mathrm{Au}$ content of the samples. The films were dissolved in aqua regia. Then, electrodes were put into the solution and $\mathrm{Au}$ plated out on to one electrode. The weight gain by the electrode was compared the weight of the sample prior to dissolution to give the Au concentration. Because this procedure gives the absolute measurement of the $\mathrm{Au}$ content, no calibration standards were required as was the case with AES/ICP. Assuming no significant impurities, the remaining mass of the sample was Ge. It was also assumed that the presence of the Ge did not affect the Au measurements. The details of the technique are given in [46]. The measurements were made with a EG\&G PAR model 310 CPC. Three measurements were taken of solutions made from the five films. A $95 \%$ confidence interval was $\pm 0.006 \mathrm{mg}$ (or about $0.3 \%$ ).

Shown in Table 18 are the CPC measurements together with the compositions determined by AES/ICP. The differences between the two sets of data were less than $2 \%$ in all cases. The precision of this technique was superior to that of the DSC data. Moreover, there was no ambiguity as to the concentration of an off-eutectic film. In conclusion, the CPC technique was the preferred technique to monitor the film composition.

This concludes the description of the development of the thin film solder bonding technique. The process selected for sensor assembly was the multilayer deposition of two layers of $\mathrm{Au}$ and one of $\mathrm{Ge}$ in the Au-Ge-Au stacking to form the eutectic composition. The selected solder thickness was $2.0 \mu \mathrm{m}$. Reflow of the actual parts was performed in vacuum; the temperature cycles were altered slightly to accommodate different fixturing and furnace facilities. 
Table 18 Composition and heat of formation of the multilayer AuGe films determined by AES/ICP.

\begin{tabular}{||c||c|c||c|c||c|c||}
\hline \multicolumn{1}{|c||}{} & \multicolumn{2}{|c|}{$\begin{array}{c}\text { Nominal } \\
\text { Composition }\end{array}$} & \multicolumn{2}{c|}{$\begin{array}{c}\text { AES-ICP Composition } \\
\text { Atomic \% }\end{array}$} & \multicolumn{2}{c||}{$\begin{array}{c}\text { CPC Composition } \\
\text { Atomic \% }\end{array}$} \\
\cline { 2 - 7 } & $\mathrm{Au}$ & $\mathrm{Ge}$ & $\mathrm{Au}$ & $\mathrm{Ge}$ & $\mathrm{Au}$ & $\mathrm{Ge}$ \\
\hline 1 & 57 & 43 & 55.8 & 44.2 & 54.97 & 45.03 \\
\hline 2 & 62 & 38 & 60.8 & 39.2 & 55.69 & 40.31 \\
\hline 3 & 67 & 33 & 67.1 & 32.9 & 66.68 & 33.32 \\
\hline 4 & 77 & 23 & 74.4 & 25.6 & 74.50 & 25.50 \\
\hline 5 & 82 & 18 & 80.8 & 19.2 & 80.30 & 19.70 \\
\hline
\end{tabular}

\subsubsection{Solder Bond Assembly Procedures.}

This section describes the processes used to assemble the DETFs and spacers into the QDA. The layers of $\mathrm{Au}$ and $\mathrm{Ge}$ were deposited on both sides of the spacers rather than the DETFs in order to eliminate handling damage to the tuning forks. The spacers had the $45 \mathrm{~nm}$ Cr-180nm Au metallization on them from the photolithographic process. The Au-Ge deposition was targeted on an area $0.9 \mathrm{~mm} \times 1.2 \mathrm{~mm}$ by means of aperture (shadow) masks placed next to the quartz wafer contained twenty pairs of spacers. Shown in Appendix A-5 is a drawing of the mask which was constructed of $175 \mu \mathrm{m}$ thick nickel-plated beryllium copper (or in some cases, simply beryllium copper).

The fixturing consisted of a Type 304 stainless steel base plate (Appendix A-5) into which were placed two dowel pins which served to maintain alignment between the masks and the quartz wafer containing the spacers. The slots cut into the plate (by wire electric discharge machining) allowed the metal vapor to reach the appropriate area on the quartz surface. One of the masks which had holes to accommodate the dowel pins was placed on to the base plate followed by the wafer of spacers. Next, a "picture frame" mask (Appendix A-5) was placed around the quartz wafer followed by a second aperture mask on top. Lastly, a steel plate similar to the base plate except that it contained holes to accommodate the dowel pins was placed over the stack (Appendix A-5). The picture frame mask was $175 \mu \mathrm{m}$ thick so that a space was formed between the quartz wafer and the masks; therefore, when the assembly was tightened down, no undue pressure was placed onto the quartz wafer. An assembly drawing appears in Appendix A-5. The assembled wafers and masks was placed inside the evaporator; the $\mathrm{Au}$ and $\mathrm{Ge}$ depositions were preformed under the operating parameters listed in Table 9.

One of two procedures were used to bond the DETFs and spacers together: (1) single unit assembly or (2) wafer scale assembly. These were the same two approaches used with the polyimide adhesive (section 5.1). The thin nature of the solder bond required intimate contact between the DETF and the Au-Ge film on the spacer. Therefore, the assembly fixturing contained springloaded pins which applied a small amount of pressure to each to the bond areas between the spacers and the DETFs. Fixturing for both the single and wafer scale assembly techniques had the spring-loaded pins. 
The reflow of the Au-Ge solder was conducted in a quartz tube furnace under a vacuum of $1 \times 10^{-7}$ torr. Shown in Figure 102 is a diagram of the heating cycle used during the reflow step.

An extensive examination of the joints made of the first several QDA assemblies in order to qualify the process. The $2.0 \mu \mathrm{m}$ solder layer thickness was the chosen value; however, some units were made with $5.0 \mu \mathrm{m}$ thick bonds. For those isolated cases in which the substrates failed to bond, the cause was typically an absence of intimate contact between the two surfaces.

\subsubsection{Summary.}

The Au-Ge thin film solder bond process was developed for attaching the single crystal quartz components of the QDA. The $2.0 \mu \mathrm{m}$ thick solder film was selected; the solder joint provided more than adequate strength, even after thermal fatigue testing. The fabrication and performance benefits from the thin, uniform bond joints; the ease of deposition of the solder to the appropriate area; and the strong adhesive strengths were fully realized. Use of the Au-Ge bond was studied only on the metallized quartz spacers. Use of the quartz spacer on the free end of the cantilever necessitated the addition of extra weight in order to obtain the

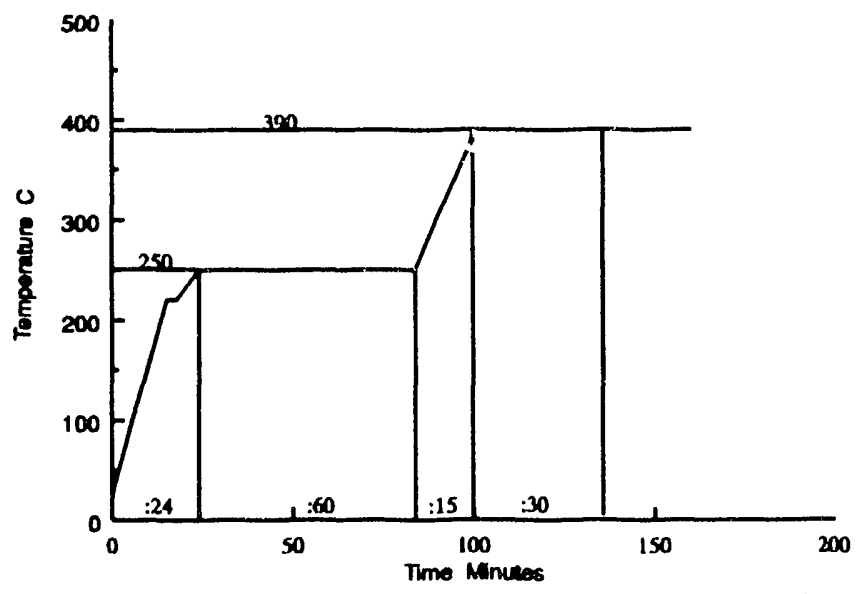

Figure 102 Heating cycle used to reflow the $\mathrm{Au}$ Ge solder in the assembly of the QDA. desired sensitivity to acceleration. Replacement of the quartz spacer with that constructed of beryllium copper would eliminate the need for the extra weight. It was shown that the Au-Ge solder was capable of wetting beryllium copper in vacuum without the need of a flux. Therefore, the solder bond technique would have worked equally well with the beryllium copper, provided that the beryllium copper spacer and a surface planarity and finish similar to the polished quartz. 


\subsection{Package Assembly.}

After assembly of the QDA sensor, the sensor was mounted inside a ceramic package and the package sealed. Subsequently, a tuning procedure was performed to adjust the frequency of each of the DETFs.

Shown in Figure 103 is a diagram of the ceramic package used in a majority of the development builds of the QDA. Figure 104 shows a frame developed late in the program. The package frame was constructed of multiple layers of alumina (per ASTM-D-2442, Type II) and manufactured by Kyocera $^{\mathrm{TM}}$. The metallized surfaces were tungsten or moly-manganese on the ceramic followed by nickel and finally an $\mathrm{Au}$ film.

Prior to installing the QDA into the package, $50 \mu \mathrm{m}$ diameter $\mathrm{Au}$ wires were bonded to the electrode pads of the DETF's using a thermal compression ball bonder. The other ends of the wires were later bonded to the electrical pick-ups on the package after the QDA had been attached to the package. The QDA was mounted to the frame using a polyimide adhesive (Abelbond 71-2, Abelstik Laboratories, Gardena, CA). The curing cycle appeared in Figure 66. At the same time that the

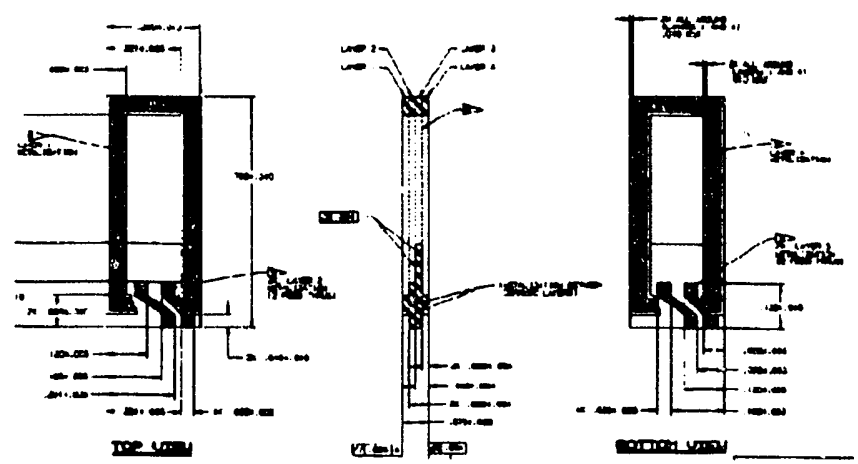

Figure 103 Early version of the custom ceramic package used to contain the QDA.
QDA was being bonded to the package, those accelerometers which used the quartz spacer at the free end had Au proof masses attached to the spacer using the same polyimide adhesive. After the QDA was fastened to the ceramic frame, the free ends of the $\mathrm{Au}$ wires were bonded to the electrode pick-ups on the inside of the package frame.

The final step of the packaging procedure was to enclose the ceramic frame. This was done by solder bonding two single crystal sapphire lids to either side of ceramic frame. Along the outside edge of one side of each sapphire lia, a tungsten or $\mathrm{Mo}-\mathrm{Mn} / \mathrm{Ni} / \mathrm{Au}$ metallization was introduceci to provide a solderable surface. The package was hermetically sealed using a $50 \mu \mathrm{m}$ thick $80 \mathrm{Au}-\mathrm{Sn}$ solder preform (melting point, $280^{\circ} \mathrm{C}$ ) located between the solderable surfaces of the frame and lid. The assembly procedure consisted of stacking the frame, solder preforms, and lids on top of oneanother. Next, a spring clip was placed over the stack so as to keep the parts from shifting out of alignment and aid in the filling of the joints by the solder. The assembly was sealed under vacuum in a quartz tube furnace. The heating cycle appears in Figure 100.

\subsection{Frequency Tuning}

The design specification of the QDA called for a frequency difference of $1000 \mathrm{~Hz}$ between the two DETF's. This precise difference could not be realized from the as-manufactured parts due to
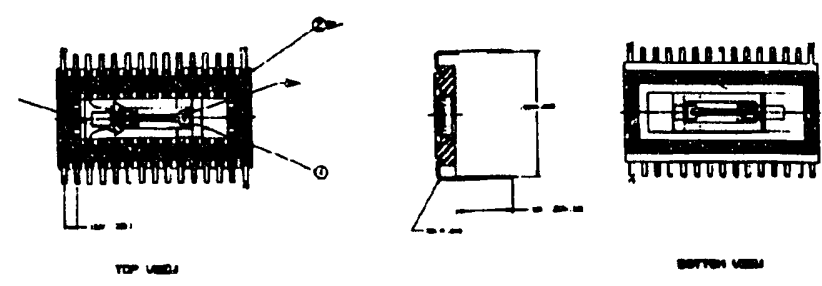

Figure 104 Revised version of the ceramic package used late in the program. 


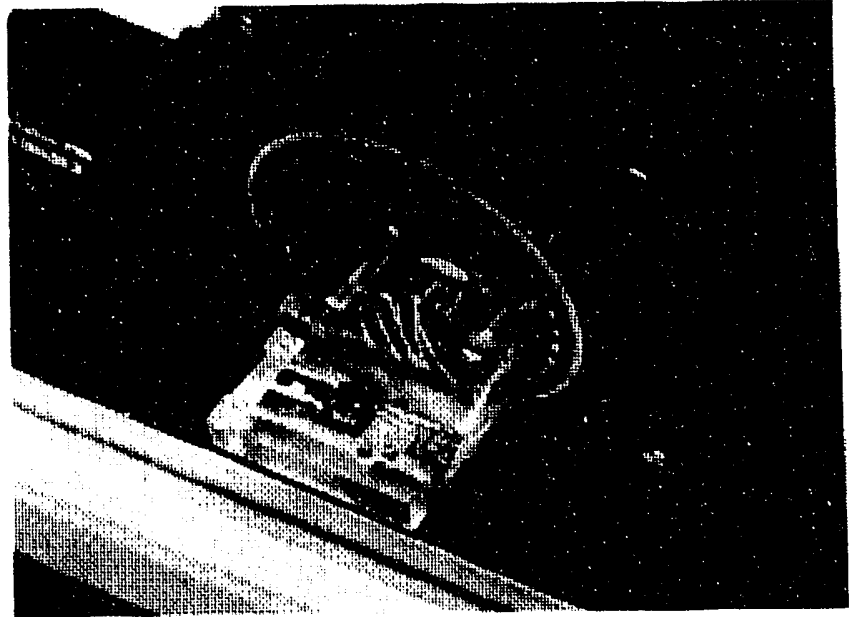

Figure 105 Photograph of the QDA package in place on the precision stage.

variations in the tuning fork geometry generated during their fabrication as well as because of misalignment which occurred during assembly and packaging of the QDA. In order to regain the 1000 $\mathrm{Hz}$ frequency difference, a technique was developed by which the resonant frequency of each tuning fork could be altered. This task was performed by first supplying extra mass to the tuning fork tines by Au plating tuning pads on the surface of the electrode metallization (section 4.5.6). The Au was then removed from the tines by striking each pad with a laser beam pulse. The laser pulse heated a spot on the pad, causing the Au to be evaporated. The loss of mass from the tine increased its resonant frequency. It was necessary to remove $\mathrm{Au}$ from both tines of the tuning fork in order not to degrade the $\mathbf{Q}$ of the device. The single crystal sapphire lids allowed passage of the laser beam to the tuning forks with a minimum loss and distortion to the beam.

The laser tuning apparatus was comprised of a U.S. Laser resistor trimmer. The Nd-YAG laser source operated at a wavelength of $1.06 \mu \mathrm{m}$. The operating parameters used on the QDA's were a spot size of $7 \mu \mathrm{m}$, a pulse duration of $0.1 \mu \mathrm{s}$ (the pulses being initiated manually); and an energy density of

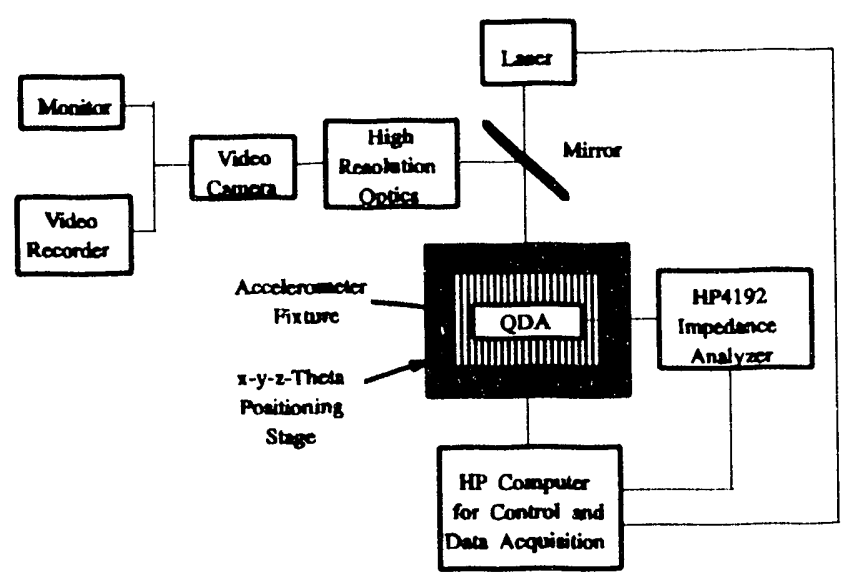

Figure 106 Schematic of laser tuning apparatus

approximately $9 \times 10^{7} \mathrm{~J} / \mathrm{m}^{2}$. A video camera was introduced in line with the optical axis of the laser beam, thus allowing for a visual determination of the position of the beam on the Au pad.

In the tuning procedure, the QDA package was secured to a movable precision stage (Figure 105). The stage movement was driven by a set of stepper motors. The frequency of the each tuning fork was monitored during the Au removal by electrical connections to an impedance analyzer (Figure 106). Shown in Figure 107 is a plot of frequency change introduced into the tuning fork as a function of the number of pulses. From the slope of the plot, the specific frequency change per pulse was $0.33 \mathrm{~Hz}$.

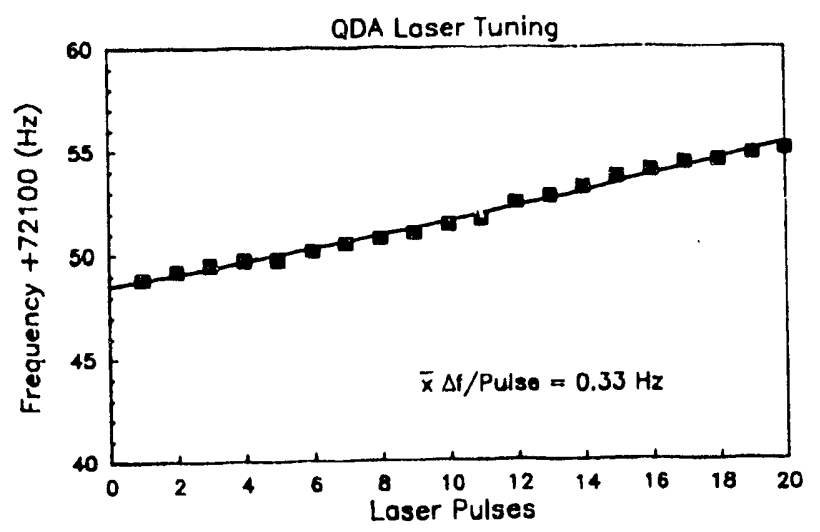

Figure 107 Plot of the tuning fork frequency as a function of the trimming pulse. 
The theoretical maximum tuning range offered by the amount of $\mathrm{Au}$ deposited on the tines was $1000 \mathrm{~Hz}$. However, the actual frequency span realized by removing the Au completely from the tines of one tuning fork (approximately 250 pulses) was $80 \mathrm{~Hz}$. This value provided feedback to the manufacturing control required for the frequency of the DETF's derived from the photolithographic processing steps. 


\section{Testing}

\subsection{Slew Testing}

Slew testing consists of measuring the DETF resonant and electrical characteristics over temperature. A schematic of the computer controlled slew tester is shown in Appendix A. The primary purpose of slew testing is to evaluate the frequency-temperature dependence of the individual DETF before and after assembly into the sensor cantilever configuration. This DETF characteristic in the cantilever assembly determines the ultimate temperature behavior of the sensor.

The secondary purpose is to determine the values of the DETF electrical parameters over temperature. These values affect the design of the oscillator circuit and the frequency stability of the DETF and cantilever assembly due to electrical noise.

Figure 108 shows an electrical model [47] for a quartz resonator. The model consists of an inductance $L_{m}$, capacitance $C_{m}$, and resistance $R_{m}$, which can be derived from the mechanical motion of the DETF; in addition, the static capacitance $\left(\mathrm{C}_{0}\right)$ is determined by the geometry of the tines and metal electrical contacts. The quality factor $(Q)$ of the DETF is also of interest and can be related to the other circuit parameters by $\mathrm{Q}=2 \pi \mathrm{fL}_{\mathrm{m}} / \mathrm{R}_{\mathrm{m}}$ where $f$ is the measured resonant frequency of the

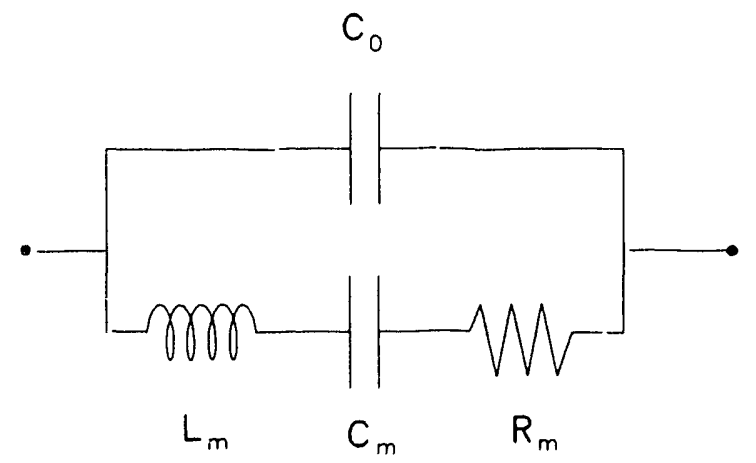

Figure 108 Electrical model for a quartz resionator.

\section{DETF.}

Figure 109 shows these electrical parameters plotted vs. temperature for two DETFs before assembly into a cantilever configuration. The parameters for both DETFs are quite similar and are fairly typical of high quality DETFs in vacuum. The parameter $R_{m}$ and $Q$ are inversely related. $R_{m}$ is related to mechanical losses within the crystal or losses through mounting of the DETF. The metallization pattern (drive electrodes) which drives the DETF also affects the motional resistance through the amount of energy which may be coupled into the crystal. An incorrect electrode connection of the electrical contacts in an early batch of DETFs resulted in an inactive section of the drive electrodes and caused a factor of four increase in $\mathbf{R}_{\mathrm{m}}$. When this problem was corrected, we observed a dramatic improvement in DETF characteristics. One direct effect observed was the ability of the electronic oscillator circuitry to more quickly start the DETF motion and maintain oscillation.

To characterize the frequency-temperature dependence of the cantilever assembly, the values of $\Delta \mathrm{f}_{0}$ are calculated from the individual DETF
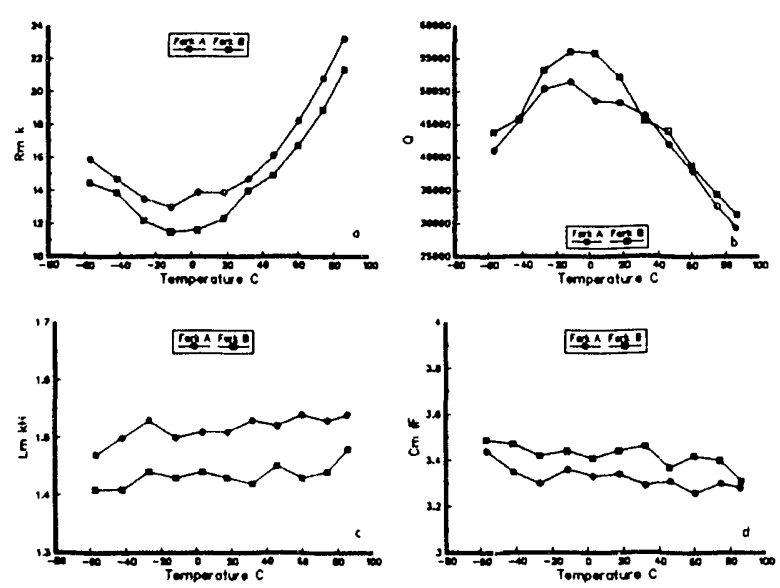

Figure 109 Electrical parameters vs. temperature for a typical DETF in vacuum. a) $R_{m}$, b) $\left.Q, c\right) L_{m}$, d) $C_{m}$. 
frequencies measured at several temperatures between $-60 \mathrm{C}$ and $90 \mathrm{C}$. These frequencies are then fit to a parabola:

$$
\Delta f_{0}=C_{0}+C_{1} T+C_{2} T^{2}
$$

The average temperature coefficient of frequency is then

$$
\frac{d \Delta f_{0}}{d T_{\text {avg }}}=C_{1}+2 C_{2} T_{\text {avg }}
$$

where $T_{\text {avg }}$ is the average temperature within the range of interest. The correspondence between the parabolic parameters used above and those from the DETF model given in eq. (20) and eq. (21) are shown in Table 19.

We find it useful to have a single parameter as a figure of merit for the frequency-temperature dependence of the cantilever assembly. Using the expression for $\mathrm{C}_{2}$ for the cantilever from Table 19 the second term in eq. (29) becomes $2 k\left(f_{\mathrm{TOa}}\right.$ - $\left.f_{\text {TOb }}\right) T_{\text {wz }}$ which evaluates to approximately $1.6 \mathrm{mHz} / \mathrm{K}$ for typical DETF values. The fork-tofork variation in temperature coefficient then is almost entirely determined by the experimentally found value of $\mathrm{C}_{1}$ for each fork; this parameter has been chosen the figure of merit. Furthermore, referring to Table 19 for the expression for $C_{1}$ from the cantilever model, because $f_{\text {TOa }}$ and $f_{\text {TOb }}$ are approximately equal, the variation in $\mathrm{C}_{1}$ is dominated by the variation in turnover temperatures $\left(\mathrm{T}_{0 \mathrm{a}}\right.$ and $\left.\mathrm{T}_{0 b}\right)$ of the two individual DETFs which comprise the cantilever.

This figure of merit, $\mathrm{C}_{1}$, is applied to evaluate the effect of assembly on the temperature behavior of the cantilever. Figure 110 shows the individual DETF frequencies measured independently before planned assembly into a cantilever. The characteristic temperature sensitivity $\left(C_{1}\right)$ is $4.6 \mathrm{mHz} / \mathrm{C}$. The turnover temperatures of the two DETFs are $18.1 \mathrm{C}$ and $18.4 \mathrm{C}$. The calculated output frequency found from subtracting the two measured DETF frequencies is shown in the right hand side of Figure 110. The estimated error in

\begin{tabular}{|c|c|c|c|c|}
\hline Parabolic Model & DETF Model & $\begin{array}{l}\text { Typical } \\
\text { Values }\end{array}$ & Cantilever Model & $\begin{array}{c}\text { Typica } \\
1 \\
\text { Values } \\
\end{array}$ \\
\hline$-\mathrm{C}_{1} / 2 \mathrm{C}_{2}$ & $\mathrm{~T}_{0 a}$ & $20 \mathrm{C}$ & $\mathrm{T}_{0 c}$ & $20 \mathrm{C}$ \\
\hline $\mathrm{C}_{0}-\mathrm{C}_{1}{ }^{2} / 2 \mathrm{C}_{2}$ & $\mathbf{f}_{\mathrm{T}}$ & $70 \mathrm{KHz}$ & $\mathbf{f}_{\mathrm{TOc}}$ & $1 \mathrm{KHz}$ \\
\hline $4 C_{2}{ }^{2} /\left(4 C_{2} C_{1}{ }^{2}-C_{1}{ }^{2}\right)$ & $\mathbf{k}$ & $-3.3 \times 10^{-8}$ & $\mathbf{k}$ & $\begin{array}{c}\text { variabl } \\
\mathrm{e} \\
\end{array}$ \\
\hline $\mathrm{C}_{0}$ & $\mathrm{f}_{\mathrm{TOa}}\left(1+\mathrm{kT}_{\mathrm{Oa}}{ }^{2}\right)$ & & $\begin{array}{c}\mathrm{f}_{\mathrm{TOa}}-\mathrm{f}_{\mathrm{TOb}}+k\left(\mathrm{f}_{\mathrm{TOa}^{2}}{ }^{2}-\right. \\
\mathrm{f}_{\left.\mathrm{TOb}_{\mathrm{b}} \mathrm{T}_{0 \mathrm{~b}}{ }^{2}\right)}\end{array}$ & \\
\hline $\mathrm{C}_{1}$ & $-2 k f_{T_{0 a}} T_{0 a}$ & & $-2 k\left(f_{T 0 a} T_{0 a}-f_{T 0 b} T_{0 b}\right)$ & \\
\hline $\mathrm{C}_{2}$ & $\mathrm{kf}_{\mathrm{TOa}}$ & & $\mathbf{k}\left(\mathrm{f}_{\mathrm{TO}_{\mathrm{a}}}-\mathrm{f}_{\mathrm{TOb}}\right)$ & \\
\hline
\end{tabular}

Table 19 Correspondence between simple parabolic parameters and fork model parameters. 

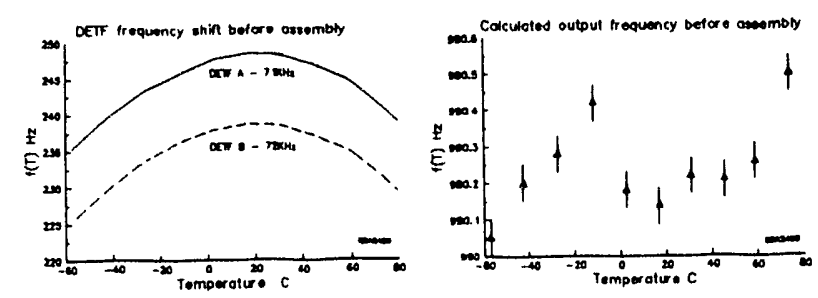

Figure 110 Typical pre-assembly characteristics of the individual DETF and the calculated output frequency determined by subtracting the individual DETF frequencies.

measuring the frequency is $\pm 0.05 \mathrm{~Hz}$. The effect of subsequent DETF processing and assembly into cantilevers is shown in Figure 111. Two effects are noticeable; the nominal frequencies of the DETFs shift by $30 \mathrm{~Hz}$ to $50 \mathrm{~Hz}$ and the turnover temperatures of each DETF shifts. The first effect will be discussed in the processing section of this report. The shift in turnover temperatures is more important in causing temperature sensitivity and is the subject of slew testing measurements.

Figure 112 shows the distribution of turnover temperatures for individual DETFs measured before assembly into cantilevers. These data indicate a fairly close match in DETF parameters.

Figure 113 shows the temperature coefficient $C_{1}$ plotted vs. the difference in turnover temperatures for the two DETFs. Data from approximately 200 cantilever assemblies are shown here. Polyimide adhesive was used in the preponderance of the assemblies. A linear relationship is apparent with
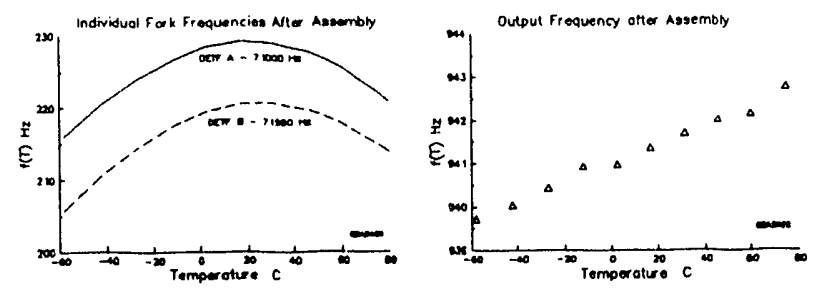

Figure 111 Post-assembly characteristics of the individual DETF and the calculated output frequency.
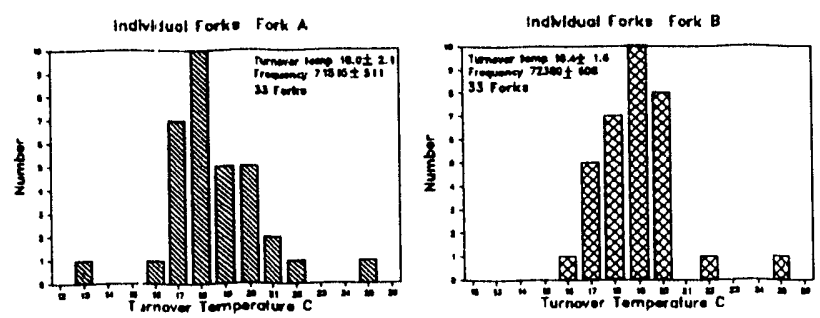

Figure 11.2 Histogram of turnover temperatures for individual forks before assembly into a cantilever beam configursition.

the slope of the line equal to $-6 \mathrm{mHz} / \mathrm{C} / \mathrm{C}$. The departure from linearity in these data is mainly due to variations in the shape of the frequencytemperature curve caused by spurious frequency modes of interference. This frequency interference results in poor adherence to a parabola and a spuricus value for $C_{1}$.

Thes: data also indicate the magnitude of the problem associated with producing a sensor assembly which maintains the individual DETF characteristics. A variation in $\mathrm{C}_{1}$ from $-50 \mathrm{mHz} / \mathrm{C}$ to $+-50 \mathrm{mHz} / \mathrm{C}$ is characteristic of the population of

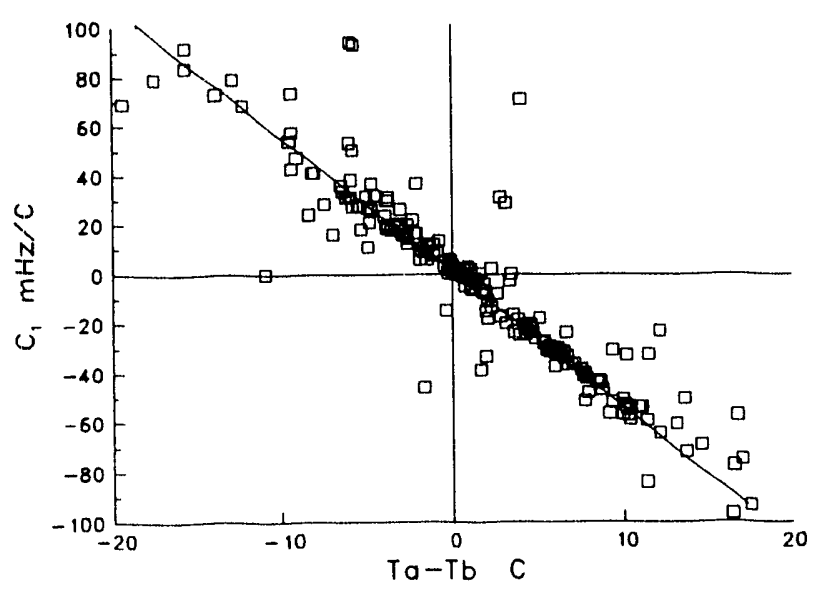

Figure 113 Temperature coefficient of the cantilever output frequency vs. difference in turnover temperature for the DETFs comprising the assembly. 
cantilever assemblies in Figure 113. The object of much of the development effort for this device was to reduce this variation by more than an order of magnitude. It was hypothesized early in the program that the cause of shifts in turnover temperature of the individual DETF in the cantilever structure was due to residual stresses in the structure. There are several readily apparent sources for such strains. These are:

1. Differential thermal expansion of the various parts of the structure, i.e. quartz [48], metallic spacers [49], polyimide bonding material [50].

2. Misalignments in the structure due to variations in assembly fixtures and the inability to maintain positioning of the structural components within the fixture.

3. Variations in the dimensions of the components of the structure, e.g. DETF tine width and thickness, spacer thicknesses, bond

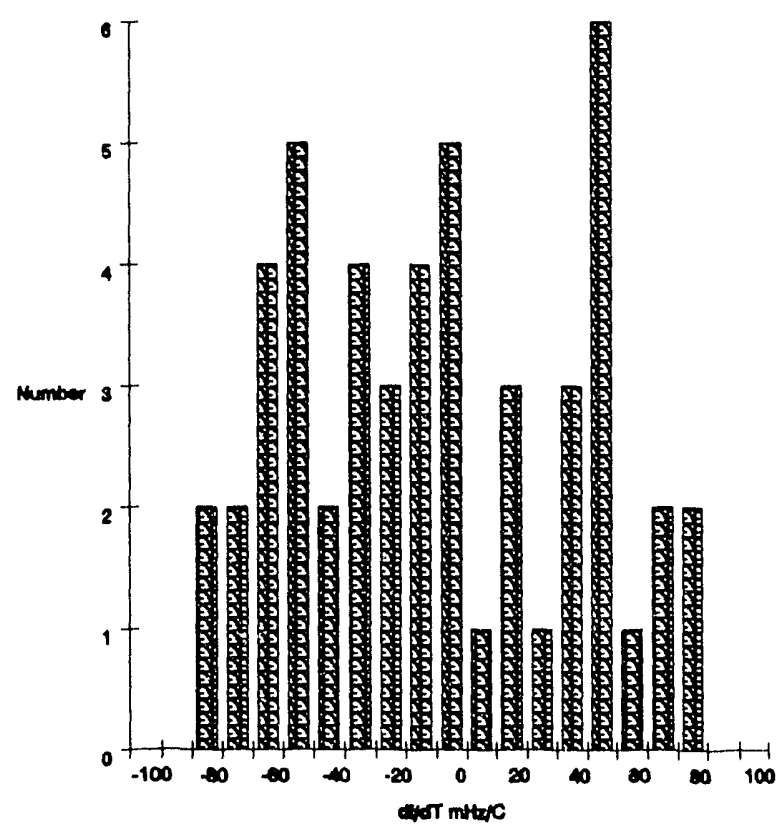

Figure 114 Temperature coefficient results for Fixtures 1710-1711 10x1 etched nest array. thicknesses.

These considerations led to a variety of techniques which were applied to improve the temperature coefficient. These were:

1. Finite element modeling to determine the sensitivity of the residual stress to the variations of the above mentioned parameters.

2. Various fixturing techniques: individually fabricated electrical discharge machined (EDM) assembly fixtures, batch fabrication in chemically etched metal fixtures, wafer scale fabrication from as produced etched quartz wafers of DETFs.

3. Fabrication of spacers from a variety of materials such as beryllium-copper, gold, and quartz.

4. Use of several bonding techniques; primarily polyimide adhesive with its

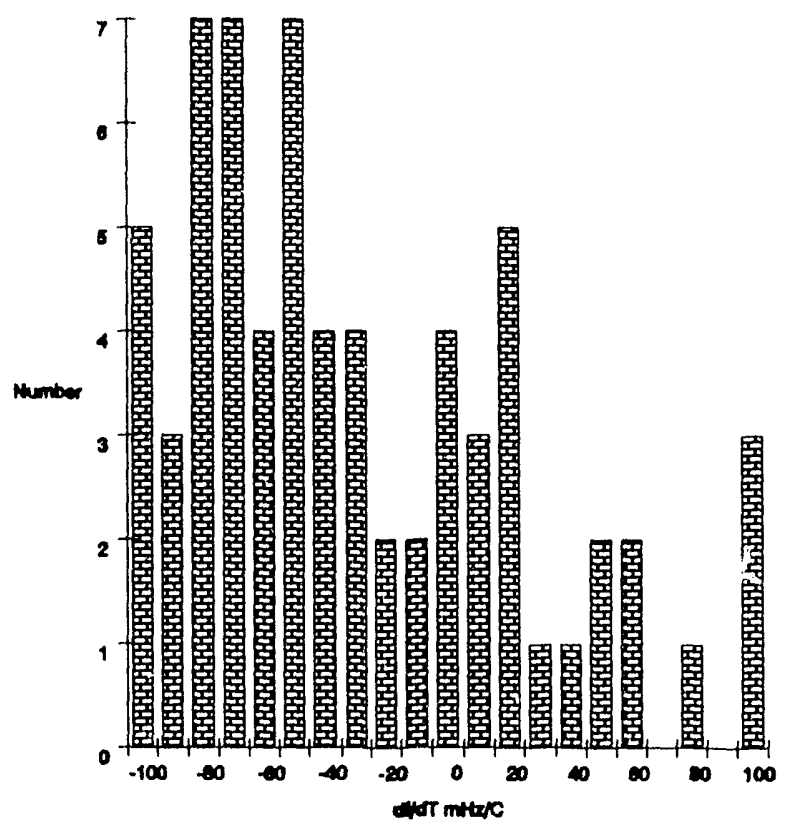

Figure 115 Temperature coefficient histogram for Fixture $17095 \times 2$ etched nest array. 


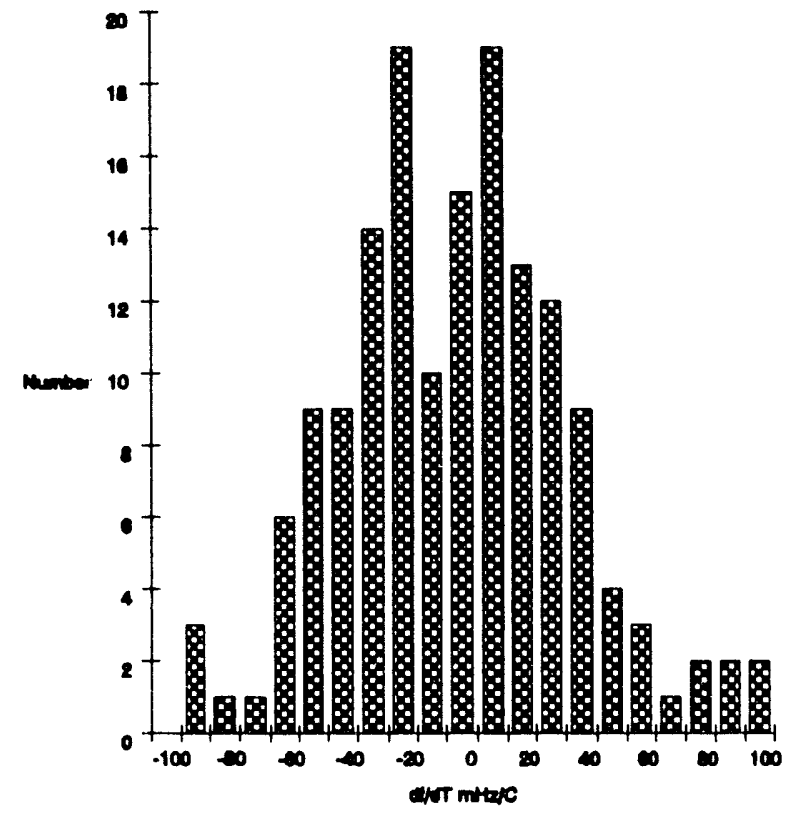

Figure 116 Temperature coefficient histogram for Fixture 1724 - all beryllium copper.

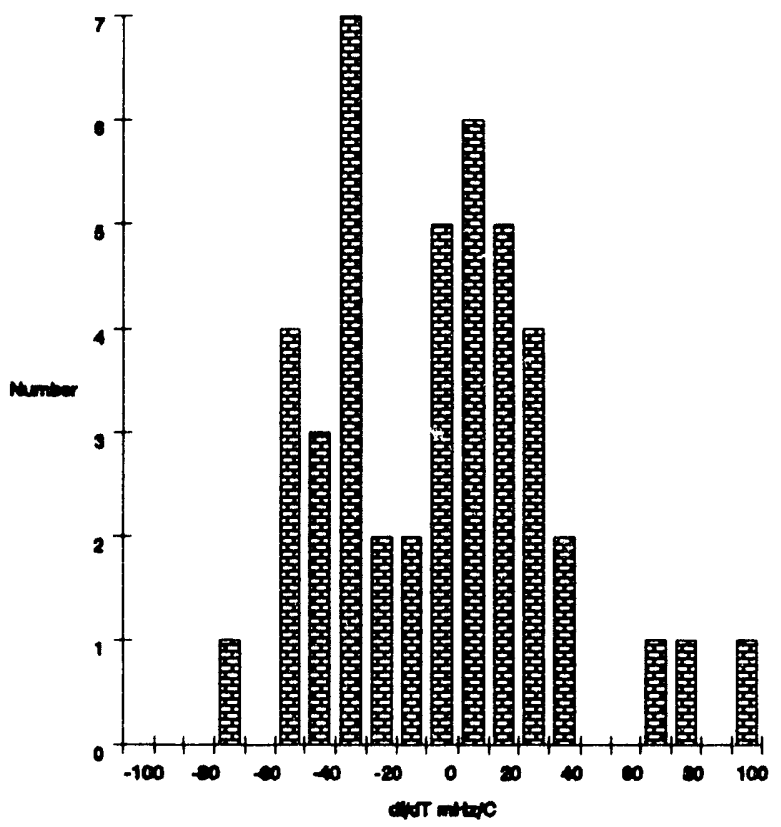

Figure 117 Temperature coefficient results for Fixtures 1725-1730 - EDM fixtures. known highly mismatched coefficient of expansion, gold-germanium eutectic bonding with a much better thermal coefficient match to quartz and field assisted bonding using intermediate layers of silicon and Pyrex to achieve the bond in an electric field.

\subsection{Assembly Method Slew Test Results}

The first assembly techniques used metal fixtures described in Section 5.1. Bonding of the DETF, proof mass and spacer components was accomplished using polyimide adhesive. The first two of these fixtures were similar to the fixture in Section 5.1 except the first fixture used a $10 \times 1$ stainless steel array nest array while the second fixture used a $5 \times 2$ array. Figure 114 and Figure 115 show the histograms of the $\mathrm{C}_{1}$ parameter described above for the population of QDAs built using these fixtures. A summary of all temperature

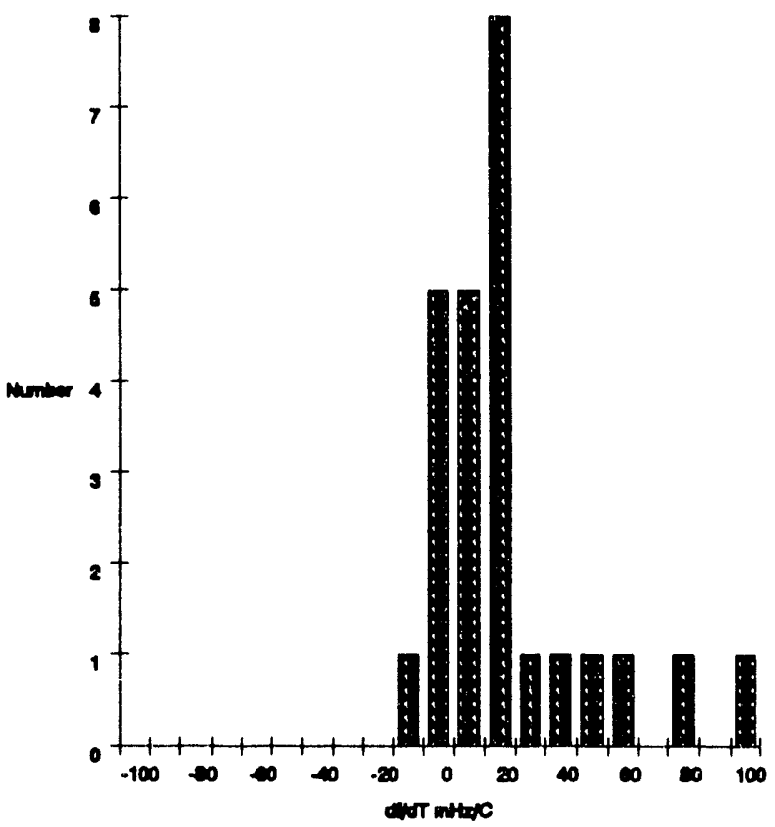

Figure 118 Temperature coefficient results for Fixture 1732 - wafer scale assembly. 
coefficient results for all the assembly techniques used is shown in Table 20. The temperature behavior of these two populations showed a significant difference in the mean value for $C_{1}$ but the variance of these two populations was very large and virtually identical.

The hypothesis developed from these results was that the different thermal expansions of the various materials which made up the nest was leading to misalignments in the assembled cantilevers. This led us to try to improve the temperature dependence by building an all beryllium copper nest. Polyimide adhesive was continued to be used as the bonding material. The temperature results from cantilevers assemblied using this technique are shown in Figure 116. This assembly method resulted in a small decrease in $\mathrm{C}_{1}$ and the variance but was not a significant improvement.

Yet another attempt was made to improve the mechanical alignment of the DETFs by using an

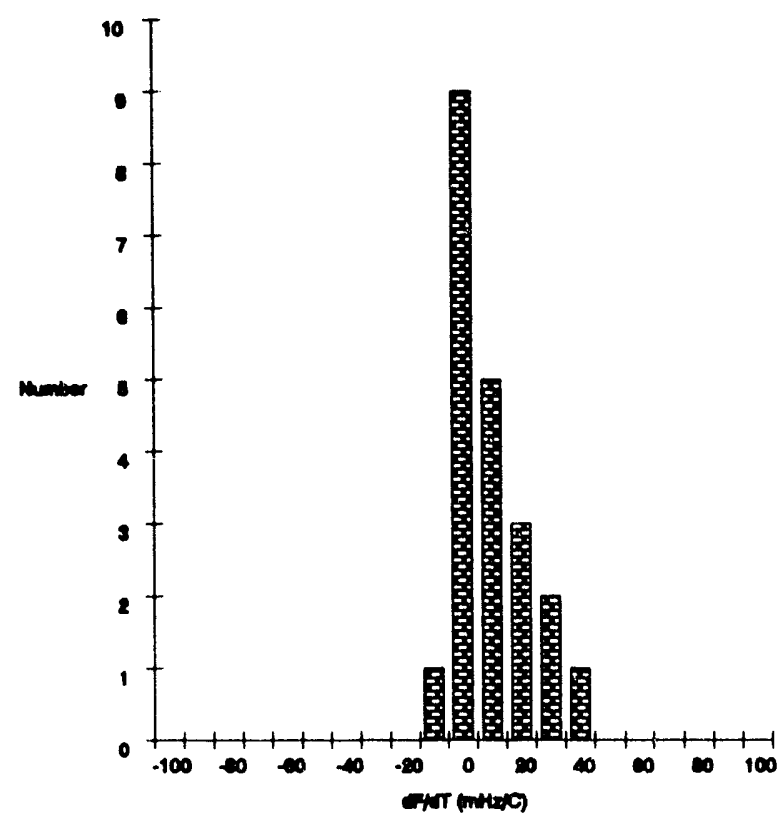

Figure 119 Temperature coefficient for eutectic bonded wafer scale assembled cantilevers.

Table 20 Temperature coefficient results for various assembly techniques used for QDA assembly.

\begin{tabular}{||c|c|c|c|l||}
\hline Fixture & $\begin{array}{c}\text { Average } \\
\mathbf{C}_{\mathbf{1}} \\
\mathbf{m H z} / \mathbf{C}\end{array}$ & $\begin{array}{c}\text { Sigma } \\
\mathbf{C}_{\mathbf{1}} \\
\mathbf{m H z} / \mathbf{C}\end{array}$ & \multicolumn{1}{|c|}{$\begin{array}{c}\mathbf{N} \\
\text { Samples }\end{array}$} & Description \\
\hline \hline 1709 & -30 & 47 & 64 & $5 \times 2$ etched nest \\
\hline $1710-1711$ & -10 & 46 & 50 & $10 \times 1$ etched nest \\
\hline 1724 & -7 & 37 & 154 & BeCu nest \\
\hline $1725-1730$ & -6 & 36 & 44 & EDM stainless steel \\
\hline $1732-1733$ & 18 & 26 & 25 & $\begin{array}{l}\text { wafer scale + Au proof } \\
\text { mass }\end{array}$ \\
\hline 1736 & 5 & 12 & 21 & $\begin{array}{l}\text { eutectic bond } \\
\text { quartz proof mass }\end{array}$ \\
\hline
\end{tabular}


assembly fixture fabricated from stainless steel by EDM (see Section 5.1). This fixture allowed only one cantilever to be assemblied in each fixture. Assembly yields were improved using this technique because the integrity of all the elements of the cantilever could be visually checked before curing the adhesive. However, there again was no significant improvement in the variance of the temperature coefficients. The temperature coefficient of cantilevers fabricated using this method is shown in Figure 117.

An assembly method was explored which was characterized as "wafer scale assembly". This method used two separate wafers of DETFs; one containing only $70 \mathrm{KHz}$ DETF and the second containing only $71 \mathrm{KHz}$ DETF. A third wafer of quartz spacers was sandwiched between the DETF wafers. This method allowed batches of 12-20 cantilevers per assembly. The adhesive used was polyimide and was applied by an automatic applicator. The major perceived advantage of this technique was the ability to fabricate large quantities of cantilevers easily. A disadvantage, however, is that the DETFs which comprise the cantilever cannot be matched to yield the optimum difference frequency. This requires that the DETFs frequencies within the wafer are more tightly controlled or that the difference frequency may be tuned after assembly. The results for this method are shown in Figure 118.

The last assembly method used was wafer scale assembly as described above but using a gold germanium eutectic as the bonding material. This method is described in detail in Section 5.2. The results of the temperature behavior of cantilevers assemblied by this technique is shown in Figure 119. This method was the most successful of the assembly methods used. The smallest average $C_{1}$ and variance was obtained. The major disadvantage of this method was that only small scale factor devices could be obtained with an all quartz cantilever assembly. The scale factor can be increased, however, by adding additional proof mass as a second assembly step. This in fact was done. A series of all quartz cantilevers was built with eutectic material in the critical bond area and polyimide was used to adhere an additional gold mass to the top of the quartz proof mass. 


\subsection{Tumble Testing}

The tumble test is used to determine the scale factor, bias frequency and misalignment of the completed accelerometer. A schematic of the tumble tester is shown in Appendix A. This test is conducted using the sensor connected to a set of test electronics. The test electronics consist of two oscillators and a mixer/filter. This assembly is mounted on a precision index head and rotated at $30^{\circ}$ increments from $0^{\circ}$ to $360^{\circ}$ and return to $0^{\circ}$. The frequency is measured at each of these positions. The output frequency of the accelerometer as a function of the index angle $\theta$ then follows the model equation shown below [6]:

$$
f(\theta)=S_{c} G_{A b q} \sin (\theta+\delta)+\Delta f_{0}
$$

where $\mathrm{G}_{\mathrm{Abq}}=9.792193 \mathrm{~m} / \mathrm{s}^{2}$, and $\delta$ is the misalignment angle between the axis of the indexhead and the accelerometer sensitive axis.

Five independent values for $\delta$ can be calculated from combinations of 20 values of the frequencyindex angle data collected. These $\delta$ values are averaged and used with the index angle to calculate the apparent acceleration shown in Figure 120. A least squares line fit is then used to obtain values

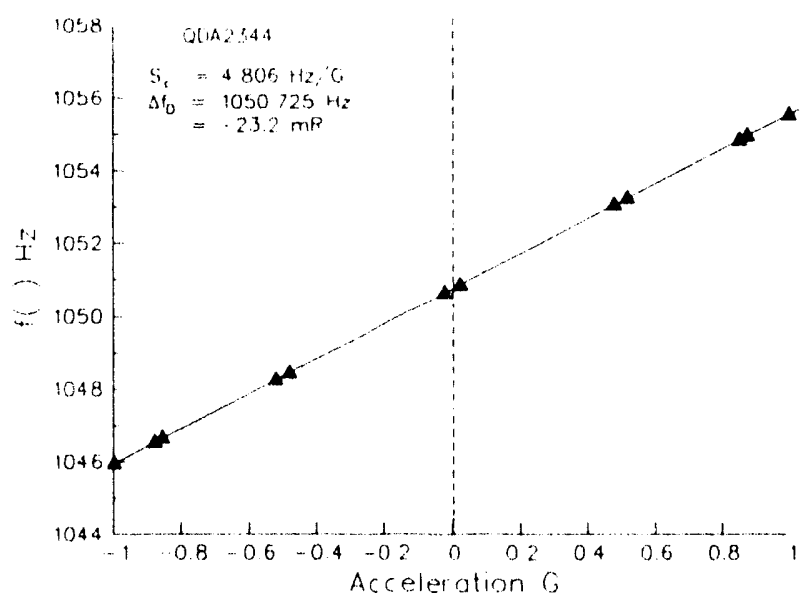

Figure 120 Output frequency change vs. corrected acceleration for QDA2344 at 62C.

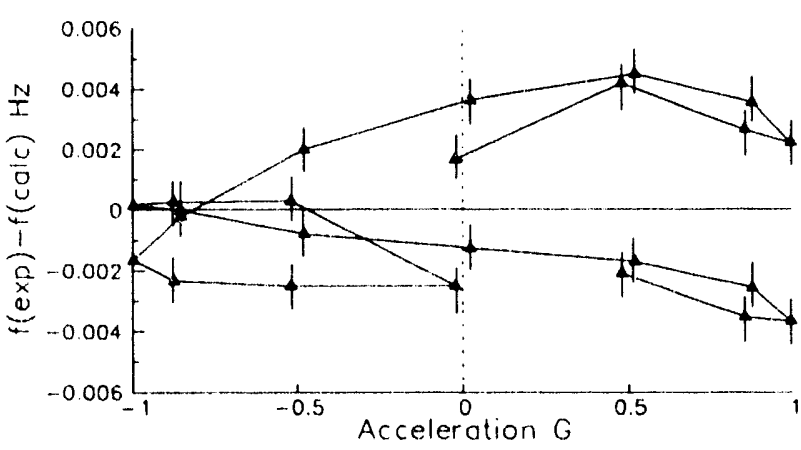

Figure 121 Residuals vs. acceleration for least squares fit to frequency data for QDA2344.

for $\Delta f_{0}$ and $S_{c}$.

Two measurements are taken at each of 12 different angles. However, because some angles would give nominally the same acceleration values if $\delta=0$, one would expect to see only 7 distinct points. The non-zero misalignment value of 0.0232 Radian, in this case, gives rise to the 12 distinct points seen in Figure 120. Repeated measurements at the same index angle at different times (and somewhat different temperatures) gives an estimate for frequency drift with either time or temperature.

The frequency is measured 100 times at each of the 24 angle values (12 out, 12 return) so that an estimate for the frequency measurement accuracy at each angle can be made $(\sigma=0.7 \mathrm{mHz}-1.0 \mathrm{mHz})$. Short term phase noise is the principle error source which determines the accuracy of this measurement.

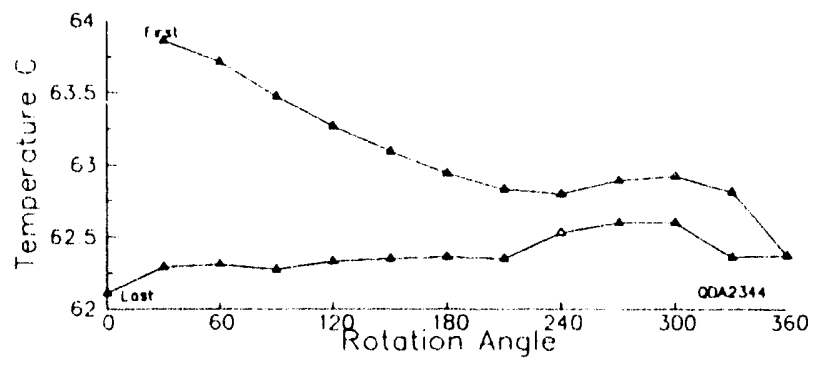

Figure 122 Temperature of QDA2344 vs. index head angle. 


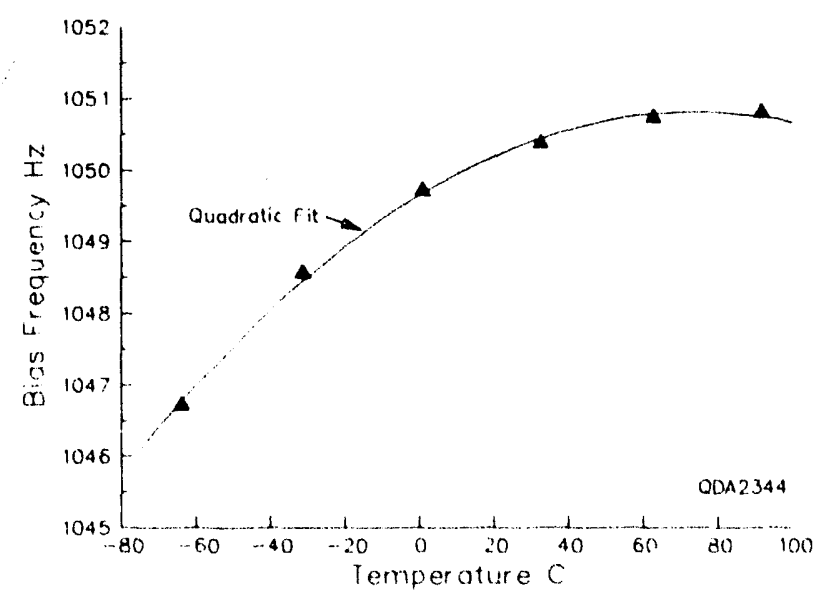

Figure 123 Bias frequency vs. temperature for QDA2344.

Figure 121 shows the residuals from the least squares fit to the frequency-acceleration data. The error bars indicate the magnitude of the frequency measurement error described above. There also appears to be a systematic error associated with either time or temperature change.

Figure 122 shows a possible cause for this systematic change. The temperature can be seen to slowly change from $64 \mathrm{C}$ to $62 \mathrm{C}$ over the 20 minute duration of the measurement cycle. This temperature change can be partly caused by the changing position of the index head in the temperature chamber or by a slow temperature equilibration from the previous measurement temperature of $90 \mathrm{C}$.

A complete tumble test consists of a set of measurements described above taken at six different temperatures $(90 \mathrm{C}, 60 \mathrm{C}, 30 \mathrm{C}, 0 \mathrm{C},-30 \mathrm{C},-60 \mathrm{C})$. These temperature data are then used to characterize bias frequency, scale factor, and misalignment behavior of the accelerometer. Figure 123 shows the bias frequency plotted versus temperature. A quadratic curve has been fit to the 6 temperature points. The coefficients of this quadratic fit are: $C_{0}=1049.64 \mathrm{~Hz}, C_{1}=$

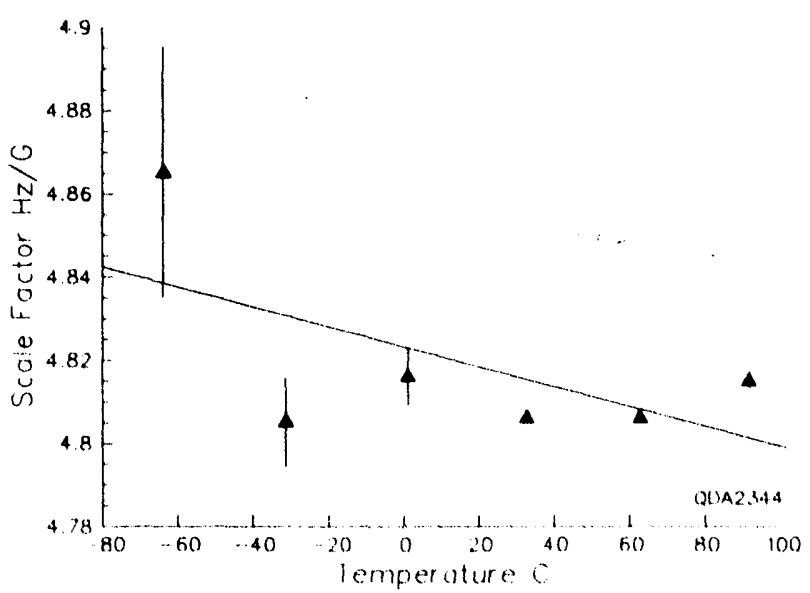

Figure 124 Scale factor vs. temperature for QDA2344.

$0.031 \mathrm{~Hz} / \mathrm{C}, \mathrm{C}_{2}=-0.00021 \mathrm{~Hz} / \mathrm{C}^{2}$. The average temperature coefficient found from a linear fit to these data is $\mathrm{C}_{1}=0.0255 \mathrm{~Hz} / \mathrm{C}$. The largest measurement error in the bias frequency is at low temperature and is $21 \mathrm{mHz}$. At room temperature and above this error is only $0.5 \mathrm{mHz}$ to $5 \mathrm{mHz}$.

Figure 124 shows the scale factor plotted for the same temperature measurements. A !inear fit to these data is shown in the plot indicating a substantial temperature dependence for the scale factor. This effect is clearly dominated by the large error in the low temperature measurement. The errors in the scale factor determination follow the same pattern as those for the bias frequency since both parameters are determined from the same set of measurements at each temperature.

Figure 125 shows the misalignment plotted vs temperature. Again the errors follow the same pattern as seen in the previous measurements for this QDA. This trend of large measurement errors at low temperature was observed for miny of the tumble test measurements made on other units. It appears to be related to the increased individual frequency measurement error at each individual index head point. 


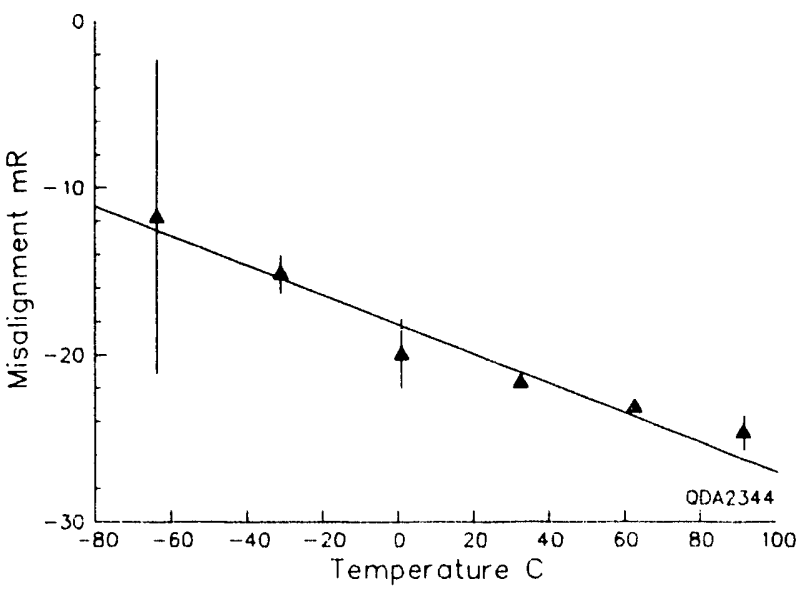

Figure 125 Misalignment vs. temperature for QDA2344.

It should be pointed out that the bias frequency determined from the tumble test measurement can be compared directly to the bias frequency calculated from slew test measurements of the two DETFs in the assembled cantilever. The difference between the measurements is that the slew test is made at a single orientation of the DETF (typically a zero $\mathrm{G}$ orientation) but this orientation is not as precisely known as the tumble orientation. Figure 126 shows the bias frequency resulting from the slew measurement together with the tumble measurement from Figure 123.

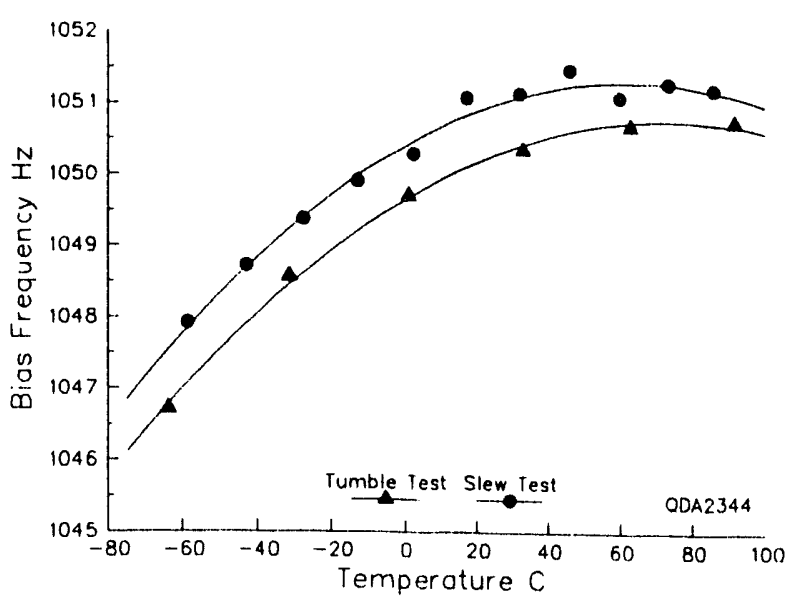

Figure 126 Comparison of bias frequency vs. temperature determined from slew and tumble tests. 


\subsection{Centrifuge Testing}

Centrifuge testing was conducted to determine the linearity of the QDA over a much wider acceleration range than was available with the tumble test. The centrifuge precision [51] was $10 \mathrm{ppm}$ to $100 \mathrm{ppm}$ over the range of $0-120 \mathrm{G}$. Room temperature tests were conducted for several QDAs and the results for one of these is shown in Figure 127. The deviations from a straight line least squares fit are several orders of magnitude to small to be observable on this graph.

In order to demonstrate the linearity of the QDA, the residuals are plotted in Figure 128. In the left hand figure, the residuals are found by fitting the frequency data to the apparent centripetal acceleration without allowing for known arm stretch. The change in arm length with acceleration [51] is $1.14 \times 10^{-6} / \mathrm{G}$. When this correction is made to the apparent acceleration values, the residuals decrease significantly from an average of $1.2 \mathrm{mHz}$ to $0.7 \mathrm{mHz}$. These values represent a non-linearity of less than $1 \times 10^{-5}$. Linear behavior is especially important in vibration environments to minimize vibration rectification, a process which is sensitive to the magnitude of the even power terms relating

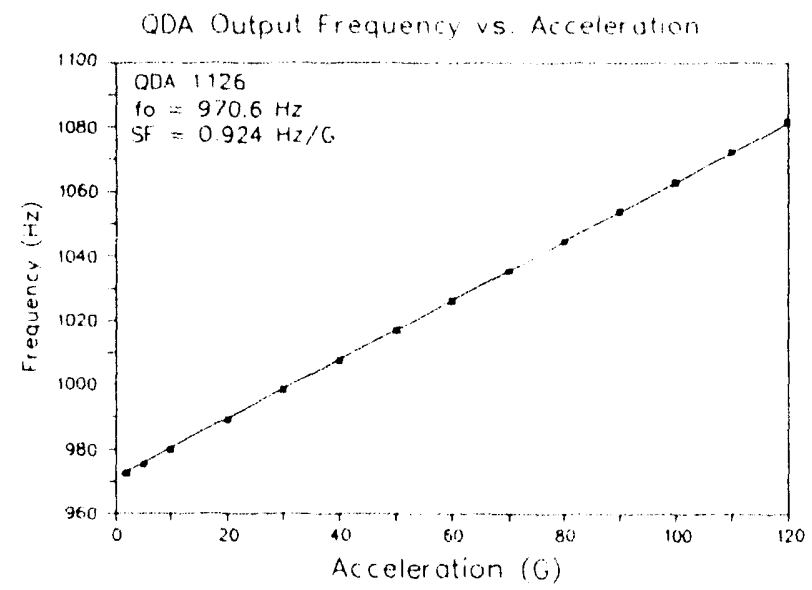

Figure 127 Centrifuge test of QDA1126 at room temperature. output to acceleration.

In addition to these measurements, nine accelerometers were measured to determine the cross-axis sensitivity up to $225 \mathrm{G}$ over a temperature range of $-50 \mathrm{C}$ to $70 \mathrm{C}$. A lower precision centrifuge $(0.1 \%)$ was used to make these measurements. Accelerometer output frequency measurements were made with the QDA in three different orientations.

The normal sensitive axis is designated the $\mathbf{x}$-axis, the cross axis in the plane of the tines perpendicular to the tine length is the $y$-axis and the axis parallel to the tine length is the $\mathrm{z}$-axis. A QDA was used with a scale factor of $1.06 \mathrm{~Hz} / \mathrm{G}$ and a nominal bias frequency of $1140 \mathrm{~Hz}$. Figure 129 shows the data for QDA1209 for the $y$-axis and z-axis measurements. The z-axis measurements were made with the accelerometer oriented so that the tuning forks would be put in tension from the centrifugal force of the proof mass on the tuning forks. The frequency change associated with this arrangement can be understood as due to any differences in geometries of the two forks which give rise to different rates of change in the expected individual tuning fork frequency change with acceleration. The $y$-axis sensitivity is less easily explained since one does not expect significant changes in the individual tuning fork frequencies under this load orientation. Because of common mode cancellation of this effect, an even smaller output (difference) frequency change would be expected.

The temperature behaviors of the bias frequencies and cross axis sensitivities are compared with similar data derived from tumble test measurements. Figure 130 compares the bias frequency and scale factor measurements for the various cross axes and sensitive axis centrifuge measurements with the tumble test data. These bias frequencies agree quite well considering the widely 

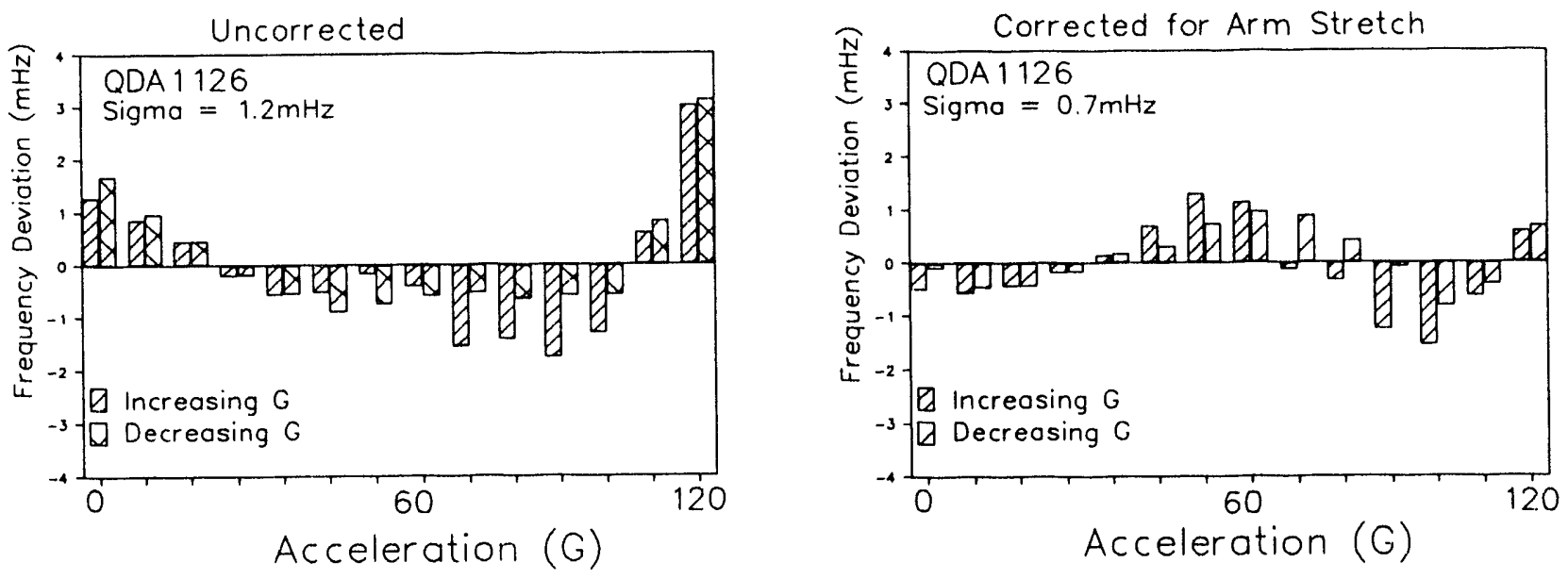

Figure 128 Frequency residuals vs. acceleration before and after centrifuge arm stretch correction.

varying conditions under which they were determined. In the centrifuge measurements they are the result of extrapolating from accelerations between $25 \mathrm{G}$ and $225 \mathrm{G}$ to $0 \mathrm{G}$. In the tumble test the bias frequency is found by measurements between $-1 \mathrm{G}$ and $+1 \mathrm{G}$. The scale factor values found from the centrifuge measurement are much more accurate because of the larger acceleration range over which they are measured. Because of the demonstrated highly linear behavior of the QDA, one would expect this to be the case. When

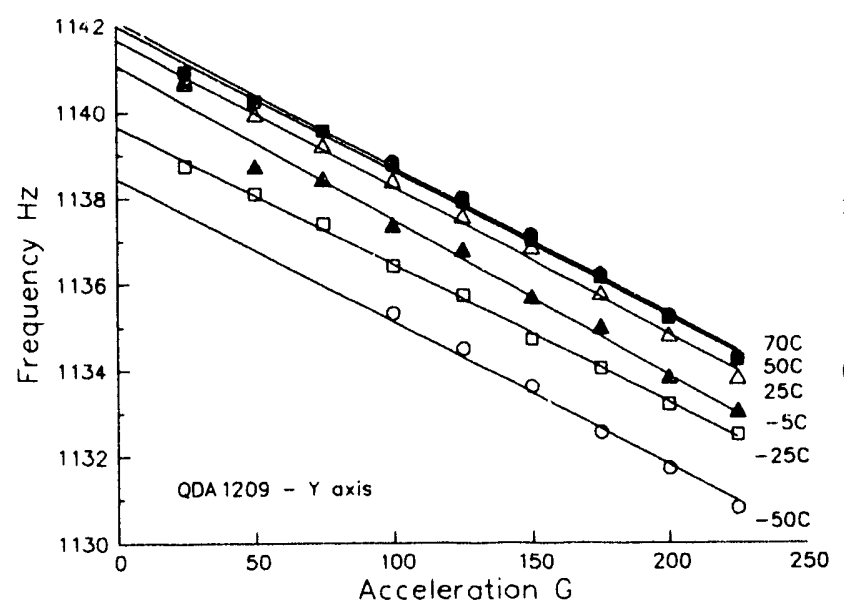

the magnitude of the errors in the tumble test are included in the comparison of the data as in Figure 130, one can see the good agreement between the two types of measurements. The agreement appears to be limited by the measurement technique rather than an inherent property of the QDA.

In Figure 131 the cross-axis sensitivity determined from the direct centrifuge measurement is compared with the apparent misalignment from the tumble

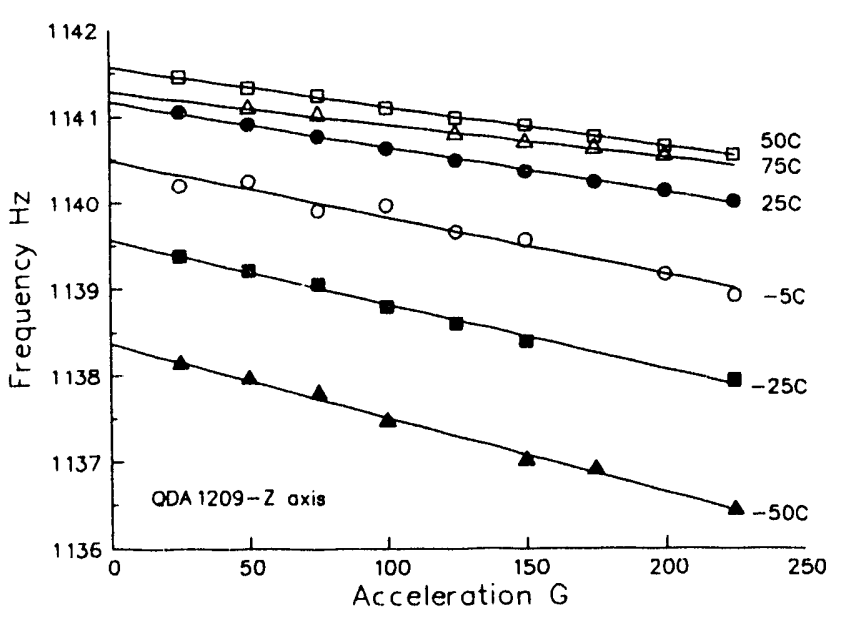

Figure 129 Cross axis sensitivity for the Y-axis and Z-axis for QDA1209. 

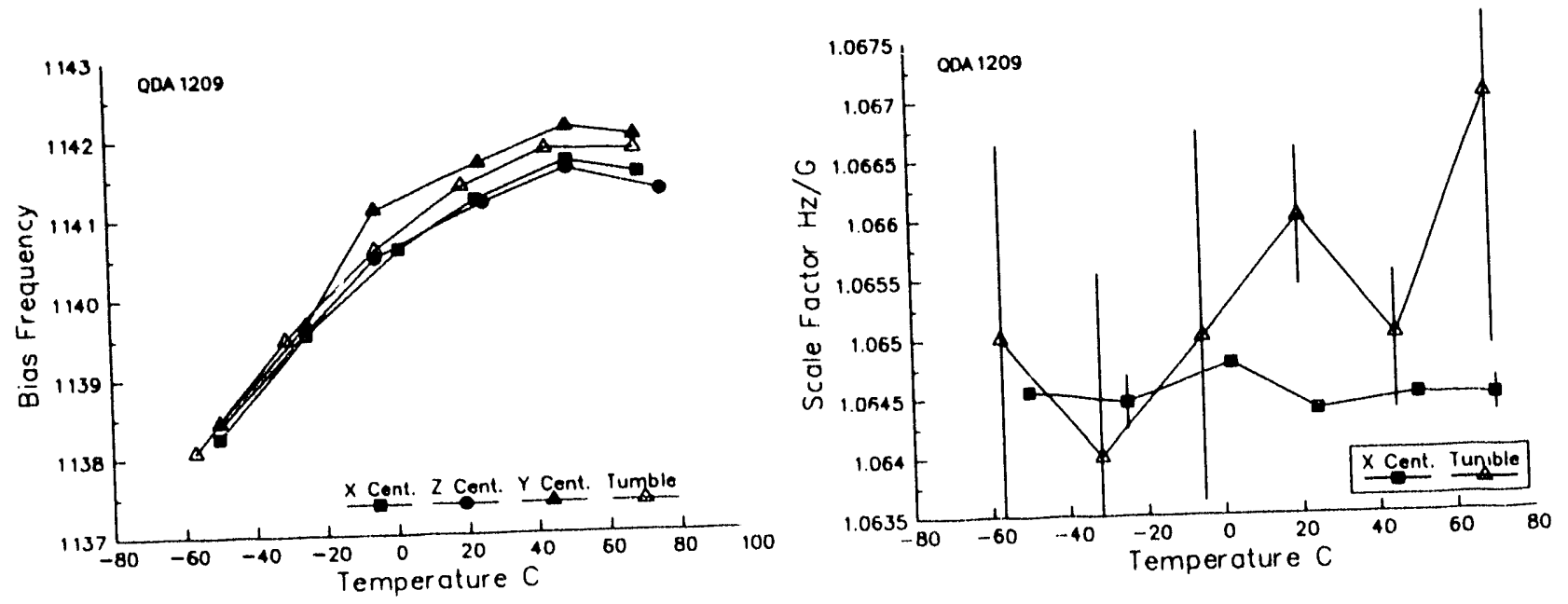

Figure 130 Bias frequency and scale factor comparisons between tumble tests and centrifuge tests for QDA1209.

test. The two types of measurement do not correlate very well. One can not identify from this comparison which cross-axis (if either) is responsible for the tumble test behavior. In all cases (centrifuge and tumble) it is not possible to separate cross-axis sensitivity from misalignment based on the measurements made. Operationally in a navigation application, it may not matter what the source of the error is, only that it can be compensated by prior calibration.

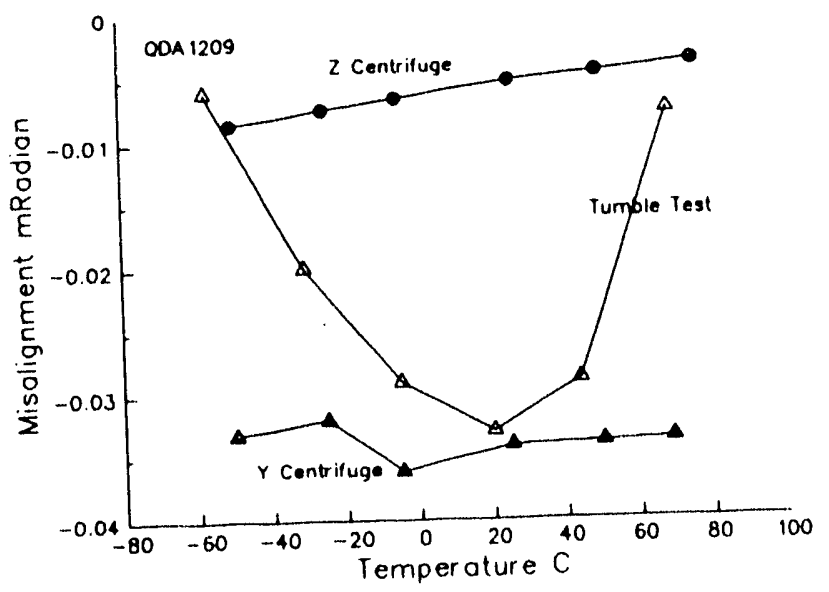

Figure 131 Misalignment vs. temperature determined from tumble tests and centrifuge test. 


\subsection{Shock and Vibration Testing}

Mechanical shock testing was performed to determine the ultimate acceleration before breaking of the accelerometers and to determine how well a QDA could measure a shock profile.

The tests were performed on a drop table with the capability to achieve an impact velocity of 100 $\mathrm{ft} / \mathrm{s}$. The table was mechanically programmed to yield a variety of shock pulses ranging from approximately $1 \mathrm{~ms}$ wide and $4000 \mathrm{~g}$ amplitude to $100 \mathrm{~ms}$ wide and $50 \mathrm{~g}$ amplitude.

Figure 132 illustrates a comparison between the acceleration profile measured by an analog reference acceleromter and QDA 1225. Although the QDA was not designed to measure this high an acceleration, it can be seen to track the acceleration profile accurately. The QDA measurements were made at approximately $1 \mathrm{~ms}$ intervals $(1 \mathrm{KHz}$ output frequency at $0 \mathrm{~g}$ ). The inherent design of the QDA filters frequencies greater than $1 \mathrm{KHz}$ which are present in the acceleration profile.

This same QDA sensor was mechanically shocked at higher levels (along the sensitive axis) until the sensor was broken. Figure 133 shows the frequency output of the QDA for each of the shock profiles. The baseline output frequency has been shifted for clarity. One can readily see limitations in the QDA sensor's ability to follow the shock pulse at higher levels. A summary of these data is shown in Figure 134 where the peak QDA measured accleration is plotted versus the peak acceleration measured by the reference accelerometer. Reasonable tracking is observed until $1000 \mathrm{~g}$; after that level the output rolls over until the QDA is unable to respond to the highest level shock pulses. These higher pulses are also of shorter duration.

Table 21 summarizes the acceleration levels at

CDA1225

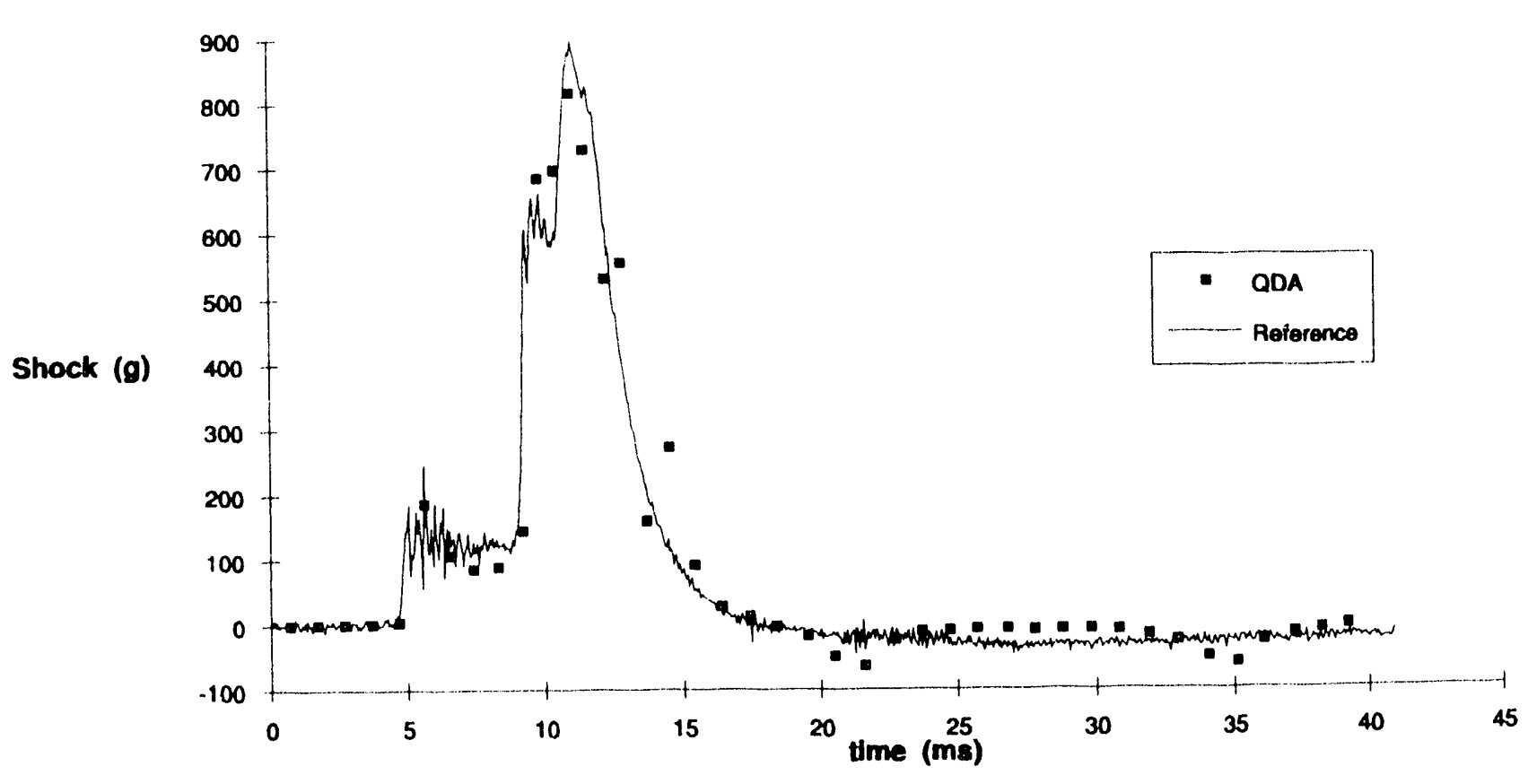

Figure 132 Acceleration measurement of a mechanical shock profile by QDA1225. 


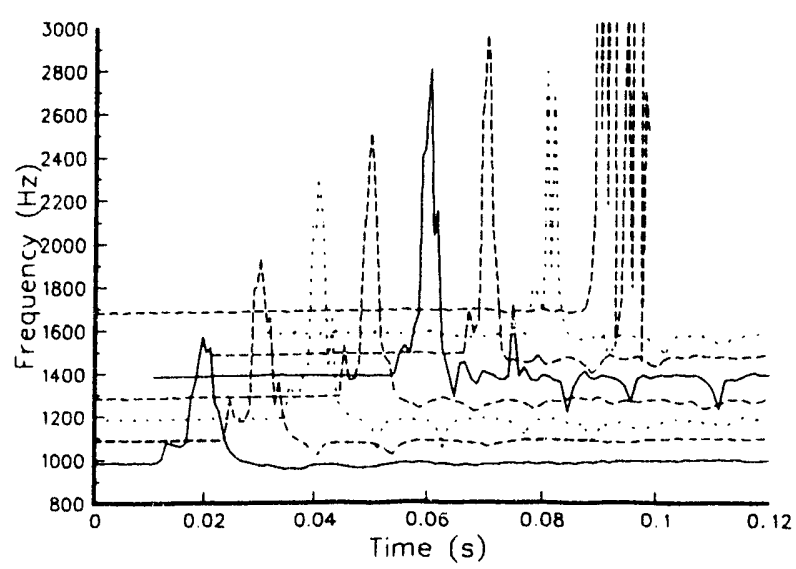

Figure 133 Mechanical shock testing of (LDA 1225 to failure.

which five similarly tested QDAs ultimately failed. Post-mortem results of these failures showed that the cause was fractures of the DETF at the inboard crotch across one or both tines of the DETF where the highest tensile stresses are present. The wide disparity in failure levels has been related to the quality of the quartz used to fabricate the DETF. Lower defect quartz results in higher shock failure thresholds. DETF were fabricated from several different batches of quartz throughout the course of development and mechanical strength was only one of several

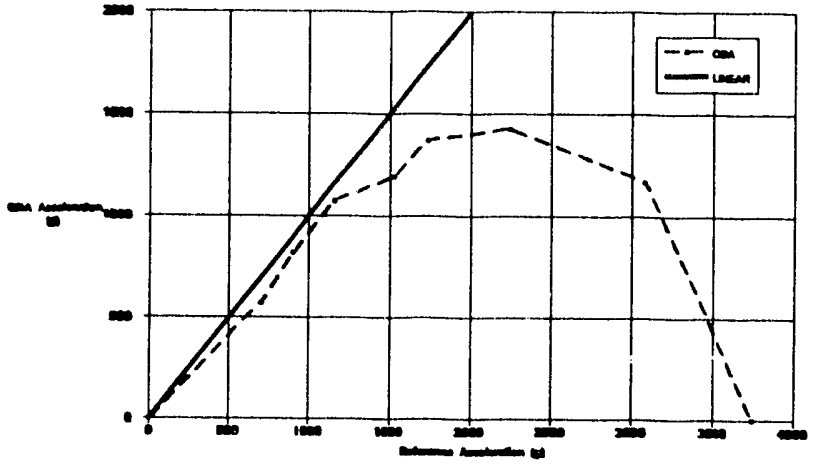

Figure 134 QDA 1225 linearity at high mechanical shock levels.

properties which varied from batch to batch.

A series of vibration tests was conducted to determine the resonant frequency of the sensor and to measure the effect on bias frequency and scale factor. Six QDAs were vibrated in their sensitive axis using a small speaker coil vibration platform driven by an audio amplifier. The vibration amplitude was adjusted at each frequency to give a constant $10 \mathrm{~g}$ peak to peak amplitude. Each cycle of the frequency output of the QDA tested was continuously monitored with a unique measurement circuit [52].

Table 21 Summary of breaking accelerations for three QDA.

\begin{tabular}{||l|l|l|l|}
\hline \multicolumn{1}{|c|}{ QDA } & \multicolumn{1}{|c|}{$\begin{array}{c}\text { Scale Factor } \\
(\mathrm{Hz} / \mathrm{g})\end{array}$} & \multicolumn{1}{|c|}{$\begin{array}{c}\text { Maximum } \\
\text { Survival } \\
\text { Shock }(\mathrm{g})\end{array}$} & $\begin{array}{c}\text { Breaking Shock } \\
(\mathrm{g})\end{array}$ \\
\hline 1222 & 0.955 & 4387 & 5273 \\
\hline 1225 & 1.023 & 3751 & 4668 \\
\hline 1226 & 1.0 & 983 & 4158 \\
\hline 1332 & 1. & 3132 & \\
\hline 1337 & 0.98 & 1160 & \\
\hline
\end{tabular}




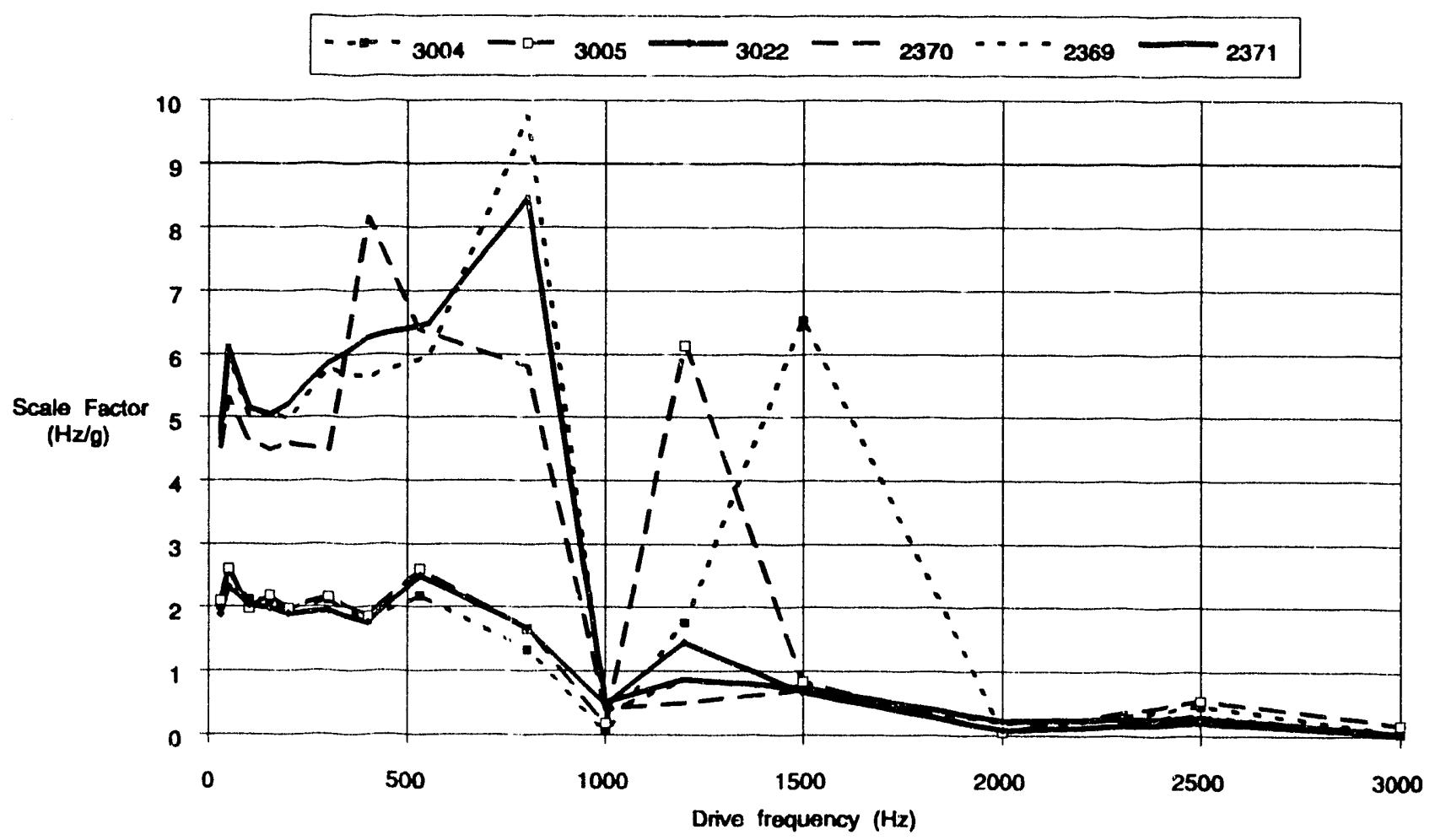

Figure 135 Scale factor vs. drive frequency for QDAs driven at $10 \mathrm{~g}$ peak-to-peak acceleration.

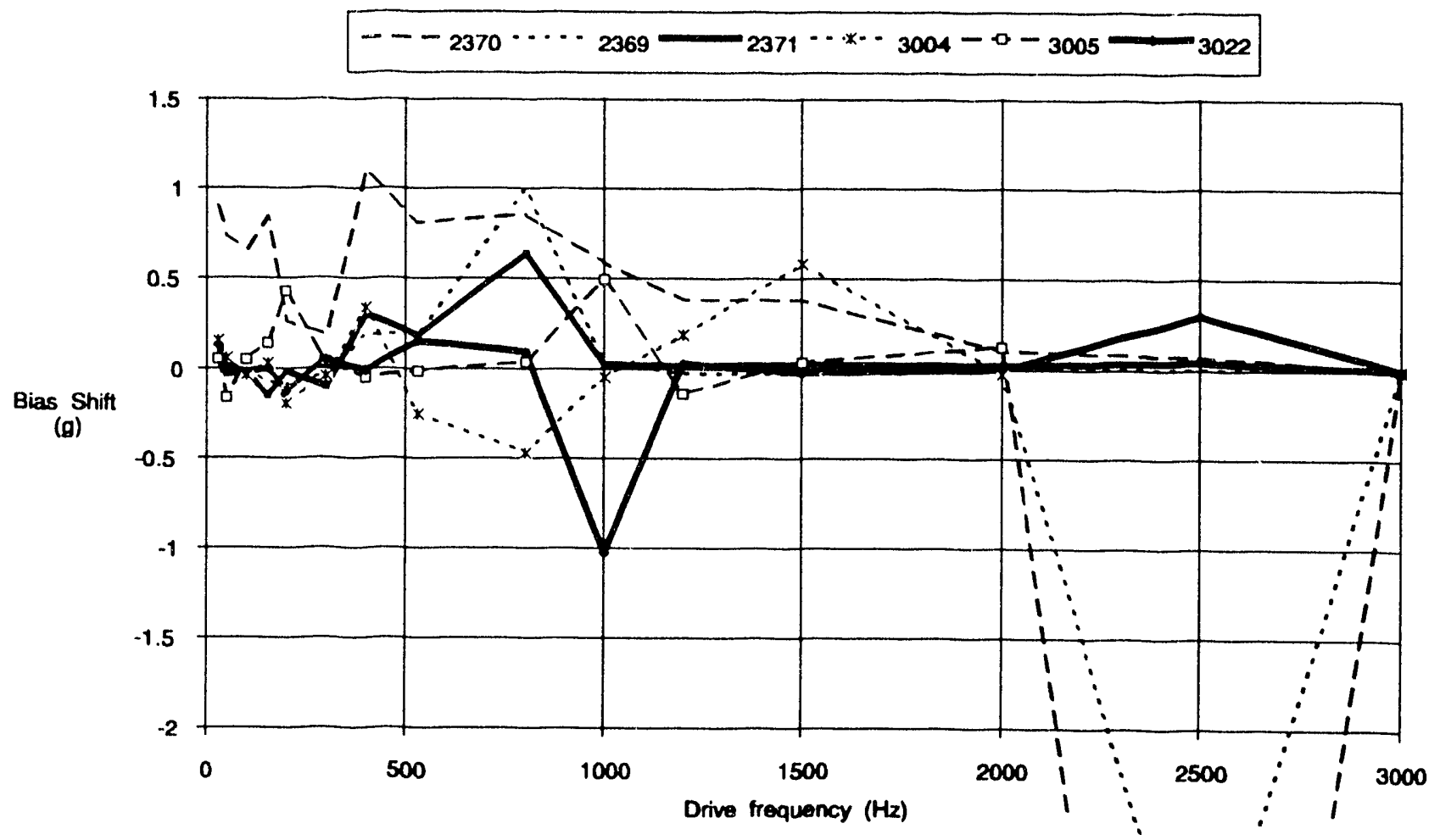

Figure 136 Bias shift of QDAs vs. frequency subjected to a drive frequency of $10 \mathrm{~g}$ peak-to-peak amplitude. 
Table 22 Characteristics of vibration tested QDAs

\begin{tabular}{|c|c|c|c|}
\hline QDA & $\begin{array}{c}\text { Bias Frequency } \\
\mathrm{Hz}\end{array}$ & $\begin{array}{c}\text { Scale Factor } \\
\mathrm{Hz} / \mathrm{g}\end{array}$ & Description \\
\hline 2369 & 1025.93 & 4.698 & $\begin{array}{c}\text { Gold PM 20.8mg } \\
\text { Polyimide bonded }\end{array}$ \\
\hline 2370 & 1028.93 & 4.773 & $\begin{array}{c}\text { Gold PM 21.3mg } \\
\text { Polyimide bonded }\end{array}$ \\
\hline 2371 & 1036.28 & 4.846 & $\begin{array}{c}\text { Gold PM, 21.1 mg } \\
\text { Polyimide bonded }\end{array}$ \\
\hline 3004 & 1000.40 & 2.056 & $\begin{array}{c}\text { Wafer assembly } \\
\text { Au PM added }\end{array}$ \\
\hline 3005 & 991.86 & 1.964 & $\begin{array}{c}\text { Wafer assembly } \\
\text { Au PM added }\end{array}$ \\
\hline 3022 & 975.51 & 1.905 & $\begin{array}{c}\text { Wafer assembly } \\
\text { Au PM added }\end{array}$ \\
\hline
\end{tabular}

One group of QDAs $(3004,3005,3022)$ had a nominal scale factor of $2 \mathrm{~Hz} / \mathrm{g}$ and the second group $(2369,2370,2371)$ had a scale factor of $4.5 \mathrm{~Hz} / \mathrm{g}$. The frequency output of the QDAs was measured and a bias frequency shift from the nominal values shown in Table 22 and scale factor was determined at each drive frequency.

Figure 135 shows the effects of the vibration on the measured scale factor. For the high scale factor QDAs $(4.5 \mathrm{~Hz} / \mathrm{g})$ the scale factor quickly increases for even small drive frequency values. The lowest cantilever resonant frequency for these QDAs is about $500 \mathrm{~Hz}$. When the drive frequency is increased abo'/e $1000 \mathrm{~Hz}$ the sensitivity of the QDA becomes greatly reduced. For the low scale factor devices similar effects occur but at a higher frequency. The lowest cantilever resonant frequency for these devices is about $1000 \mathrm{~Hz}$.

The effect of vibration on the QDA bias frequency is shown in Figure 136. There is less than a $\mathrm{lg}(2 \mathrm{~Hz}$ to $5 \mathrm{~Hz})$ shift in bias for all the QDAs until the drive frequency exceeds $2000 \mathrm{~Hz}$. Bias shifts are a measure of vibration rectification which is related to the non-linearity of the acceleration sensor.

These results indicate the desirability of a damped sensor. Damping the sensing element effectively extends the operational range of the device [53]. In addition, shock survival and vibration excitation of resonant frequencies would be substantially improved with damping. Adding stops which limit the travel of the cantilever during shock or vibration would also have a positive benefit. 


\subsection{Aging}

Aging data were measured for four QDAs for a period of approximately two years. The test units were originally maintained at $50 \mathrm{C}$ for approximately 6 months. The temperature was then changed to $70 \mathrm{C}$ for 18 months. The aging tester was a modified tumble tester. The major difference between the aging tester and the tumble tester was that the individual fork frequencies were measured in the aging tester. The tester used a Hewlett Packard Model 5335A Frequency Counter with a high stability time base. The aging characteristics of the time base are $<5 \times 10^{-10} /$ day. Even an aging rate this low will yield a measurement error of $0.02 \mathrm{~Hz}$ for a $70 \mathrm{KHz}$ DETF over a 500 day period.

The aging data for two different QDAs are shown in the figures in this section. Figure 137 shows the time-temperature profile for QDA1801. The temperature remains between $69 \mathrm{C}$ and $70 \mathrm{C}$ throughout the duration of the aging data. However, several temperature excursions of less than 1C can be observed. Figure 138 and Figure 139 reflect these temperature excursions by changes in the individual fork frequencies and individual scale factors in which the changes in frequencies of the fork pairs in a given QDA track each other extremely well. In order to amplify the changes in the observed parameters, the beginning frequencies of each fork are subtracted from the subsequent frequency data. The scale factor data are treated similarly.

The common mode cancellation of the QDA is seen in Figure 140 and Figure 141 where the individual fork frequencies are subtracted to provide the cantilever output frequency and the beginning frequency is subtracted from the subsequent cantilever frequencies. We see that frequency changes of the individual forks of $0.2 \mathrm{~Hz}$ become reduced to less than $.025 \mathrm{~Hz}$ for the cantilever bias

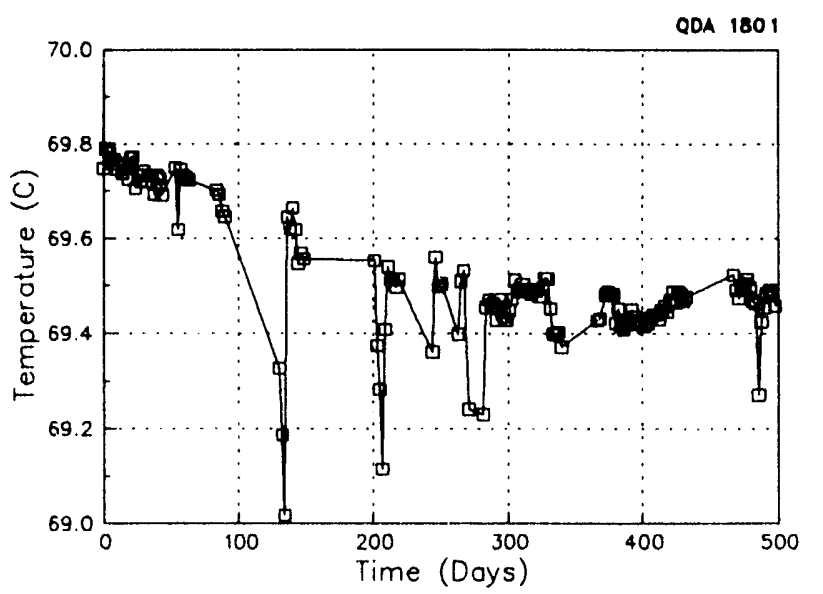

Figure 137 Temperature history for aging of QDA1801.

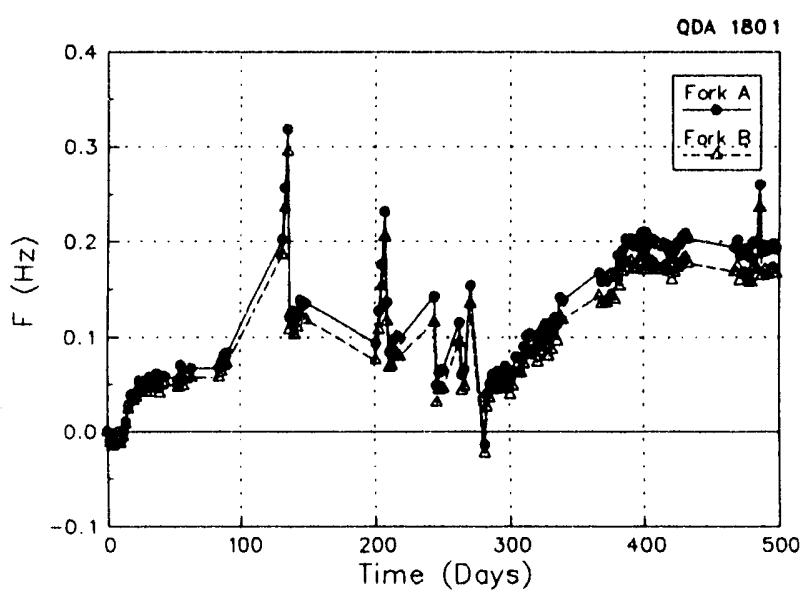

Figure 138 Individual fork and cantilever bias frequencies vs. time for QDA1801.

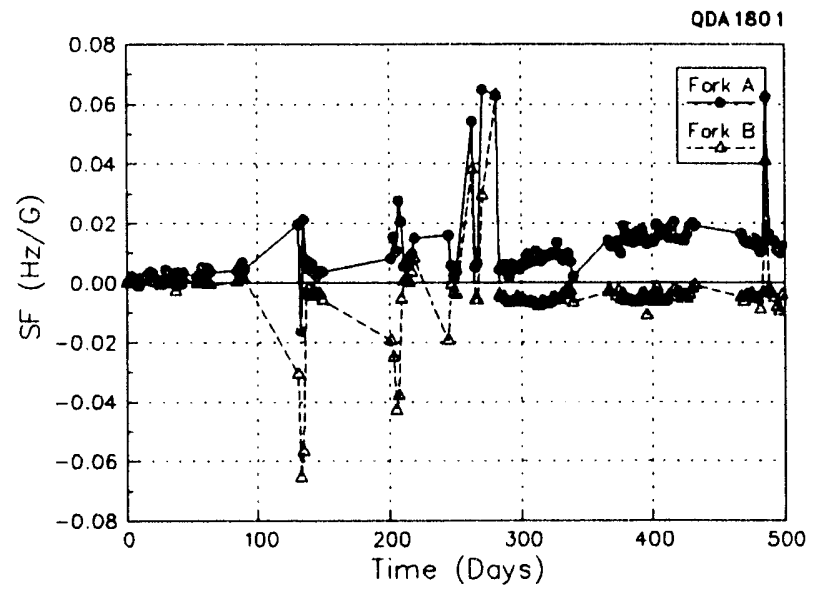

Figure 139 Scale factor aging for QDA1801. 


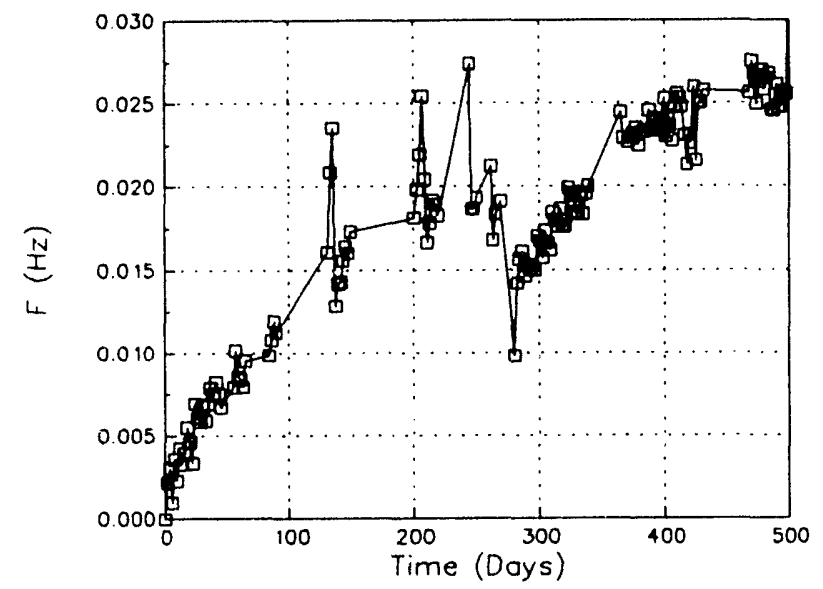

Figure 140 Cantilever bias frequency aging characteristics for QDA1801.

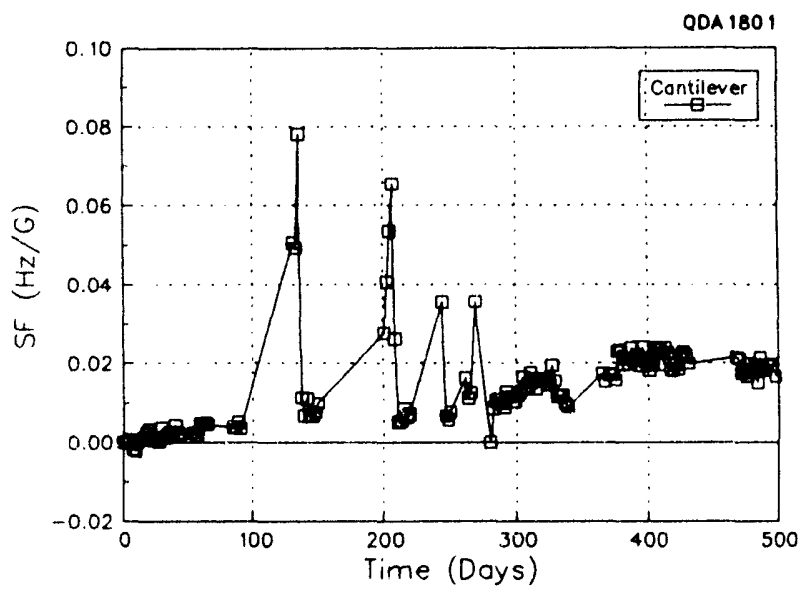

Figure 141 Cantilever scale factor aging with time. frequency. Common mode effects do not compensate the scale factor as well. The cantilever scale factor aging is approximately the same as the individual DETF scale factors.

Table 23 gives a summary of the frequency and scale factor values of the DETFs used in the aging tests as well as the temperature sensitivity of these same parameters. The temperature sensitivity was determined by slew and tumble characterization measurements on the DETFs before aging tests were performed.

A second set of aging results is shown in Figure 142, Figure 143 and Figure 144. Most of the frequency and scale factor excursions appear associated with temperature changes. Since both of these QDAs have fairly large negative temperature coefficients for the bias frequency and the bias frequency changes opposite to the temperature, this effect is expected.

These results show that the QDA bias frequency aging effect is greatly reduced by the dual DETF design over the aging of a single DETF. However, the scale factor aging is not compensated in this way. For an aging model where increasing contamination (increasing the mass of the tuning fork tines) is the cause for frequency shift one

Table 23 Frequency and scale factor parameters for QDAs used in aging study.

\begin{tabular}{|c|c|c|c|c|c|c|}
\hline QDA & $\begin{array}{c}\mathrm{F}_{2} \\
\mathrm{~Hz}\end{array}$ & $\begin{array}{c}\mathrm{F}_{\mathrm{b}} \\
\mathrm{Hz}\end{array}$ & $\begin{array}{c}\mathrm{F}_{\mathrm{c}} \\
\mathrm{Hz}\end{array}$ & $\begin{array}{c}\mathrm{dF}_{\mathrm{d}} / \mathrm{dT} \\
\mathrm{Hz} / \mathrm{C}\end{array}$ & $\begin{array}{c}\mathrm{SF} \\
\mathrm{Hz} / \mathrm{G}\end{array}$ & $\begin{array}{c}\mathrm{d}(\mathrm{SF}) / \mathrm{dT} \\
\mathrm{Hz} / \mathrm{G} / \mathrm{C}\end{array}$ \\
\hline \hline 1801 & 72207.91 & 71227.89 & 980.02 & -.0389 & 0.910 & 0.000086 \\
\hline 1834 & 73241.67 & 72295.97 & 945.70 & -.0269 & 0.962 & 0.000013 \\
\hline
\end{tabular}




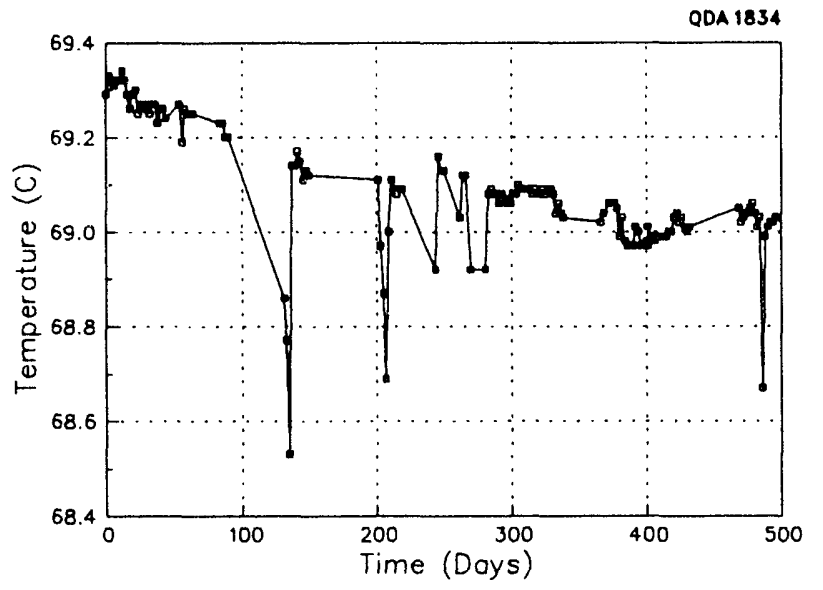

would expect both DETFs to similarly increase in frequency and compensate because their frequencies are subtracted. In the case of the scale factor, an increase in mass on the cantilever would increase the individual scale factors associated with each DETF and therefore the effect would add rather than subtract. A model of this type could explain the observed phenomenon.

Figure 142 Temperature profile for aging of QDA1834.

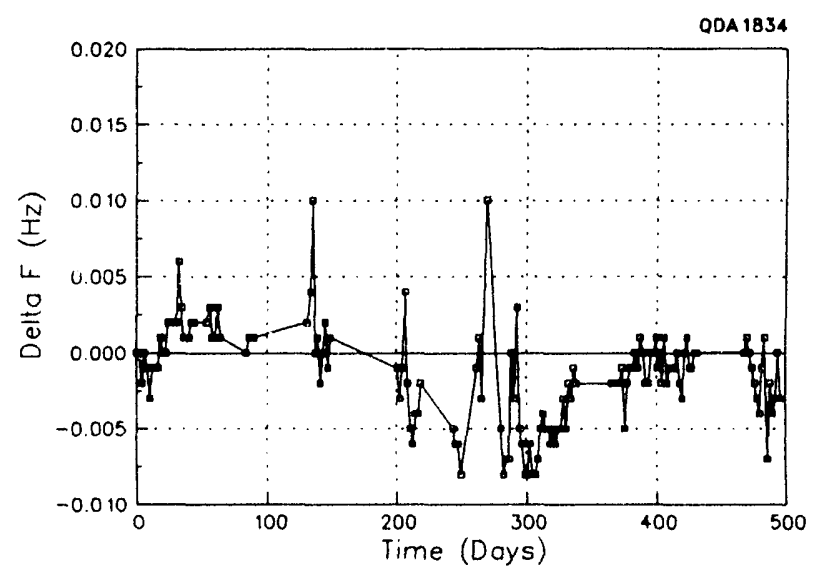

Figure 143 Cantilever bias frequency aging of QDA1834.

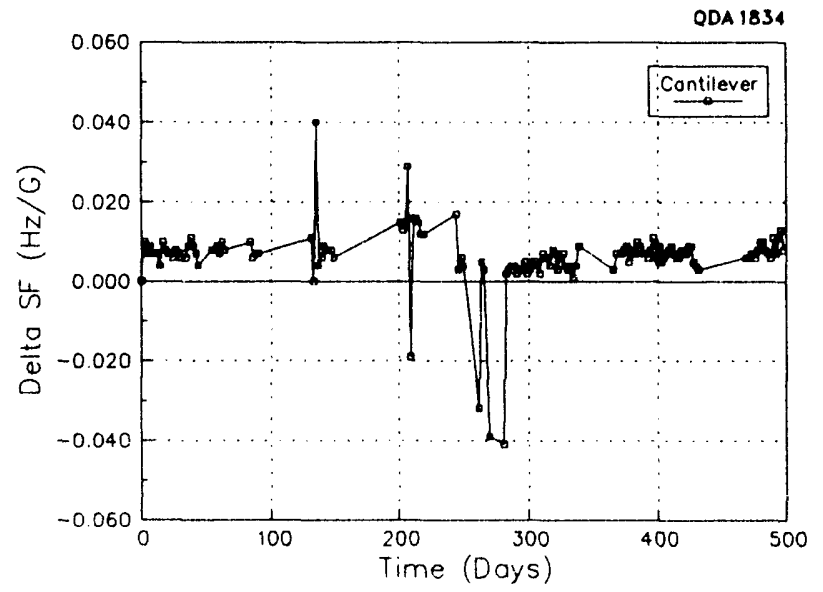

Figure 144 Scale factor aging of QDA1834. 


\section{Conclusion}

Several design variations of quartz digital accelerometers were generated using a simple mechanical design model. This model predicted the behavior of the accelerometer to within $\pm 5 \%$. In addition, finite element modeling was extensively and successfully used to predict more deailed frequency-temperature behavior. Finite element modeling resulted in confirming the importance of matching the temperature coefficient of expansion for the bonding materials which comprised the QDA. This technique also indicated the importance of mechanical alignment of the spacers and tuning forks.

A fabrication facility was built which had the capability to prepare quartz wafers for etching, etch quartz wafers into DETFs and metallize and define the electrode pattern. The resulting DETFs became the fundamental building block of the QDA.

Many variations of accelerometers were built using the basic DETF and several bonding and assembly techniques. Most QDAs were built using polyimide adhesive as the bonding medium. However, the most effective technique proved to be goldgermanium euectic bonding. The temperature behavior of the QDA was used as the figure of merit for overall accelerometer performance and gold-germanium bonded QDAs performed best in this respect. A great deal of effort was expended to characterize and understand the bonding materials and assembly processes.

Automated assembly techniques were developed to take advantage of the ability to batch fabricate sensors. Batches of 20 sensors were made using these techniques.

A custom ceramic package was developed to hermetically seal the sensor and allow visual access which permitted laser tuning of the sensor frequency. A laser system was constructed for tuning and several sensors were successfully tuned to specific bias frequencies (e.g. 1024Hz).

The performance of the QDA was characterized using centrifuge, mechanicai shock, vibration, long term ageing, short term stability, slew (temperature) tests and tumble $( \pm 1 G)$ tests. The centrifuge tests indicated the extreme linearity of the QDA and the potential for use as an inertial naviagation device. The mechanical shock and vibration tests demonstrated the ruggedness of the devices and indicated the direction for design changes which would result in yet more rugged devices. These tests also served to define the response time and usefulness of the QDA for environmental sensing applications. The temperature tests served as a screen for useful devices and demonstrated their functional temperature range . 


\section{References}

[1] J. H. Staudte, "Subminiature quartz tuning fork resonator," Proceedings of the 27th Annual Symposium on Frequency Control, 1973, pp50-54.

[2] Errol P. EerNisse, "Miniature Quartz Resonator Force Transducer, " U. S. Patent \#4,215,570, Aug. 5, 1980.

[3] Dale R. Koehler, "Double Resonator Cantilever Accelerometer, " U. S. Patent $\# 4,479,385$, Oct.30, 1984.

[4] Gary S. Snow, William R. Abel, and Jon R. Bryan, "Quartz Resonator Acceleration Sensor. Progress Report I." SAND83-1985, Sandia National Laboratories, Albuquerque, New Mexico, October 1983.

[5] Gary S. Snow and Jon R. Bryan, "Quartz Resonator Acceleration Sensor. Progress Report II." SAND84-0465, Sandia National Laboratories, Albuquerque, New Mexico, April 1984.

[6] Gary S. Snow, Richard A. Adams, and Jon R. Bryan, "Quartz Resonator Acceleration Sensor. Progress Report III. " SAND85-0363, Sandia National Laboratories, Albuquerque New Mexico, April 1985.

[7] William J. Kass and Gary S. Snow, "Double-ended Tuning Fork Quartz Accelerometer, "Proceedings of the 40th Annual Symposium on Frequency Control, 1986, pp230-236.

[8] E. D. Reedy to W. J. Kass, "Finite Element Analysis of a Quartz Digital Accelerometer", October 21, 1987; September 28, 1988; January 25, 1989; and May 10, 1989.

[9] E. D. Reedy and W. J. Kass, "Finite Element Analysis of a Quartz Digital Accelerometer", IEEE Transactions on Ultrasonics, Ferroelectrics, and Frequency Control, 1990, 37, 464-474.

[10] Harold I. Laursen, Structural Analvsis. 2nd Edition. McGraw Hill, New York, 1978.

(11) John W. Rayleigh, The Theory of Sound. Vol. I. Second Edition, Dover Publications, New York, 1945, pp255-305.

[12] William C. Albert, "Force Sensing Using Quartz Crystal Flexure Resonators", Proceedings of the 38th Symposium on Frequency Control, 1984, pp233-239.

[13] Errol P. EerNisse and Jerome M. Paros, "ResonatorForceTransducer",U.S.Patent \#4,372,173, February 8, 1983. 
[14] William T. Thomson, Theorv of Vibration With Applications. Second Edition. Prentice-Hall, Englewood Cliffs, NJ, 1981, pp78-84.

[15] Jacques C. L. van Peppen, Klaas B. Klaassen, "Damping of Compression and Shear Piezoelectric Accelerometers", Instrument and Measurement Technical Conference, IEEE, 1988.

[16] These equations are developed in more detail in [4] and [6]; however, in [4] the assumption was made that the beam behaved as a cantilever rather than a frame. This assumption led to a calculated beam resonance frequency approximately three times higher than actually observed, a correct value for the scale factor was calculated, however. In [6] the correct frame analysis was used and verified by finite element modeling and results consistent with experiment were obtained.

[17] J. P. den Hartog, Mechanical Vibrations. Third Edition. McGraw Hill Book Co., Inc., 1947, p.458.

[18] C. H. Scholz, "Static Fatigue of Quartz,"J. of Geophysical Research, 1972, 77, 2104-2144.

[19] Statek Corporation, 512 North Main Street, Orange, CA

[20] P. R. Hoffman Materials Processing, Carlisle, PA

[21] Sawyer Crystal Systems, Conroe, TX

[22] XECO Inc., 3921 E. La Palma, Anaheim, CA

[23] Solid State Component Processing Division, Division 7415

[24] Photographic Sciences, Rochester, NY, Model MP2000

[25] GCA/Tropel, Rochester, NY, PlatmasterIM

[26] F. J. Gray Co. Jamaica, NY

[27] R. H. Strasbough, Inc., Huntington Beach, CA, Model 6BK

[28] Rodel Inc., Newark, DE

[29] Brunswick Instruments, Niles, IL, Model XL-7500-01

[30] Solid State Component Processing Division, Division 7415

[31] Temescal/Edwards, Oakland, CA, Model BJD-1800 
[32] Shipley Company, Newton, MA,

[33] Photosciences, Inc., Torrance, CA

[34] Karl Suss, USA, Waterbury Center, VT

[35] A. M. Romero and C. T. Gebert, SAND 89-0913, "Improved Assembly Processes for the Quartz Digital Accelerometer Cantilever.

[36] Ablebond is a trademark of Ablestick Laboratories, Gardena, CA

[37] E. D. Reedy and W. J. Kass, Finite element analysis of a Quartz Digital Accelerometer, IEEE Trans. Ultrasonics, Ferroelectrics, and Frequency Control, 37,464474 (1990).

[38] G. S. Snow, W. R. Abel and J. R. Bryan, "Quartz Resonator Accelerometer Sensor Progress Report I". SAND83-1985.

[39] Binary Allov Phase Diagrams Vol. 1, ed. T. B. Masalski (Materials Park, OH, ASM International 1986) p. 264.

[40] ibid p. 315

[41] ibid pp. 312-313

[42] Timoshenko, S. "Analysis of Bi-Metal Thermostats", J. Optical Soc. Amer. 11, (1925) p233.

[43] J. Thorton, "Coating Deposition by Sputtering", Deposition Technologies for Films and Coatings (Noyes Pub., 1982) pp 170-243.

[44] P. T. Vianco, W. R. Conley and J. K. G. Panitz, "Resistivity adhesive Strength and Residual Stress Measurements of Thin Film Metallizations on Single Crystal Quartz", Proc. 44th Annual Symposium on Frequency Control (1990), pp. 207-215.

[45] H. Manko, "Solders and Soldering", McGraw-Hill, NY, NY; 1979

[46] "Gold Content of AuGe Films by Controlled Potential Coulometry", Memo, M. R. Keenan to J. A. Romero, Nov. 7, 1988, Sandia National Laboratory

[47] Virgil E. Bottom, Introduction to Ouartz Clvstal Unit Design. Van Nostrand Reinhold Co., 1982, pp82- 100.

[48] J. C. Brice, "Crystals for Quartz Resonators," Rev. Mod. Phys., 1985, 57, pplO5-146. 
[49] Colin J. Smithells, Metals Reference Book. Third Edition. Butterworths, Washington, 1962.

[50] Abelbond 71-1, Abelstik Laboratories, 833 W. 182 St., Gardena, CA 90248

[51] Frank J. Peter, Guidance and Control Division I, Private Communication

[52] J. J. Snyder, An Ultra-high Resolution Frequency Meter, Proc. 35th Ann. Freq. Control Symposium, May 1981, pp464-469. This circuit was constructed by Jon R. Bryan, Sandia National Labs.

[53] See for example: "Theory of Vibration with Applications", W. T. Thomson, Second Ed., PrenticeHall Inc., Englewood Cliffs, NJ 


\section{APPENDIX A}

TESTER SCHEMATICS 

SLEW TESTER

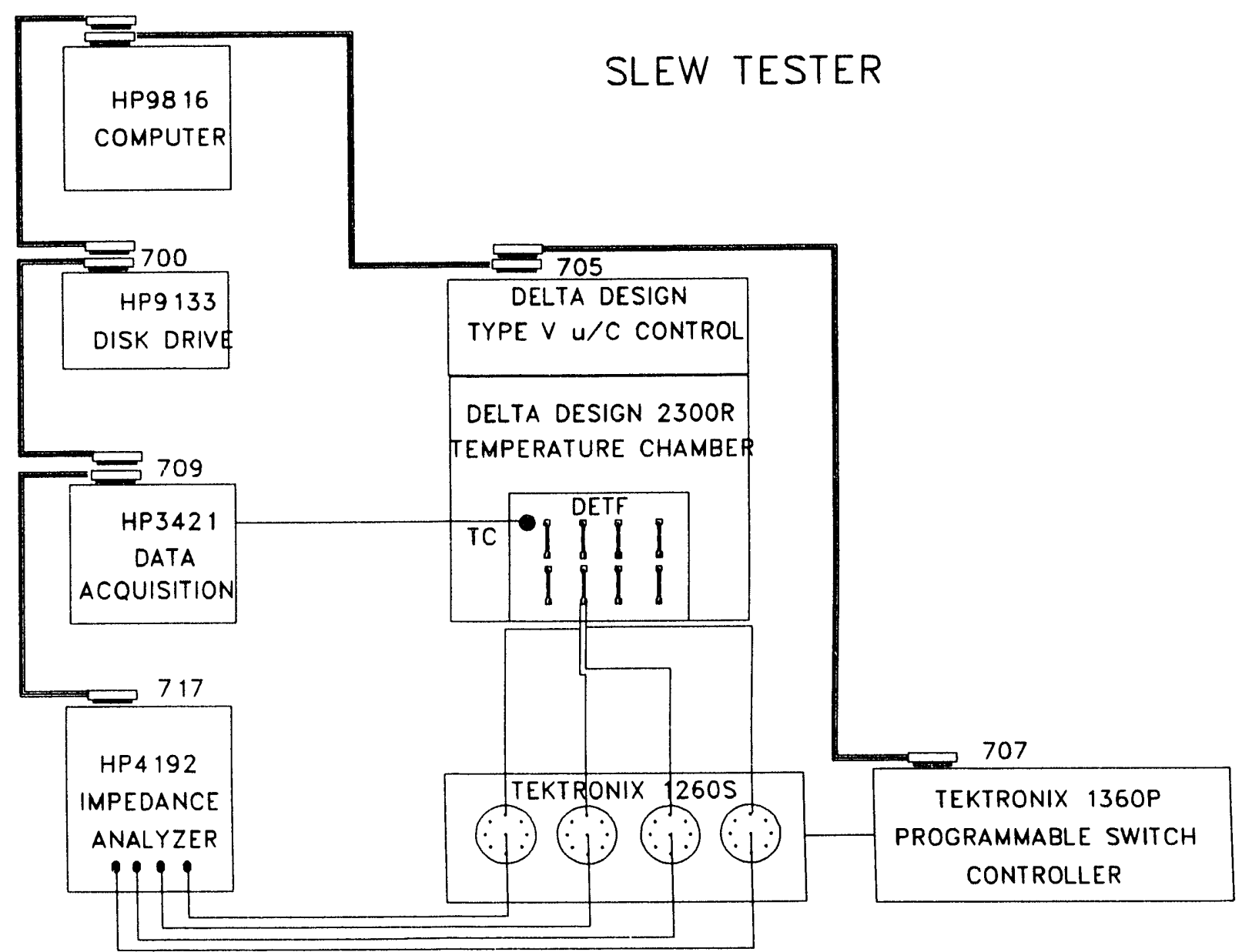


WAFER TESTER

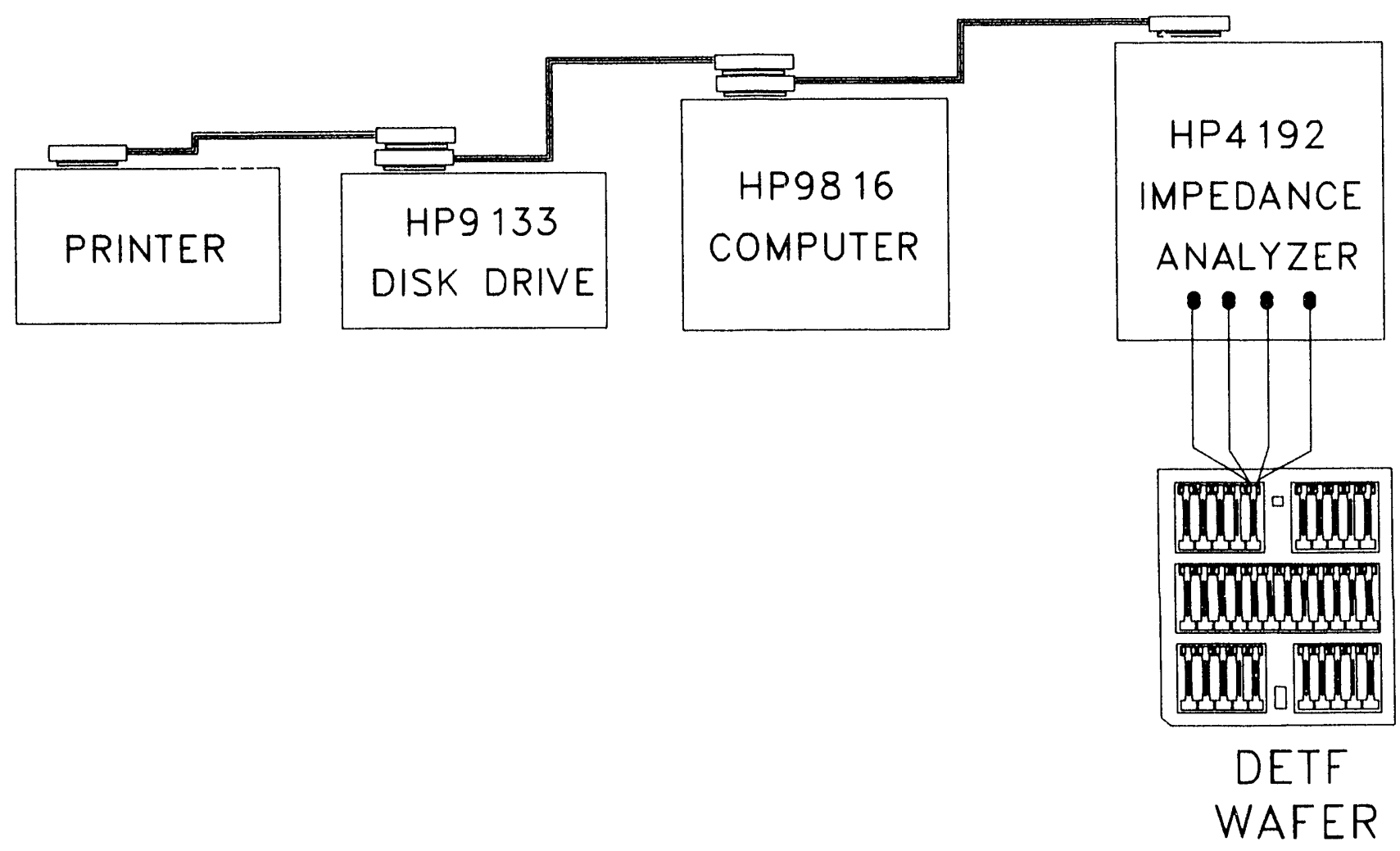




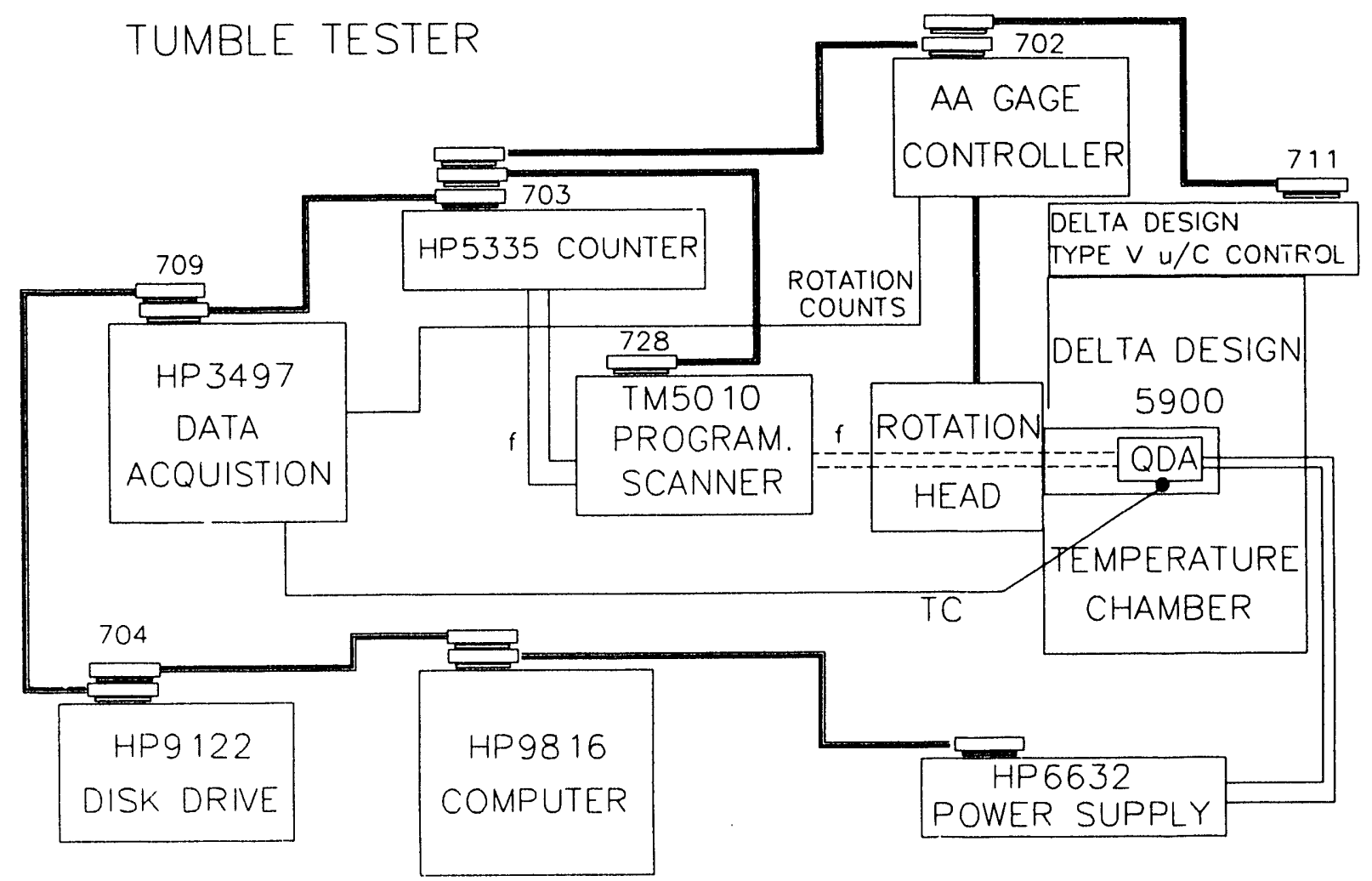




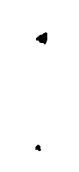

I

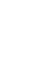




\section{APPENDIX B}

Frequency and Electrical Properties of Early Statek Fabricated DETFs 
FREQUENCY AND ELECTRICAL PROPERTIES OF EARLY (1985) STATEK FABRICATED DETF

WAFER $\quad 8410-7-5$

\begin{tabular}{|c|c|c|c|c|c|c|c|}
\hline & UNIT & $\begin{array}{r}\text { FREQ } \\
\text { kHz }\end{array}$ & $\begin{array}{r}\mathrm{R} \\
\text { kOhm }\end{array}$ & $\underset{k H}{L_{m}}$ & $\begin{array}{c}C_{m} \\
f F\end{array}$ & $\underset{\mathrm{pF}}{\mathrm{C}_{0}}$ & 0 \\
\hline & 1 & 71783 & 388 & 7.53 & 0.653 & 0.49 & 8757 \\
\hline & 2 & 71417 & 417 & 7.71 & 0.644 & 0.44 & 8304 \\
\hline & 3 & 71557 & 397 & 7.63 & 0.648 & 0.44 & 8654 \\
\hline & 5 & 71427 & 418 & 7.64 & 0.650 & 0.43 & 8209 \\
\hline & 11 & 71875 & 396 & 7.56 & 0.648 & 0.43 & 8633 \\
\hline & 12 & 71688 & 394 & 7.60 & 0.649 & 0.43 & 8682 \\
\hline & 13 & 71689 & 400 & 7.61 & 0.648 & 0.43 & 8566 \\
\hline & 14 & 71783 & 404 & 7.61 & 0.646 & 0.43 & 8488 \\
\hline & 15 & 71665 & 404 & 7.62 & 0.647 & 0.43 & 8504 \\
\hline & 16 & 71629 & 405 & 7.61 & 0.649 & 0.42 & 8464 \\
\hline & 23 & 71650 & 392 & 7.57 & 0.652 & 0.43 & 8697 \\
\hline & 24 & 71476 & 403 & 7.61 & 0.651 & 0.43 & 8486 \\
\hline & 25 & 71524 & 401 & 7.61 & 0.650 & 0.42 & 8529 \\
\hline & 26 & 71292 & 430 & 7.66 & 0.651 & 0.44 & 7983 \\
\hline & 27 & 71266 & 415 & 7.77 & 0.642 & 0.43 & 8384 \\
\hline Average & & 71581 & 404 & 7.62 & 0.649 & 0.43 & 8489 \\
\hline Std Dev & & 173 & 11 & 0.06 & 0.003 & 0.02 & 198 \\
\hline & 6 & 70579 & 478 & 7.78 & 0.654 & 0.44 & 7210 \\
\hline & 7 & 70635 & 435 & 7.74 & 0.656 & 0.44 & 7892 \\
\hline & 8 & 70456 & 411 & 7.85 & 0.650 & 0.42 & 8450 \\
\hline & 9 & 70445 & 427 & 7.76 & 0.657 & 0.43 & 8049 \\
\hline & 10 & 70576 & 420 & 7.81 & 0.652 & 0.44 & 8235 \\
\hline & 17 & 70676 & 411 & 7.79 & 0.651 & 0.43 & 8417 \\
\hline & 18 & 70657 & 613 & 8.33 & 0.609 & 0.44 & 6025 \\
\hline & 19 & 70608 & 441 & 7.80 & 0.651 & 0.43 & 7845 \\
\hline & 20 & 70491 & 414 & 7.75 & 0.658 & 0.45 & 8285 \\
\hline & 21 & 70577 & 525 & 8.54 & 0.596 & 0.44 & 7211 \\
\hline & 29 & 70473 & 412 & 7.82 & 0.652 & 0.44 & 8405 \\
\hline & 30 & 70020 & 984 & 10.3 & 0.501 & 0.43 & 4605 \\
\hline & 31 & 70447 & 440 & 7.83 & 0.652 & 0.44 & 7886 \\
\hline & 32 & 70581 & 406 & 7.75 & 0.656 & 0.44 & 8475 \\
\hline verage & & 70515 & 487 & 8.06 & 0.635 & 0.44 & 7642 \\
\hline Std Dev & & 157 & 148 & 0.66 & 0.041 & 0.01 & 1063 \\
\hline
\end{tabular}




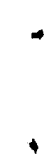

- 


\section{APPENDIX C}

SNL Fork Parameters 


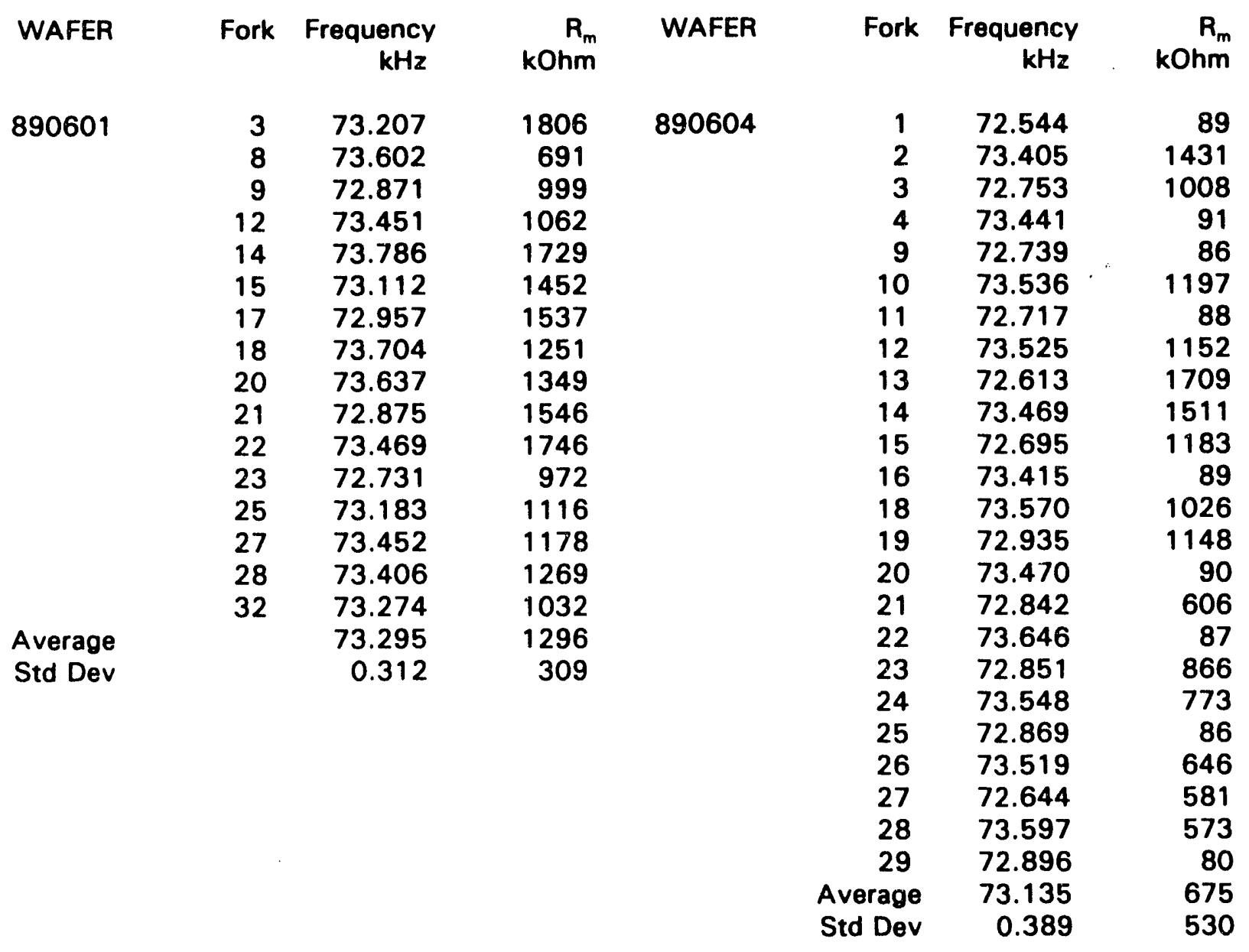


4 


\section{APPENDIX D}

Later Statek Fork Parameters 
$\checkmark$

. 


\begin{tabular}{|c|c|c|c|c|c|c|}
\hline $\begin{array}{l}\text { WAFER } \\
\text { Fork }\end{array}$ & $\begin{array}{r}8720-1-6 \\
\text { Frequency } \\
\mathrm{Hz}\end{array}$ & $\begin{array}{r}R_{m} \\
\text { kOHm }\end{array}$ & $\underset{k H}{L_{m}}$ & $\begin{array}{l}C_{m} \\
f F\end{array}$ & $\begin{array}{l}\mathrm{C}_{0} \\
\mathrm{pF}\end{array}$ & Q \\
\hline 1 & 71140 & 86 & 1.61 & 3.109 & 2.11 & 8339 \\
\hline 14 & 71056 & 91 & 1.63 & 3.072 & 2.15 & 7984 \\
\hline 15 & 71040 & 86 & 1.54 & 3.250 & 2.22 & 8058 \\
\hline 17 & 70950 & 87 & 1.55 & 3.251 & 2.25 & 7894 \\
\hline 18 & 71104 & 84 & 1.63 & 3.077 & 2.24 & 8635 \\
\hline 26 & 70662 & 85 & 1.56 & 3.248 & 2.25 & 8113 \\
\hline 28 & 70719 & 84 & 1.56 & 3.244 & 2.25 & 8213 \\
\hline Average & 70953 & 86 & 1.58 & 3.179 & 2.21 & 8177 \\
\hline Std. Dev. & 175 & 2 & 0.04 & 0.081 & 0.05 & 231 \\
\hline 9 & 72075 & 90 & 1.55 & 3.150 & 2.20 & 7775 \\
\hline 10 & 72151 & 84 & 1.50 & 3.243 & 2.20 & 8067 \\
\hline 11 & 71964 & 82 & 1.51 & 3.241 & 2.20 & 8345 \\
\hline 12 & 72125 & 82 & 1.49 & 3.261 & 2.22 & 8257 \\
\hline 20 & 72006 & 84 & 1.53 & 3.187 & 2.24 & 8281 \\
\hline 24 & 72005 & 86 & 1.54 & 3.181 & 2.27 & 8045 \\
\hline 33 & 71715 & 98 & 1.57 & 3.144 & 2.29 & 7185 \\
\hline 34 & 71710 & 88 & 1.58 & 3.125 & 2.37 & 8067 \\
\hline Average & 71969 & 87 & 1.53 & 3.192 & 2.25 & 8003 \\
\hline Std. Dev. & 165 & 5 & 0.03 & 0.049 & 0.06 & 365 \\
\hline WAFER & $8720-2-1$ & & & & & \\
\hline 3 & 71134 & 83 & 1.50 & 3.348 & 2.09 & 8100 \\
\hline 4 & 71145 & 82 & 1.50 & 3.345 & 2.04 & 8112 \\
\hline 13 & 71065 & 79 & 1.42 & 3.538 & 2.16 & 8026 \\
\hline 14 & 71025 & 85 & 1.46 & 3.431 & 2.11 & 7648 \\
\hline 15 & 71001 & 81 & 1.44 & 3.493 & 2.16 & 7970 \\
\hline 17 & 70979 & 82 & 1.45 & 3.470 & 2.16 & 7915 \\
\hline 18 & 70943 & 80 & 1.45 & 3.465 & 2.16 & 8106 \\
\hline 27 & 70588 & 80 & 1.44 & 3.525 & 2.19 & 8015 \\
\hline 29 & 70626 & 80 & 1.45 & 3.502 & 2.18 & 8011 \\
\hline Average & 70945 & 81 & 1.46 & 3.457 & 2.14 & 7975 \\
\hline Std. Dev. & 190 & 2 & 0.02 & 0.057 & 0.05 & 137 \\
\hline 8 & 72131 & 79 & 1.41 & 3.458 & 2.12 & 8091 \\
\hline 9 & 72072 & 96 & 1.44 & 3.392 & 2.05 & 6789 \\
\hline 10 & 71895 & 82 & 1.47 & 3.331 & 2.06 & 8135 \\
\hline 11 & 72010 & 81 & 1.46 & 3.340 & 2.05 & 8153 \\
\hline 12 & 72057 & 82 & 1.46 & 3.340 & 2.05 & 8067 \\
\hline 21 & 71877 & 79 & 1.41 & 3.465 & 2.15 & 8109 \\
\hline 24 & 71914 & 78 & 1.40 & 3.507 & 2.16 & 8039 \\
\hline 32 & 71531 & 152 & 1.46 & 3.382 & 2.18 & 4329 \\
\hline 33 & 71502 & 81 & 1.42 & 3.478 & 2.16 & 7929 \\
\hline Average & 71888 & 90 & 1.44 & 3.410 & 2.11 & 7444 \\
\hline Std. Dev. & 208 & 22 & 0.03 & 0.065 & 0.06 & 1312 \\
\hline
\end{tabular}


, 


\section{APPENDIX E}

Twenty Fork Wafer Parameters 


\section{$+$}

- 
TWENTY FORK WAFER PARAMETERS

\begin{tabular}{|c|c|c|c|c|c|c|c|}
\hline WAFr: & Fork & $\begin{array}{c}\text { Frequency } \\
\qquad \mathrm{kHz}\end{array}$ & $\begin{array}{r}R_{m} \\
\text { kOhm }\end{array}$ & $\underset{k H}{L_{m}}$ & $\begin{array}{c}C_{m} \\
f F\end{array}$ & $\begin{array}{l}\mathrm{c}_{0} \\
\mathrm{pF}\end{array}$ & Q \\
\hline 891501 & $\begin{array}{r}6 \\
7 \\
8 \\
9 \\
10\end{array}$ & $\begin{array}{l}71.964 \\
72.087 \\
71.953 \\
71.980 \\
71.928\end{array}$ & $\begin{array}{r}331 \\
364 \\
942 \\
1431 \\
1057\end{array}$ & 6.05 & 0.808 & 0.99 & 8273 \\
\hline & 11 & 71.826 & 374 & 6.52 & 0.753 & 0.97 & 7872 \\
\hline & 12 & 71.945 & 461 & 5.72 & 0.854 & 1.03 & 5622 \\
\hline & 16 & 72.256 & 518 & 6.03 & 0.804 & 1.20 & 5292 \\
\hline & 17 & 72.258 & 525 & 7.05 & 0.687 & 1.11 & 6110 \\
\hline & 18 & 72.194 & 630 & 10.50 & 0.464 & 1.07 & 7545 \\
\hline & 19 & 72.148 & 417 & 4.13 & 1.180 & 1.37 & 4485 \\
\hline Average & & 72.049 & 641 & 6.57 & 0.793 & 1.11 & 6457 \\
\hline Std. Dev. & & 0.140 & 336 & 1.81 & 0.198 & 0.13 & 1339 \\
\hline 891502 & $\begin{array}{l}1 \\
2\end{array}$ & $\begin{array}{l}72.123 \\
72.250\end{array}$ & $\begin{array}{r}914 \\
1569\end{array}$ & 14.30 & 0.340 & 0.99 & 7105 \\
\hline & 3 & 72.291 & 296 & 5.18 & 0.934 & 1.19 & 7967 \\
\hline & 4 & 72.290 & 364 & 6.02 & 0.805 & 1.13 & 7517 \\
\hline & 5 & 72.252 & 104 & 1.71 & 2.840 & 1.76 & 7462 \\
\hline & 6 & 71.966 & 357 & 6.29 & 0.778 & 1.16 & 7966 \\
\hline & 8 & 70.811 & 244 & 3.28 & 1.540 & 1.50 & 5985 \\
\hline & 9 & 72.283 & 478 & 8.06 & 0.601 & 1.09 & 7668 \\
\hline & 10 & 72.141 & 183 & 3.31 & 1.470 & 1.35 & 8205 \\
\hline & 11 & 72.164 & 228 & 4.09 & 1.190 & 1.31 & 8133 \\
\hline & 12 & 72.330 & 219 & 3.73 & 1.290 & 1.31 & 7793 \\
\hline & 13 & 72.427 & 135 & 2.44 & 1.980 & 1.54 & 8225 \\
\hline & 15 & 72.601 & 315 & 5.52 & 0.870 & 1.11 & 8003 \\
\hline & 16 & 72.462 & 209 & 3.84 & 1.260 & 0.93 & 8345 \\
\hline & 17 & 72.499 & 310 & 5.59 & 0.862 & 0.84 & 8219 \\
\hline & 18 & 72.492 & 242 & 4.35 & 1.110 & 0.99 & 8177 \\
\hline & 19 & 72.548 & 613 & 10.10 & 0.478 & 0.98 & 7491 \\
\hline & 20 & 72.399 & 457 & 5.88 & 0.821 & 1.00 & 5862 \\
\hline Aver & & 72.241 & 402 & 5.51 & 1.128 & 1.19 & 7654 \\
\hline Std. Dev. & & 0.382 & 339 & 2.96 & 0.585 & 0.24 & 713 \\
\hline
\end{tabular}




\title{
APPENDIX $\mathrm{F}$
}

\author{
Drawings
}


ASSEMBLY DRAWING

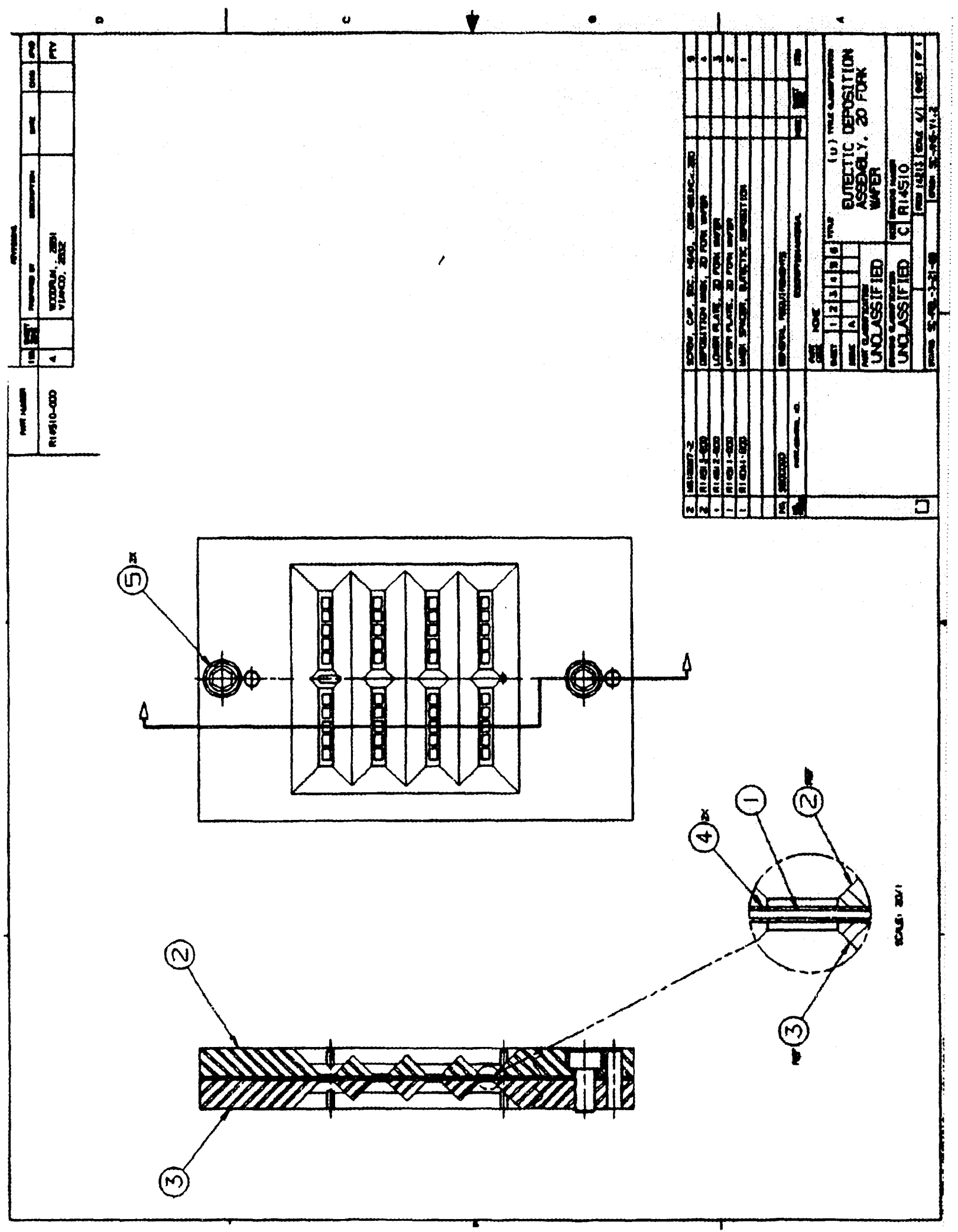




\section{ASSEMBLY BASE PLATE Part 1}
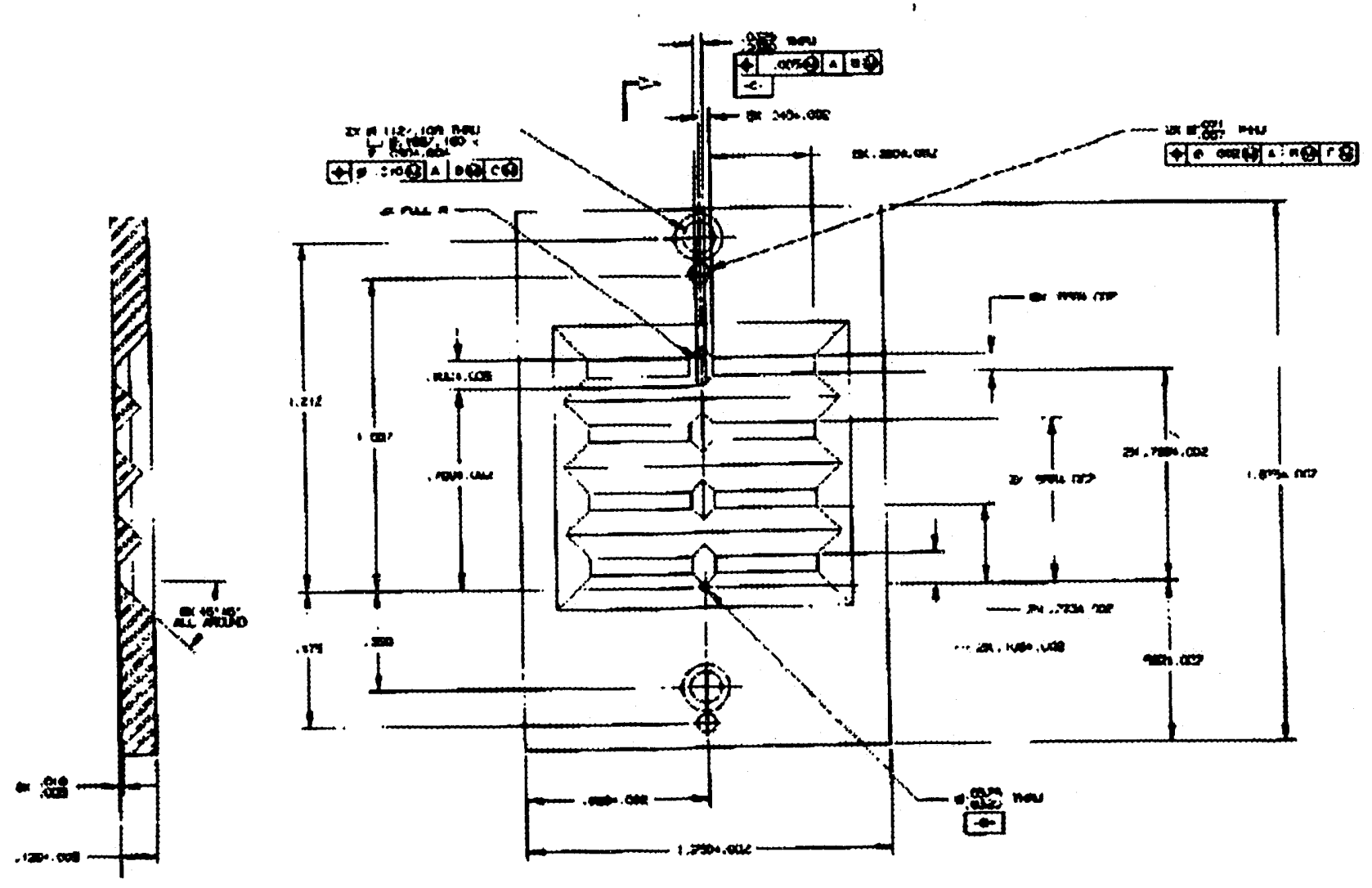
ASSEMBLY BASE PLATE Part 2
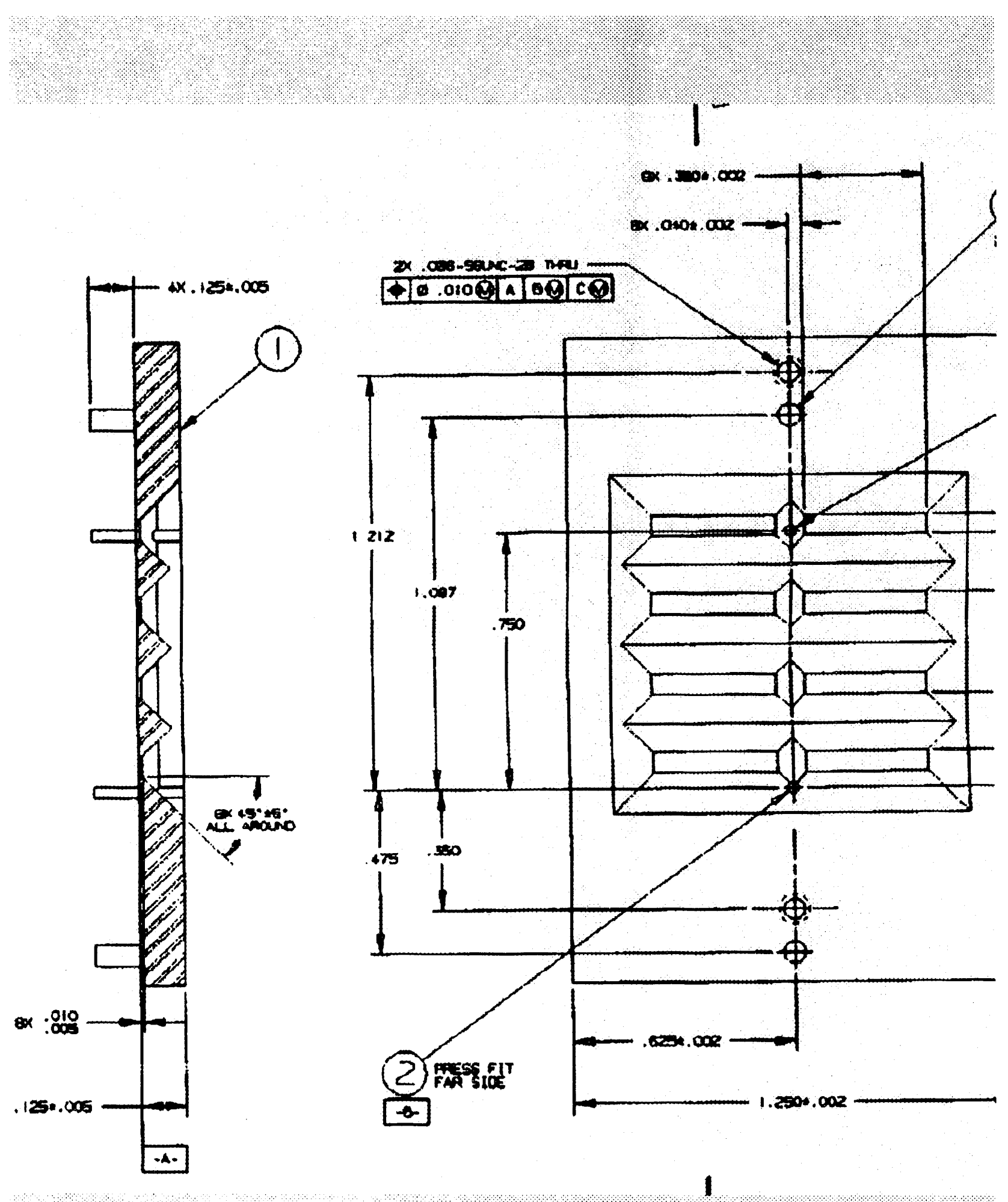
DEPOSITION MASK

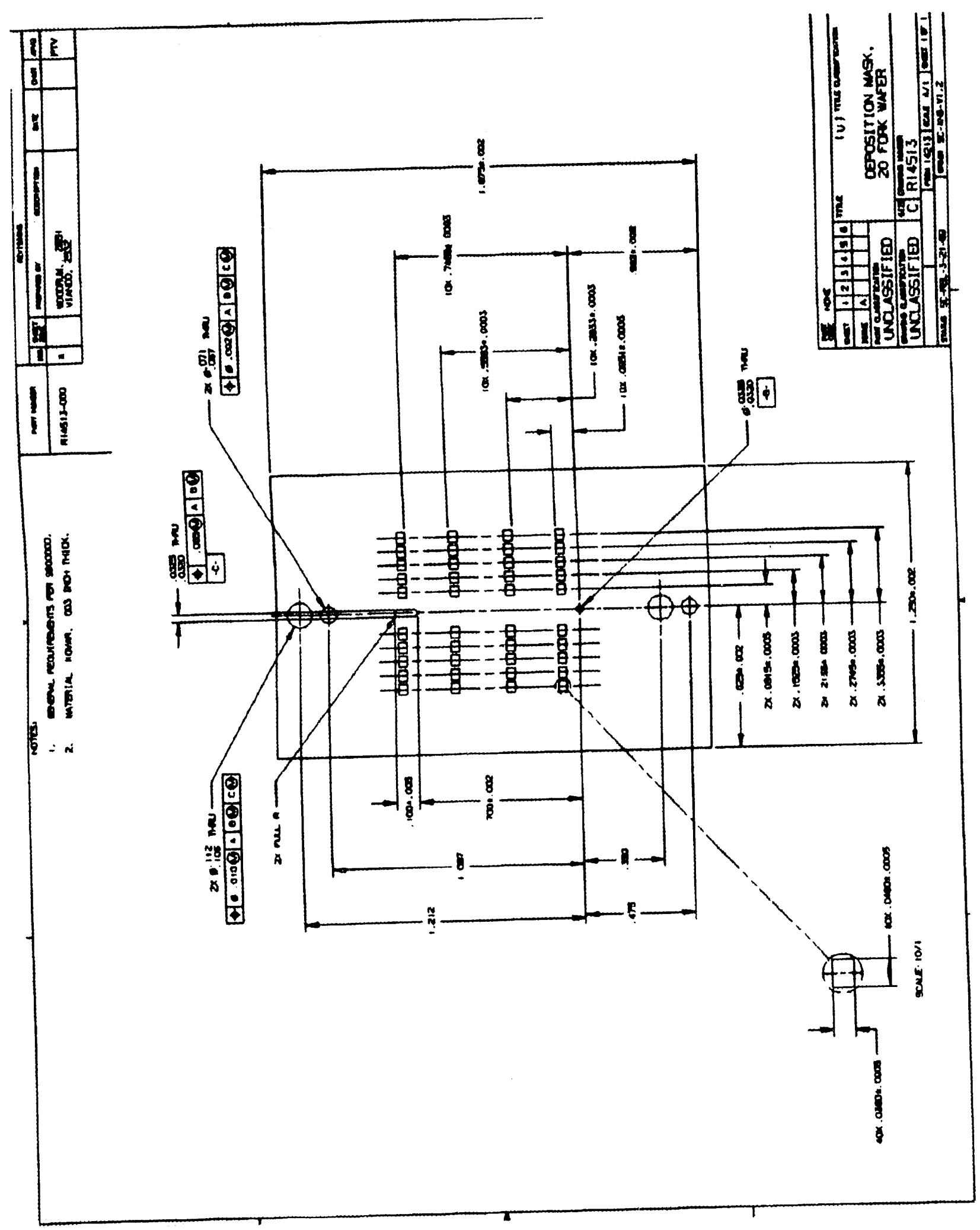




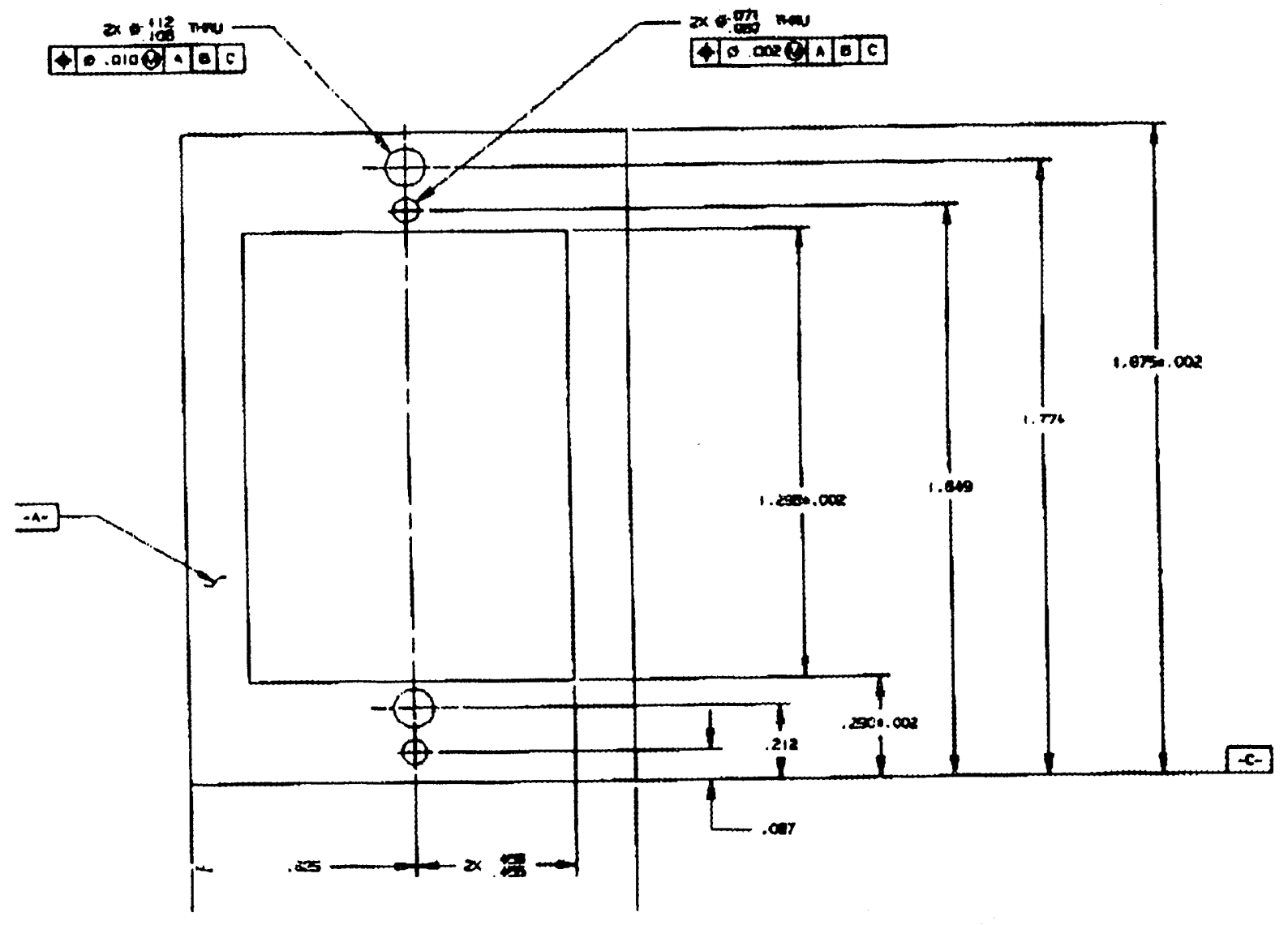


Distribution:

1562 E. D. Reedy

1700 R. J. Eagan

1800 A. D. Romig

1831 M. J. Cieslak

1831 F. G. Yost

1831 P. T. Vianco (10 copies)

1833 J. L. Jellison

2234 D. R. Koehler

2234 G. S. Snow

2235 W. J. Kass (10 copies)

2334 G. M. Heck

2337 G. R. Laguna

2471 R. M. Curlee

7141 Technical Library (5 copies)

7151 Technical Publications

7613-2 Document Processing for DOE/OSTI (10 copies)

8523-2 Central Technical Files 

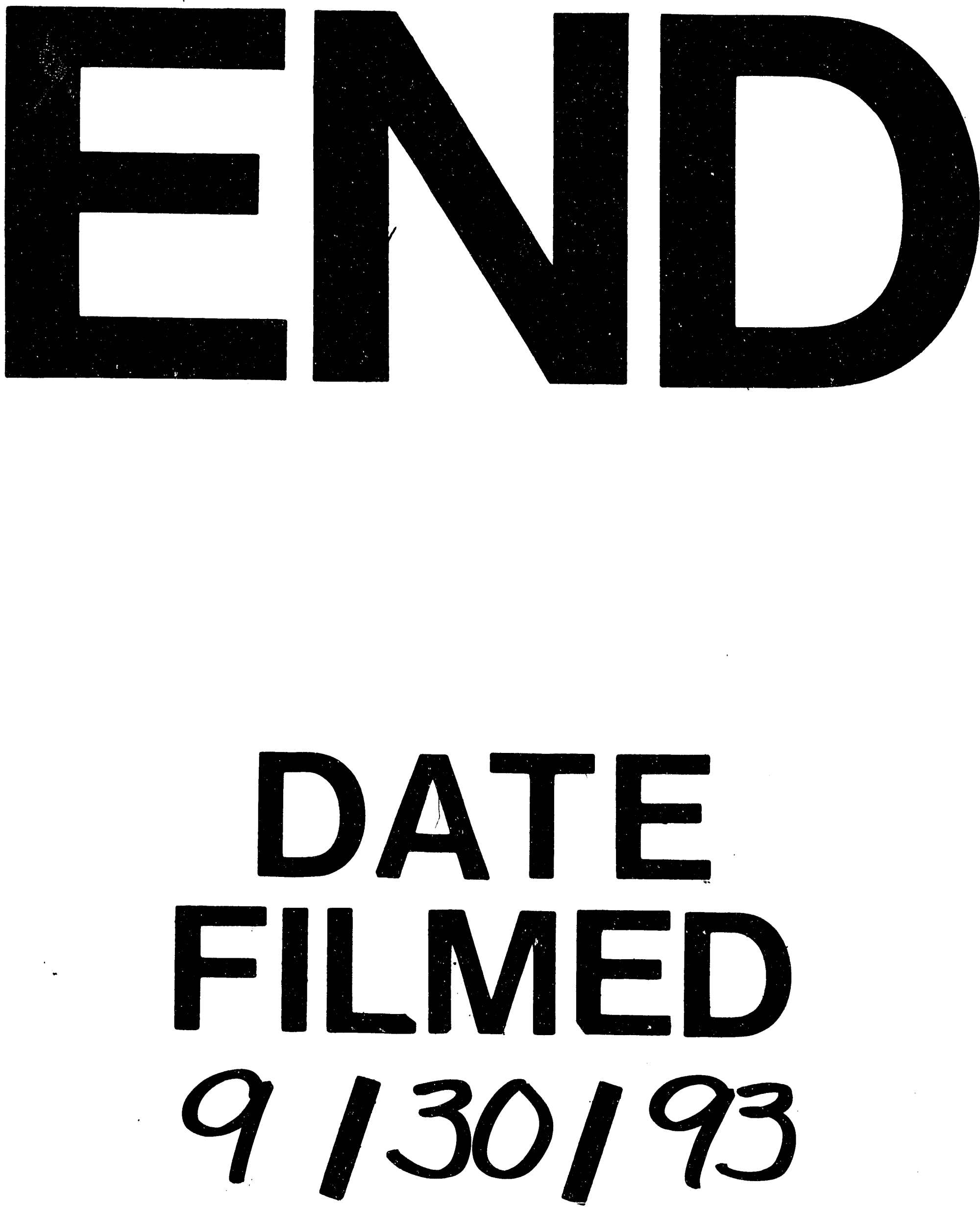
